\title{
Volume 110, Number 2
}

Summer 2010 ISSN 0042-8639

\section{The Volta Review} Alexander Graham Bell Association for the Deaf and Hard of Hearing

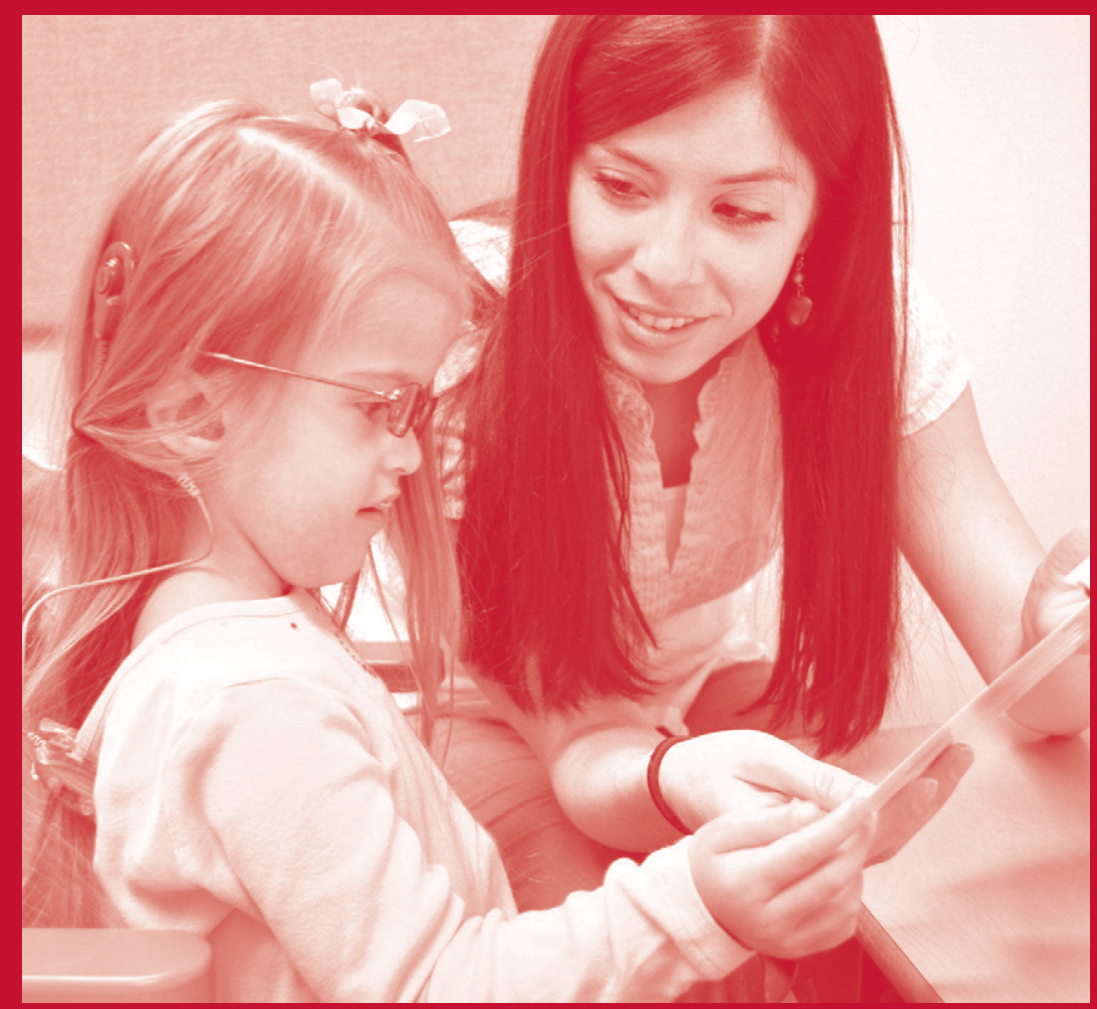

\section{Professional Preparation for Listening} and Spoken Language Practitioners

Edited by

K. Todd Houston, Ph.D., CCC-SLP, LSLS Cert. AVT, and Christina B. Perigoe, Ph.D., CCC-SLP, CED, LSLS Cert. AVT 


\section{The Volta Review}

Volume 110, Number 2

Summer 2010

ISSN 0042-8639

The Alexander Graham Bell Association for the Deaf and Hard of Hearing helps families, health care providers and education professionals understand childhood hearing loss and the importance of early diagnosis and intervention. Through advocacy, education, research and financial aid, AG Bell helps to ensure that every child and adult with hearing loss has the opportunity to listen, talk and thrive. With chapters located in the United States and a network of international affiliates, AG Bell supports its mission: Advocating Independence through Listening and Talking!

\section{Professional Preparation for Listening and Spoken Language Practitioners}

85 Editors' Preface

K. Todd Houston, Ph.D., CCC-SLP, LSLS Cert. AVT, and

Christina B. Perigoe, Ph.D., CCC-SLP, CED, LSLS Cert. AVT

\section{Considerations for Professional Preparation Programs}

89 Highlights in the History of Oral Teacher Preparation in America Alan L. Marvelli, M.E.D., Ed.D.

I 17 Trends and Challenges in Teacher Preparation in Deaf Education Susan Lenihan, Ph.D., CED

I29 AG Bell Academy Certification Program for Listening and Spoken Language Specialists: Meeting a World-Wide Need for Qualified Professionals

Donald M. Goldberg, Ph.D., CCC-SLP/A, FAAA, LSLS Cert. AVT;

Cheryl L. Dickson, M.Ed., LSLS Cert. AVT; and

Carol Flexer, Ph.D., CCC-A, LSLS Cert. AVT

I 45 A Survey of LSLS Cert. AVTs Who Mentor: Fostering Independence to Endow the Future

Helen M. Morrison, Ph.D., CCC-A, LSLS Cert. AVT;

Christina B. Perigoe, Ph.D., CCC-SLP, CED, LSLS Cert. AVT; and Anita Bernstein, Sp. Ed., M.Sc., LSLS Cert. AVT

I69 Listening, Language, and Learning: Skills of Highly Qualified

Listening and Spoken Language Specialists in

Educational Settings

Ellen L. Estes, M.S., LSLS Cert. AVEd

179 Professional Preparation: Developing Language in

Children with Hearing Loss

John Muma, Ph.D., CCC-SLP, and

Christina B. Perigoe, Ph.D., CCC-SLP, CED, LSLS Cert. AVT 
191 From Pedagogy to Practice: Mentoring and Reciprocal Peer Coaching for Preservice Teachers

Blane Trautwein, Ed.D., and Sarah Ammerman, Ph.D.

207 Educational Preparation of Pediatric Audiologists Jackson Roush, Ph.D.

219 Speech-Language Pathologists: Vital Listening and Spoken Language Professionals

K.Todd Houston, Ph.D., CCC-SLP, LSLS Cert. AVT, and

Christina B. Perigoe, Ph.D., CCC-SLP, CED, LSLS Cert. AVT

23 I Professional Development for In-Service Practitioners Serving Children who are Deaf and Hard of Hearing Kathryn Wilson, MA, CCC-SLP, LSLS Cert. AVT; Mary Ellen Nevins, Ed.D.; and K. Todd Houston, Ph.D., CCC-SLP, LSLS Cert. AVT

249 State and National Accreditation of One University Program: A Case Study Maura Martindale, Ed.D., LSLS Cert. AVEd, and Carol A. Bartell, Ed.D.

\section{Program Profiles}

26 I John Tracy Clinic/University of San Diego Graduate Program: A Distance Learning Model Mary McGinnis, LSLS Cert. AVT

27 Washington University School of Medicine: A Distinctive Program in Deaf Education Studies at the Program in Audiology and Communication Sciences (PACS) Heather Hayes, Ph.D.

279 The University of Hartford and CREC Soundbridge:

A New Master's of Education in Aural Habilitation and Education of Hearing Impaired Children

Marietta M. Paterson, Ed.D., and Elizabeth Cole, Ed.D.

293 Fontbonne University: Collaboration in Speech-Language Pathology and Early Intervention in Deaf Education Gale Rice, Ph.D., CCC-SLP, and Susan Lenihan, Ph.D., CED

297 Nazareth College: Specialty Preparation for Speech-Language Pathologists to Work With Children who are Deaf and Hard of Hearing Paula M. Brown, Ph.D., CCC-SLP, and Cathy Quenin, Ph.D., CCC-SLP 
305 University of Akron:Training Speech-Language Pathology Specialists to Provide Quality Service to Children who are Deaf or Hard of Hearing - A Collaborative Preservice Program Denise Wray, Ph.D., CCC-SLP, LSLS Cert. AVT, and Carol Flexer, Ph.D., CCC-A, LSLS Cert. AVT

315 The University of Southern Mississippi: Developing a State-ofthe-Art Graduate Program in Early Oral Intervention Christina B. Perigoe, Ph.D., CCC-SLP, CED, LSLS Cert. AVT, and Henry Teller, Ed.D., C.E.D.

323 Utah State University: Cross-Discipline Training Through the Graduate Studies Program in Auditory Learning and Spoken Language K. Todd Houston, Ph.D., CCC-SLP, LSLS Cert. AVT

33I Professional Training in Listening and Spoken Language A Canadian Perspective Elizabeth Fitzpatrick, Ph.D., LSLS Cert. AVT

\section{Future Directions}

339 Future Directions in Professional Preparation and Development K. Todd Houston, Ph.D., CCC-SLP, LSLS Cert. AVT, and Christina B. Perigoe, Ph.D., CCC-SLP, CED, LSLS Cert. AVT

Monograph Appendices

34I Appendix A: Nine Domains of Listening and Spoken Language

342 Appendix B: LSLS Recommended Reading List

346 Appendix C: Professional Preparation Resource List

\section{Regular Features}

348 Directory of Professional Programs

350 Information for Contributors to The Volta Review

Permission to Copy: The Alexander Graham Bell Association for the Deaf and Hard of Hearing, as copyright owner of this journal, allows single copies of an article to be made for personal use. This consent does not extend to posting on Web sites or other kinds of copying, such as copying for general distribution, for advertising or promotional purposes, for creating new collective works of any type, or for resale without the express written permission of the publisher. For more information, contact AG Bell at 3417 Volta Place, NW, Washington, DC 20007, email editor@agbell.org, or call (202) 337-5220 (voice) or (202) 337-522I (TTY). 


\section{Editors' Preface}

Just over 40 years ago - when some of us were entering the field - the first man walked on the moon, computers took up an entire room, cochlear implants were experimental, and children who were deaf or hard of hearing were, for the most part, living and being educated in institutional settings. Difficult as it is to believe, the computers astronauts used were cruder than today's video games, the cochlear implant was 20 years away from being approved for use in children, and hearing screenings for all newborns was even further down the road. It is truly amazing to see the changes that have occurred in our own lifetimes.

As technology and early intervention services have improved, programs preparing professionals to work with children who are deaf or hard of hearing and their families have adapted to keep pace. New technologies and early intervention have made it easier, but our ultimate goal has stayed the same to facilitate the development of listening and spoken language so that children with hearing loss seeking a spoken language outcome can reach their full potential and participate to the utmost of their ability in their families and in their communities.

Some of the key factors that impact the communication development of a child with hearing loss include the knowledge, skills, and experience of the professionals serving the child and family. While other factors certainly play a role in the child's language acquisition - such as age of identification of hearing loss, immediate use of hearing technology, enrollment in early intervention, and the active involvement of parents in the child's intervention and habilitation - the child's audiologist, early interventionist, speechlanguage pathologist, teacher of the deaf, and/or Listening and Spoken Language Specialist (e.g., LSLS Cert. AVT or LSLS Cert. AVEd) provide essential support and guidance that can have a lifelong impact on the child's overall developmental and educational success. Without access to well-trained professionals, children with hearing loss whose families seek spoken language outcomes will not fully achieve the communicative potential that is now possible.

While advances in newborn hearing screening, hearing technology, and service delivery have created greater opportunities for success with spoken language, too many young children with hearing loss and their families are not receiving appropriate services. The reasons vary as to why families are not receiving services to which they are entitled and can differ locally and regionally. For example, in some locations there may be a lack of public awareness and limited access to appropriate information about communication options, 
especially listening and spoken language. When this occurs, parents and caregivers will not have the information to make informed decisions about desired communication outcomes.

There may also be a shortage of early intervention or educational programs that use evidence-based practices to facilitate listening and spoken language in young children with hearing loss. Either the programs do not exist in the community or conversely, when programs are in place, the professionals on staff may not have adequate training to facilitate spoken language aquisition. These professionals may have graduated from university programs that provided only minimal instruction and practica focused on developing listening and spoken language. Likewise, in-service training opportunities can be scarce, and the professionals may not have had access to instruction in current evidence-based practices and technological advances that are the neurological and linguistic underpinnings of an auditory-based approach within pediatric audiology, speech-language pathology, and education of the deaf and hard of hearing.

In this monograph, we hope to shine a light on the issue of professional preparation and the need for more preservice and in-service training in audiology, speech-language pathology, and education of the deaf. Unfortunately, there is a dearth of appropriately trained and competent LSLSs. By focusing on this important issue through a series of articles and program profiles, we hope to inform, instruct, and inspire. That is, we wish to inform you about the history of spoken language approaches and personnel preparation and instruct you in the current trends and practices that support quality preservice and in-service professional preparation programs. But most importantly, we hope to inspire you to improve your own knowledge and skills, to raise the confidence of the undergraduate or graduate students you're teaching, or, perhaps, to increase the independence of the young professionals you are mentoring.

Looking back, could we in 1970 have imagined the Internet, e-mail, laptop computers, cell phones, text messaging, Bluetooth technology, iPods, iPads...or that amazing addition to our own field - cochlear implants? While one monograph is inadequate to capture all of the issues related to professional training, we hope that we've added significantly to this important discussion.

The contributors to this monograph represent a broad cross section of university programs, in-service training opportunities, and perspectives on professional development. We acknowledge that other stellar university programs and training formats exist that are not included in the monograph. We have focused on programs in the United States and Canada, but there are programs in other countries around the world working towards similar goals. In an upcoming Volta Voices, we hope to assemble information from other countries that will serve as a companion piece to this monograph. 
To all who are working to enhance the training of current and future professionals, we applaud your continued efforts. Through your diligence and hard work, more children with hearing loss and their families will receive critical services and a higher number of these same children will learn to listen and speak for themselves. This is truly inspiring!

\section{Sincerely,}

K. Todd Houston, Ph.D., CCC-SLP, LSLS Cert. AVT Assistant Professor of Speech-Language Pathology and Director, Graduate Studies Program in Auditory Learning \& Spoken Language Department of Communicative Disorders and Deaf Education Utah State University

Christina Perigoe, Ph.D., CCC-SLP, CED, LSLS Cert. AVT Associate Professor, Coordinator of the Early Oral Intervention Graduate Program, Education of the Deaf Department of Speech and Hearing Sciences The University of Southern Mississippi 

The Volta Review, Volume 110(2), Summer 2010, 89-115

\title{
Highlights in the History of Oral Teacher Preparation in America
}

\author{
By Alan L. Marvelli, M.E.D., Ed.D.
}

The history of oral teacher preparation in America is both significant and diverse. There are numerous individuals and events that shifted and defined the professional practices of individuals who promote the listening and spoken language development of children with hearing loss. This article provides an overview of this rich history and offers a background to the current state of teacher preparation for listening and spoken language practitioners.

\section{Introduction}

A single chapter does not permit me to honor all the dedicated professionals who have enriched the development of listening and spoken language professionals since auditory-based education was established in America. Ultimately, I was guided by this statement attributed to Galileo Galilei: "All truths are easy to understand once they are discovered; the point is to discover them" (Quotations, 2007). I looked for the acknowledged visionaries whose groundbreaking efforts influenced listening and spoken language professional preparation in America, changed the lives of children with hearing loss, and led the way for those of us who followed.

To understand the influences on the preparation of listening and spoken language professionals, one must be acquainted with the origins of education for deaf children in America. Although this manuscript cannot offer a comprehensive history, those interested in such details may consult two classic texts: Ruth Bender's Conquest of Deafness (1981) and Edward Scouten's Turning Points in the Education of Deaf People (1984). However, I hope that the brief chronology provided, which I have extracted from

Alan L. Marvelli, M.E.D., Ed.D., is Professor and Director of the Smith College-Clarke Graduate Teacher Education Program. Correspondence concerning this article may be directed to Dr. Marvelli at amarvell@smith.edu. 
their outstanding research and my own doctoral studies, will be of some help.

\section{Significant Historic Events}

Prior to the 19th century, most, if not all, of the advances in deaf education occurred in Western Europe. Although references to deafness and societal rights can be traced to the pre-Christian era, the feasibility of educating children who are deaf or hard of hearing was not considered until the 16th century when the Italian physician and mathematician, Girolamo Cardano, read about a young man who was "deaf from the cradle," but had learned to read and write. This led to speculation that the minds of individuals with hearing loss might be intact and that deafness simply blocked their access to auditory information. If one could find a way to circumvent this barrier, learning might be possible. Cardano never tested his theory, which at the time was quite revolutionary.

The first recognized schooling of children who were deaf or hard of hearing began prior to 1550 at the Mission of San Salvador in Madrid, Spain, under the tutelage of Pedro Ponce de Leon, a Benedictine monk. His goal was to save the souls of these children by acquainting them with the word of God. He employed what would become known as "oral" methods, teaching them to read lips and to develop spoken language and literacy, apparently with considerable success.

As the word of his accomplishments spread across Europe, others engaged in this endeavor, some emulating Ponce de Leon's methods, others employing manual signs and finger spelling inspired by military and ecclesiastic communications, the so-called "manual" methods. By the end of the 18th century, schools for children with hearing loss were being opened throughout Western Europe. Those that had the greatest influence on American education were located in France, Germany, and Britain.

In 1760 a French Catholic priest, Abbé Charles Michel de l'Épée, established a program for the deaf in Paris. By 1790 it would become France's first statesupported school, the Institut National des Sourds-Muets. From its inception, the school welcomed even the poorest children. Although he had read about methods of oral teaching, de l'Épée adopted and refined a system of manual communication for instruction.

In Germany and Great Britain, Samuel Heinicke and Thomas Braidwood also established schools; their curricula focused on oral methods. These secular enterprises, like their French counterpart in its early days, were not state subsidized; they relied on private support. Their leaders, not having taken religious vows of poverty, expected to have incomes; hence, they were less willing to share "trade secrets." By the beginning of the 19th century, the Braidwood family schools in Scotland and England were widely known and well respected for their work with children who were deaf or hard of hearing. 


\section{Beginning of American Education}

During this time, children with hearing loss in America had no similar opportunities available to them. The situation began to change in 1814 when Thomas Hopkins Gallaudet, a Yale graduate, returned home to Hartford, CT, after completing ministerial training at Andover Theological Seminary. He planned to become a traveling minister but reconsidered those plans when he met a young neighbor, 9-year-old Alice Cogswell, who became deaf at age 2 from "spotted fever." He took an immediate interest in instructing her, which led ultimately to a group of prominent Hartford citizens, including Alice's father, sponsoring him to study European practices for teaching children with hearing loss. The plan called for him to visit schools in Britain, France, and Germany collecting ideas, which would lead to the establishment of a school in Hartford.

Gallaudet first visited the Braidwood family schools in England and Scotland, and received a less-than-cordial reception. The Braidwoods, determined to guard their professional secrets, were troubled by Gallaudet's plan to found a public school where their methods could be observed. They also thought that a member of their family, who had recently emigrated to America, had opened a school for children who were deaf in Maryland. ${ }^{1}$ They considered Gallaudet to be a potential competitor (Bell, 1918).

Realizing that the Braidwoods would be of little help, Gallaudet sought other assistance, meeting with Abbé Roch Sicard, who had succeeded Abbé de l'Épée as head of the Institut National. Sicard had taken refuge in England during Napoleon's "100 Days sojourn" in Paris ${ }^{2}$ and used the opportunity to conduct a series of public lectures to demonstrate the French manual method with two former pupils, who were now teachers at the Institut. One young teacher, Laurent Clerc, was a multilingual genius. Gallaudet attended one of the lectures, met Sicard, and was invited to Paris to learn the French method of communication.

In 1816, Gallaudet returned to America accompanied by Clerc, who had agreed to help establish a school in Hartford. The Connecticut Asylum for the Education and Instruction of Deaf Persons opened its doors to seven pupils on April 15, 1817, becoming America's first permanent "special education" school. Student tuition and fees for Connecticut residents were provided by the state, a precedent-setting action. For a half century, the school's French

\footnotetext{
${ }^{1}$ John Braidwood, grandson of Thomas Braidwood, had been forced to abandon the superintendence of his family's school in Edinburgh after falling deeply into debt, due in large measure to a problem with alcohol. Faced with the possibility of imprisonment, he fled to America arriving in Baltimore in 1812. Although he hoped to salvage his career and open a school for children who were deaf or hard of hearing, he was unsuccessful, not being able to overcome his alcoholism.

${ }^{2}$ Sicard nearly lost his life during the French Revolution and chose not to risk being caught in another civil uprising (Scouten, 1984).
} 
method of communication and instruction was the only method used with American children who were deaf or hard of hearing and would spread across the country as new schools were established. ${ }^{3}$

In 1857 Gallaudet's son, Edward, arrived in Washington, DC, to establish the Columbia Institution for the Deaf, Dumb, and Blind. Eight years later his efforts led to President Lincoln's signing of a law "empowering this institution to confer collegiate degrees upon deaf-mutes," thus establishing the National Deaf-Mute College, now known as Gallaudet University.

In 1845, noted educators Horace Mann and Samuel Gridley Howe, having visited German schools for children who were deaf or hard of hearing, attempted to persuade the Massachusetts' legislature to grant a charter for an oral school. Their challenge to the exclusive use of manual communication was unsuccessful, and resistance from Hartford's experienced educators was a key factor. It would be more than 20 years before the first oral school was chartered.

\section{The "Articulation Method" Comes to America}

Historically, there has been friendly debate concerning the location of America's first school to use the oral or "articulation" method. During the mid-1860s, two independent and nearly simultaneous efforts were underway to establish programs that would come to be known as the Lexington School for the Deaf in New York City and the Clarke School for Hearing and Speech in the Boston area. In both cases, the work was spearheaded by prosperous, educated, highly motivated parents of children who had become deaf early in life. Through various means, these parents had learned about the oral method widely used in German and Austrian schools as an alternative to sign language. They wanted to make this opportunity available to their children.

Bernard Englesmann ${ }^{4}$, a German Jewish immigrant and skilled oral teacher, had come to New York in 1863 after teaching at an oral school in Vienna for several years. He hoped to continue his profession in America and was subsequently introduced to Isaac and Hannah Rosenfeld, whose daughter, Carrie, had lost her hearing as an infant to scarlet fever. In 1864 the Rosenfelds offered Englesmann a 5-year contract to teach Carrie and a class of five other children, ages 8 to 12 . The class met at the Rosenfelds' home until 1867, when they succeeded in persuading a group of citizens, organized under the name of The Association for the Improved Instruction of Deaf-Mutes, ${ }^{5}$ to support Engelsmann's small class. The Association became known as The Institution

${ }^{3}$ It is interesting to consider how different American education of children with hearing loss might be today had the Braidwoods been more hospitable toward Gallaudet.

${ }^{4}$ Bender (1981) refers to him as Bernard Engleman, Scouten (1984) as Bernhard Englesmann.

${ }^{5}$ The Association was legally incorporated by the New York Department of State on January 9, 1869 (Connor, 1992). 
for the Improved Instruction of Deaf-Mutes and opened with two classrooms and 14 pupils. The school flourished and within 6 years was serving more than 90 pupils. It would become an acknowledged leader in the field of oral education, and eventually be renamed the Lexington Avenue School for the Deaf ${ }^{6}$ (Connor, 1992).

In 1862, Gardiner Greene Hubbard and his wife, Gertrude, of Cambridge, MA, experienced a crisis similar to the Rosenfelds when their 4-year-old daughter, Mabel, lost her hearing to scarlet fever. Wanting to preserve her already-established speech, they were dismayed to learn from the experts in Hartford that she would become mute and could then enroll as a pupil at age 10. Undaunted by this news, they began to search for alternatives. They learned of two other families in the region, the Lippetts and Cushings, whose young daughters were similarly affected by childhood illnesses. Like the Rosenfelds, all were prominent, well-educated members of their communities determined to act decisively on behalf of their children. By 1864, the Cushings had engaged a young teacher named Harriet Rogers to work with their daughter, Fannie. Miss Rogers had read about, but had had no practical experience with, the German oral method. ${ }^{7}$

Under Hubbard's leadership and with the help of Samuel Gridley Howe, the families petitioned the Massachusetts legislature on March 16, 1864, to grant a charter for an oral school, but the Hartford opposition to the articulation method prevailed again and the effort failed. Ultimately, the Hubbards and Cushings pooled their financial resources and convinced Miss Rogers to accept the challenge of teaching by oral methods to a class of seven students, ages 8 to 17, in a rented room in Chelmsford, MA. The families resubmitted a charter petition to the legislature in spring 1867. This time Miss Rogers and some of her pupils were invited to Boston to provide direct evidence of the effectiveness of her method of instruction. The legislature was easily convinced and sent a bill authorizing the charter of an "articulation school" to Governor Bullock, which he signed on June 1, 1867.

Concurrent with, but apparently independent of this petition, a wealthy merchant banker named John Clarke, who resided in Northampton in western Massachusetts, had informed the governor of his desire to endow a school for children who were deaf in the amount of $\$ 50,000$ on the condition that the school be located in his home town. ${ }^{8}$ Miss Rogers and the families of the

\footnotetext{
${ }^{6}$ In 1880 , the Trustees leased an entire block on Lexington Avenue between $67^{\text {th }}$ and $68^{\text {th }}$ Streets in Manhattan, and built a new school, which opened in November 1882.

${ }^{7}$ Miss Rogers' sister was teaching deaf-blind children in Boston at that time at Samuel Gridley Howe's Perkins School for the Blind. It is likely that this is where she learned about German oral teaching.

${ }^{8} \mathrm{John}$ Clarke was experiencing the isolating effects of a severe hearing loss as he aged. He also had friend in Northampton whose young daughter was deaf. These two situations probably influenced his action.
} 
children readily agreed to move the fledgling Chelmsford school the requisite 100 miles in order to avail themselves of Clarke's offer. ${ }^{9}$ The Clarke Institution for the Instruction of Deaf-Mutes, known today as the Clarke School for Hearing and Speech, opened its doors in Northampton on October 1, 1867 (Bell, 1918). Because of its isolated location and the tradition of the times, both pupils and teachers resided at the school except during vacation periods. Teachers then, and for a century to come, saw this as a positive situation, fostering children's round-the-clock development. ${ }^{10}$

As word spread about the new school, enrollment grew. Almost immediately, Miss Rogers was required to hire and train new teachers. Among them would be Caroline A. Yale, who joined the faculty in 1870 and would become a world leader in the field of oral education.

The roots of oral education in America had been firmly planted with the formal chartering of two articulation schools within a period of months. Both schools would become beacons for others who wished to provide children who were deaf or hard of hearing the opportunity to acquire spoken language and listening abilities.

\section{Meeting the Need for New Teachers in America}

Subsequent to its founding, when vacancies occurred at the Connecticut Asylum, new teachers were provided on-the-job training in manual communication by Laurent Clerc, who was fluent in French sign language and had become proficient in written English. For his services, each teacher paid Clerc a fee of $\$ 50$ (Williams, 1893). Gallaudet realized that the school's teachers needed more extensive preparation and made his feelings known in various reports (Brill, 1971). However, no action was taken to organize a formal teacher preparation program, a fact easier to understand when one realizes that the first program designed to prepare teachers of children with typical hearing was not offered until 1823 when Reverend Samuel Hall established a privately supported "normal school"11 in Concord, VT. It would be another 16 years before the opening of the country's first state-funded normal school in Lexington, MA (DeYoung \& Wynn, 1970).

While it is probable that well-organized preservice teacher education programs would have improved the quality of education for children who were deaf or hard of hearing, the need was apparently not a priority until after the

\footnotetext{
${ }^{9}$ Upon his death in 1870 , Clarke bequeathed an additional $\$ 256,000$ to the school. His total gift, in annualized dollars, is one the largest, if not the largest, ever given to a school for children with special needs.

${ }^{10}$ This view was so widely accepted that even the Institution for Improved Instruction in New York was predominantly a residential school. In 1900, the Institution enrolled 210 pupils; only 27 were day students (Connor, 1992).

${ }^{11} \mathrm{~A}$ term derived from the French école normal, a training school for teachers.
} 
Civil War. During this time, the number of schools for the deaf grew to 22, all supported directly or indirectly by public funds, which permitted them to offer salaries sufficiently high to employ well-educated men, mostly college graduates, as teachers..$^{12}$ All of these schools adopted the manual approach for communication and instruction. In-service instruction in sign language was apparently considered sufficient for their professional preparation.

During the 1860s, a series of events combined to change the picture dramatically. The outbreak of the Civil War put tremendous pressure on state budgets, and many states were unable to provide adequate salaries for teachers. Teachers enlisted for military service; others were lured away by more lucrative economic opportunities outside the teaching profession. Often, the men were replaced by women who were not as well educated as their predecessors. Undoubtedly, many schools reconsidered their needs for in-service teacher preparation.

The advent of oral schools in America also presented new problems to the profession. The oral method required a distinctly different, more complex type of preparation for teachers, creating a need for formalized training of new teachers at the oral schools in New York and Northampton. As with the manual schools before them, in-service training was the primary method; many ad hoc classes were created to meet the specific needs of new teachers. However, the groundwork was being laid for the development of more formal teacher education programs.

The oral method of instruction was new to America in the early 1870s, and much of the early work in teacher preparation was experimental. The fundamental issue in New York and Northampton was the same: Trained teachers of articulation could not be found in the United States (Connor, 1992). At first, it is likely that Bernard Englesmann had an advantage in preparing new teachers in New York given his teaching experience in Vienna. Nonetheless, Miss Rogers was determined to learn as much as she could on behalf of the Clarke staff and children. She traveled to Germany in 1871 for a year's study of the oral methods and approved, during her absence, a visit to Northampton by Dr. Alexander Graham Bell to experiment with his father's system of "Visible Speech," a system of graphic symbols used to display the features of human speech, as a possible tool to help teachers with speech development for children at Clarke. During this time, Bell also opened a school in Boston to train oral teachers in his father's method, but soon returned to his family's earlier work in elocution training (Bender, 1981). He also devoted evenings to experiments with electricity that eventually led to patenting the telephone.

The Visible Speech experiment was discontinued by the Clarke teachers after 3 years because the system seemed to "delay the formation of voluntary

\footnotetext{
${ }^{12}$ In 1851 only three women were employed as teachers in America's schools for children who were deaf (Brill, 1971).
} 
speech [which] was greatly to be deplored" (Yale, 1931, p. 57). Eventually, Bell's phonetic symbols were transcribed by Yale and her colleague, Alice Worcester, into common English spellings that represented each sound. These transcriptions became the basis for the "Northampton [Speech] Charts" that are still used in the education of teachers and children.

\section{Formalized In-Service Teacher Training}

Because the New York and Northampton schools (and other oral schools, as they were incorporated) were commonly required to offer instruction to new teachers, these orientation sessions gradually turned into more formalized structures:

Early in the history of the [Clarke] School, a new year opened with two or three unexpected vacancies in the teaching force. These were filled with novices who gathered every afternoon after school hours to have mapped out for them the next day's work. The Principal spent her day in going from one school room to another, giving suggestions and advice. The next year, although the need was possibly somewhat less, it was decided to continue this afternoon conference, and several of the teachers of the School who had been here longer also asked for admission, and the work became more general. Principles of language work, and suggestions in regard to speech work were applicable to all classes. (Yale, 1931, p. 177)

In New York in 1886, Lexington's Principal David Green "initiate[d] the position of a 'teacher in training,' which in years to come would become a group to serve as substitute teachers. In time these novices also became a source of new teachers for the school" (Connor, 1992, p.41).

By 1889, Clarke's teacher training courses had become so well organized that Lewis J. Dudley, chairman of the school's board, noted, "Indeed it may be said that our Institution is not only a school for the practical instruction of deaf pupils, but a normal school for the training of our teachers" (Dudley, 1890). This was the beginning of a formalized teacher preparation program. Dudley describes a twice-a-week program of instruction taught by Yale that covered:

1. Anatomy of the vocal organs and of the ear, illustrated by diagrams.

2. Elementary sounds of the English language and their classification.

3. Formation of elementary sounds, with the methods of eliciting each from the pupil.

4. Visible Speech - a thorough knowledge imparted, not to be taught to the pupil but as an essential requisite to complete equipment for teaching articulation.

5. Detailed plans for elementary instruction in language. 
6. General suggestions in regard to mental development, religious instruction, discipline, industrial training, etc.

7. Different methods of deaf-mute instruction, including those now practiced with blind deaf-mutes.

8. History of deaf-mute education.

This was followed by 2 days of written examination at the end of the school year (Dudley, 1890).

\section{Preservice Oral Teacher Preparation for the Profession-at-Large}

In 1891, Congress granted Gallaudet University permission to establish a normal training class for graduates of hearing colleges (Brill, 1971), which represented the first departure from the tradition of in-service training. The previous August, at the Convention of American Instructors of the Deaf, a group of oral teachers encouraged by Bell formed the American Association to Promote the Teaching of Speech to the Deaf (Dudley, 1893), now known as the Alexander Graham Bell Association for the Deaf and Hard of Hearing (AG Bell). Apparently, when members of this new organization became aware of the Gallaudet training program, they sought a similar opportunity for prospective oral teachers. At its 1892 summer meeting, the AG Bell board unanimously voted that trustees of the Clarke Institution be asked to enlarge their training class for teachers to include those from other schools. Clarke complied (Hubbard, 1893) and, through a cooperative agreement with the association, funds were provided to educate these additional trainees. This program was implemented on an experimental basis in September 1892 with five trainees (Yale, 1893).

The agreement continued with favorable results. ${ }^{13}$ "The work in the classroom takes on a higher value in the eyes of teacher and pupil alike when counted worthy of observation and imitation by others" (Yale, 1894). The teacher training program became such an integral part of the school that the graduation of a class was regarded as a loss to the school. By the program's third year (1894), the size of the training class had grown to 10. Apparently this number placed excessive pressure upon the teaching staff, and the size of subsequent classes was fixed at a maximum of four per year until 1900 (Yale, 1901).

With the exception of an increase in fees, the training program remained unaltered until 1906 when the curriculum was expanded to include blackboard drawing. At that time, an entrance examination became a requirement for all applicants, including college graduates. Funds provided by the Alexander

\footnotetext{
${ }^{13}$ It will celebrate its 118 th anniversary in June 2010, having graduated more than 1,500 teachers.
} 
Melville Bell Memorial Fund also made it possible to increase the size of the training class to as many as 10 students a year (Annual Report, 1906).

\section{Summer Schools for Oral Teachers, I 904-I 924}

The teaching of speech to individuals who were deaf or hard of hearing became more widespread throughout the United States in the 1890s and early 1900s (Connor, 1992). Increasing numbers of teachers were requesting specialized training. In 1904, Clarke offered the country's first summer school program for oral teachers:

This originated...with the request of the Superintendent of the Texas School for such a session for himself and a group of his teachers. The arrangement was made that they should arrive two weeks before the close of school and remain two weeks after the pupils left. During the first period of each day, they were to observe classroom work, a portion of the day being devoted to instruction in special subjects. This instruction was given by the Principal and Associate Principal. This extra work was naturally a heavy task for our teachers, coming as it did at the close of a long school year (Yale, 1931, p. 177).

Six months after Clarke concluded its first summer session, the AG Bell board requested that Clarke seek funds to support another summer program (Yale, 1905). Clarke administrators and teachers acceded to the request, and the second summer session enrolled 16 oral teachers from 10 states. Each enrollee had at least 1 year of teaching experience. Between 1904 and 1924, Clarke held nine summer sessions, most of which were sponsored by AG Bell. During this period, 235 teachers received instruction (Clarke School for the Deaf, 1924). Finally, at the conclusion of the 1924 summer session, Yale noted that it seemed best to discontinue them and ask AG Bell to make other arrangements for summer instruction (Yale, 1931).

\section{The Central Institute for the Deaf: "Breaking the Barrier of Silence"}

Until the early years of the 20th century, most work in American oral education had been visual and vibro-tactile in nature with emphasis placed upon lipreading, speech and language acquisition, and literacy. Electrically powered personal hearing devices, based upon Bell's telephone technology, were being developed for adults who lost their hearing, but teachers rarely considered the possibility of accessing the auditory potential of children born deaf. Just as oral schools had been a radical departure from the 50-year American tradition of manual communication, the advent of auditory-based teaching methods to supplement oral education, especially for pupils who were profoundly 
deaf, was viewed with cautious concern if not outright skepticism, even by the oralists ${ }^{14}$.

One visionary champion of the new acoustic method was a highly respected St. Louis otologist named Max Goldstein. Following completion of his medical degree at the Missouri Medical College in 1892, Goldstein studied abroad in London, Strasbourg, and then, because of his desire to become an ear, nose, and throat specialist, at the internationally renowned Vienna Polyclinic. He became most interested in the ideas and work of Professor Victor Urbantschitsch, who had developed "methods of improving the education of congenitally deaf children with apparent remnants of hearing by concentrating on stimulation of what he termed a dormant auditory sense" (Lane, 1981). After spending a year under Urbantschitsch's tutelage, Goldstein returned to St. Louis in 1894, convinced that acoustic stimulation would be of great value in teaching children who were deaf or hard of hearing to talk intelligibly.

In the ensuing years, Goldstein established his medical practice, founded and edited the medical journal Laryngoscope, and continued to promote acoustic methods by instructing students who were deaf or hard of hearing and their teachers at the St. Joseph Institute in St. Louis. He invented an acoustic amplification device, which he called a simplex tube (basically a funnel with a tube attached), and used it for auditory training. As he refined his ideas and techniques, he realized that closer cooperation was needed among teachers of the deaf and scientists in otolaryngology, neurology, phonetics, and acoustics (Bender, 1981). He also studied teaching methods and realized that many oral teachers needed more preparation. Ultimately this led to "the idea of establishing an institute for the deaf in which effective cooperation between the teacher, the otologist, and other specialties could flourish as well as the opportunity to give a liberal and unbiased trial to forward looking methods of education of deaf children and professionally preparation of teachers" (Lane, 1981). The Central Institute for the Deaf (CID) opened on September 23, 1914, serving four pupils in rooms above Goldstein's medical office. The Institute's first teacher was Ruth Paxon, Goldstein's office receptionist whom he had trained. The following year CID moved to larger quarters, and the cornerstone was laid for its first school building on September 27, 1916.

In the following decades, CID would become a recognized world leader in the field of acoustic research and auditory-based education, thoughtfully integrating science, technology, medicine, and education. CID publications would become classics in the fields of medicine, oral education, and teacher preparation. Goldstein's pioneering work and that of his European contemporaries

\footnotetext{
${ }^{14}$ In 1910, the Lexington School began to offer limited training to "students shown to be hearing vowels." Those who were "practically totally deaf" did not receive training. Follow-up evaluations of 100 pupils were conducted in 1911: "42 were dropped as making no improvement; the improvement in 30 was slight but noticeable; the improvement in 28 was very pronounced" (Connor, 1992, p. 52).
} 
laid a foundation for professionals who formulated the principles and practices of acoupedics and auditory-verbal therapy later in the 20th century. (See Goldberg, et al., in this issue for a history of the development of auditoryverbal therapy and the Listening and Spoken Language Specialist certification process.)

Goldstein's firm belief in teacher preparation led to implementation of a program with basic courses titled similarly to those offered at Clarke. The chief distinction was the emphasis on his scientific, interdisciplinary approach embracing progressive acoustic methods. CID graduated its first class of four teachers in 1915. CID also inspired sister oral schools to incorporate auditory training into their curricula. In summer 1915, CID held its first session for teachers from other schools. The curriculum focused on methods of oral instruction with acoustic training.

Upon learning that AG Bell had not met since 1912 and planned no meeting for 1918, Goldstein established The Society of Progressive Oral Advocates to improve teacher education and disseminate information on acoustic research, and scheduled its first meeting for July 1918 (Lane, 1981). This group later would become the professional section of AG Bell (Central Institute for the Deaf [CID], 2009).

\section{Scientific and Technological Support for Auditory Learning}

In the early 1920s, Bell Telephone Laboratories developed and patented the audiometer, a major scientific and technological breakthrough (Fletcher, 1992). For the first time, scientific measurement of human response to sound became possible, and the fields of audiometry and education of children with hearing loss owe much to this development. Audiological research resulted in a better understanding of hearing, leading to the design of increasingly effective amplification devices and influencing the teaching and learning process. Auditory training curricula and related technology became a standard part of every oral teacher preparation program and virtually every oral classroom.

Bell Laboratories' research in the 1940s led to the invention of solid-state semiconductors, so-called transistors, and the subsequent miniaturization of electronic circuitry that would revolutionize the field of assistive devices for individuals who were deaf or hard of hearing (Public Broadcasting Service [PBS], 1999). Refinements in the quality of both group and personal amplification systems would increase their use and effectiveness.

\section{Certification Procedures for Teachers of the Deaf: Early Efforts}

As early as 1914, teacher educators expressed a need to systematize and standardize teacher preparation nationally. At the 1914 Convention of American 
Instructors of the Deaf, papers addressed the shortage of trained teachers and the variety of programs being offered (Yale, 1914). However, little appears to have been done to implement and standardize procedures during the following 5 years. In May 1919, Dr. Edwin LaCrosse suggested that AG Bell establish an examination system for granting certificates to proficient teachers (Winnie, 1919). For another 5 years, no action was taken. In 1924, an editorial in The Volta Review indicated a growing interest in standardized teacher training (Brill, 1971).

\section{The Standards of 1926}

Between 1924 and 1926 much thought was given to the development of standards. Naturally, this led to a controversy concerning whether prospective teachers should be required to receive training in manual communication. Yale and Percival Hall, president of Gallaudet University, conducted a "war of letters." Both individuals were serving on a committee appointed by the Conference of Superintendents and Principals ${ }^{15}$ to propose a course of study for preparing teachers of the deaf (Brill, 1971). Apparently this controversy was settled by removing the proposed requirement for manual communication training, for the course outline approved by the Conference in 1926 does not include it (see Appendix for a list of recommended courses).

\section{Certification Controversies}

The 1926 recommendations did little to establish uniform standards. By 1928, AG Bell and the Conference each had developed separate standards, although several individuals held prominent positions in both organizations. It is likely that the reasons for this situation stemmed from the basic differences in educational philosophy and methodology of the two groups, the Conference leaning toward manual or combined instruction for the deaf and AG Bell supporting auditory-based methods. Both organizations issued separate certificates until March 1935 when representatives from both groups tried to resolve the differences. The meeting resulted in the selection of the Conference as the sole certifying agency for the profession. The Conference standards were based, in large part, upon the criteria adopted in 1926 and remained in effect until their revision in 1951 (Brill, 1971). They have subsequently undergone revisions about once each decade. ${ }^{16}$

\footnotetext{
${ }^{15}$ This organization later became known as the Conference of Executives of American Schools of the Deaf (CEASD).

${ }^{16}$ In 1960, the CEASD delegated its authority for certification to the newly formed Council on Education of the Deaf.
} 


\section{The Advent of the Cooperative Teacher Preparation Programs}

Concurrent with the efforts to standardize teacher training programs were several independent attempts to upgrade the quality of prospective teachers of the deaf. Despite the fact that teachers were in short supply, it was essential to attract the best possible candidates. Since it was common for normal school graduates to go directly into teaching without considering additional training (Yale, 1914), it seemed advisable for schools for the deaf to affiliate with normal schools to attract prospective teachers before they sought other employment.

In 1913, the first cooperative degree-granting program was established as an affiliation between the Milwaukee State Normal School and the Milwaukee Day School [for the Deaf], where the program had been developed. It began as a 2-year program and was extended to 3 years in 1916 (Winnie, 1919).

Smith College and Clarke School, situated adjacent to each other, had exchanged faculty members since the late 1800s. In 1916, Yale became a lecturer in phonetics at Smith College. By 1925, the Clarke Normal Class was taking psychology and education courses from members of the Smith faculty as a regular part of the program, (Annual Report, 1926) and Smith students were taking special courses from the Clarke School staff. In 1926, credit for graduate work at Clarke was added to the regular Smith curriculum (Putnam, 1926).

In 1930, CID received a $\$ 125,000$ grant from the Rockefeller Foundation for planning and implementing a new collaborative teacher training program with University College at Washington University. ${ }^{17}$ The proposed program would include 2 years of liberal studies at University College and 2 years in teacher training courses at CID leading to a bachelor of science in education. Although Washington University would not formally approve the program until February 1931, CID's apparent faith in its approval led it to accept its first group of 17 prospective degree candidates in September 1930 (Lane, 1981). CID's success prompted officials at Clarke School to take similar action, which led to the implementation of a master's degree program in 1932.

At the same time, a process to upgrade teaching credentials was underway at the Lexington School in New York. In 1932 the school's board of trustees approved a resolution that, "beginning September 1, 1934, only graduates of 'standard' (approved) colleges would be employed as teachers in the academic department." By the 1935-36 school year, the school's teacher-in-training program had been approved for 16 graduate credits, half a master's degree, by both New York University and Teachers College at Columbia University (Connor, 1992, p.62).

\footnotetext{
${ }^{17}$ Another major purpose of this grant was to help CID establish a preschool program for children with hearing loss, an innovative concept at the time that was gaining favor in oral schools (Lane, 1981).
} 


\section{Parents Join "The Team"}

From the very beginning, education of children with hearing loss in America had been offered exclusively by professional teachers who mostly lived and worked with these children in residential schools. Parents were expected to place their children's future in the hands of these experts and with few alternatives available, they complied..$^{18}$ It was common into the 1960 s for students to be in residence at least during the school week. In rural schools, students might remain for weeks at a time, even for an entire term, without seeing their parents, in effect almost becoming strangers in their own homes. Parents seemed to accept that they had no active role in the children's education. As early as the 1940s, however, a change could be seen:

After Spencer and Louise Tracy's infant son was diagnosed with profound hearing loss in 1925, Louise Treadwell Tracy devoted her time and energy to studying how deaf children could be taught to communicate with the hearing and speaking world. She patiently guided her son, John, into an understanding of language and lip-reading. With her encouragement, he learned to speak. In 1942, Mrs. Tracy responded to a desperate call for help from twelve other mothers of young deaf children by founding John Tracy Clinic. (John Tracy Clinic [JTC], 2009)

Although this statement captures the essence of Louise Tracy's journey of discovery, it does not do justice to her years of selfless dedication to her son and to parents of other children who are deaf. The study group she organized was the first step in creating the world's preeminent center for parent education and early intervention, which would offer direct parent-child services at its Los Angeles, CA, site and provide worldwide outreach through correspondence courses for parents of infants and preschoolers with hearing loss.

The University of Southern California (USC) provided a small frame dwelling for the original mothers' group, which they named the John Tracy Clinic "for deaf and hard of hearing children and their parents"; the Clinic opened in October 1942 (JTC, 1957, p.1).

By 1946, the Clinic's programs were sufficiently developed to be shared with others interested in parent education and preschool development of children who are deaf or hard of hearing. A summer training course for teachers was started in conjunction with USC. "The program was coordinated with the summer program for mothers and children. The purpose was to enable already trained teachers of the deaf to learn the Clinic's philosophy and observe the teaching done at the Clinic" (Jamison \& Desler, 1965, p. 34).

\footnotetext{
${ }^{18}$ Because of transportation (and perhaps safety) concerns, even urban schools had only limited numbers of commuting pupils.
} 
USC added a course in preschool teaching to the Clinic's teacher training program in 1951. In January 1954, USC approved a new cooperative master of science $^{19}$ for prospective teachers who wished to specialize in work with preschool-aged children who were deaf (Lane, 1974). The collaboration between the two institutions would last for 5 decades. ${ }^{20}$ The John Tracy Clinic became yet another pioneering oral school and a highly respected "professional development school" conducting its courses on location and sending its teaching alumni worldwide to provide "parent-centered services to young children with a hearing loss offering families hope, guidance, and encouragement" (JTC, 2009).

\section{Pursuit of Federal Aid for Teacher Education: The First Attempt}

The acute national shortage of trained teachers of the deaf that had existed for more than a century showed no signs of reduction by the late 1950s; in fact, it was becoming "desperate" (Clarke, 1959). The Clarke School would play a prominent role in addressing this situation.

As part of its development campaign during the mid-1950s, Clarke School had included fundraising for research and teacher education. In February 1958, Evan Johnston, Clarke's director of development, was in Washington, $\mathrm{DC}$, seeking funding from various government agencies. Johnston's visits were deliberate; the Supreme Court's landmark Brown v. Board of Education ${ }^{21}$ decision in 1954 had given renewed impetus to the American civil rights movement with special emphasis on education. Coupled with the 1957 launch of Sputnik by the Soviet Union, the federal government was concerned about America's status as a world power. Unparalleled national attention was being focused on American education.

However, until then the federal government had played a very limited role in education. The Constitution of the United States is clear that powers not delegated to the federal government are "reserved to the States..." (Amendment X). With regard to education, the Constitution is silent. Prior to the 1950s only a few federal laws affected special education. ${ }^{22}$ In 1958, President Eisenhower signed Public Law 85-905, creating a loan service to provide captioned films for the deaf that would be housed in and funded through the Department

\footnotetext{
${ }^{19}$ Members of the inaugural class optimistically began their courses in September 1953, 4 months before USC's official approval of the graduate degree program (JTC, 1957).

${ }^{20}$ In recent years, a new JTC-based master's program has been established with the University of San Diego (see McGinnis in this issue).

${ }^{21}$ Brown v. Board of Education, 347 U.S. 483, decided May 17, 1954.

${ }^{22}$ The first in our field was Public Law 34-5, which established the Columbia Institution for the Deaf, Dumb and Blind in 1857, which was followed in 1864 by the law establishing Gallaudet University.
} 
of Health Education and Welfare (Captioned, 1977). The needs of individuals who were deaf or hard of hearing were gaining recognition at a national level.

Clarke School officials learned about a bill before Congress "to encourage expansion of teaching in the education of mentally retarded [sic] through grants to institutions of higher learning and to State educational agencies. Mr. Johnston had very encouraging meetings with Senators [John] Kennedy, [Leverett] Saltonstall, and [Joseph] Clark, and enlisted their aid in an attempt to have [this] pending legislation reworded to include deaf children..." (Magna, 1958).

Senator Kennedy arranged for a meeting with Senator Lister Hill of Alabama, chairman of the Labor and Public Welfare Committee of the Senate to which bills concerning such matters would be referred. Senator Hill was largely responsible for shepherding the bill for the expansion of special education teachers. Influenced by deafness in his own family, he wanted to help, believing that the problem should be tackled on a national level. He thought, and Senators Kennedy and Saltonstall agreed, that the needs of the deaf would best be served by a separate bill rather than an amendment to the current bill. Thus began a 3-year struggle to enact training legislation for prospective teachers of the deaf (Clarke, 1959).

In October 1958, the Conference of Executives passed a resolution in support of this legislation (Conference of Executives of American Schools for the Deaf, 1958). Hearings began in April, and the bill was finally passed by a voice vote on May 27, 1959. However, problems arose in the House. The legislation became stalled in the Subcommittee on Special Education due to opposition from the Department of Health, Education, and Welfare, ${ }^{23}$ which cited three objections: the bill's financing should remain a state responsibility; greater needs existed within the mandate of the Department; and various agencies already had responsibility for providing services. Amendments were attempted, but the bill "died" in committee, ending Round 1 (Clarke, 1959).

\section{Founding of the Council on Education of the Deaf (CED)}

The potential impact of teacher training legislation in 1959 prompted a unification effort unparalleled in the history of American deaf education. Arguments concerning methodology dropped by the wayside as school officials joined to support a common cause. On January 20, 1960, representatives of the Conference of Executives, American Instructors, and AG Bell met in Washington, DC, and mapped out a plan to unify the three organizations in matters of common concern by forming the Council on Education of the Deaf (CED). CED was to coordinate training practices, legislation, meetings,

\footnotetext{
${ }^{23}$ Predecessor to the now-separate U.S. Department of Education.
} 
outreach to lay and peripheral groups, teacher certification, and public information. Each of the three constituent organizations would have four representatives, and each representative would have one vote. To avoid conflicts, each group also was to have veto power (Council on Education of the Deaf, 1960).

By the summer of 1960, a constitution and bylaws had been adopted and approved by the executive committees of all three organizations. CED's first regular meeting was held in October 1960 in Washington, DC. Clarke School Principal George Pratt was appointed chairman of CED's Legislative Committee. Round 2 was about to begin.

\section{The Second Legislative Attempt}

Hopes brightened for passage of teacher training legislation with the election of John F. Kennedy as president, because he had been instrumental in organizing and co-sponsoring the 1959 resolution. On January 10, 1961, Senator Hill introduced a bill identical to the first. Representative Joseph Montoya of New Mexico introduced the same bill to the House on February 20. The Senate bill passed, and the House bill was referred to the Special Committee on Education (Committee, 1961). On July 17, Senator Hill notified Dr. Pratt that the House bill had not been considered favorably by the House committee. An urgent appeal went out to all coordinators, schools, and classes for the deaf to contact their Representatives and urge them to support the legislation (Pratt, 1961). The appeal worked. On September 22, 1961, President Kennedy signed Public Law 87-276 into law (Pratt, 1961).

The advisory committee authorized by the law began its work in January 1962 to develop plans for awarding scholarships and grants-in-aid. Initially, 446 scholarships were awarded to 43 institutions of higher learning in 30 states and the District of Columbia. ${ }^{24}$ During the first 2 years the legislation was in effect, 948 scholarships were granted. Nationwide, 470 teachers of the deaf graduated in 1963. Prior to the legislation's enactment, approximately 150 teachers graduated each year (Withrow, 1967).

The long-term impact of this legislation cannot be overstated; it has been subsumed into numerous other federal laws. ${ }^{25}$ Although priorities periodically have changed, the federal government has continued to support personnel preparation, and the legislation CED so strongly promoted in 1961 has

\footnotetext{
${ }^{24}$ Included in this group were Smith College, Columbia University, Washington University, and USC plus several other institutions that had by then established oral training programs.

${ }^{25}$ In 1963, President Kennedy signed Public Law 88-164. This law amended P.L. 85-926 (1958 Mental Retardation Act) to include six other areas of exceptionality. This law also extended P.L. 87-276 for one more year, after which it would be included as part of P.L. 85-926. Public Law 85-926, as amended, remained in effect until April 13, 1970, when President Nixon signed Public Law 91-230, which extended the Elementary and Secondary Education Act of 1965. Title VI of this law was the "Education of the Handicapped Act" which consolidated all activities associated with special education (Trudeau, 1972).
} 
had an immeasurable impact on the education of children with hearing loss in America. Detailed demographic data are not available, but thousands of teachers who otherwise might not have had the financial resources to undertake further studies have entered this field.

\section{Landmark Legislation on Behalf of Families and Children}

The 1960s and 1970s were decades of unprecedented legislation in the areas of civil rights and education, and the laws passed on behalf of racial minorities and those enacted to improve the quality of American education also had a noticeable impact on individuals who were deaf or hard of hearing. Public Law 89-36, the National Technical Institute for the Deaf Act signed by President Johnson in 1965, met the criteria of serving a minority population and advancing America's need for improved technical education. However, other laws in the works would revolutionize the education of deaf children.

In 1972, Massachusetts enacted the Omnibus Special Education Act, which would become known as Chapter 766 and would take effect in 1974.

Parents were the prime movers behind this law, believing always that even students with the most significant disabilities had a fundamental right to receive a public education that would enable them to maximize their own potential. Working with educators, administrators, policy makers and others, parents formed unprecedented coalitions to ensure passage of this law. (Robinson, 2004)

Chapter 766 had its origin in the mistreatment of children in one of the state's schools for children with mental challenges. ${ }^{26}$ The resulting litigation $^{27}$ and legislation radically changed America's educational landscape. The key mandates of the new law were incorporated into Public Law 94-142, The Education for All Handicapped Children's Act, and are well known today. The law required that children be provided with a free, appropriate public education in the least restrictive environment, creation of an Individualized Education Program (IEP), and direct parent involvement in the decisionmaking that affects their children's education.

For children with hearing loss, this legislation would have far-reaching consequences related to the interpretation of terms such as "appropriate" and "least restrictive." In 1975, 49\% of American students who were deaf or hard of hearing were in residential or day schools (Office of Demographic Studies, 1976). Although the trend toward mainstreaming students who used spoken language was underway, the new laws accelerated it.

\footnotetext{
${ }^{26}$ For details, consider reading: Ricci, B. (2004). Crimes against humanity: A historical perspective. Lincoln, NE: iUniverse, Inc., 2004.

${ }^{27}$ Ricci v. Greenblatt (1972).
} 
For those who were preparing oral teachers, program curricula needed to change with those trends. More consideration had to be given to individualizing services in resource rooms and itinerant settings rather than in traditional settings. ${ }^{28}$ Increasingly, teachers would find themselves serving as support personnel, and would need to become familiar with working on teams for IEP development and coordinating services for children. Because parents were required to be more actively involved with their children's education, prospective teachers also needed to be better prepared to offer them direct assistance in planning and problem solving. New teachers had to be ready to serve as educational consultants for teachers who had no preparation for the inclusion of children with hearing loss in their classrooms. It also became increasingly important for teachers to collaborate in designing new curricula to meet the mandates and the challenges that the new law presented.

\section{Creation of a New Organization for the Educators of Teachers}

In the mid-1970s, about 60 programs in North America were preparing teachers to serve students who were deaf or hard of hearing and their families. Fewer than a dozen were preparing oral teachers. The majority of teacher preparation programs were affiliated with the manually orientated schools, which acknowledged in some instances the value of listening and spoken language skills for children but maintained a strong commitment to developing manual communication skills in their trainees. ${ }^{29}$ Although some teacher educators might gather at the alternating biennial meetings of AG Bell and the American Instructors of the Deaf, there was no organized forum in which they could meet to share ideas and discuss matters of common concern until 1975 when Lee Murphy at the University of Tennessee teacher education program invited colleagues to a conference in Knoxville.

Public Law 94-142, The Education for All Handicapped Children's Act, was affecting children with hearing loss irrespective of communication methodology, and teacher educators were facing new issues that transcended methodological beliefs. The Knoxville conference concentrated on these concerns, and a second meeting was held the following year. For the first few years these were large, informal round-table discussions. However, by 1979 participants began to form a professional organization, the Association of College

\footnotetext{
${ }^{28}$ Residential and day schools for children who were deaf would steadily lose "market share" in the ensuing years as public school administrators usually considered them to be inappropriate and more restrictive than local schools.

${ }^{29}$ During the 20th century, oral educational practices had been incorporated into the curricula of many of schools that originally had been established as manual schools. This was particularly true for children in the early grades.
} 
Educators for the Hearing Impaired (ACE-HI), which was later renamed the Association of College Educators-Deaf and Hard of Hearing (ACE-DHH) ${ }^{30}$

Recognizing that the educational landscape for children with hearing loss was changing and that teacher educators must know more about oral education, the group invited Daniel Ling, who was then the director of McGill University's teacher education program, to the 1980 annual meeting to talk about his views on the future of teacher education. R. Orin Cornett of Gallaudet University, creator of Cued Speech, spoke about its use by individuals who were deaf or hard of hearing for the reception and development of spoken language (H. Teller, personal communication, February 15 and March 29, 2010).

In the years that followed, ACE-DHH successfully petitioned to become the fourth official member of CED. The organization played a key role in shaping the 2003 CED teacher preparation standards to address each program's philosophy (i.e, auditory-oral, bilingual-bicultural, or comprehensive) and the underlying assumptions and objectives of the program (CED, 2003).

ACE-DHH remains a small, informal organization ${ }^{31}$ with an active membership. For 36 years, members have met annually to discuss teacher education issues of both common concern and specific methodological interest in an atmosphere of mutual respect and collaboration. ACE-DHH was awarded a series of federal personnel preparation grants from the late 1990s through the mid2000s to advance the educational technology skills of both members and their students. In 2010, this collegiality resulted in ACE-DHH's participation in a multimillion dollar federal grant awarded to the National Leadership Consortium in Sensory Disabilities for member-affiliated universities across the country for the purpose of preparing future doctoral level leaders in this field.

\section{Impact of the Cochlear Implant "Revolution" on Teacher Preparation}

Although amplification devices and auditory-based teaching techniques had become highly refined and effective by the early 1980s, in numerous instances children and adults who were profoundly deaf still had only limited access to auditory information. That would change dramatically with the introduction of the cochlear implant.

In the early 1980s there was considerable skepticism about the device's potential effectiveness, a situation similar to that encountered by Dr. Goldstein at the beginning of the century. The first generation of implants pioneered by William House of California's House Ear Institute did have relatively limited

\footnotetext{
${ }^{30}$ Impetus came, in part, from advocates of the growing Deaf Culture movement, who did not view hearing loss as an "impairment."

${ }^{31}$ ACE-DHH was not legally incorporated until February 2006 (Finnegan, 2010). Prior to that, legal matters related to grants were handled by various universities affiliated with ACE-DHH members.
} 
capabilities; however, they proved it was possible to electrically stimulate the cochlea, thereby permitting the brain to process sound. Many were implanted successfully in adults and some children.

Australian researchers led by Graeme Clark developed a more technically sophisticated, multi-channel device capable of delivering a wider array of stimulation to the brain increasing the potential for speech discrimination and language acquisition; clinical trials with adults confirmed the implant's effectiveness (Clark, 1997). By 1990, the device had undergone numerous trials with adults and children and was approved by the U.S. Food and Drug Administration (FDA) for use with children as young as 2 years old (NIH, 2006). ${ }^{32}$

Cochlear implants have provided these children with the potential for living and learning alongside their peers with typical hearing. Substantial parental and professional support is usually necessary to realize their full potential, especially in the early years, but the results since 1990 have been remarkable. Across America many new early intervention programs have opened to serve these children, supported in many instances by generous, private foundation grants. In an effort to ensure that children will have skilled professionals to serve them, similar grants have been awarded to teacher education programs in support of their students.

To remain relevant, teacher education programs have changed their curricula to address the needs of the growing population of children with cochlear implants and their families. Attention has shifted to early detection, intervention in natural (home) settings, working with families, teaming with professionals in allied disciplines, and development of family service plans. Special consideration also is given to the impact of cochlear implants on the acquisition of listening and spoken language. In short, the needs of children ages birth to 5 years has become the primary focus, without forgetting that these children also may need special services throughout their years of schooling.

\section{Conclusion}

When we examine the history of professional preparation programs in America, it is clear that we owe much to the dedicated parents, educators, legislators, and scientists who saw their responsibility to foster the positive development of children with hearing loss. They devoted themselves to finding the most effective ways to help these children acquire the skills necessary to succeed in a world where listening and spoken language are the norm. They sought the advice of others, experimented with new concepts, procedures, and tools, and proposed new laws yet also recognized their obligation to share their wisdom and expertise with others including generations of future

${ }^{32}$ In 2000, the FDA lowered its minimum to 1 year of age. 
professionals. They created models for professional development schools and cooperative teacher preparation programs of today and tomorrow.

\section{References}

Alexander Graham Bell Association for the Deaf and Hard of Hearing (AG Bell). (1931). Plan for teacher registration as adopted at the 14th program meeting of the American association to promote the teaching of speech to the deaf. Washington, DC: The Volta Bureau.

Annual Report[s]. (1901-1936). Clarke School for the Deaf, Nos. 34-69. Northampton, MA: Press of the Gazette Printing Co. and Metcalf Printing Co.

Bell, A.G. (1918). The Growth of the Oral Method in America. In Fiftieth Annual Report of the Clarke School for the Deaf. Northampton, MA: Press of the Gazette Printing Co.

Bender, R.E. (1981). The conquest of deafness ( $3^{\text {rd }}$ ed.). Cleveland, OH: The Press of the Western Reserve University.

Brill, R. (1971). Administrative and professional developments in the education of the deaf. Washington, DC: Gallaudet College Press.

Captioned Films for the Deaf, A Brief History of...(1977). Bloomington, IN: Indiana University Audio Visual Center. Retrieved January 30, 2010, from http://www.dcmp.org/caai/nadh91.pdf.

Central Institute for the Deaf. (2009). About our founder. Retrieved February 6, 2010, from http:/ / cid.edu/AboutCID/History / AboutOurFounder.aspx.

Clark, G., et al. (1997). Cochlear implantation for infants and children. Florence, KY: Cengage Learning.

Clarke School for the Deaf. (1924). Summer school (Folder in the teacher education file, president's office). Northampton, MA: Author.

Clarke School for the Deaf. (1959-1960). Progress reports - federal legislation (Nos. 1-18, file in the president's office). Northampton, MA: Author.

Conference of Executives of American Schools for the Deaf. (1958). Minutes of the 30th meeting. Washington, DC: Author.

Connor, L. (1992). The history of the Lexington School for the Deaf (1864-1985). New York: Lexington School for the Deaf.

Council on Education of the Deaf. (1960). Founding of the Council on Education of the Deaf. American Annals of the Deaf, 105(2), 222-224.

Council on Education of the Deaf. (2003). Standards for programs preparing teachers of students who are deaf and hard of hearing. Retrieved February 6, 2010, from http://www.deafed.net/activities/manualonerevised.htm.

DeYoung, C., \& Wynn, R. (1970). American education (6 ${ }^{\text {th }}$ ed). New York: McGraw-Hill Book Co.

Dudley, L.J. (1890) Report of the corporation. In Twenty-third annual report of the Clarke Institution for Deaf-Mutes. Northampton, MA: Gazette Printing Co. 
Dudley, L.J. (1893). Report of the corporation. In Twenty-sixth annual report of the Clarke Institution for Deaf-Mutes. Northampton, MA: Press of the Gazette Printing Co.

Fletcher, S. (1992). Harvey Fletcher (1884-1981): A biographical memoir. Washington, DC: National Institutes of Science. Retrieved March 31, 2010, from http:/ /books.nap.edu/html/biomems/hfletcher.pdf.

Hubbard, G.G. (1893). Founding and early history of the Clarke Institution. Addresses delivered at the twenty-fifth anniversary of the opening of the Clarke Institution for Deaf-Mutes. Northampton, MA: Press of the Gazette Printing Co.

Jamison, A.M., \& Desler, J.E. (1965). John Tracy Clinic: A brief historical account, 1942-1964. (Master's theses, University of Southern California, 1990).

John Tracy Clinic. (1957). Some history high lights[sic]. Los Angeles: Notes from the Clinic's files provided by Dr. Barbara Hecht.

John Tracy Clinic. (2009). Retrieved April 28, 2010, from http:/ /www.jtc.org.

Lane, H.S. (1981). The history of Central Institute for the Deaf. St. Louis, MO: The Central Institute for the Deaf.

Lane, M.C. (1974). The melbo years: A history of the school of education of the University of Southern California, 1953-1973. Los Angeles, CA: University of Southern California Press.

Magna, E. (1958). Report of the general chairman of the centennial development program (Files of the president's office). Northampton, MA: Clarke School for the Deaf.

National Institutes of Health. (2006). Cochlear implants - fact sheet. Retrieved March 29, 2010, from http://www.nih.gov/about/researchresultsforthe public/CochlearImplants.pdf.

Office of Demographic Studies. (1976). Annual survey of hearing-impaired children and youth, 1975-76. Washington, DC: Gallaudet College.

Public Broadcasting Service. (1999). Transistorized. Retrieved January 15, 2010, from http://www.pbs.org/transistor/album1/index.html.

Pratt, G.T. (1961). Memoranda-federal legislation (Nos. 1-8). Northampton, MA: Clarke School for the Deaf.

Putnam, W. (1926). Report on survey of work for the deaf in the United States. New York: Tamblyn and Brown.

Quigley, S.P. (1958). Major problems in teacher education and recruitment. The Volta Review, 60(7), 366-370.

Quigley, S.P (Ed.). (1964). The preparation of teachers of the deaf. A report of a national conference, Virginia Beach, Virginia, March 15-19, 1964. Washington, DC: U.S.O.E.

Quotations Page, The. (2007). Quotations by author - Galileo Galilei. Retrieved April 28, 2010, from http://www.quotationspage.com/quotes/ Galileo_Galilei/.

Report of the Committee on the Standardization of Normal Courses for Teachers of the Deaf. (1927). American Annals of the Deaf, 72(1), 153-161. 
Robinson, R.J. (2004, Winter). 30 years: Then and now! Retrieved January 28, 2010, from http://www.fcsn.org/aboutus/ed/ed21.php.

Scouten, E. (1984). Turning points in the education of deaf people. Danville, IL: Interstate Publishers and Printers.

Trudeau, E. (1972). Digest of state and federal laws: Education of handicapped children (2nd ed.). Arlington, VA: Council for Exceptional Children.

Williams, J. (1893). The American asylum. In Histories of American schools for the deaf, 1817-1893, Vol. I. Washington, DC: The Volta Bureau.

Winnie, A.J. (1919). Normal training of teachers of deaf children. The Volta Review, 21(1).

Withrow, F. (1967). Public law 87-276: Its effect on the supply of trained teachers of the deaf. The Volta Review, 69(10), 656-663.

Yale, C. (1893-1914) Report[s] of the principal. In Annual Report[s], Nos. 26-47. Northampton, MA: Clarke School for the Deaf.

Yale, C. (1931). Years of building. New York: The Dial Press. 


\section{Appendix: Suggested Outline for the Course of Study of Normal Classes (1926)}

1. Study of the young deaf child on entering school/Study of the semideaf and semi-mute child.

2. Preparatory sense training (sight and touch).

3. Anatomy of the organs of speech and hearing.

4. Phonetics (or speech training). One hour daily throughout the entire year.

(a) Vowel and consonant charts

(b) Diagrams of positions for elementary sounds.

(c) Formation and development of elementary sounds.

(d) Melville Bell's symbols of visible speech.

5. Voice development and placing.

6. Speech reading.

7. Residual hearing.

(a) Measurement of.

(b) Training of.

8. Language for the deaf child.

(a) Elementary vocabulary.

(b) Methods of sentence construction.

(c) Stories for speech reading.

(d) Stories for thought reading.

9. Methods employed in the teaching of elementary geography, arithmetic, etc. Methods employed in the teaching of advanced arithmetic, algebra, science, history, civil government, current events, etc.

10. Daily programs for different grades.

11. Outline of general course of study.

12. The habit of reading for information and for pleasure. How formed? How encouraged?

13. Educational psychology.

14. History of the education of the deaf.

15. Religious instruction.

16. The deaf as a class.

(a) Terminology concerning

(b) Methods of instruction

(c) Occupations of the deaf

(d) Organizations of the adult deaf

17. Types of schools. Organizations and officials.

18. Speech reading for adults. 
19. Daily observation of classroom work of experienced teachers. One hour per day. (Notes on these handed in regularly for examination and correction).

20. Daily practice work in teaching under supervision. One to two hours per day, not including any work as a substitute teacher.

21. Observation of physical training.

22. Observation of manual training. (Report, 1927) 



\title{
Trends and Challenges in Teacher Preparation in Deaf Education
}

\author{
Susan Lenihan, Ph.D., CED
}

Recent developments in deaf education are influencing teacher preparation programs, which are facing challenges in meeting the critical need for highly qualified teachers. Of approximately 65 teacher preparation programs in the United States, 11 programs focus primarily on preparing teachers to work with children who are deaf or hard of hearing and who use listening and spoken language, and 54 programs focus primarily on visual communication strategies. Advances in technology, changes in the population of children served, and shifts in educational placements and certification requirements are trends that impact teacher preparation programs. Challenges to these programs include issues related to faculty, university support, curriculum development, student recruitment, and recognition of the profession's value.

\section{Introduction}

The history of teacher preparation in deaf education is rich and reflects changes in society, developments in education, innovations in technology, and a number of controversies related to how best to educate children who are deaf or hard of hearing (see Marvelli in this issue for a history of teacher preparation programs). Recent developments in deaf education are influencing teacher preparation, and the programs are facing challenges to meet the critical need for highly qualified teachers.

In the last 20 years, three developments have dramatically changed deaf education in the United States: universal newborn hearing screening, early intervention services, and the development of cochlear implants. The passage of the Walsh Act in 1997 increased the number of states requiring newborn hearing screening so that now all U.S. states and territories have screening programs, which has resulted in $95 \%$ of all newborns being screened for hearing loss compared to 3\% in 1993 (NCHAM, 2010; White, 2006). Although

Susan Lenihan, Ph.D., CED, is a Professor and Director of Deaf Education at Fontbonne University. Correspondence concerning this article should be addressed to Dr. Lenihan at slenihan@fontbonne.edu. 
loss to follow-up remains a problem in the early diagnosis of hearing loss, the average age of identification has decreased from 30 months to 6 months of age (Harrison, Roush, \& Wallace, 2003).

Research consistently shows that outcomes are significantly better for children with hearing loss when they receive early intervention services beginning before age 1 (Moeller, 2000; Nicholas \& Geers, 2006; Yoshinago-Itano \& Sedey, 2000). The Joint Committee on Infant Hearing (JCIH, 2007) recommends that early intervention services be provided by professionals with expertise in hearing loss and cites the shortage of trained professionals as a challenge to providing services. In addition, quality early intervention services must be family-centered and collaborative (Rice \& Lenihan, 2005).

In the United States, more than 25,000 children have received cochlear implants (NIDCD, 2009). Children who receive cochlear implants at an early age have access to sound during the critical language learning window from birth to approximately 3 years of age (Sharma, Dorman, \& Spahr, 2002). By the age of 6 , children who received implants between ages 1 and 2 showed similar language skills on many language measures as their peers with typical hearing (Svirsky, Teoh, \& Neuburger, 2004). Studies of children who use cochlear implants and who are enrolled in programs that focus on listening and spoken language alone consistently demonstrate better speech and language performance outcomes than children using CIs who are enrolled in programs that utilize sign language (Moog \& Geers, 2003). Moreover, increasing numbers of children are using bilateral cochlear implants with better outcomes in speech perception and localization, particularly in noisy environments, than children who use a unilateral implant (Johnston, Smith, O'Connor, Benzies, Fitzpatrick, \& Angus, 2009).

Although the exact number of teacher preparation programs in deaf education changes from year to year, there are two sources that provide the most current information. These sources are the listing of professional preparation programs published annually in the April issue of the American Annals of the Deaf, and the program listing on the website www.deafed.net (Deaf Ed Teacher Preparation Programs, 2009; Programs for Training Teachers, 2009). These lists are updated periodically and include information such as number of graduates, program philosophy, Council on Education of the Deaf (CED) accreditation status, and contact information. Although discrepancies between the lists exist, it is reasonable to estimate that approximately 65 U.S. universities have teacher preparation programs in deaf education, including 29 undergraduate programs and 51 graduate programs. Thirty-five states have at least one teacher preparation program, with California, Texas, New York, and Ohio each having four or more programs. Most of the teacher preparation programs have one or two faculty members and most have fewer than 15 graduates each year (Programs for Training Teachers, 2009). There has been a critical shortage of deaf education teachers nationwide for many years (Johnson, 2004). With the small number of graduates, the closing or suspension of several programs 
in recent years (Deaf Ed Teacher Preparation Programs, 2009) and the anticipated retirement of many "baby boomer" professionals, it is likely that the critical shortage will continue (Johnson, 2004).

Another feature that differentiates these programs is their departmental structure. Many of the deaf education programs are in either education or special education departments, or speech and hearing departments (Deaf Ed Teacher Preparation Programs, 2009; Programs for Training Teachers, 2009). Teacher preparation programs must integrate the content of education, special education, and speech and hearing sciences into the curriculum, and program faculty must collaborate with faculty in those disciplines to provide the needed knowledge and experience. Programs that lack this integration and collaboration are not as effective in developing the future teacher's ability to facilitate the development of listening and spoken language and provide quality instruction (Rice \& Lenihan, 2005).

While CED-accredited programs are required to identify communication mode philosophy, not all provide this information. Based on data from 2004, White (2006) identified seven programs that focus primarily on preparing teachers to work with children acquiring listening and spoken language. In 2009 , these programs, along with four new programs that emphasize listening and spoken language, graduated approximately 60 students (see Appendix A for a list of programs). Anecdotal information from directors of listening and spoken language programs in both OPTION schools (private schools that focus on listening and spoken lanuage education for children with hearing loss) and public schools shows that this number of graduates does not meet the need for teachers prepared for listening and spoken language programs.

\section{Trends in Teacher Preparation}

In the 21st century, teachers of the deaf and hard of hearing have many more professional roles than they previously held. Today's teacher in deaf education may be teaching children ranging in age from 3 to 21 years in a public or private school setting; providing early intervention services to infants, toddlers, and their families; supporting children in general education settings through itinerant services; or serving as program administrators (Dolman, 2008; Rice \& Lenihan, 2005; Teller \& Harney, 2005/2006; Winn, 2007). Prior to the 1975 passage of Public Law 94-142 - Education of the Handicapped Act, most children with hearing loss were in self-contained classes or residential programs with other children with hearing loss. In the last 30 years, there has been a huge shift from self-contained placements to inclusive placements (Moores, 2006). Teacher preparation programs need to train teachers who are prepared to adapt to changing roles and for a variety of educational settings (Luckner \& Howell, 2002).

To prepare teachers, some teacher preparation programs include an emphasis in curriculum and practicum that provides more depth on a particular 
professional role. For example, the Early Intervention in Deaf Education program at Fontbonne University includes coursework and practicum that focuses on family-centered early intervention (Fontbonne University, 2010). The program at the University of Hartford collaborates with the CREC-Soundbridge program, which provides services to children in public schools in Connecticut (University of Hartford, 2010) (see Paterson \& Cole in this issue). The John Tracy Clinic/University of San Diego program includes an emphasis on serving multicultural children and families (John Tracy Clinic, 2010) (see McGinnis in this issue). The program at the University of Southern Mississippi offers two courses in working with children with additional disabilities (University of Southern Mississippi, 2010) (see Perigoe \& Teller in this issue).

In addition to the multiple roles that teachers in deaf education fill, changes in the population they are serving also require additional knowledge and skills. The success of universal newborn hearing screening has increased the number of children identified in the first six months of life, increasing the number of children ages 0 to 3 years who seek services (White, 2006). The knowledge and skills required to serve young children and their families are different from the skills required for preschool through secondary teaching $(\mathrm{JCIH}, 2007)$. Now that the number of children using cochlear implants in the United States is more than 25,000, teachers serving children with cochlear implants need knowledge of the devices and skills necessary to maximize the benefits of cochlear implants. The number of children identified as having additional disabilities has increased in the last 25 years and is currently estimated to be approximately $40 \%$ of children with hearing loss (Bruce, Dinatale, \& Ford, 2008; Luckner \& Carter, 2001). The number of children who are English language learners and whose families do not use English as the primary language in the home also has steadily increased (Rhoades, Price, \& Perigoe, 2004), and an understanding of various approaches to providing services to children and families whose home language is not English is essential to effectively serve these children. Recent economic problems have increased the number of children living in poverty. Their families have difficulty accessing health care and educational services, and educators need to understand how advocacy and support can dramatically improve the outcomes for these children (White, Chau, \& Aratani, 2010; Lenihan, Rice, \& Voss, 2010).

Another expanding area of knowledge and skill for teachers in deaf education is technology - both listening technology and instructional technology (Marttila, 2004; Roberson, 2001). An effective teacher must be knowledgeable about the array of listening technologies that will optimize outcomes for a child with hearing loss. The improvements in hearing aid technology, cochlear implants, and the ongoing changes in candidacy for implantation require teachers to keep abreast of these developments (Teller \& Harney, 2005/2006). Teachers must also be able to recommend and use classroom listening systems. Depending on the professional role, this knowledge and skill will have a different focus. For example, an early interventionist needs to support parents 
and collaborate with audiologists in the early fitting of hearing aids or cochlear implants and on the early use of listening (Rice \& Lenihan, 2005). An itinerant teacher must effectively troubleshoot devices, communicate with audiologists, and teach general education classroom teachers about listening devices, classroom listening systems, and classroom acoustics (Luckner \& Howell, 2002). Teacher preparation programs must include content and experiences that prepare future teachers for these roles and for the use of listening technology.

Teachers in self-contained classrooms or providing itinerant services need to understand how to use the latest instructional technology, including interactive whiteboards, laptops, Internet technology, and educational and administrative software (which is used for record keeping for Individualized Education Program [IEP] development, progress reports, and other materials). Web-based programs that provide teletherapy or distance education will also be needed by teachers. Students with hearing loss will benefit from having access to technology, and teachers will be more effective if they are skilled users of an array of technologies (Johnson, 2004; Roberson, 2001).

Another trend teacher preparation programs face is the ever-changing certification requirements and the implementation of new state and federal legislation that impacts deaf education (Easterbrooks, 2008; Johnson, 2004). Each program must meet state requirements to ensure that students are eligible for certification when they complete the program. These requirements vary a great deal in each state and often require graduates who relocate to another state to complete additional requirements, including standardized tests and course work. For example, Minnesota requires every teacher to have a course in drug and alcohol awareness. A number of programs are also accredited by the National Council for Accreditation of Teacher Education (NCATE), which requires additional reporting and site visits. Most states require that certified teachers pass a general education test and a subject-specific test in deaf education. For most states, the subject-specific test is the PRAXIS exam for the education of students who are deaf or hard of hearing. This comprehensive test covers content on human development, the learning process, and educational policies and practices. The exam is currently being revised, but likely will continue to include content on American Sign Language (ASL) and Deaf culture, as well as content on listening and spoken language.

Thirty-six teacher preparation programs, including seven programs that focus on listening and spoken language, are approved by the Council on Education of the Deaf (CED). The Council for Exceptional Children (CEC) has collaborated with CED for nearly 20 years in the development of mutually agreed upon standards for teachers of children with hearing loss (Easterbrooks \& Putney, 2008). CED accreditation requires self-study based on a set of standards, a site visit every 10 years, and a report every 5 years (Easterbrooks, 2008; Easterbrooks \& Putney, 2008; Jones and Ewing, 2002). Administrators identify a program's philosophy as auditory-oral, bilingual-bicultural, or comprehensive and indicate specialization areas such as early childhood or 
elementary. A panel of CED evaluators reviews the self-study and the site visit and makes a recommendation to the CED Board, which then determines whether the program will receive accreditation. Graduates of CED-approved programs are eligible for CED certification. Applicants for CED certification may only apply for one or two areas of specialization based on the program's areas of approval.

Teacher preparation programs that focus on listening and spoken language now seek to include content and experiences designed to prepare students for the AG Bell Academy for Listening and Spoken Language certification process when they have completed the required post-graduation years of experience. While programs previously have included this content, program directors are reviewing curriculum to ensure that it addresses all nine domains of listening and spoken language covered on the certification exam (see Monograph Appendix A; AG Bell Academy, 2007) and that the practicum and student teaching placements include opportunities for supervision and mentoring by professionals who are certified Listening and Spoken Language Specialists.

In addition to the challenges of meeting certification requirements from state, national, and professional organizations, teacher preparation programs must continually update content to reflect changes in federal legislation (Dodd \& Scheetz, 2003). In the last decade, No Child Left Behind (NCLB) has greatly increased the emphasis on assessment. Federally mandated services, such as Response to Intervention (RTI), have also required teachers to approach assessment and service provision in new ways. Current federal efforts to design a common core of knowledge for all kindergarten through 12th grade students nationwide will further impact teacher preparation programs.

\section{Challenges of Teacher Preparation}

Teacher preparation programs face a number of challenges related to faculty, university support, curriculum, students, and recognition of the need for trained professionals. Finding qualified faculty for teacher preparation programs is a critical demand (LaSasso \& Wilson, 2000). In most cases, faculty members are expected to possess a doctoral degree and have experience teaching children with hearing loss. Programs that focus on preparing teachers for listening and spoken language outcomes need faculty members with experience teaching in a listening and spoken language setting. Demographic data on faculty show a population that is approaching retirement (Johnson, 2004). While some faculty members have completed doctoral studies in recent years and young professionals are currently in doctoral programs, meeting the demand for faculty in 10 years will be a challenge. The U.S. Department of Education Office of Special Education Programs has awarded a federal grant to the National Leadership Consortium in Sensory Disabilities. By providing funding for doctoral studies in vision, deafness, and deaf/blind, this project may assist in meeting the need for faculty. 
Several teacher preparation programs that focus on listening and spoken language have been in place for 50 years or more including those at Smith College in Northampton, MA, Washington University in St. Louis, MO, and Fontbonne University in St. Louis, MO (see Hayes; Rice \& Lenihan in this issue). These well-established programs have benefitted from excellent university support and, along with newer programs, must constantly demonstrate that their value is deserving of university support. Changes in administration, economic difficulties, and low student enrollment can erode support. Funding from private foundations, alumni, federal grants, and, in the case of public institutions, tax dollars have encouraged university commitment to these programs. Establishing and sustaining that commitment is an ongoing challenge for deaf education programs, which tend to have small numbers of students due to the low incidence of deafness.

Curricular challenges are primarily related to trends, including the changing role of the teacher, certification, the rapidly evolving technology available to children with hearing loss, and the lack of evidence-based research. Today's teacher needs more collaboration and coaching skills in addition to instructional skills (Foster \& Cue, 2009; Luckner \& Howell, 2002). Approaches to speech, listening, and language development that were considered best practices 25 years ago have been adapted to meet the needs of children who are identified early, receive listening devices, and participate in quality early intervention services (Lartz \& Litchfield, 2005, 2006).

Another challenge teacher preparation programs face is the recruitment and retention of an academically strong and diverse group of students. The challenges faced in recruiting future teachers in all areas of education have been well documented (Johnson, 2004). Deaf education programs have additional specialized content when compared to general education programs, and students in these programs must complete rigorous course work and practica (Easterbrooks, 2008). Many prospective students come to deaf education with an interest in sign language, so programs that focus on listening and spoken language need to recruit and educate potential students about the options available for children with hearing loss and why listening and spoken language is so important. Alumni and partner professional development schools are often very important in the recruitment process.

Finally, teacher preparation programs face the challenge of school districts hiring professionals without certification in deaf education to serve as teachers for children with hearing loss (Johnson, 2004). School administrators who have difficulty finding qualified applicants may think that a special educator or a speech-language pathologist can accomplish the same outcomes achieved by providing children with hearing loss the services of a teacher of the deaf. The move to educating children in local school districts, as well as the improved skills of children who received quality services at a very young age, have allowed a number of children with hearing loss to be served in local schools with support services from a special educator or a speech-language 
pathologist. While this may be effective for some children, the role that a teacher of the deaf plays in the education of a child with a hearing loss is critically important, particularly in early intervention, early childhood education, and for children who have additional disabilities (Bruce et al., 2008; Luckner \& Carter, 2001; Rice \& Lenihan, 2005).

\section{The Future of Teacher Preparation Programs}

For teacher preparation programs to successfully prepare educators to provide effective educational services to children with hearing loss, programs must acknowledge trends in deaf education and actively address challenges. Research on approaches for best educating the changing population of children with hearing loss, collaboration with professional organizations and programs serving children birth through age 21, curriculum redesign, and the recruitment of highly qualified prospective teachers are action steps that university program directors will need to implement. Teacher preparation curricula need to reflect the latest research findings and the experience of teachers in partner programs that serve children. The curriculum for future teachers must include content and experiences that enhance the development of knowledge and skills for serving children who are using the newest listening technology, children who have additional disabilities, children whose families use languages other than English in the home, and children who are identified in the first months of life.

In March 2009, a group of program directors met and established the Consortium of Teacher Preparation Programs for Children Using Listening and Spoken Language. This group participates in quarterly conference calls or meetings to address ways in which teacher preparation programs can best meet the needs of children with hearing loss. Topics of discussion include the challenges and trends described in this article, including the need for more research to inform practice, approaches to educating and assessing the knowledge and skills of future teachers, and ways to fund teacher preparation programs. Through collaboration and creative approaches, teacher preparation programs in deaf education will become more effective in preparing teachers to provide the services needed to increase opportunities for children with hearing loss to develop listening and spoken language skills and demonstrate strong academic achievement.

\section{References}

AG Bell Academy for Listening and Spoken Language. (2007). AG Bell Academy international certification program for listening and spoken language specialists (LSLS): Nine domains of listening and spoken language. Retrieved April 6, 2010, from http:/ / nc.agbell.org/NetCommunity/Page.aspx?pid=344. 
Bruce, S., Dinatale, P., \& Ford, J. (2008). Meeting the needs of deaf and hard of hearing students with additional disabilities through professional teacher development. American Annals of the Deaf, 153(4), 368-375.

Deaf Ed Teacher Preparation Programs. (2009). Retrieved December 4, 2009, from http:/ / www.deafed.net/PageText.asp?hdnPageId=120.

Dodd, E.A., \& Scheetz, N.A. (2003). Preparing today's teachers of the deaf and hard of hearing to work with tomorrow's students: A statewide needs assessment. American Annals of the Deaf, 148(1), 25-30.

Dolman, D. (2008). College and university requirements for teachers of the deaf at the undergraduate level: A twenty-year comparison. American Annals of the Deaf, 153(3), 322-327.

Easterbrooks, S.R. (2008). Knowledge and skills for teachers of individuals who are deaf or hard of hearing. Communication Disorders Quarterly, 30(1), 12-36.

Easterbrooks, S.R., \& Putney, L.L. (2008). Development of initial and advanced standards of knowledge and skills for teachers of children who are deaf or hard of hearing. Communication Disorders Quarterly, 30(1), 5-11.

Fontbonne University. (2010). Early intervention in deaf education, program requirements. Retrieved on March 12, 2010, from http://www.fontbonne. edu/academics/graduateprograms/earlyinterventionindeafedu/pro gramdetails.htm.

Foster, S., \& Cue, K. (2009). Roles and responsibilities of itinerant specialist teachers of deaf and hard of hearing students. American Annals of the Deaf, 153(5), 435-449.

Harrison, M., Roush, J., \& Wallace, J. (2003). Trends in age of identification and intervention in infants with hearing loss. Ear and Hearing, 24, 89-95.

Johnson, H.A. (2004). U.S. deaf education teacher preparation programs: A look at the present and a vision for the future. American Annals of the Deaf, 149(2), 75-91.

Johnston, J.C., Smith, A.D., O'Connor, A., Benzies, K., Fitzpatrick, E., \& Angus, D. (2009). The development and piloting of a decision aid for parents considering sequential bilateral cochlear implantation for their child with hearing loss. The Volta Review, 109(2\&3), 121-141.

John Tracy Clinic. (2010). Level 1 education specialist credential: Deaf and hard of hearing master of education in special education, partnership with the John Tracy Clinic. Retrieved on March 12, 2010, from http:/ / www.johntracyclinic.org/ professional-ed/masters-credential/teacherEdbrochure.pdf.

Joint Committee on Infant Hearing. (2007). Year 2007 position statement: Principles and guidelines for early hearing detection and intervention programs. Retrieved on March 12, 2010, from http://www.asha.org/aud/articles/ EHDI.htm.

Jones, T.W., \& Ewing, K.M. (2002). An analysis of teacher preparation in deaf education: Programs approved by the Council on Education of the Deaf. American Annals of the Deaf, 147(5), 71-78. 
Lartz, M.N., \& Litchfield, S.K. (2005/2006). Administrators' ratings of competencies needed to prepare preservice teachers for oral deaf education programs. American Annals of the Deaf, 150(5), 433-442.

LaSasso, C., \& Wilson, A. (2000). Results of two national surveys of leadership personnel needs in deaf education. American Annals of the Deaf, 145, 429-435.

Lenihan, S., Rice, G., \& Voss, J. (2010). Improving the outcomes for children living in poverty. Presented at the 2010 Early Hearing Detection and Intervention, Chicago, IL.

Luckner, J.L., \& Carter, K. (2001). Essential competencies for teaching students with hearing loss and additional disabilities. American Annals of the Deaf, 146, 7-15.

Luckner, J.L., \& Howell, J. (2002). Suggestions for preparing itinerant teachers: A qualitative analysis. American Annals of the Deaf, 147(3), 54-61.

Marttila, J. (2004). Listening technologies for individuals and the classroom. Topics in Language Disorders, 24(1), 31-50.

Moeller, M.P. (2000). Early intervention and language development in children who are deaf and hard of hearing. Pediatrics, 106(3), e43.

Moog, J.S., \& Geers, A.E. (2003). Epilogue: Major findings, conclusions and implications for deaf education. Ear and Hearing, 24(18), 124.

Moores, D.F. (2006). Professional training emphases. American Annals of the Deaf, 151(1), 3-4.

National Center for Hearing Assessment and Management (NCHAM). (2010). EHDI legislation. Retrieved on April 7, 2010, from http:/ / www.infanthearing. org/states_home.

Nicholas, J.G. \& Geers, A.E. (2006). Effects of early experience on the spoken language of deaf chidren at 3 years of age. Ear and Hearing, 27(3), 286-298.

National Institute on Deafness and Other Communication Disorders (NIDCD). (2009). Cochlear implants. Retrieved on March 12, 2010, from http://www. nidcd.nih.gov/health/hearing/coch.asp.

Programs for Training Teachers. (2009). American Annals of the Deaf Reference Issue, 154(2), 197-204.

Rhoades, E.A., Price, F., \& Perigoe, C.B. (2004). The changing American family \& ethnically diverse children with hearing loss and multiple needs. The Volta Review, 104(4), 285-305.

Rice, G., \& Lenihan, S. (2005). Early intervention in auditory/oral deaf education: Parent and professional perspectives. The Volta Review, 105(1), 73-96.

Roberson, L. (2001). Integration of computers and related technologies into deaf education teacher preparation programs. American Annals of the Deaf, 146(1), 60-66.

Sharma, A., Dorman, M.F., \& Spahr, A.J. (2002). A sensitive period for the development of central auditory system in children with cochlear implants: Implications for age of implantation. Ear and Hearing, 23(6), 532-539. 
Svirsky, M.A., Teoh, S.W., \& Neuburger, H. (2004). Development of language and speech perception in congenitally, profoundly deaf children as a function of age at cochlear implantation. Audiology \& Neurotology, 9(4), 224-233.

Teller, H., \& Harney, J. (2005/2006). Views from the field: Program directors' perceptions of teacher education and the education of students who are deaf or hard of hearing. American Annals of the Deaf, 150(5), 470-479.

University of Hartford. (2010). Deaf education (masters). Retrieved on March 12, 2010, from http://enhp.hartford.edu/prospective/prog_details.asp?prog= ah\&sel=curriculum.

University of Southern Mississippi. (2010). Masters degree, early oral intervention for children who are deaf and hard of hearing. Retrieved on March 12, 2010, from http://www.usm.edu/shs/dat/greoi.htm.

White, K.R. (2006). Early intervention for children with permanent hearing loss: Finishing the EHDI revolution. The Volta Review, 106(3), 237-258.

White, V.R., Chau, M., \& Aratani, Y. (2010). Who are America's poor children: The official story. Retrieved on March 12, 2010, from http:/ / www.nccp.org/ publications/pdf/text_912.pdf.

Winn, S. (2007). Preservice preparation of teachers of the deaf in the twentyfirst century: A case study of the Griffith University, Australia. American Annals of the Deaf, 152(3), 312-319.

Yoshinago-Itano, C., \& Sedey, A.L. (2000). Language, speech, and socialemotional development of children who are deaf or hard of hearing: The early years. The Volta Review, 100(5). 


\section{Appendix: Teacher Preparation Programs with an Emphasis on Listening and Spoken Language}

California Lutheran University

Fontbonne University

John Tracy Clinic/University of San Diego

Smith College

University of Hartford

University of Nebraska-Omaha

University of Southern Mississippi

University of Texas Health Science Center in San Antonio

Utah State University

Vanderbilt University

Washington University in St. Louis 


\title{
AG Bell Academy Certification Program for Listening and Spoken Language Specialists: Meeting a World-Wide Need for Qualified Professionals
}

\author{
Donald M. Goldberg, Ph.D., CCC-SLP/A, FAAA, LSLS Cert. AVT; \\ Cheryl L. Dickson, M.Ed., LSLS Cert. AVT; and \\ Carol Flexer, Ph.D., CCC-A, LSLS Cert. AVT
}

This article discusses the AG Bell Academy for Listening and Spoken Languagean organization designed to build capacity of certified Listening and Spoken Language Specialists (LSLS) by defining and maintaining a set of professional standards for LSLS professionals and thereby addressing the global deficit of qualified LSLS. Definitions and descriptions will be presented as the journey to identifying professionals highly qualified in auditory-based practices unfolds - a journey that will prepare professionals to better serve children who are deaf or hard of hearing and their families now and in the future.

\section{Introduction}

Only $8 \%$ of the world's children who are deaf or hard of hearing and whose family desires a spoken language outcome have access to a qualified

Donald M. Goldberg, Ph.D., CCC-SLP/A, FAAA, LSLS Cert. AVT, is currently the Co-Director of the Hearing Implant Program at the Cleveland Clinic's Head and Neck Institute and President of the AG Bell Academy for Listening and Spoken Language. Cheryl L. Dickson, M.Ed., LSLS Cert. AVT, is the Clinical Director for The Hearing House in Auckland, New Zealand, and is the President-Elect of the AG Bell Academy for Listening and Spoken Language. Carol Flexer, Ph.D., CCC-A, LSLS Cert. AVT, is a Distinguished Professor Emeritus of Audiology in the School of Speech-Language Pathology and Audiology at The University of Akron and Past President of the AG Bell Academy for Listening and Spoken Language. Correspondence concerning this article should be addressed to Dr. Goldberg at goldbed@ccf.org. 
professional (AVI Strategic Plan, 2002). Eight percent worldwide! A global saturation of professionals is desperately needed for today's families choosing listening and spoken language to communicate and for meeting the needs of generations to come. (See Figure 1 and Table 1 for a current list of the number of Listening and Spoken Language Specialists [LSLS] world-wide and in the United States.)

\section{The AG Bell Academy for Listening and Spoken Language}

The AG Bell Academy for Listening and Spoken Language (Academy) is an independent, non-membership subsidiary of the Alexander Graham Bell Association for the Deaf and Hard of Hearing (AG Bell). Founded in 2005, the Academy is responsible for the global certification of LSLS. The Academy is governed by a volunteer board of directors that is appointed by the AG Bell Board of Directors.

The sole mission of the Academy is advancing listening and talking for infants and young children who are deaf or hard of hearing through standards of excellence and international certification of professionals (www.agbellacademy.org).

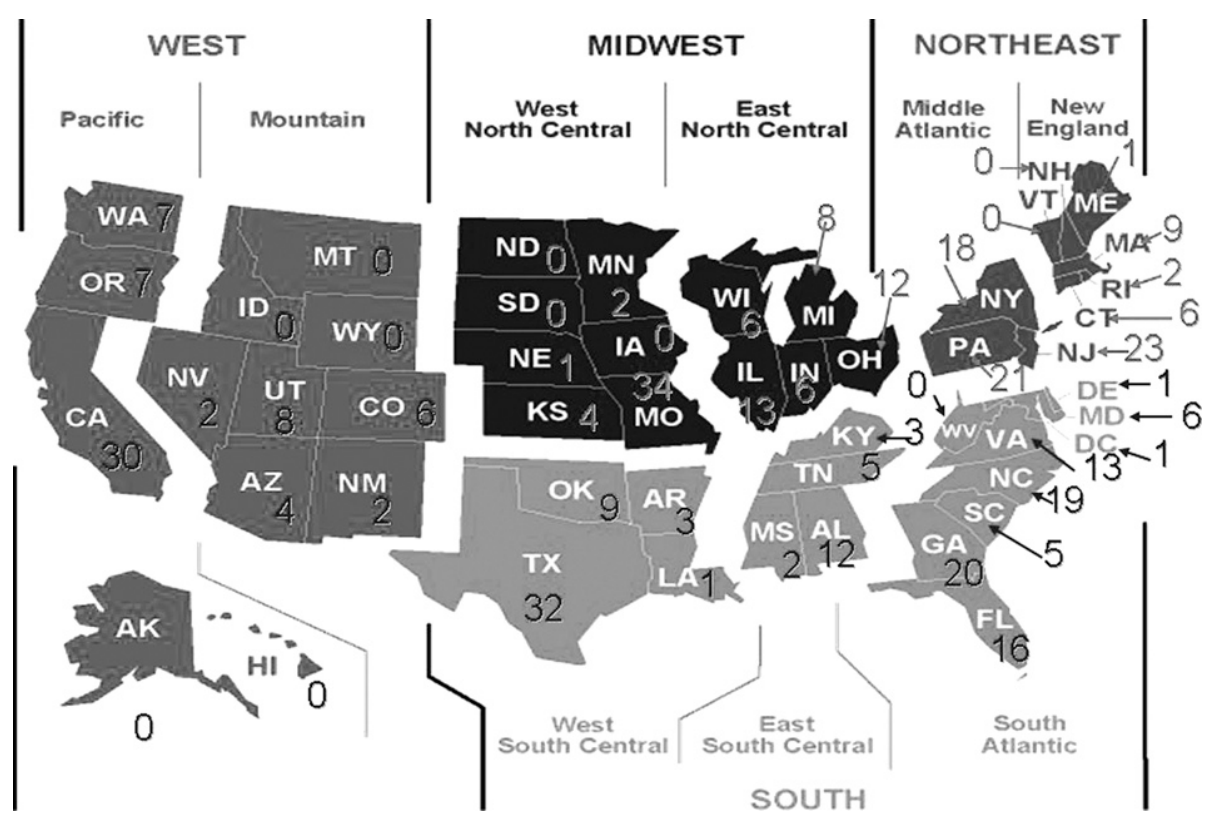

Figure I. U.S. map of LSLS by state. These numbers are accurate as of May 1, 2010. LSLS registration is voluntary, so these numbers may not represent all current U.S. LSLS. 
Table I. World-wide Listening and Spoken Language Specialists (LSLS)

\begin{tabular}{lc}
\hline Country by Continent & Total Number of LSLS* \\
\hline North America & 70 \\
Canada & 379 \\
United States & 2 \\
South America & 1 \\
Argentina & 1 \\
Chile & 1 \\
Mexico & 32 \\
Paraguay & 6 \\
Australia & \\
New Zealand & 1 \\
Europe & 1 \\
Germany & 1 \\
Italy & 3 \\
Spain & 1 \\
Sweden & 10 \\
Switzerland & \\
United Kingdom & 1 \\
Asia & 1 \\
China & 1 \\
Hong Kong & 1 \\
India & 3 \\
Philippines & 1 \\
Singapore & 2 \\
Tauth Korea & \\
Middle East & 1 \\
Israel & \\
\hline
\end{tabular}

*These numbers are accurate as of May 1, 2010. LSLS registration is voluntary, so these numbers may not represent all current LSLS.

\section{The Purpose of LSLS Certification Program}

The landscape of deafness continues to change as truly exciting and limitless possibilities for newborns, infants, toddlers, and children who are deaf or hard of hearing become a reality. With the growing implementation of Universal Newborn Hearing Screening programs, childhood hearing loss is being identified earlier than ever before. The prompt fitting of personal hearing aids and FM/IR systems and the implementation of early intervention programs that emphasize the parents' role as a child's first and most important teacher (Pollack, Goldberg, \& Caleffe-Schenck, 1997) have resulted in impressive outcomes for many children (Yoshinago-Itano, Sedey, Coulter, \& Mehl, 1998). Cochlear implants (CIs) have become an efficacious option for children, especially very young children for whom personal hearing aids do not amplify the entire speech sound spectrum sufficiently (Hammes, Novak, Rotz, Willis, 
Edmonson, \& Thomas, 2002; Vohr, Jodoin-Krauzk, Tucker, Johnson, Topol, \& Ahlgren, 2008).

Advances in hearing technology, early screening, and identification of hearing loss have greatly improved opportunities for children who are deaf or hard of hearing to listen and talk. However, these children cannot optimize listening and spoken language outcomes most effectively without the assistance of a qualified professional.

Infants, toddlers, and children learn language most efficiently through consistent and continual auditory interactions in a supportive environment with their caretakers (Owens, 2005). Therefore, it is crucial that once a child is identified as having a hearing loss, the use of appropriate amplification and medical technology to stimulate hearing begin as early as possible in order for a child to benefit from the "critical periods" of neurological and linguistic development (Sharma, 2009; Sharma, Dorman, \& Kral, 2005; Sharma, Dorman, \& Spahr, 2002).

If a child's auditory brain centers are not accessed, stimulated, and developed during the critical language learning years, the child's ability to use acoustic input in a meaningful way will decline due to physiological (retrograde deterioration of auditory pathways) and psychosocial (attention, practice, and learning) factors. Current information about language development in children with typical hearing provides the framework and justification for the structure of auditory-based practice in the development of spoken language through learning to listen. Highly qualified LSLS are therefore essential to support, guide, and coach the family/caretakers during these critical early learning years.

The Academy's function is to certify professionals who then help families seeking a listening and spoken language outcome for their child with hearing loss achieve that goal. Because of the increasing demand for spoken language outcomes and the growing deficit of qualified providers and certified professionals, the Academy determined it was necessary to analyze the requirements of a certification program that would best serve and support families and future generations of children pursuing spoken language opportunities.

The Academy looked towards the Institute for Credentialing Excellence [ICE; formerly the National Commission for Certifying Agencies (NCCA)] to evaluate the certification program. ICE establishes accreditation standards, evaluates compliance with the standards, recognizes organizations/programs that demonstrate compliance, and serves as a resource on quality certification. The Academy is currently an organizational member of ICE. According to ICE, the first step was to conduct an audit of the Academy's existing certification - the Certified Auditory-Verbal Therapist (Cert. AVT) - which was created and previously administered by Auditory-Verbal International (AVI) prior to AVI's formal dissolution in 2004; the first class of Cert. AVTs was certified in 1994.

Guided by the expertise of Prometric, Inc., a global provider of testing and assessment services, the Academy conducted an audit of the Cert. AVT 
credential followed by a job task analysis that included not just existing Cert. AVTs (those who work one-on-one with the child and his or her family), but also professionals who teach listening and spoken language to children with hearing loss, such as auditory-oral educators (many of whom work in classroom settings), speech-language pathologists, and audiologists. Subject matter experts interpreted the results of the survey that had been psychometrically analyzed by Prometric. The findings were intriguing and definitive - today's listening and spoken language professionals are more alike than different in their teaching strategies and techniques. Their work settings may be different, but their knowledge, skill base, and goals are truly similar.

The statistical evidence showed that a carefully designed test of essential knowledge could prove competency for both therapists and educators seeking certification as "auditory-verbal" professionals. This process resulted in the clarification of the nine domains of listening and spoken language competencies (Figure 2; also see Monograph Appendix A for a full description of each domain) (AG Bell Academy, 2009). In addition, the evidence supported the Academy's decision to recognize and recommend an audiological protocol that includes a collaborative approach to achieving a listening and spoken language outcome (AG Bell Academy, 2008) (article Appendix).

\section{ESSENTIAL KNOWLEDGE AREAS OF A LISTENING AND SPOKEN LANGUAGE SPECIALIST}

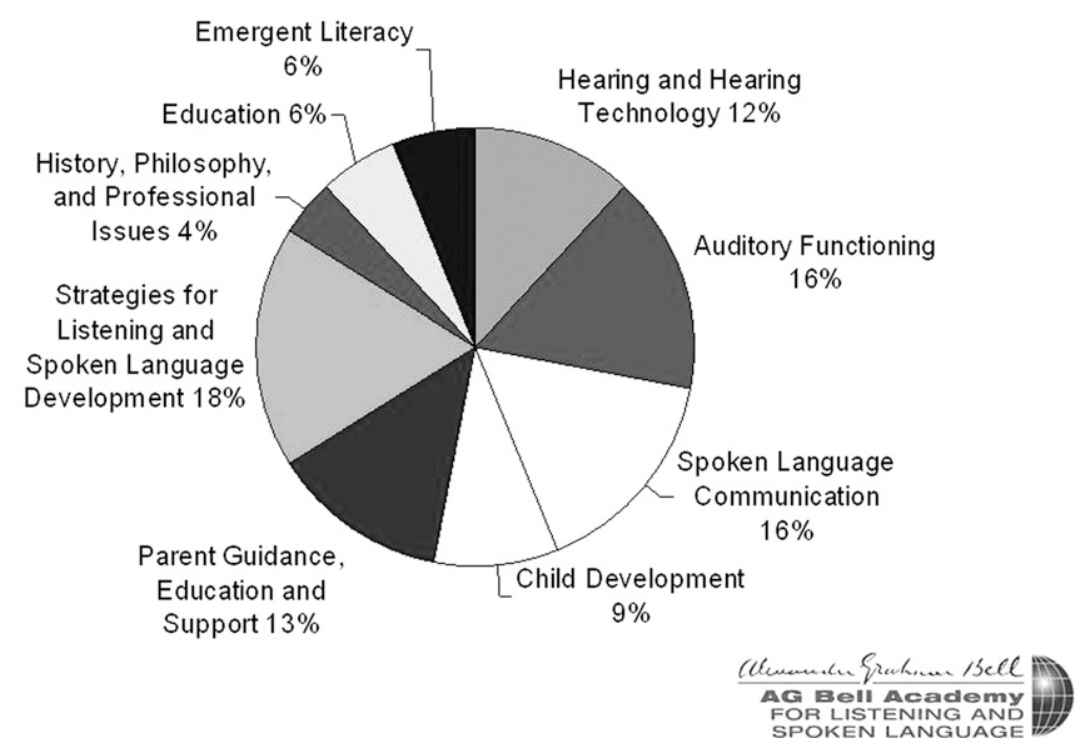

Figure 2. Nine domains of study for listening and spoken language. 
As a direct result of these findings, in July 2007 the Academy announced its new certification program: Listening and Spoken Language Specialist $₫$, which now encompasses two designations: Certified Auditory-Verbal Therapists (LSLS Cert. AVT) and Certified Auditory-Verbal Educators (LSLS Cert. AVEd). The program's expansion is designed to build an international network of distinguishable spoken language specialists who can provide services to families in their own communities. All of the above-noted efforts were designed to systematically reverse this "crisis of capacity." Thus, the Academy set a course of action to certify listening and spoken language professionals around the world with a focus on increasing the number of future certified professionals.

\section{A Single LSLS Test - One Certification with Two Designations}

With the guidance of Prometric, the Academy convened several groups of subject matter experts, including Cert. AVTs, speech-language pathologists, audiologists, and educators, to create the new, single certification examination for LSLS Cert. AVT and LSLS Cert. AVEd applicants. While there are two separate designations within LSLS certification - one for auditory-verbal therapists and one for auditory-verbal educators - the examination is the same for both designations. The official designation (LSLS Cert. AVT or LSLS Cert. AVEd) will differ depending on the academic background and professional experience of the individual. LSLS certification is meant to be the gold standard of care to assist parents seeking a listening and spoken language outcome for their child. A key message is for parents and others to have an assurance of professional preparedness and qualifications via the LSLS designation. In other words, all LSLS need the same knowledge foundation, thus one exam. The main differences include the practice settings and adherence to either the Principles of Auditory-Verbal Therapy or the Principles of Auditory-Verbal Education (Table 2). All candidates must also meet robust requirements in the categories of mentorship, continuing education, academic background, and professional experiences.

\section{LSLS Description}

LSLS professionals help children who are deaf or hard of hearing develop spoken language and literacy primarily through listening - that is, accessing, stimulating, and developing the auditory centers of the brain (AG Bell Academy, 2009). LSLS professionals also focus on education, guidance, advocacy, family support, and the rigorous application of techniques, strategies, and procedures that promote optimal acquisition of spoken language through listening by newborns, infants, toddlers, and children who are deaf or hard of hearing. Finally, LSLS professionals guide parents in helping their children develop intelligible spoken language through listening and coach them in advocating their children's inclusion in the mainstream school. Ultimately, 


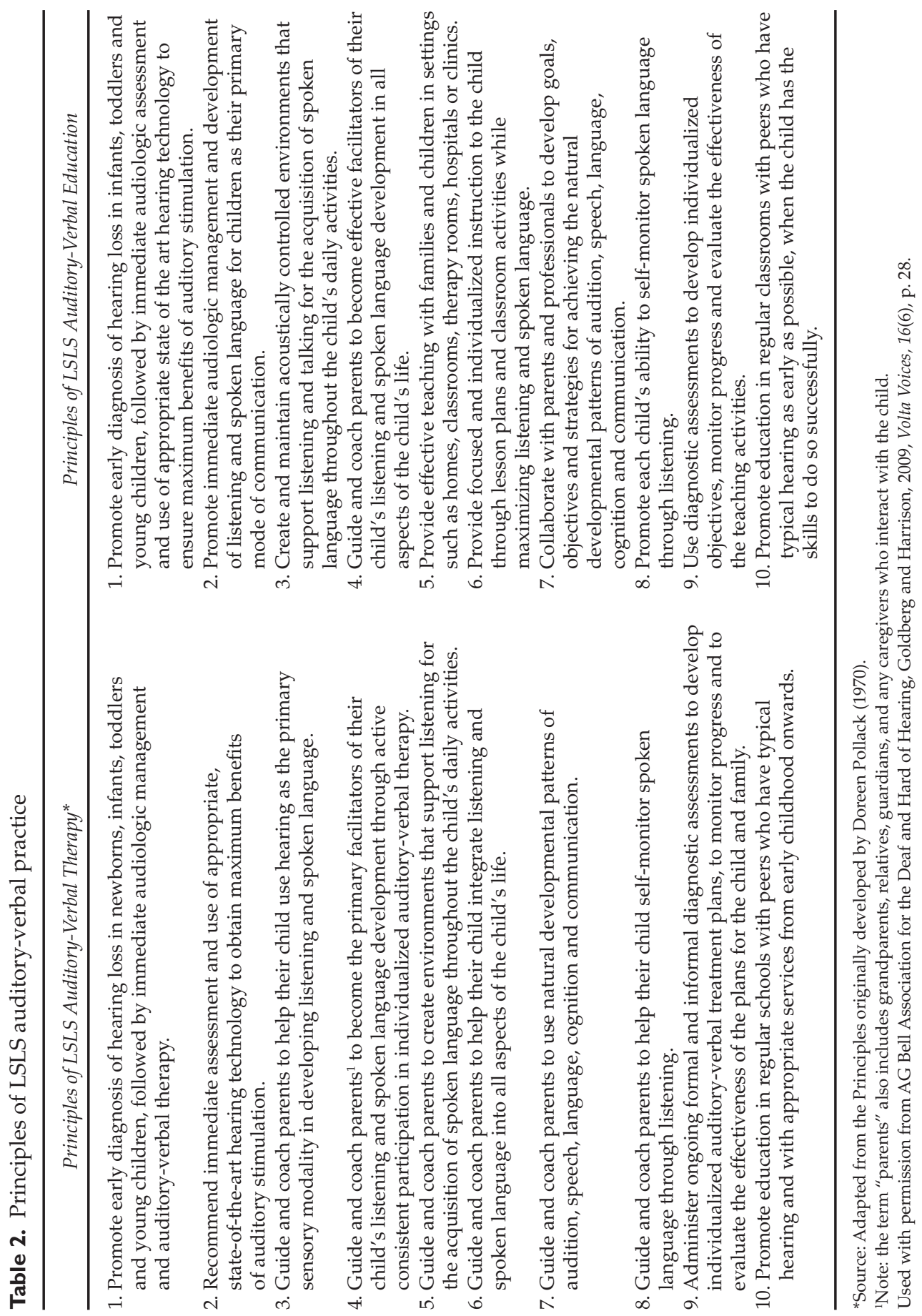


parents gain confidence that their children will have access to the full range of educational, social, and employment choices in life.

\section{LSLS Designations}

A LSLS Cert. AVT works one-on-one with the child and family in all intervention sessions. A LSLS Cert. AVEd involves the family and also works directly with the child in individual or group/classroom settings. LSLS Cert. AVTs and the LSLS Cert. AVEds both follow developmental models of audition, speech, language, cognition, and communication; use evidence-based practices; and strive for excellent outcomes in listening, spoken language, literacy, and independence for children who are deaf or hard of hearing.

\section{Mentoring: A Critical Component of the LSLS Certification Program for Ensuring Fidelity of LSLS Practice}

A LSLS "Mentor" is a person who has fulfilled the three requirements to become a certified LSLS practitioner: 1) a Master's degree ${ }^{1}$ or international equivalent in audiology, speech-language pathology, or education of the deaf or hard of hearing; 2 ) the required number of years of mentored supervision as per the certification requirements; and 3) a passing score on the LSLS certification exam. Once a person has become certified in their respective category, they are then able to mentor other professionals seeking certification. A LSLS Cert. AVT is able to mentor a professional seeking LSLS Cert. AVEd. or LSLS Cert. AVT, and vice-versa. The Application for Certification thoroughly explains the portfolio of required documents that should be forwarded electronically to the Academy office staff for review by the Academy's Certification Committee (AG Bell Academy, 2010a, 2010b).

Not all certified LSLS practitioners, however, provide mentoring. A list of currently certified professionals is available by geographic region on the Academy website. Some mentors charge a fee for their service while other mentors work in programs that provide specific training in the areas of listening and spoken language and provide the mentoring as part of their program. The world is a large place and there are a variety of models currently in use through which mentoring is provided, for example some mentors prefer onsite supervision while others mentor from a distance via online technologies such as Skype or video messaging. It is up to each professional seeking certification to find a model and a mentor that meets his or her individual needs.

The AG Bell Academy is currently exploring various options to enable mentors to register in order to make it easier for professionals seeking certification to find a mentor. The Academy is also investigating the possibility of providing training guidelines for mentors to support high quality mentoring.

${ }^{1}$ This educational degree requirement is currently under review by the Academy. 


\section{The Application Portfolio Process}

Professionals seeking certification as a LSLS must document their training, mentoring, academic background, continuing education, and supervision using the guidelines available on the Academy website. The processes for each designation are different and are described in detail in the Certification Application Packets and respective appendices, provided free of charge. Once all the requirements for certification have been met, the professional seeking certification submits a completed portfolio to the Academy office for review, verification, and approval. Timelines are provided on the Academy website for submission of portfolios depending on where and when the exam will be offered. The exam has been offered in a variety of geographic locations throughout the world and on different dates throughout the year. Exact locations and dates of administration of the exam are published on the Academy website as locations are confirmed.

\section{LSLS: A World-Wide Certification}

The LSLS designation is the only one of its kind in the world. It is the only voluntary certification for the purpose of ensuring that professionals serving children with hearing loss have the essential knowledge and skills to maximize a child's spoken language development through listening so that he or she can be on par with his or her peers who have typical hearing. Numerous professionals from 20 countries other than the United States and Canada have sought and achieved the LSLS designation. Regardless of formal acknowledgement or monetary reward, the knowledge and skills obtained during the 3-year mentoring period is second to none. Practitioners with the LSLS designation lead the field in the theory, methods, and skills necessary to bring children with hearing loss to the desired outcome of age-appropriate spoken language. In order to maintain the LSLS designation and ensure LSLS remain up-to-date in their knowledge and ability to provide services equating to international best practice standards, the Academy requires LSLS to earn continuing education credits approved by the Academy.

The Academy clearly acknowledges that in more isolated regions in North America, as well as throughout various locales in the world, meeting the requirements to sit for the LSLS exam can be a bit more of a challenge. However, there are currently 22 countries with LSLS providing an invaluable service to families (see Table 1). The first step is to link with a certified LSLS and obtain mentoring. Information about LSLS currently registered is available on the Academy's website at www.agbellacademy.org/locate-therapist.htm. To encourage certification in more remote locations, mentoring and supervision can be supported through the use of technology, such as web-based conferencing, Skype, DVDs, etc. It is not necessary for a person seeking LSLS certification to actually meet 
a mentor in person, as it can all be done using the advancing technology available to us in the 21st century.

Professionals interested in pursuing LSLS certification can also access the required theoretical content in a variety of ways. E-learning is becoming more and more available through organizations such as:

- Advanced Bionics: www.advancedbionics.com/calendar/index.cfm? langid $=1$

- Audiology Online: www.audiologyonline.com/total-access/

- Cochlear Americas HOPE online: www.cochlearamericas.com/Support/ 291.asp

- MED-EL Corporation: www.medel.com

AG Bell intends to launch an online Listening and Spoken Language Knowledge Center, which will provide professionals seeking LSLS certification a wide-range of opportunities needed to learn the theoretical content in the nine domains of study.

\section{Conclusion}

The landscape of deafness has truly been altered and the opportunities for children with hearing loss to develop age-appropriate spoken language and literacy skills have never before been seen. With the Academy, capacity building through the certification of highly trained and qualified providers is becoming a reality throughout the world. Children who are deaf or hard of hearing will be the true beneficiaries of these efforts. Each child and parent's right and opportunity to choose a listening and spoken language outcome can in fact become reality with our combined efforts.

\section{References}

AG Bell Academy for Listening and Spoken Language. (2008). Recommended LSLS protocol for audiological assessment, hearing aid evaluation, and cochlear implant monitoring. Retrieved April 28, 2010, from http://nc.agbell.org/ NetCommunity /Page.aspx?pid=360.

AG Bell Academy for Listening and Spoken Language. (2009). About the academy. Retrieved April 28, 2010, from http://nc.agbell.org/NetCommunity/ Page.aspx?pid=331.

AG Bell Academy for Listening and Spoken Language. (2010a). Certified auditory-verbal educator (Cert. AVEd) application packet. Washington, DC: Alexander Graham Bell Association for the Deaf and Hard of Hearing.

AG Bell Academy for Listening and Spoken Language. (2010b). Certified auditory-verbal therapist (Cert. AVT) application packet. Washington, DC: Alexander Graham Bell Association for the Deaf and Hard of Hearing. 
Auditory-Verbal International. (2002). Strategic plan. Alexandria, VA: Author. Felzien, M., \& Harrison, J. (2009). Leveraging professional development opportunities. Volta Voices, 16(6), 22-24.

Goldberg, D.M., \& Harrison, J. (2009). Taking the next step: Seeking LSLS certification. Volta Voices, 16(6), 26-28.

Hammes, D., Novak, M., Rotz, L., Willis, M., Edmonson, D., \& Thomas, J. (2002). Early identification and cochlear implantation: Critical factors for spoken language development. Annals of Otology, Rhinology, Laryngology, 111(Suppl.189), 74-78.

Owens, R. (2005). Language development: An introduction (6 $6^{\text {th }}$ ed.). Boston, MA: Allyn \& Bacon/Pearson.

Pollack, D. (1970). Educational audiology for the limited-hearing infant. Springfield, IL: Charles C. Thomas Publishers.

Pollack, D., Goldberg, D., \& Caleffe-Schenck, N. (1997). Educational audiology for the limited-hearing infant and preschooler: An auditory-verbal program. Springfield, IL: Charles C. Thomas Publishers.

Sharma, A. (2009). Brain plasticity in persons with hearing loss: Clinical perspectives. American Speech-Language-Hearing Annual Convention presentation, New Orleans, LA.

Sharma, A., Dornan, M., \& Kral, A. (2005). The influence of a sensitive period on central auditory development in children with unilateral and bilateral cochlear implants. Hearing Research, 2(3), 134-143.

Sharma, A., Dorman, M., Spahr, A. (2002). A sensitive period for the development of the central auditory system in children with cochlear implants: Implications for age of implantation. Ear and Hearing, 23(6), 532-539.

Vohr, B., Jodoin-Krauzyk, J., Tucker, R., Johnson, M.J., Topol, D., \& Ahlgren, M. (2008). Early language outcomes of early-identified infants with permanent hearing loss at 12 to 16 months of age. Pediatrics, 122(3), 535-544.

Yoshinago-Itano, C., Sedey, A., Coulter, D., \& Mehl, A. (1998). Language of early- and later-identified children with hearing loss. Pediatrics, 102(5), $1161-1171$. 


\section{Appendix: Recommended LSLS Protocol for Audiological Assessment, Hearing Aid Evaluation and Cochlear Implant Monitoring}

This audiological protocol is intended to support programs for early detection of hearing impairment, which should include medical evaluation/clearance for hearing aid use for infants and children. This protocol also is a guide to appropriate and ongoing audiology services recommended by LSLS Cert. AVTs and LSLS Cert. AVEds in listening and spoken language programs.

The AG Bell Academy for Listening and Spoken Language (Academy) recognizes and recommends an audiological protocol that includes the test battery approach as an optimum means to access spoken language. No single test should be used in isolation to define and describe the nature and extent of a hearing loss. Ideally, every listening and spoken language program will have on-site audiological services. But regardless of setting, close collaboration of parents, audiologists, therapists and educators is essential. Parents should be present and participate in all assessments. The Listening and Spoken Language Specialist (LSLS) also should be present at audiological assessments whenever possible or send a report identifying his/her questions or concerns regarding the child's hearing or technology.

The recommended procedures and elements in this document are consistent with the following guidelines and position statements:

- Joint Committee on Infant Hearing. (2007).Year 2007 Position Statement: Principles and guidelines for early hearing detection and intervention programs. PEDIATRICS, 120 (4), 898921.

- American Speech-Language-Hearing Association. (2004a). Guidelines for the audiologic assessment of children from birth to 5 years of age. Available at http://www.asha.org/members/deskref-journals/deskref/default.

- American Speech-Language-Hearing Association. (2006). Roles, knowledge, and skills: Audiologists providing clinical services to infants and young children birth to 5 years of age. Available at http://www.asha.org/members/deskref-journals/deskref/default.

- Pediatric Amplification Guideline: Position Statement of the American Academy of Audiology. (2004). Audiology Today, 16(2), 46-53.

\section{Overview of Audiological Management}

- Initial screening and diagnosis and confirmation should be completed within the first three months of life - as soon as possible after birth - in order to ensure that appropriate amplification and habilitation is underway prior to age six months.

- If a hearing loss is diagnosed, routine evaluation should occur ideally at four to six week intervals until full audiograms are obtained, and at three month intervals through age 3 , although new earmolds may need to be obtained more frequently.

- Assessment at six month intervals from age 4 is appropriate if progress is satisfactory.

- Immediate evaluation should be undertaken if parent or caretaker concern is expressed or if behavioral observation by parent, therapist or teacher suggests a change in hearing or device function.

More frequent evaluation is appropriate when middle ear disease is chronic or recurrent or when risk factors for progressive hearing loss are present.

\section{Recommended Elements of the Initial Audiological Diagnostic Assessment}

(The following section is based on the Joint Committee on Infant Hearing 2007 Position Statement) 


\section{Audiological Evaluation}

Comprehensive audiological evaluation of newborns and young infants who fail newborn hearing screening should be performed by audiologists experienced in pediatric hearing assessment. The initial audiological test battery to confirm a hearing loss in infants must include electrophysiological measures and, when developmentally appropriate, behavioral methods. Confirmation of an infant's hearing status requires a test battery of audiological test procedures to assess the integrity of the auditory system in each ear, to estimate hearing sensitivity across the speech frequency range, to determine the type of hearing loss, to establish a baseline for further monitoring, and to provide information needed to initiate amplification-device fitting. A comprehensive assessment should be performed on both ears even if only one ear failed the screening test.

\section{Evaluation: Birth to 6 Months of Age}

For infants from birth to a developmental age of approximately 6 months, the test battery should include a child and family history, an evaluation of risk factors for congenital hearing loss, and a parental report of the infant's responses to sound. The audiological assessment should include:

- Otoscopic Inspection

- Child and family history.

- ABR testing using air-conducted click and tone burst stimuli and bone-conducted stimuli when indicated. When a hearing loss is detected, frequency-specific ABR testing is needed to determine the degree and configuration of hearing loss in each ear for fitting of amplification devices.

- Click-evoked ABR testing using both condensation and rarefaction single-polarity stimulus, if there are risk indicators for neural hearing loss (auditory neuropathy/auditory dyssynchrony) such as hyperbilirubinemia or anoxia, to determine if a cochlear microphonic is present.

- ASSR testing may be used as another means of assessing ear and frequency specific thresholds. ASSR testing can also be used to assess auditory nerve function when no ABR is present.

- Distortion product or transient evoked OAEs. (otoacoustic emissions)

- Tympanometry using a $1000-\mathrm{Hz}$ probe tone, and acoustic reflex testing.

- Parent and clinician observation of the infant's auditory behavior as a cross-check in conjunction with electrophysiologic measures. Behavioral observation alone is not adequate for determining whether hearing loss is present in this age group, and it is not adequate alone for the fitting of amplification devices.

\section{Evaluation: 6 to 36 Months of Age}

For subsequent testing of infants and toddlers at developmental ages of 6 to 36 months, the confirmatory audiological test battery includes:

- Otoscopic Inspection

- Child and family history.

- Parental report of auditory and visual behaviors and communication milestones.

- Behavioral audiometry (either visual reinforcement or conditioned-play audiometry, depending on the child's developmental level), including pure-tone audiometry across the frequency range for each ear and speech detection or speech recognition measures.

- OAE testing. (Otoacoustic emissions)

- Acoustic immittance measures (tympanometry and acoustic reflex thresholds).

- Electrophysiological testing as described above if responses to behavioral audiometry are not reliable or if ABR testing has not been performed in the past. ${ }^{\text {Insert }}$ footnote to $\mathrm{JCIH}$ doc. 
For children of all ages, the Academy recommends that all results, questions, and recommendations are discussed with the parents in a culturally sensitive manner and in the family's native language. Written reports should be provided and include:

a. Descriptions of test procedures, conditions of testing, and reliability estimate

b. A complete audiogram (if available at the initial diagnosis) with symbol key, calibration, and stimuli identified, as well as plotting results on a "Familiar Sounds" audiogram to support parent/teacher counseling

c. Copies to parents, primary care provider, Listening and Spoken Language Specialist and other health/education providers as requested in writing by parents

d. Referral to medical, otolaryngological or other resources (e.g. genetic counseling, social services, psychological counseling, occupational therapy) as appropriate.

\section{Recommended Procedures to Assess Amplification}

Identify the hearing instrument, including manufacturer, model, output and response, compression or special feature settings, earmold specifications, and quality of fit. In addition, earmolds need to be well made and acoustically tuned (e.g. tubing, venting, bore size to match the child's hearing loss in order to maximize the child's access to sound).

I. Electro-acoustic analysis of hearing aids to document hearing aid performance at the following times:
a. At initial fitting
b. At regular intervals (e.g., at follow-up appointments)
c. Upon return from repairs
d. If parental concerns arise from behavioral observation or listening check

II. Real-Ear-to-Coupler Measures (RECD's)
a. Used with prescription method such as DSL or NAL to establish target gain and output
b. To convert hearing aid performance in $2 \mathrm{cc}$ coupler to real ear hearing aid performance
c. To convert hearing levels in $\mathrm{dB}$ HL to ear canal SPL
d. To assess change in earmold style and fit

III. Cortical evoked response testing to validate hearing aid fittings, where available.

IV. Sound Field Aided Response
a. To demonstrate the child's response to speech for parent education purposes
b. To monitor the child's auditory progress
c. To assess speech perception at soft (e.g. $35 \mathrm{~dB}$ HL) and at average conversational levels (e.g. $50 \mathrm{~dB} \mathrm{HL}$ ) in quiet and in the presence of noise to evaluate the effectiveness of amplification technology. Each hearing aid should be evaluated separately and then both tested together.
d. Assessment of speech audibility using Ling 6 Sound Test at varying distances (e.g. through 6 meters or 20 feet).


e. Comparison of Ling results with NAL speech-o-gram if available to evaluate hearing aid fitting.

NOTE: Functional gain measure is an appropriate verification procedure for bone conduction hearing aids and cochlear implants only. Verification of amplification requires a real ear to coupler (RECD) measure appropriate for children.

\section{$\underline{\text { Recommended Audiological Management for Children with Cochlear Implants }}$}

- If adequate access to the full spectrum of acoustic information of spoken language cannot be achieved for an infant or child through conventional amplification, information should be provided as soon as possible to the family regarding cochlear implant technology including benefits and risks as documented in published, peer-reviewed literature along with referral to a pediatric cochlear implant center.

- Upon parental consent the cochlear implant team will review the audiologic information obtained to date and perform further assessments to evaluate the child's suitability for cochlear implantation.

- Following initial mapping of the cochlear implant speech processor(s), re-mapping should be conducted on the schedule recommended by the cochlear implant team given the child's age, device(s) implanted, number of electrodes activated, and additional individual considerations such as a bilateral or bimodal fitting.

- Once the speech processor is programmed to provide optimal access to the speech spectrum, ongoing evaluation at regular intervals is recommended (e.g. at 3 month intervals for the first year). After this period, routine assessment of performance with the cochlear implant continues to be recommended at six to 12 month intervals if progress is satisfactory.

- Sound Field warble tone or narrowband noise thresholds and speech perception testing should be performed whenever the speech processor is programmed or whenever problems are suspected. Additional purposes of sound field testing are:

a. To demonstrate the child's response to speech for parent education purposes

b. To monitor the child's auditory progress

c. To assess speech perception at average (e.g. $50 \mathrm{~dB}$ HL) and at soft (e.g. $35 \mathrm{~dB}$ HL) conversational levels in quiet and in the presence of noise, to evaluate the effectiveness of the cochlear implant, or of each cochlear implant in the case of bilateral fitting.

d. Subjective assessment of distance hearing using the Ling 6 Sound Test to demonstrate the range of audibility provided by the technology. In a quiet environment, the child should be able to detect all of the Ling sounds at close distances (e.g. 1 meter or 3 feet) and at substantial distances (e.g. approximately 12 meters or 40 feet).

- Immediate evaluation is recommended if parent, caregiver or educator/therapist observe behaviors suggesting a negative change in performance or express concern regarding device function. 

The Volta Review, Volume 110(2), Summer 2010, 145-168

\title{
A Survey of LSLS Cert.AVTs Who Mentor: Fostering Independence to Endow the Future
}

\author{
Helen M. Morrison, Ph.D., CCC-A, LSLS Cert. AVT; \\ Christina B. Perigoe, Ph.D., CCC-SLP, CED, LSLS Cert. AVT; and \\ Anita Bernstein, Sp. Ed., M.Sc., LSLS Cert. AVT
}

The authors surveyed 64 Listening and Spoken Language Specialist Certified Auditory-Verbal Therapists (LSLS Cert. AVTs) who mentor professionals seeking certification. Mentors answered questions regarding demographic characteristics, the organization and delivery of mentoring practice, and challenges and solutions faced by mentors. This group of mentors mirrored the larger population of LSLS Cert. AVTs in distribution of professions, work sites, and countries of origin. Respondents averaged more than 8 years of experience. Highest on the list of desirable goals for mentors was the development of mentee independence in the application of auditory-verbal principles, techniques, and case management. Mentors desired guidelines for practice and networking opportunities.

\section{Introduction}

Twenty-first century advancements in newborn hearing screening, access to appropriate technologies, and early intervention enable children with hearing loss to optimize hearing and learn spoken language from an early age (Cole \& Flexer, 2007) creating a seismic shift in intervention paradigms for children with hearing loss. This has necessitated a transfer in focus from early childhood

Helen M. Morrison, Ph.D., CCC-A, LSLS Cert. AVT, is an Associate Professor in the Department of Communication Sciences and Disorders at Texas Christian University. Christina B. Perigoe, Ph.D., CCC-SLP, CED, LSLS Cert. AVT is the Coordinator of the Early Oral Intervention Graduate Program in Speech and Hearing Sciences at The University of Southern Mississippi. Anita Bernstein, Sp. Ed., M.Sc., LSLS Cert. AVT, is the Director of Therapy and Training Programs at VOICE for Hearing Impaired Children in Toronto, Ontario, Canada. Correspondence concerning this article may be directed to Dr. Morrison at h.morrison@tcu.edu. 
to infancy, from visual teaching to auditory skill development, and from educational management in segregated classrooms to teaming and consultation in mainstream settings. Intervention programs cannot make this shift without certified professionals who possess the knowledge and skills that enable children with hearing loss to realize their full potential. In short, the field lacks an adequate number of prepared professionals (Bess, 2004).

The AG Bell Academy for Listening and Spoken Language certification program sets standards for certification as a Listening and Spoken Language Specialist (LSLS). Professionals who earn the LSLS Certified Auditory-Verbal Therapist (LSLS Cert. AVT) or Certified Auditory-Verbal Educator (LSLS Cert. AVEd) credentials must meet these standards for knowledge and skills essential to helping children with hearing loss learn to listen to and communicate with spoken language (AG Bell Academy, 2009a, 2009b). The current program calls for supervisors and mentors to play an essential role in the LSLS certification process. In the case of the LSLS Cert. AVT:

Over a 3-year period of professional experience, the professional seeking certification must be supervised for a total of 18 hours by a LSLS Cert. AVT ( 8 hours in Year 1, 5 hours in Year 2 and 5 hours in Year 3). Supervision may be conducted live or using video technology. (AG Bell Academy, 2010b, p. 5.)

In the case of the LSLS Cert. AVEd:

The professional seeking certification must be observed by a supervisor for a total of 18 sessions/lessons during the third year of their teaching experience in a variety of teaching activities. Observation may be conducted live or using video technology. Supervisors must attest to the completion of 10 supervised lessons and must complete an evaluation for three observed lessons. (AG Bell Academy, 2010a, p. 6.)

The terms "supervisor" and "mentor" are used interchangeably in Academy application materials. We will use the terms "mentor," "mentee," and "mentoring" when we describe the support and feedback that experienced, certified professionals contribute during the 3-year mentorship period.

The International Mentoring Association (2009) describes mentoring as a relationship between an expert (mentor) and novice (mentee) in a developmental process that is characterized by 1) increased mentee skill and confidence and 2) mentor adaptation to changing mentee strengths and needs. The American Speech-Language-Hearing Association (1985) describes four goals of mentoring: to transmit knowledge and skills, to help mentees realize their goals, to help the mentee self-evaluate, and to help the mentee become an independent, problem-solving learner. Mentoring achieves various outcomes such as orienting new personnel to a work setting (Greene \& Puetzer, 2002); establishing contacts that can benefit the mentee's career (Allen, Eby, Poteet, 
Lentz, \& Lima, 2004; Kram, 1985; Wright-Harp \& Cole, 2004); increasing productivity (Sambunjak, Straus, \& Marusic, 2006); improving mentee self-confidence and work satisfaction (Allen, Eby, Poteet, Lentz, \& Lima, 2004; Wright-Harp \& Cole, 2004); and skill-building (Hall, Draper, Smith, \& Bullough, 2008).

Anderson (1988) fuses the developmental and adaptive aspects of mentoring by describing the supervisory or mentoring relationship as a three-stage process. The first is the evaluation/feedback stage when the mentor is direct and active, giving specific instructions and stepping in when needed. In the second stage, the transitional stage, the mentor takes on a collaborative role. At the third stage, self-supervision, the mentor acts as a consultant, typically upon mentee request.

Despite mentees' designation as novices, they typically bring competency to the process that must be recognized in order for mentoring to be successful. As adult learners, they have foundational knowledge, skills, and life experiences. They are self-directed and goal-oriented, usually know how they best learn, and have an established learning style. The mentor, in turn, must recognize and adapt to the mentee's experience and learning style (Walker \& Wooten, 2005).

Mentoring candidates for LSLS certification is a developmental and adaptive process aimed at helping mentees achieve independent auditory-verbal practice. Mentors provide feedback and support, guiding mentees through skill building, knowledge acquisition, resource finding, and networking with other LSLS. Mentees typically have some professional experience prior to seeking LSLS certification and have fulfilled credentialing requirements in their professions as speech-language pathologists, educators, or audiologists. Throughout the course of the mentoring process, mentees build upon foundational knowledge, employ established skills in new ways, and, in some cases, may even shift attitudes about childhood deafness.

Despite the fundamental role that mentors play in LSLS certification, there is little data on the LSLS professionals who mentor - specifically, their practices or the challenges they face. Knowledge about LSLS mentoring is essential for developing programs that recruit and support mentors in order to achieve the larger goal of increasing the number of certified LSLS professionals to meet the needs of children with hearing loss. A survey of mentors was developed to address this gap in the literature.

\section{Method}

\section{Survey Design and Construction}

In order to better understand the role of mentors in the LSLS certification process, in 2008 an online survey was sent to 288 LSLS Cert. AVTs. At the time of this survey, individuals were just beginning to earn the LSLS Cert. AVEd designation and were not available to participate. The complete questionnaire 
appears in the Appendix. Among the questions, three overarching themes appeared:

1. What are the characteristics of LSLS Cert. AVTs who mentor?

2. How do LSLS Cert. AVTs mentor?

3. What challenges and solutions to mentoring are faced by LSLS Cert. AVTs?

The authors developed a list of possible survey questions. Questions selected for the survey were ones agreed upon by all three authors as being relevant to the goals of the investigation and likely to yield analyzable data. Two additional LSLS Cert. AVTs reviewed the survey, and their suggestions were incorporated into the final product.

The survey consisted of 27 questions, 15 of which were closed, requiring the respondent to select from a group of answers or provide specific information such as the length of time that the respondent had been a certified LSLS. Each closed question was accompanied by an opportunity for the respondent to comment. The remaining 12 survey questions were open-ended. Questions other than those asking for demographic information were optional and could be left unanswered by the respondent.

\section{Participants}

There were 311 LSLS Cert. AVTs at the time the survey was conducted in 2008. Of these, 288 (92.9\%) listed their emails on the AG Bell Academy website. Survey Monkey, a free online survey software, was used to conduct the research and it required communication with members who had email addresses to send the survey and Internet access to complete the survey. An email message invited all 288 LSLS Cert. AVTs with email addresses to complete the survey. This invitation was followed up with two more requests for members to participate.

\section{Results}

Overall the participation rate of those solicited was 30.9\% (89 responses to 288 invitations). This comprised $28.6 \%$ of all LSLS Cert. AVTs at the time of data collection. Not all respondents answered every question. Sixty-four, or $71.9 \%$, of the respondents indicated that they were currently mentoring or had mentored in the past. These mentors were directed to complete the remainder of the survey and their responses were used for the analysis.

\section{Response Analysis}

Responses to closed questions were analyzed via descriptive statistical methods that yielded frequencies of occurrence, percentages, means, and ranges. Investigators applied an inductive technique for analysis of responses 
to open-ended questions (Bogdan \& Biklen, 2006). The first author and three research assistants formed two teams. Each team worked with half of the openended questions, creating categories from themes suggested by the responses and coding each response by category. The teams then switched coded responses. Each team rated the coded responses as being either congruent or incongruent with the category code for that open-ended question. The rate of agreement between first team codes and second team ratings of congruency was $95.6 \%$ across all the responses obtained from open-ended questions.

\section{Mentor Characteristics}

The distribution of professions among LSLS mentors who responded to the survey was as follows: $42.9 \%$ were educators of the deaf or hard of hearing; $34.9 \%$ were speech-language pathologists; $4.9 \%$ were audiologists; and $17.3 \%$ held credentials in more than one discipline. The combinations of disciplines were fairly evenly distributed. Respondents holding speech-language pathology and audiology certification comprised $4.8 \%$ of the group. Educators who were also speechlanguage pathologists or audiologists were equally represented among the sample at $6.3 \%$ from each category. The international distribution of mentors reflected the general population of LSLS Cert. AVTs: $79.4 \%$ from North America; $12.7 \%$ from Australia; 4.7\% from Mexico and South America; and 3.2\% from Asia.

Mentors who responded to the survey worked in a variety of settings, as indicated in Figure 1. Half worked in either private practice $(28.8 \%)$ or medical settings $(21.2 \%)$. University clinics or private, nonprofit schools/centers were reported as work settings by $30.8 \%$ of mentors, with each setting reported by an equal number of respondents. Eleven-and-a-half percent of mentors were located in public schools, and 7.7\% reported other settings such as state/regional early childhood intervention programs and the hearing technology industry.

Figure 2 shows the length of time that mentors held LSLS certification. The mean number of years was 8.8 (which ranged from 1 to more than 14 years), with the most frequently reported length of certification at 14 years. The majority, $64.6 \%$, had no specific training as mentors. Those who had received training obtained instruction through their employment, at professional meetings, by completing professional development coursework, or by watching others, most often their own mentor.

\section{Mentor Practice}

\section{Getting Started}

Mentors were asked how they were contacted by mentees. The most frequent means of contact was by individuals requesting mentoring, comprising $41.9 \%$ of responses. Almost a third, or $31.9 \%$, mentored as part of their job description. Public agencies, such as local schools or health departments, engaged $26.2 \%$ of mentors. 


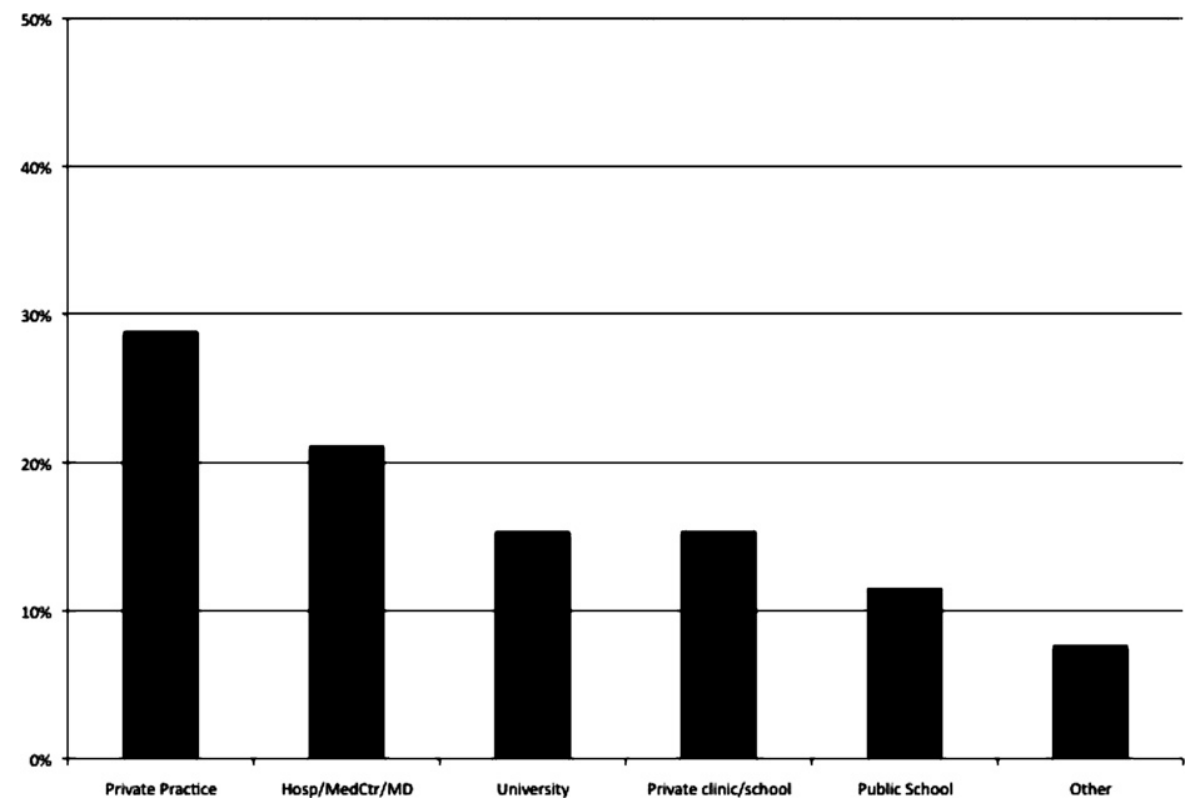

Figure I. Distribution of mentor work settings.

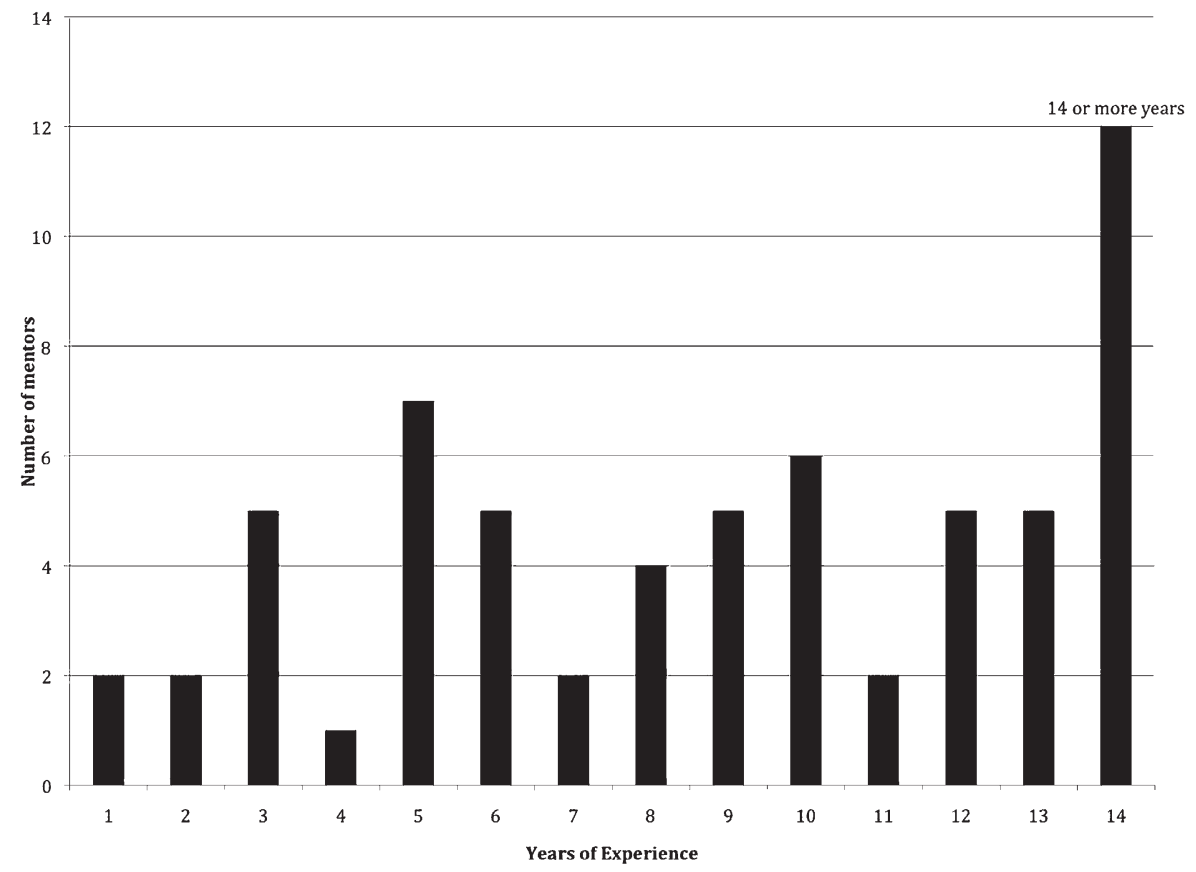

Figure 2. Distribution of mentors by years certified. 
The majority of mentors, $76.6 \%$, applied criteria that a candidate must meet in order to be eligible for mentoring. Table 1 lists the most frequently reported criteria. The categories listed in Table 1 comprise $90 \%$ of the 48 comments offered by mentors. The remaining $10 \%$ of responses were too varied to be fit into categories with reliability. Mentors required candidates to possess the degree and certification credentials required to sit for the LSLS exam, have an understanding and commitment to auditory-verbal principles and techniques, have a caseload available to begin auditory-verbal practice; and be accessible to the mentor for observation in person or via video technology.

Although the majority of mentors applied LSLS certification eligibility criteria for mentoring, $66 \%$ also reported that they had an informal arrangement and did not have a written agreement between both parties at the outset of the mentoring period. A similar finding was obtained with regard to compensation for mentoring $-63.8 \%$ of mentors received no compensation for mentoring or mentored as part of their job requirements without additional salary. The remaining mentors were compensated by the mentee or an outside agency $(15.9 \%$ in each case) or received additional salary for mentoring within their settings (4.4\%).

Mentors were asked how many professionals they were willing to mentor at any one time. The mean was 2.4 , the most frequently reported number of mentees was 2 (28 out of 64 responses), with only 5 mentors offering services to 5 mentees at a time and 2 LSLS Cert. AVTs working with 6 mentees at a time.

\section{Observing Mentees and Providing Feedback}

Table 2 shows how frequently mentees were observed during the 3 years leading to the LSLS certification exam. The survey was distributed in 2008 when observation was required only during the third year and fewer than the

Table I. Most frequently reported criteria for candidates to be accepted by a mentor $(n=40)$

\begin{tabular}{|c|c|}
\hline Percent Responses & Criteria \\
\hline $25 \%$ & $\begin{array}{l}\text { Possess academic and professionals credentials required to sit for } \\
\text { LSLS exam }\end{array}$ \\
\hline $20 \%$ & Commitment to auditory-verbal approach and motivation to learn \\
\hline $10 \%$ & Access to auditory-verbal caseload \\
\hline $10 \%$ & $\begin{array}{l}\text { Accessible to mentor for observation, either live or through } \\
\text { real-time technology }\end{array}$ \\
\hline $10 \%$ & $\begin{array}{l}\text { Prior coursework (university or postgraduate professional } \\
\text { development) in auditory-verbal principles and techniques }\end{array}$ \\
\hline $5 \%$ & Prior observation of mentor \\
\hline $5 \%$ & $\begin{array}{l}\text { Understanding that mentor does not guarantee that the mentee } \\
\text { will be eligible to sit for the LSLS exam or will pass the exam }\end{array}$ \\
\hline $5 \%$ & Pursuing the LSLS Cert. AVT from the two LSLS options \\
\hline
\end{tabular}


Table 2. Frequency of therapy observations

\begin{tabular}{llll}
\hline \multicolumn{1}{c}{ Frequency } & Year 1 & Year 2 & Year 3 \\
\hline Weekly or several times a month & $42.1 \%$ & $20.0 \%$ & $13.3 \%$ \\
Monthly & $24.5 \%$ & $26.7 \%$ & $26.7 \%$ \\
Quarterly or every few months & $33.4 \%$ & $53.3 \%$ & $46.7 \%$ \\
As needed & 53 & 30 & $13.3 \%$ \\
$\mathrm{~N}=$ & 53 & 30 \\
\hline
\end{tabular}

full number of respondents answered the questions pertaining to observation frequency. Approximately 25\% of mentors who responded observed therapy on a monthly basis each year across the 3-year mentorship. The percentage of mentors who observed more frequently than once a month decreased over the 3 years. In corresponding fashion, the percentage of mentors who observed less frequently than once a month increased from Year 1 to Year 2. At Year 3, mentors also indicated that they scheduled observation visits as needed, typically occurring less often than once a month.

Mentors were asked to describe how they observed therapy. They were directed to select options from a list, and multiple selections were permitted for a total of 130 responses to this question. Observations were most frequently reported as occurring in real time, comprising $63.9 \%$ of responses. Real-time observation was conducted with the mentor present in the therapy session $(39.2 \%)$, by remote observation from within the same building through a window or via a television camera positioned in the room $(18.5 \%)$, or from a remote location by means of Skype or other videoconferencing technology (6.2\%). Just over onethird of observations (36.1\%) were accomplished by viewing recorded sessions.

On the survey form, mentors selected from a list the means by which they delivered feedback to mentees. In similar fashion to the question described above, respondents were able to select more than one feedback method. A total of 253 responses were collected. Just over half $(51.4 \%)$ of the feedback was delivered during the therapy session. Feedback delivered during the session was somewhat evenly distributed across demonstration teaching $(18.2 \%)$, co-teaching $(17.0 \%)$, and coaching from the sidelines $(16.2 \%)$. Feedback that involved direct conversation between the mentor and mentee after the session comprised just over a third (34.7\%) of the options selected and included meetings between the mentor and mentee, telephone conversations, and videoconferencing. Written reports delivered after the session electronically or by mail comprised the remainder of approaches to delivering feedback $(13.9 \%)$.

\section{Mentee Goals}

Mentors established goals for mentees in a variety of ways. Fifty-eight of the 64 mentors used the "LSLS Cert. AVT Supervisor's Evaluation" (Attachment F 


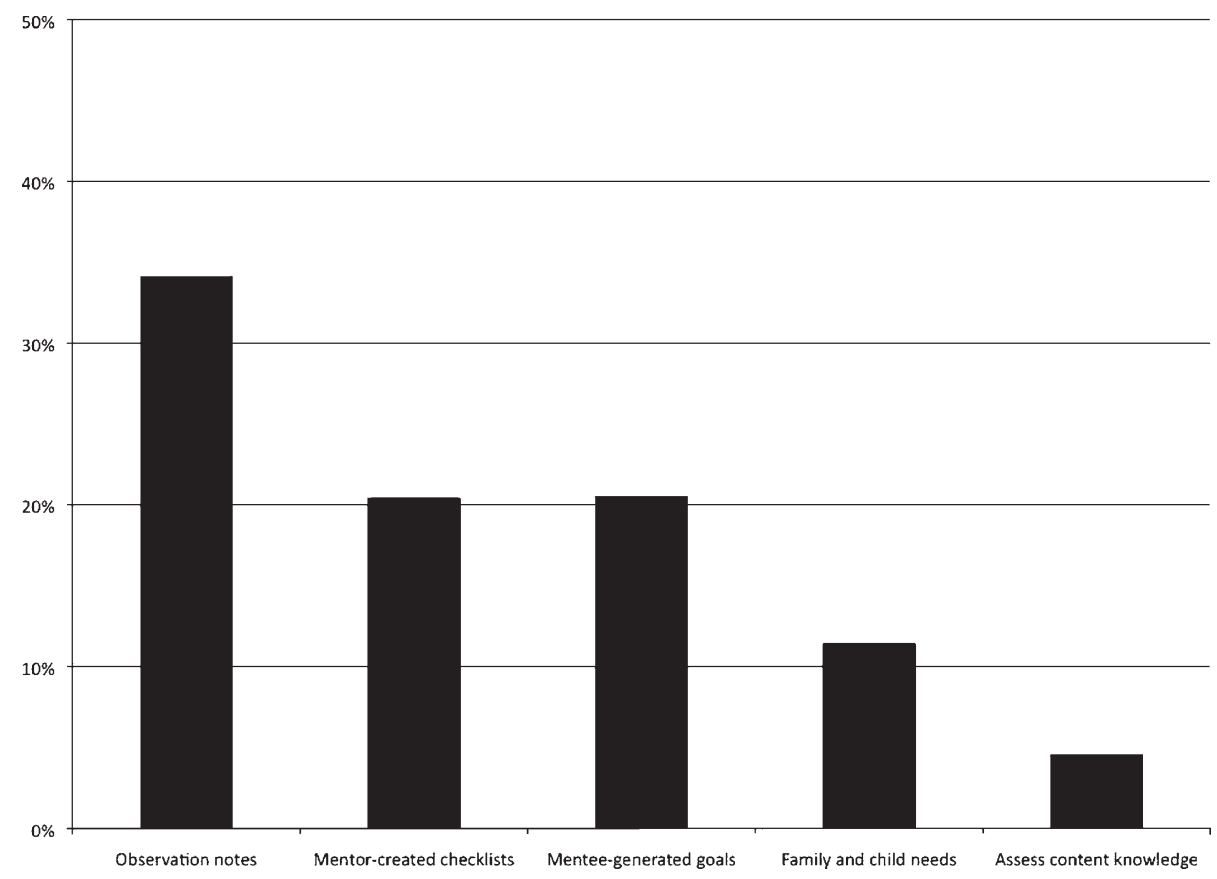

Figure 3. Approaches to creating mentee goals.

of the LSLS exam application packet) and the "Auditory-Verbal Teaching Behaviors Checklist" (Attachment G of the LSLS exam application packet) (AG Bell Academy, 2009b)1. Forty-four of these mentors also offered alternatives to the Application Packet forms. These alternatives are summarized in Figure 3. Just over one-third of the mentors responding (22) noted the adaptive nature of mentoring; they adjusted goals based on ongoing observations of mentee performance. Mentors created their own teaching checklists. Several noted that they evaluate independence in addition to the mastery of auditory-verbal techniques. Mentors further promoted independence by encouraging mentees to participate in shared goal setting or to create their own goals. Finally, mentors established goals for content knowledge using the nine domains of listening and spoken language (see Monograph Appendix A) or the Auditory-Verbal Standardized Curriculum (2003).

The respondents were asked to list the goals that were typically established during the 3 years prior to the LSLS exam. Forty mentors responded to this question. The goals, summarized in Table 3, depict a developmental process of skill and knowledge acquisition across multiple domains that proceed

\footnotetext{
${ }^{1}$ Please note that the application packet has since been updated and these forms revised. Please contact the AG Bell Academy at academy@agbell.org for additional information.
} 
Table 3. Mentee goals over the 3-year mentorship

Year 1: Mentor Directed

A-V Principles

A-V Techniques
Assessment/Goal Setting Parent Coaching

Content Knowledge

Independence
- Know A-V principles.

- Identify A-V techniques when observing LSLS Cert. AVTs in therapy.

- Master specific techniques: positioning, maximizing audition, acoustic highlighting, "Talk, then show."

- Master Year 1 behaviors from "Auditory Teaching Behaviors Checklist."

- Shift to auditory-based practice after years of visual practice.

- Write lesson plans that are auditory-based.

- Communicate A-V principles to parents effectively.

- View the parent as the client.

- Hand the session over to parents.

- Able to role-play parent coaching.

- Understand theoretical constructs and evidence supporting A-V principles and techniques.

- Understand auditory development.

- Begin to self-identify strengths and weaknesses.

Year 2: Transitional

A-V Principles

A-V Techniques

\section{General Teaching Expertise}

Assessment/Goal Setting

Parent Coaching

Classroom Placement

Atypical Cases
- Adhere to A-V principles in practice consistently.

- Strengthen use of A-V strategies from Year 1.

- Integrate audition, language, speech, and cognition into a lesson/activity.

- Independently apply speech acoustics information while teaching.

- Target speech development/remediation needs.

- Move a child from one level on a developmental hierarchy to the next.

- Work a child and family through plateaus.

- Generate goals from an A-V perspective.

- Begin to engage in diagnostic therapy.

- Develop specific parent goals.

- Provide specific feedback.

- Brainstorm with parents.

- Identify and troubleshoot parent needs, including parental involvement issues.

- Learn and implement adult learning strategies.

- Assess and integrate academic preparation into goals and teaching.

- Coach parents in establishing goals for the Individualized Educational Plan at the child's school.

- Recognize "red flags." 
Year 2: Transitional

\begin{tabular}{ll}
\hline Content Knowledge & - Continue professional development in areas \\
& identified in Year 1. \\
& - Specific content areas: speech acoustics, acoustic \\
& physics, auditory anatomy and physiology, hearing \\
& technology. \\
- Engage in guided self-assessment as part of the & observation routine. \\
Independence & Make contact with other LSLS Cert. AVTs. \\
Professional Collaboration & M
\end{tabular}

Year 3: Mentee Directed

A-V Principles

A-V Techniques

General Teaching Expertise

Assessment/Goal Setting

Parent Coaching

Classroom Placement

Atypical Cases

Content Knowledge

Independence

Professional Collaboration
- Lecture on A-V principles and therapy.

- Master all items on "A-V Teaching Behaviors Checklist."

- Use A-V techniques in all activities.

- Show adaptability during lesson.

- Lay the cognitive foundation for higher level skills.

- Master diagnostic therapy.

- Generate higher-level auditory, language, and speech goals.

- Conduct evaluations and write reports from an A-V perspective.

- Determine when to discharge or to recommend to other programs.

- Function as true parent coach.

- Counsel families regarding educational placement

- Coach teachers and others involved with the child in the regular educational setting.

- Include special needs, atypical cases on caseload.

- Serve as case manager for special needs, atypical children and their families.

- Master all LSLS domains/core competencies

- Specific content areas: history of auditory-verbal therapy, etiologies, and sequelae.

- Critique and self-identify strengths and weaknesses.

- Generate requests for mentoring; mentoring occurs on an as-needed basis

- Collaborate with other professionals

- Problem-solve with more novice clinicians on cases

Note: A-V = auditory-verbal

from being directed by the mentor in Year 1 to being directed by the mentee in Year 3.

Year 1. The principles of auditory-verbal therapy and auditory-verbal techniques predominate Year 1 goals. The mentee is expected to know the theoretical constructs and research evidence upon which the principles are based, and to 
communicate the principles in a way that parents will understand. Mentees are also expected to recognize auditory-verbal techniques when observing auditory-verbal sessions and to be able to use techniques in their own therapy. Mentees are expected to shift from perceiving the child as the focus in therapy to engaging the parent as a client. Mentees are expected to shift the focus in lesson plans to auditory-based activities.

Year 2. Goals in Year 2 build upon knowledge and skills attained in Year 1, are more specific, and expand to new content areas. Mentees apply knowledge of a child's audiogram, hearing technology, and speech acoustics to develop spoken language and remediate speech production. Mentees create individualized parent goals, provide feedback, and address family needs. The expectation that the Year 1 mentee create auditory-based lesson plans is extended to include the establishment of long-term goals from an auditory-verbal perspective.

The mentee is expected to expand areas of competence into other domains of auditory-verbal practice during the second year. The mentee engages in diagnostic therapy and identifies child behaviors that may indicate a need for further assessment of other disabilities. Mentees also begin to facilitate the child's participation in the regular classroom; assess his or her skills guided by the mentor; and begin creating a network of other professionals who engage in auditory-verbal practice.

Year 3. Mastery and independence characterize Year 3. By the end of this period, mentors' comments indicated that the mentee was expected to function independently by demonstrating mastery of all items on the "AuditoryVerbal Behaviors Checklist." Mentees should be able to collaborate with other professionals and engage in advanced clinical decisions, including determining when a child and family are ready to be discharged from auditory-verbal therapy or when they may need another type of intervention program. Year 3 mentees should be able to convey information about auditory-verbal principles and practices to colleagues, and provide support to teachers in regular classrooms. They also should be able to self-critique and identify the amount and kind of guidance they require from a mentor.

\section{Evaluating Mentor Effectiveness}

Forty-two mentors described how they measured the effectiveness of their mentoring. Eighteen looked to mentee progress as evidence for effectiveness. Another 23 elicited feedback from their mentee, predominantly in the form of verbal feedback (16 responses). Only 1 listed successful completion of the LSLS exam as an indicator of effectiveness, but made the statement in a larger context, including a continuing relationship between mentor and mentee:

Several people I have mentored or who have taken my classes have gone on to successfully pass the examination in AV development and become 
certified AV therapists. But that is only one measure of success. Another is that some of them still email me for advice on difficult cases they work with.

\section{Challenges and Solutions}

Mentors were asked about challenges they faced and the solutions they had found. Forty-four mentors offered ideas. These are summarized in Table 4 . Among those most frequently cited were the challenge of insufficient time, challenges in the management and practice of mentoring, finding support from other auditory-verbal mentors, and finding practical solutions.

Mentors are proactive. Prior to mentoring, they discuss mutual expectations of the mentoring partnership with the mentee and design a schedule of observations and feedback sessions for the mentored time. They forecast the cost of mentoring and either secure funding or absorb the costs themselves. In their responses, they wrote that they anticipated their own weaknesses and rehearsed coaching strategies. They also reported that they made an effort to avoid taking over sessions.

LSLS mentors were also asked to describe what kind of support they need to provide optimal service and how the number of mentors might be increased. Responses to both questions were similar and were, therefore, combined in analysis. Seventy-four responses from 46 mentors were obtained and analyzed. The themes categorized from these responses appear in Figure 4 and represent $93.3 \%$ of the responses. Three themes accounted for just over $60 \%$ of the responses, with an equal number of responses falling into each of these categories: compensation, AG Bell Academy support, and professional development. The majority of mentors who cited compensation as an incentive wrote about financial compensation; four reported that time allotted by their employer also would provide adequate compensation.

Respondents suggested several ways that the AG Bell Academy could support the work of mentors. Suggestions included simpler reporting tools and clearer guidelines. They sought validation of the "Auditory-Verbal Teaching Behaviors Checklist" and benchmarks for mentee completion of each year of the 3-year preparation period. Mentors were also interested in their own professional development to improve their mentoring skills. They were willing to attend presentations at conferences and videoconferences and to take part in online coursework.

In addition, mentors expressed a desire to connect with one another. Several commented that they are the only mentors in their area and felt as though they were working without role models. They suggested creating a shared interest group within the Alexander Graham Bell Association for the Deaf and Hard of Hearing (AG Bell), a link to the shared interest group on the AG Bell Academy website (www.agbellacademy.org), and a registry of LSLS mentors. Suggestions for marketing also included a registry and recognition of mentors 


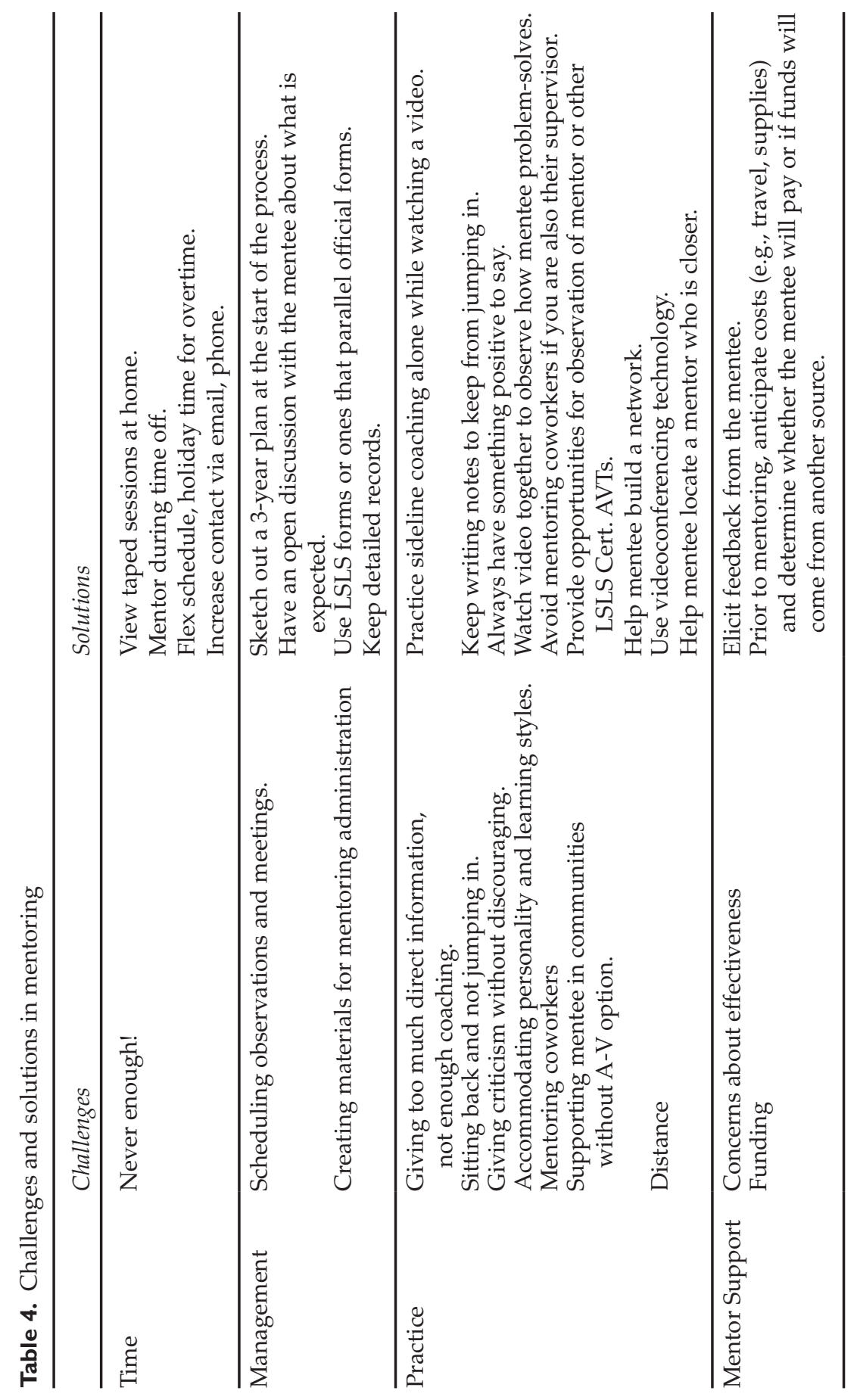




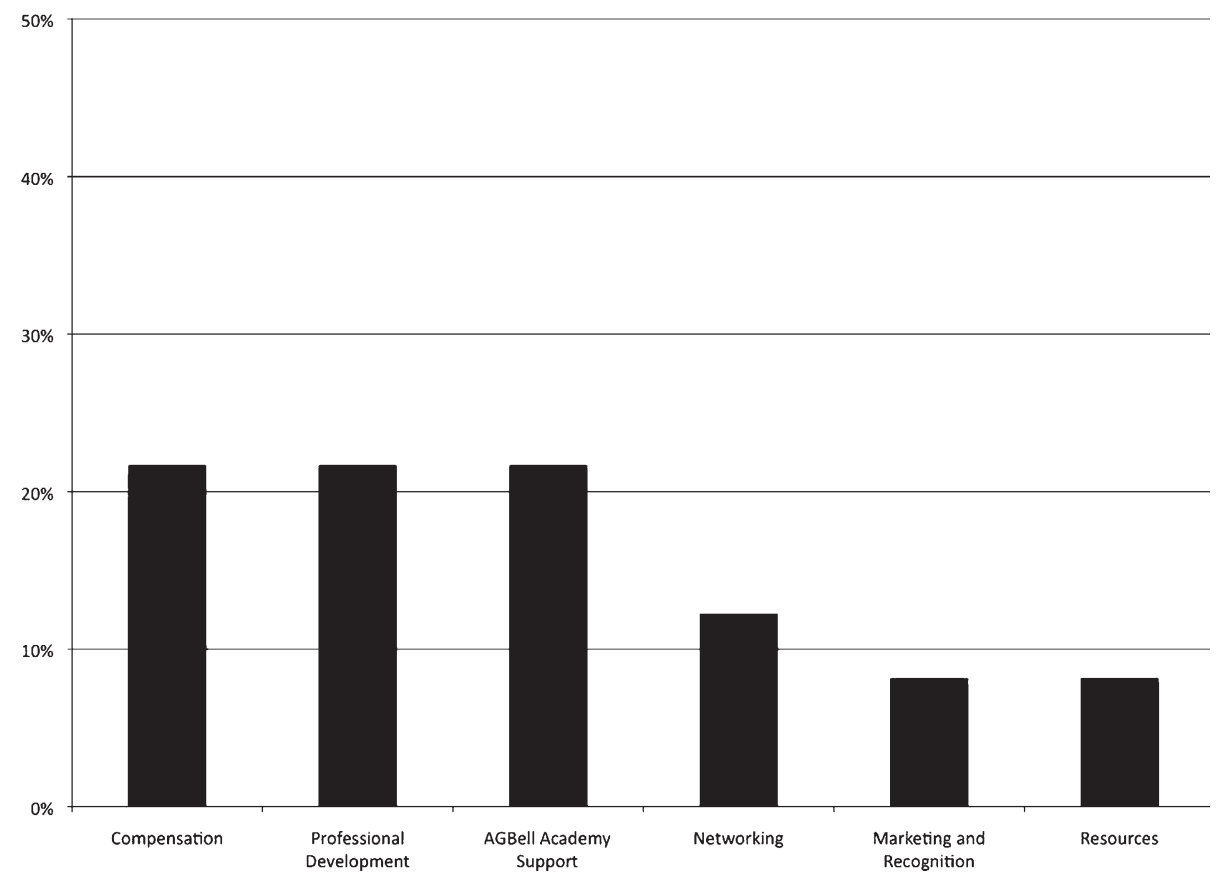

Figure 4. Categories of support desired by LSLS Cert. AVTs.

and successful mentees by AG Bell at conventions. Finally, mentors were eager for resources and were particularly interested in access to the readings recommended by the AG Bell Academy for professionals seeking certification. Several also voiced a desire for the Auditory-Verbal Standardized Curriculum to be updated and published on the website.

\section{Discussion}

The results of the survey indicate that professionals mentoring those seeking certification are experienced clinicians. They tend to mentor no more than two individuals at a time. They describe themselves as proactive and direct in their interactions with mentees, and they tend to conduct their observations in real time, providing feedback during the course of therapy. Nevertheless, the primary goal is for mentors to facilitate mentee competence and independence within the 3-year period. They set goals for mentees to self-identify areas of skill development, and they schedule contact hours in a way that gradually allows mentees to become increasingly self-reliant. The goals reveal a developmental process that advances from the acquisition of fundamental 
auditory-verbal techniques to case management and application of auditoryverbal practice and, finally, to atypical cases. Mentors adapt themselves to the pace at which mentees progress. They recognize that mentees are adult learners who bring experience and individual learning styles to the mentoring relationship. They consciously work to remain on the sidelines while coaching, to point out the accomplishments of mentees, and to identify the mentee's style.

Mentors also clearly desire to connect with one another and to learn about various ways they can mentor new professionals. They want guidelines for mentoring practice and benchmarks for mentee performance in order to provide the best possible service.

\section{Proto-Type Program for Successful Mentoring}

One mentoring program that has been particularly successful was developed in Ontario, Canada, by VOICE for Hearing Impaired Children. Funded by the Ontario Ministry of Education, VOICE currently provides eight LSLS to serve as mentors to accredited teachers of the deaf or speech-language pathologists from school programs and clinics that provide service to children with hearing loss. The program is an intensive 2-year internship that includes 150 hours of study in auditory-verbal principles, techniques, development, and associated domains.

The mentoring portion of the program consists of 40 full days of coaching over the internship period. In the first year, mentoring is provided weekly for 5 months, followed by bimonthly sessions for a total of 30 days of mentoring during the 10 months comprising the school year. In the second year of the internship, mentoring is provided monthly for a total of 10 days. The mentoring program makes use of a peer coaching model that utilizes the mentee's own caseload and provides the mentee with the opportunity to work closely with a VOICE LSLS mentor. This allows for an exchange of information and development of skills particular to the needs of the mentee. Sessions may take place at a VOICE clinic, at the mentee's work place, or at the child's school. Individualized mentee goals are developed jointly by the mentor and the mentee and are based on knowledge and skills promoted by the AG Bell Academy.

The VOICE mentoring program assesses various outcome measures. Mentees record a therapy session at the start of the program and at the end of the first and second years. VOICE mentors and mentees rate the intervention sessions using the "Auditory-Verbal Teaching Behaviors Checklist." Outcomes are used to identify areas of focus that require further attention and skill development. There are two benchmarks for successful mentoring. First is the establishment of the necessary foundation for a mentee to successfully meet requirements for and pass the LSLS exam. Second is the ability of mentees to ultimately act as mentors themselves. 
The VOICE program monitors child outcomes as well, applying two benchmarks. First, they follow the progress of children who transition to school with age-equivalent language skills and who continue to make 1 year of progress each year in measures of listening, speech, language development, and literacy. Second, they evaluate whether the child meets targets outlined in Ministry of Education documents for oral and written language.

To ensure a consistent mentoring program model and to support the work of VOICE mentors, VOICE created a mentor manual. The manual includes curriculum guidelines based on the domains identified by the AG Bell Academy, modules developed by VOICE mentors, supporting journal articles, and texts and resources. Mentors gather twice yearly for training sessions to discuss challenges in mentoring and to exchange information and materials. Thus, a network of mentors who share their expertise and support each other has been established and continues to grow.

\section{Endowing the Future}

The results of the LSLS survey suggest several important steps needed for the future. These include creating a network of LSLS mentors, validating auditory-verbal teaching behaviors, adapting evaluation forms, exploring options for distance mentoring, determining the numbers of LSLS certified personnel currently mentoring, and, ultimately, providing for the recruiting and training of mentors for the next generation of professionals.

The creation of a network of LSLS mentors who can share models of mentoring practice would be efficacious. The results also highlight the need for the collection of data to validate the "Auditory-Verbal Teaching Behaviors Checklist" in order to confirm the behaviors expected of mentees by the end of each year of mentored practice.

The theme of supporting mentee independence recurs throughout the mentoring process, in the literature on the subject, and among responses by mentors to this survey. However, the tools for observing and rating mentee performance used in the LSLS certification process, the "Supervisor's Evaluation Form" and the "Auditory-Verbal Teaching Behaviors Checklist," do not measure mentee independence. Creation of a tool to measure mentee independence would be useful in assessing readiness to practice as a LSLS professional.

The preference among mentors to observe therapy in real time and provide feedback during the course of the therapy session may seem at odds with the need for training clinicians in regions where there are no LSLS professionals. Present technology, however, makes real time observation and feedback possible in almost any global locale, and programs are encouraged to explore these options.

The true number of LSLS Cert. AVTs who mentor was not determined by this study, perhaps due to the use of an online survey tool. In addition, it is 
possible that LSLS Cert. AVTs who do not mentor did not feel the need to respond. It is noteworthy that more than $25 \%$ of the LSLS Cert. AVTs worldwide at the time of the survey reported that they engage in mentoring. This strikes the authors as an extraordinarily high percentage of individuals who are committed to passing on their knowledge to the next generation. Obtaining an ongoing count of mentors from among all certified LSLS is needed for anticipating the number of mentors available to support those seeking future certification. Therefore, a question regarding mentoring should be added to the LSLS renewal protocols. This also could be designed to supply data on those retiring. Plans for mentor recruitment, training, and funding can follow from that data. A careful examination of the mentors (Figure 1) indicates a high number of LSLS Cert. AVTs with 14 or more years of experience. One can presume that some LSLS are nearing the end of their careers and must be replaced with equally dedicated and trained successors. While the number of certified LSLS increases every year, newly certified professionals may not feel ready to be mentors themselves. This gives further justification for mentor training. Looking at successful models of mentoring would be an important first step.

We conclude with some comments written by LSLS mentors, regarding the rewarding time they had as mentees:

- I grew into an AV therapist that I am proud of, due mostly to my two mentors. I learned the kind of information you can't learn from books.

- He believed in me. I had to have high expectations for my work and the outcome of my efforts because he expected this.

- I can always run a "tough case" by them or ask for specific guidance. I tried to understand the latest ideas from them all through my career.

- I learned "nuggets of wisdom" far beyond my clinical experience. I took those nuggets and shared them with the families I teach - telling the parents that I learned that from Beebe (or Ling or Simser). I think it made me seem more knowledgeable in the early days of my career - to share why I was doing what I was doing and where I learned how to do it.

It is clear that LSLS Cert. AVTs enjoy a tradition of passing along to others the clinical wisdom they themselves learned from their mentors.

\section{References}

AG Bell Academy for Listening and Spoken Language (2009a; 2010a). Certified auditory-verbal educator (Cert. AVEd) application packet. Washington, DC: Alexander Graham Bell Association for the Deaf and Hard of Hearing.

AG Bell Academy for Listening and Spoken Language (2009b; 2010b). Certified auditory-verbal therapist (Cert. AVT) application packet. Washington, DC: Alexander Graham Bell Association for the Deaf and Hard of Hearing. 
Allen, T.D., Eby, L.B, Poteet, M.L., Lentz, E., \& Lima, A.L. (2004). Career benefits associated with mentoring for protégés: A meta-analysis. Journal of Applied Psychology, 89, 127-136.

American Speech-Language-Hearing Association. (1985). Clinical supervision in speech-language pathology and audiology [Position Statement]. Retrieved December 3, 2009, from http://www.asha.org/docs/html/PS1985-00220. html.

Anderson, J.L. (1988). The supervisory process in speech-language pathology and audiology. Boston, MA: College Hill Press.

Auditory-Verbal International, Inc.® (2003). Auditory-Verbal Standardized Curriculum. Alexandria, VA: Author.

Bess, F.H. (2004). Funding for personnel preparation in communication sciences and disorders. Paper presented at the Summit on Deafness, Spoken language options in the $21^{\text {st }}$ century: Predicting future trends in deafness, Washington, DC.

Bogndan, R., \& Bicklen, S.K. (2006). Qualitative research for education: An introduction to theory and methods ( $5^{\text {th }}$ ed.). Boston, MA: Allyn and Bacon.

Cole, E.B., \& Flexer, C. (2007). Children with hearing loss: Developing listening and talking birth to six. San Diego, CA: Plural Publishing, Inc.

Greene, M.T., \& Puetzer, M. (2002). The value of mentoring: A strategic approach to retention and recruitment. Journal of Nursing Care Quality, 17, 67-74.

Hall, K., Draper, R., Smith, L.K., \& Bullough, R.V. (2008). More than a place to teach: Exploring the perceptions of the roles and responsibilities of mentor teachers. Mentoring and Tutoring: Partnerships in Learning, 16, 328-345.

International Mentoring Association (2009). A glossary of mentoring terms. Retrieved April 19, 2010, from http:/ / mentoring-association.org/Mglossary. html.

Kram, K.E. (1985). Mentoring at work: Developmental relationships in organizational life. Glenview, IL: Scott Foresman.

Sambunjak, D., Straus, S.E., \& Marusic, A. (2006). Mentoring in academic medicine: A systematic review. Journal of the American Medical Association, 296, 1103-1115.

Walker, B., \& Wooten, H. (2005). Supporting AVT through mentoring and coaching. Paper presented at the meeting of Auditory-Verbal International, Inc., Toronto, ON.

Wright-Harp, W., \& Cole, P. (2008). A mentoring model for enhancing success in graduate education. Contemporary Issues in Communication Science and Disorders, 35, 4-16. 


\section{Appendix: LSLS Cert. AVT Mentoring Survey}

\section{Who's Mentoring?}

1. How long have you held certification as a LSLS Cert. AVT? years

2. What certificate(s) do you hold? (Indicate all that apply)
a. CED
b. CCC/SLP
c. $\mathrm{CCC} / \mathrm{A}$
d. State or regional certification in education of the deaf
e. Other: (Please specify)

3. In what country do you reside?

4. What is your primary work setting?
a. Public school
b. Private school
c. Hospital/medical center/physician's office
d. Private practice
e. University
f. Other: (Please specify)

5. Did you receive mentoring while you were working toward your LSLS Cert. AVT?
a. yes
b. no

If yes, what were some positive aspects of your experiences as a mentee? What are some suggestions for improving your experience? 
6. Are you currently or have you previously mentored an individual who is seeking LSLS certification?
a. yes
b. no

\section{Mentoring Organization}

1. What types of mentees are you mentoring or have you mentored in the past? (Indicate all that apply)
a. LSLS Cert. AVT
a. LSLS Cert. AVEd

2. How do mentees connect with you? (Indicate all that apply)
a. I mentor colleagues as part of my job requirements
b. Agencies/centers contact me.
c. Individuals contact me
d. Other: (Please specify)

3. Do you have requirements that a professional must meet prior to your agreeing to be a mentor?
a. yes
b. no

Comments:

4. Do you have a mentoring agreement that both parties sign?
a. yes
b. no

Comments: 
5. How many professionals are you willing to mentor at any one time?

6. Do you mentor in locations away from where you live? (Indicate yes or no)
a. I mentor in different cities
b. I mentor in different states/provinces
c. I mentor in different countries

7. Do you mentor professionals who speak a language other than your own?
a. yes
b. no

If yes, how do you manage communication?

8. How are you compensated for mentoring?
a. Part of my employment responsibilities
b. My employer compensates mentoring in addition to regular salary
c. I receive a contract from an outside agency for mentoring
d. The mentee compensates me directly
e. I receive no compensation for mentoring.

Other or comments:

9. Has a mentoring agreement been ended either by the mentee or yourself?
a. yes
b. no

If yes, what are some of the reasons an agreement has ended?

\section{Mentoring Practice}

1. How do you observe therapy? (Please indicate all that apply) 

a. Sit in room with mentee
b. Observe through a two-way mirror or video camera in the same building
c. Observe real-time via Skype or videoteleconferencing
d. View taped sessions
e. Other or comments:

2. How do you deliver feedback to your mentees? (Please indicate all that apply)
a. Co-teaching
b. Demonstration teaching
c. Coaching from the sidelines
d. face-to-face meetings after the session
e. by email
f. by telephone
g. face-to-face via video-teleconferencing
h. by regular mail
I. Other or comments:

3. How do you and your mentee set goals? (Indicate all that apply)
a. LSLS Cert. AVT Supervisor's Evaluation Form
b. Auditory-Verbal Teaching Behaviors Checklist
c. Other or comments:

4. What are typical mentee goals during the 3-year period of candidacy for Auditory-Verbal certification?
a. Year 1:
b. Year 2: 

c. Year 3:

5. How do you and your mentee measure progress toward goals?
a. LSLS Cert. AVT Supervisor's Evaluation Form
b. Auditory-Verbal Teaching Behaviors Checklist
c. Other or comments:

6. How do you measure your effectiveness as a mentor?

7. How often do you typically observe a mentee over the 3-year period:
a. Year 1:
b. Year 2:
c. Year 3:

8. How often do you typically meet with a mentee over the 3-year period:
a. Year 1:
b. Year 2:
c. Year 3:

The Future for Mentoring

1. Did you receive training as a mentor?
a. yes
b. no

If yes, what sort of training?

2. What are your primary challenges as a mentor?

3. What solutions have you found for your challenges?

4. What support would you like to see for LSLS mentors?

5 . How can the number of Cert. AVTs who mentor be increased? 


\title{
Listening, Language, and Learning: Skills of Highly Qualified Listening and Spoken Language Specialists in Educational Settings
}

\author{
By Ellen L. Estes, M.S., LSLS Cert. AVEd
}

The knowledge base required of Listening and Spoken Language Specialists (LSLS) has been outlined in AG Bell Academy for Listening and Spoken Language publications and is available to applicants through these publications and the Academy website (www.agbellacademy.org). The LSLS certification exam serves to evaluate the applicant's breadth of knowledge. The concomitant specialized skills that are necessary to stimulate listening and spoken language acquisition with children who are deaf or hard of hearing are developed during the mentoring process. Acquisition of skills comes from guided practice of these skills as mentors and potential applicants work together to develop proficiency with selection and application of LSLS techniques. This article describes many of the specialized skills demonstrated by highly qualified LSLS working in educational settings.

\section{Introduction}

Various articles in the professional literature describe the generalized knowledge and skills necessary for intervention with children who require speech-language remediation or who require services for hearing loss (American Speech-Language-Hearing Association, 2002, 2009; Easterbrooks, 2008; Luckner, Goodwin Muir, Johnson Howell, Sebald, \& Young, 2005; Sheetz \& Martin, 2008). However, professionals who demonstrate competence

Ellen L. Estes, M.S., LSLS Cert. AVEd, is the Curriculum and Instruction Specialist in the Katherine Hamm Center at the Atlanta Speech School. She is also a member of the education faculty at the Atlanta site of the Professional Preparation in Cochlear Implants program, and a part-time instructor at Georgia State University. Correspondence concerning this article can be addresses to Ms. Estes at eestes@atlspsch.org. 
as a Listening and Spoken Language Specialist (LSLS) have acquired specialized knowledge and skills in developing listening and spoken language above and beyond that which is acquired in traditional professional preparation programs (Cosby, 2009; Teller \& Harney, 2005/2006). The AG Bell Academy for Listening and Spoken Language oversees the certification of professionals who provide this specialized intervention, and provides extensive information for the development of the knowledge base that is foundational to providing qualified listening and spoken language intervention. While this knowledge base is vital, LSLS must also possess the skills necessary to carry out appropriate intervention in a wide variety of settings, including one-onone therapy with a child, parent and child sessions focusing on informing and empowering the parent, small group classes, and sessions supporting children being served in general education settings. The specialized skills reviewed in this article are founded on a firm understanding of the requisite knowledge and require application with ease and alacrity. The mentoring aspect of LSLS certification is essential to the development and evaluation of the specialized skills exhibited by an effective LSLS. The information in this article is offered to support professionals seeking certification and mentors as they work together to learn and practice LSLS skills throughout the mentoring process and ultimately develop the expertise to effectively provide auditory-based services to children and their families.

The listening and spoken language intervention skills and strategies listed in this article are organized into three levels of focus. The initial level examines the direct, personal interactions between the LSLS and parent/caregiver and the child, and reviews the skills necessary to optimize the efficacy of specific exchanges. The second level of focus examines the wider scope of planning, organizing, and evaluating the setting through which listening and spoken language is developed. The third level of focus examines the broad scope of maximizing listening and spoken language access throughout the child's environment outside the classroom or therapy room. The organizational schema and lists of skills and strategies presented here are based on many years of observation and analysis of effective listening and spoken language intervention as well as extensive experience providing preservice and in-service training and mentoring to professionals who promote spoken language acquisition through stimulating and refining auditory perception in children who are deaf or hard of hearing.

\section{Optimize the Effectiveness of Each Interaction}

"The aspects of classroom quality that relate directly to improved child outcomes... are aspects of the social and instructional climates reflected in teacherchild interactions" (La Paro, Pianto, \& Stuhlman, 2004, p. 411). This section of skills focuses on optimizing the effectiveness of each specific "teachable moment" and involves the techniques and strategies incorporated into each 
exchange between the LSLS and the child. The LSLS is often called upon to coach others (such as parents, caregivers, educators, and support personnel) to develop proficiency incorporating these strategies and techniques into their interactions with their child(ren). The LSLS must be able to describe, demonstrate, and implement a solid repertoire of strategies for making the auditory signal comprehensible, stimulating language acquisition, and promoting cognitive development. Skills required for optimizing the effectiveness of each interaction are listed in Table 1.

Table I. Skills for optimizing the effectiveness of each interaction

Promote the child's reliance on the auditory signal:

- Ensure success through careful presentation of stimuli that is perceivable to the child.

- Quickly and accurately assess a child's misunderstanding (or other error) as it occurs and appropriately modify the signal to ensure understanding (or successful completion of the task).

- Discourage guessing, especially at the early levels of auditory skill development.

- Encourage the child to indicate when he or she does not adequately perceive the auditory signal being presented.

- Note when extra structured work may be necessary for development or refinement of a skill and provide opportunities for this work.

- Reinforce the child's appropriate response to the auditory signal when at odds with other non-auditory cues (sabotage).

Provide the appropriate mode of presentation:

- Present stimuli with or without visual cues as is fitting to the child and situation.

- Establish eye contact as necessary.

- Use expectant facial expressions and posture to establish attention and anticipation when directing the child to listen.

- Promote the development of the spontaneous awareness and comprehension of auditory stimuli.

- Provide a suitable mechanism for obscuring the face. For example, adopt an obvious mechanism that cues the child to listen, such as a listening hoop, or a subtle means, such as sitting beside the child and directing attention to the objects or activity in front of him/her.

- Control unconscious non-auditory cues that deter the child from focusing on the auditory signal.

\section{Promote interaction:}

- Actively listen to the child.

- Wait an appropriate length of time for the child to respond.

- Encourage turn taking.

- Respond to child-initiated communication and incidental language opportunities.

- Provide meaningful reinforcement to the child's responses to auditory stimuli.

- Promote peer communication and support for learning. 
Work within the child's zone of proximal development (the level between a child's current independent performance [current ability] and his/her performance with guidance [potential ability]) (Vygotsky, 1978):

- Control factors that increase or decrease the level of task difficulty, such as the size of the set of possible answers, number of critical elements, and complexity of language, vocabulary, and auditory skills.

- Use sandwich techniques to scaffold learning: Unknown $\rightarrow$ Known $\rightarrow$ Unknown; Known $\rightarrow$ Unknown $\rightarrow$ Known; and Auditory $\rightarrow$ Auditory/Visual $\rightarrow$ Auditory (see Easterbrooks \& Estes, 2007, pp. 70-72).

- Address goals in a controlled linguistic context as applicable: framing unfamiliar vocabulary in familiar language structures, presenting unfamiliar language structures using familiar vocabulary, developing speech targets in phonetic contexts, and carrying over established speech targets to phonological contexts.

- Utilize acoustic highlighting and low-lighting to make target features more salient.

\section{Provide appropriate levels of modeling and prompting:}

- Be purposeful about the language and vocabulary being prompted and modeled.

- Have the specific goals at the forefront during each exchange with the student.

- Select the appropriate modeling techniques (e.g., expansion, reduction, or elaboration) to practice unhabituated skills and to increase auditory memory.

- Choose the appropriate prompting technique when strengthening maintenance of a skill of which the child is determined to be capable (Calvert \& Silverman, 1983). For example, when eliciting the child's production: use facial expression, ask questions, or provide an opening phrase; when improving errors: signal, specify, or correct.

- Accurately determine when to expect a response, present a prompt, or provide a model during the course of a communication exchange.

- Provide additional prompts or models as necessary to avoid letting errors persist.

- When necessary, provide a "brief recourse to multi-modal remedial strategies" (Ling, 1993, p. 194), such as allowing the child to see lip placement for a speech sound that the child cannot auditorally discriminate from another, similar sound.

- After leading the child to the correct response using additional cues, provide the child with an opportunity to perform the task with less cueing.

Apply strategies that facilitate cognitive and communicative development:

- Employ strategies to develop executive functioning (e.g., decision making, problem solving).

- Support the child to make cognitive connections and solve problems by appropriately providing cues and scaffolding of thought processes. Allow enough time for the child to come to the appropriate answer or conclusion.

- Provide the child experience with the adverbial system, a key to higher-order thinking including asking questions and prompting the child's use of question forms that obligate the use of adverbials (e.g., How? Why?) (Easterbrooks \& Estes, 2007).

- Determine "how and when to use [strategies] most effectively and efficiently" (Easterbrooks, 2008, p. 19). 


\section{Organize the Setting}

La Paro, Pianto, \& Stuhlman (2004) state, “children's competencies depend largely on the quality of their experiences in educational settings" (p. 410). The skills involved in organizing the setting to optimize listening and spoken language development are the skills necessary in planning, conducting, and evaluating intervention. A highly qualified LSLS determines appropriate goals for each child and organizes the scope of the intervention, mapping out how these goals will be addressed in the short-term and long-term. The LSLS must be able to plan specific experiences to support the acquisition of a variety of goals in the context of the developmental and academic needs of the child. The LSLS must conduct these lessons with efficiency and accuracy in a meaningful and engaging manner. Evaluation of the effectiveness of the intervention occurs during each lesson and is supported by periodic formal assessment of progress. Intervention strategies and goals are modified as necessary based on the results of evaluation. Factors of the physical environment, such as managing the acoustic environment and supporting listening technology, are also important aspects of organizing the setting. Specific skills are listed in Table 2.

Table 2. Skills for organizing the setting

Develop appropriate goals:

- Focus on goals that establish communicative competence.

- Take into account the variety of factors that affect progress, including "whether the child has the ability to detect the key elements in the acoustic stimuli... provide[d]" (Ling, 1993, p. 193).

- Base goals on an understanding of the appropriate next steps in auditory development and language acquisition.

- Promote the use of "intrinsically meaningful connected-language forms that relate to the child's interests" (Ling, 1993, p. 194).

- Merge listening goals with language, vocabulary, speech production, and academic and developmental goals.

- Integrate intervention goals "within [and across] content area activities...to maximize language use" (Easterbrooks, 2008, p. 30).

- Promote the development and use of communication repair strategies (such as rephrasing, elaborating, or simplifying the message) to facilitate independent communication (Easterbrooks, 2008).

- Support the development of literacy skills by establishing a familiarity with reading conventions and the expectation of comprehension, leading to the child's active engagement in construction of meaning.

- Support the development of decoding skills (such as letter-sound associations) by establishing the child's underlying knowledge of the phonological system beyond mere auditory skill development, leading to the ability to focus on and manipulate phonemes in spoken words. 
Organize the scope of the intervention:

- Stimulate the desire to communicate.

- Plan focused language stimulation throughout the day.

- Orchestrate a variety of contexts and activities to provide practice of chosen listening, speech, and/or language goals.

- Incorporate a variety of skills into each activity.

- Repeat target goals meaningfully and naturally throughout the session.

- Establish skills through a balance of formal exercises and informal stimulation.

- Incorporate elements of intrigue and the unexpected to engage and maintain the child's active participation in communication.

- Anticipate upcoming target structures or vocabulary and expose the child to these targets by using them meaningfully and naturally during the period of time prior to their specific introduction and practice.

- Promote "access to incidental language experiences" (Easterbrooks, 2008, p. 21), providing opportunities for the child to be actively engaged in making connections with the language he or she perceives in the environment.

- Incorporate the development of conversational strategies, attention, cognitive maturation, and thinking behaviors.

\section{Conduct effective lessons:}

- Establish the auditory feedback loop wherein the child modifies what he or she says to more closely match what he or she hears, thereby providing opportunities for the child to make the connection between perception and production, which leads to the development of self-monitoring.

- Ensure that each child: a) understands the concept underlying the structure and vocabulary, knowing; b) perceives it, hearing; c) comprehends it, processing;

d) produces it, saying; and e) uses it, influencing his or her world.

- Progress to comprehension of finer, more taxing discriminations; longer sequences; less redundant information; increasing distance; and listening in the presence of a variety of competing sounds.

- Work toward higher and higher levels of precision in expressive production.

- Ensure that the children are challenged while providing a level of success for each child through positive interaction, differentiated instruction, and expansion of previously attained skills.

\section{Evaluate the effectiveness of instruction:}

- Actively engage in diagnostic teaching and analysis throughout each session.

- Conduct a variety of "objective ongoing and periodic evaluations to ensure that... efforts are, indeed, effective" (Ling, 1993, p. 194).

- Determine the appropriate evaluation instrument to use in relation to the information being probed.

- Ascertain whether errors in speech production are "due to auditory perceptual problems stemming from hearing impairment [sic] [or] are simply phonological processes" (Ling, 1993, p. 194). 
Table 2. Cont.

- Incorporate data from assessments and diagnostic teaching to develop appropriate strategies for remediation and "make informed decisions regarding the student's instructional program" (Cohen \& Spenciner, 2003, p. 19).

- Assess whether the effectiveness of auditory-verbal intervention for a particular child has been established or if the child should be "referred on to an alternative program" (Ling, 1993, p. 194).

Manage the environment and/or technology:

- Determine "whether even minimally acceptable levels of amplification are being provided" (Ling, 1993, p. 194).

- Design "a classroom environment that maximizes opportunities for...auditory learning and meets developmental and learning needs" (Easterbrooks, 2008, p. 22).

- Consistently utilize amplification technology.

- Conduct regular and frequent monitoring of functionality and effectiveness of listening devices.

- Readily perform troubleshooting procedures on equipment.

\section{Maximize Listening and Spoken Language Access}

"Two major behaviors... are emphasized in the research...providing support to and collaborating with families and professionals" (Sheetz \& Martin, 2008, p. 332). When the child can successfully communicate with the greater world, he or she develops the drive to control the world using listening and talking. Empowering the child to successfully communicate in the wider world often requires careful planning and active collaboration with others. The skills required for maximizing listening and spoken language access throughout the child's environment involve coaching parents and colleagues in developing the child's dependence on listening and spoken language for communication, while stimulating language maturation and academic progress. The LSLS acts to ensure the child's access to information in the greater world and to develop the child's confidence in his or her ability to communicate with others. The LSLS is often the individual whose expertise is necessary to advocate for appropriate services and support educational transitions. Skills necessary for maximizing listening and spoken language access can be found in Table 3.

Table 3. Skills for maximizing listening and spoken language access

Actively involve parents and caregivers in language stimulation and educational support:

- Provide and advocate for services that will inform and empower parents and caregivers to support growth in their ability to stimulate spoken language acquisition and to effectively articulate and promote the needs of their child.

- Care for the child "in full partnership with the parents" (Ling, 1993, p. 194). 
Empower children to self-monitor and self-advocate:

- Determine potential causes of communication breakdowns.

- Teach and practice various strategies for problem solving and communication repair in all environments.

Coordinate and collaborate with the efforts of the members of the educational team:

- Involve the family as directors of their child's team.

- Coach professionals unfamiliar with the needs of children who are deaf or hard of hearing acquiring spoken language through listening.

- Provide a shared model, such as a collaborative lesson plan, for addressing auditory, speech, and language development to maximize communication among the team, leading to focused intervention and carryover of goals. (Easterbrooks \& Estes, 2007).

- Join forces with audiologists and physicians to ensure maximal use of residual hearing with the most appropriate hearing technology.

Provide an environment that nurtures and expands communication competency to all educational settings:

- Evaluate the extent to which the child needs educational and therapeutic support to develop listening and spoken language.

- Determine the most effective educational environment for each child (U.S. Department of Education, 2005).

- Provide aggressive assistance to support communicative competence in every environment.

- Remediate environments in which the child's capacity to communicate is compromised.

- Plan and implement smooth and effective transitions among educational placements "to ensure that valuable instructional time is not lost" (Easterbrooks, 2008, p. 41).

\section{Advocate for students:}

- Determine the aspects of educational law and policy that positively and negatively affect students who are deaf or hard of hearing acquiring spoken language and academic content primarily through listening.

- Advocate for the child's needs, such as special time in the child's day for listening and spoken language intervention, improved classroom acoustics, and appropriate supports for communication in the general education classroom.

\section{Summary}

In the article "Most Likely to Succeed," Malcolm Gladwell (2008) identifies "withitness" as an essential characteristic demonstrated by proficient teachers. Withitness is the ability to "deal with more than one issue at a time" (Teacher Matters, 2009). The effective LSLS deals with many issues at a time, managing listening and spoken language interactions while adroitly embedding listening and spoken language techniques into academic or developmental goals in the myriad contexts where children learn. Gladwell also states that the "complex elements of effective teaching" aren't related to a professional's cognitive skills, tests scores, credentials, or graduate degrees. Gladwell concludes that 
on-the-job development and evaluation of a professional's skills is essential. He suggests instituting "an apprenticeship system that allows candidates to be rigorously evaluated." The mentorship component of LSLS certification, providing on-the-job development and evaluation of skills, is essential for promoting the quality of intervention necessary to maximize listening and spoken language outcomes. The information presented here is offered to mentors and potential applicants to serve as points for further research, discussion, and practice.

This article is not all-inclusive. Additional essential components of a scope of practice include providing effective, developmentally appropriate content instruction at all levels; establishing a cooperative, rigorous, and supportive classroom community; and creating life-long learners. Applicants and mentors are encouraged to actively collaborate to determine how to incorporate all these skills into specific educational and therapeutic environments.

\section{References}

American Speech-Language-Hearing Association (2009). Knowledge and skills acquisition (KASA) summary form for certification in audiology. Retrieved April 26, 2010, from http://www.asha.org/uploadedFiles/ KASASummaryFormAud.pdf

American Speech-Language-Hearing Association (2009). Knowledge and skills acquisition (KASA) summary form for certification in speech-language pathology. Retrieved April 26, 2010, from http:/ / www.asha.org/uploadedFiles/ KASASummaryFormSLP.pdf

American Speech-Language-Hearing Association. (2002). Knowledge and skills required for practice of audiologic/aural rehabilitation: Executive summary. ASHA Supplement (22).

Calvert, D. \& Silverman, S.R. (1983). Speech and deafness. Washington, DC: Alexander Graham Bell Association for the Deaf and Hard of Hearing.

Cohen, L., \& Spenciner, L. (2003). Assessment of children and youth with special needs. Upper Saddle River, NJ: Pearson Education.

Cosby, J. (2009, February 10). Pediatric cochlear implants: Knowledge and skills of speech-language pathologists. The ASHA Leader.

Easterbrooks, S. (2008). Knowledge and skills for teachers of individuals who are deaf and hard of hearing. Communication Disorders Quarterly, 30(1), 37-48.

Easterbrooks, S., \& Estes, E. (2007). Helping deaf and hard of hearing students to use spoken language: A guide for educators and families. Thousand Oaks, CA: Corwin Press.

Gladwell, M. (2008). Most Likely to Succeed. New Yorker Magazine. December 15, 2008. Retrieved August 7, 2009, from http://www.newyorker.com/ reporting/2008/12/15/081215fa_fact_gladwell?currentPage=all

La Paro, K., Pianto, R., \& Stuhlman, M. (2004). The classroom assessment scoring system: Findings from the prekindergarten year. The Elementary School Journal, 104(5), 409-426. 
Ling, D. (1993). Auditory verbal options for children with hearing impairment: Helping to pioneer an applied science. The Volta Review, 95(3), 187-195.

Luckner, J., Goodwin Muir, S., Johnson Howell, J., Sebald, A., \& Young, J. (2005). An examination of the research and training needs in the field of deaf education. American Annals of the Deaf, 150(4), 359-368.

Scheetz, N., \& Martin, D.S. (2008). National study of master teachers in deaf education: Implications for teacher education. American Annals of the Deaf, 153(3), 328-342.

Teacher Matters. (2009). The Kounin Model. Retrieved December 5, 2009, from http://www.teachermatters.com/index.php.

Teller, H., \& Harney, J. (2005/2006). Views from the field: Program directors' perceptions of teacher education and the education of children who are deaf or hard of hearing. American Annals of the Deaf, 150(5), 470-479.

U.S. Department of Education. (2005). Deaf students education services. Retrieved December 3, 2009, from http://www.ed.gov/about/offices/list/ocr/docs/ hq9806.html.

Vygotsky, L. (1978). Mind in society: The development of higher psychological processes. Cambridge, MA: Harvard University Press. 
The Volta Review, Volume 110(2), Summer 2010, 179-190

\section{Professional Preparation: Developing Language in Children with Hearing Loss}

John Muma, Ph.D., CCC-SLP, and Christina Perigoe, Ph.D., CCC-SLP, CED, LSLS Cert AVT

Children with hearing loss are increasingly being identified at an early age and receiving family-centered intervention from infancy. This means that they are more likely to follow typical developmental sequences of learning. Therefore, professionals working with them need to be aware of developments in the scholarly literature that drive intervention with children who have typical hearing. This paper addresses some of these developments including: family-centered services, the centrally of intent, language functions, social-based intervention, theory of mind, rational evidence, and ecologically valid services.

\section{Introduction}

Three factors have facilitated spoken language acquisition in children with all levels of hearing loss: a) early identification through universal newborn hearing screening; b) early intervention; and c) advances in hearing technology (Cole \& Flexer, 2007). These developments also influence how programs prepare professionals to work with children who are deaf or heard of hearing and their families. In particular, the focus has changed from remedial to developmental approaches. These provide early support to families, infants, and young children.

In addition, the knowledge and skills needed by listening and spoken language (LSL) professionals has changed considerably. This is due in large measure to developments in the literature. Some of these developments occurred several decades ago and are still being adjusted while others are more recent. Accordingly, training of these professionals has changed.

John Muma, Ph.D., CCC-SLP, is a Professor in the Department of Speech and Hearing Sciences at the University of Southern Mississippi. Christina B. Perigoe, Ph.D., CCC-SLP, CED, LSLS Cert. AVT, is Coordinator of the Early Oral Intervention Graduate Program in Speech and Hearing Sciences at The University of Southern Mississippi. Correspondence concerning this article should be directed to Dr. Muma at john.muma@usm.edu. 
Table. Important clinical services for infants and preschool children with a hearing loss

1. Family-centered services: Parents/caregivers as the primary service providers and professionals as mentors.

2. Centrality of intent.

3. Language functions.

4. Social-based intervention: Peer modeling.

5. Theory of Mind

6. Rational evidence: Philosophical views and theoretical perspectives.

7. Ecologically valid services.

This article recognizes some of the most important changes for clinical services at the infant and preschool level. The Table lists the changes that are considered here.

\section{Family-Centered Services}

In the past, traditional services in developing language for children with hearing loss were instructional in nature. Professionals instructed small groups of children and were in control of the content, sequencing, pacing, and reinforcement. Thus the pace, themes, and expectations were dictated by the professional. Historically, language instruction was based on vocabulary development and on the acquisition of syntax in drill and structured practice (Easterbrooks \& Baker, 2002; Stone, 1988). The focus was primarily on developing grammatical structures. Some of the tools developed over the years include the Fitzgerald Key (Fitzgerald, 1929), "APPLETREE," which stands for "A Patterned Approach for Linguistic Expansion Through Reinforced Experiences and Evaluations" (Caniglia, Cole, Howard, Krohn, \& Rice, 1972), and "Lessons in Syntax" (McCarr, 1980).

With early identification, intervention, and a shift to family-centered services, the instructional approach was replaced by a more natural, facilitation approach (Muma, 1978, 1998) that focuses on the parents or caregivers as the primary intervention providers and language facilitators for the child (Estabrooks, 2006). The role of early intervention professionals is to coach and mentor parents. Thus, the professional is no longer the "sage on the stage" but the "guide on the side" (Stinson \& Milter, 1996). Many parents want to play an active role in a family-centered model that calls for parent participation (Simser, 2001; Estabrooks, 2006). Indeed, several exemplary programs were started by parents (John Tracy Clinic, 2010; Easterbrooks \& Baker, 2002).

Both parents and professionals are governed in large measure by the child's "readiness" to deal with various aspects of communication. Vygotsky called this the zone of proximal development, which reflects the difference between the child's ability to do something on his/her own versus what he/she can achieve with the assistance of a more knowledgeable conversational partner, 
such as an adult or older child (Kaufman, 2004; Vygotsky, 1962, 1978). The professional can become skilled at recognizing what the child brings to the learning process and how to enhance the learning environment to facilitate language acquisition through scaffolding (building on previous success) techniques. Then, modeling the techniques for scaffolding the child to the next level of language learning becomes part of the parent mentorship process.

Mentorship can take many forms. However, the overriding principle is that the professional facilitates parental efforts by observing the parents and the child, then modeling, guiding, and coaching parents to improve language learning. Cole presents a framework for evaluating and promoting caregiverchild interaction that is designed to improve adult responsiveness and enhance social and verbal interactions between the parent/caregiver and child (Cole, 1992; Cole \& Flexer, 2007). For example, a parent who directs their child to talk or to play particular ways could be mentored to allow the child to talk or to play for his/her own purpose. Thus, the parent learns to appreciate intentionality of communication and play. Family-centered services are based to a large extent on ecologically valid evidence and intentionality. Ecological valid evidence (Bronfenbrenner, 1979) is based on observations of how an individual functions in his or her world as contrasted to a priori evidence, such as test performances and checklists. Intentionality will be discussed in the next section.

\section{Centrality of Intent}

One of the most important developments in the literature on language development is the centrality of intent (Bruner, 1986; Nelson, 1985, 1996; Searle, 1992). When a child wants or intends to communicate in whatever language form (gesture, word, sentence) it is the most opportune time for learning to take place. The implication is that whenever a child initiates a topic, a "tunedin" parent or professional should follow the child's lead. This is the communicative payoff intervention principle (Muma, 1986).

Children typically exhibit two important behaviors in response to communicative payoff. First, they will talk more because they realize that their communication attempt worked as intended (Sperber \& Wilson, 1986). Second, they will try new aspects of language. By doing so, they will expand their repertoires - an effect which cannot be accomplished by reinforcement alone.

The purpose of a message is to make intentions recognizable. Thus, intent has become regarded as the "irreducible nucleus of language" (Bruner, 1986, p. 17; Nelson, 1985, 1996; Searle, 1992). Furthermore, "intention is immediately and intuitively recognizable" (Bruner, 1986, p. 17). Thus, language intervention should be oriented on a child's intentions to communicate.

The most successful parents/caregivers provide the appropriate language for a child's preverbal linguistic development. For example, when the young child looks at the parent with arms raised and the parent responds by saying, 
"Oh, you want up" and then picks the child up, the parent is providing the language related to the child's communicative intent.

\section{Language Functions}

Traditional language intervention approaches have been oriented on structure, i.e. parts-of-speech, sentence types, etc. However, the emphasis has shifted away from structure toward a broader use of language functions. Nelson $(1985,1996)$ outlined the basic language functions. The two main cognitive functions are representation and mediation; and the two main communicative functions are intent and content. There are two kinds of content: implicit content and explicit content.

Language is used to represent concepts and referents. For example, the word "apple" can represent either a particular apple or the concept of apple-ness (its taste, color, shape, smell, crispness). Mediation occurs when an individual talks about something and the act of talking leads to new understandings. The new understandings are said to be mediated via language.

Implicit content pertains to an individual's knowledge of the world and is the result of an individual's experiences. What a person knows of the world varies from one individual to another. Thus, what is possible for one individual does not have the same possibilities for another. That is why Bruner (1986) regarded a person's knowledge of the world as possible worlds.

Explicit content is the basic idea entailed in a message. For example, the following sentence has the basic idea someone-wants-something: "The boy wants a cookie."

\section{Social-Based Intervention}

Communication is a social enterprise. Within the culture and context of the family, the child's social interactions provide the backdrop for language learning (Kretschmer \& Kretschmer, 1999). Early on, babies become aware of the interaction between themselves and others (Sugarman, 1984). Then they become aware of joint reference. Bates (1979) indicated that this awareness of joint reference is one of two moments in the dawning of language. The other moment is the realization that names can be used to signify the world. This allows the child to be able to use words to represent concepts (Mandler, 1983).

Joint reference has two components: addressing the point and the line-ofregard (Bates, 1979; Bruner, 1981). A young child will point to something then turn to the person whom he/she wants to notice the referent (object, person, event). This is known as addressing the point. Then, that person will use the young child's line-of-regard to locate the joint reference. Parents can establish joint reference prior to the infant's ability to vocalize, which is often reinforced by redirecting the baby's gaze and by early vocal turn-taking (Kretschmer \& Kretschmer, 1999). 
A second way for the child to establish joint reference is to make a vocalization to identify a referent. For example, a young child may make a motor sound for a truck as he/she plays with it. Thus, the child learns to use vocal productions to direct the adult's attention. The use of vocalization by the child in addition to pointing is an important step in early communication (Cole \& Flexer, 2007).

A third way to establish joint reference is to display a referent (Muma, 1998). Sometimes children will hold an item up for all to see. They might even push an item in your face thereby forcing you to see the item. There are many other ways to establish joint reference. Professionals can guide parents towards establishing joint reference, especially when the child is making early attempts to master this behavior.

Once joint reference is established, the role of the parent is to name the referent. This is known as the "initial dubbing ceremony" (Bruner, 1981; Kripke, 1972 , p. 302). For young children with hearing loss, Learning to Listen sounds (Estabrooks, 2006) or sound-object, sound-event-associations (Cole \& Flexer, 2007) are often used because they provide more salient acoustic information for the child to discriminate. For example, "woof-woof" and "meow" are more distinctly different than "dog" and "cat" - and are both easier to perceive and easier to produce.

When a child names an item, it is necessary to "raise the ante" by commenting on the function of the item (Bruner, 1981). For example, if a child says "Truck," the parent could say, "Go, truck, go." These types of language expansions that focus on the function of objects, rather than the attribute (e.g. "Red truck") appeal to the cognitive and linguistic level of the child.

As a child's daily routines expand to include siblings and, eventually, peers, the social base of language acquisition expands accordingly. Then peer modeling takes on increased importance, not only for language acquisition but also for social, emotional, and cognitive development. This is an essential point because it underscores that the best environment for language acquisition is in a social context. Children learn language in social communication with conversational partners (Stone, 1988). The potency of language acquisition in a social context is the product of calibration (Bruner, 1981). Children watch their peers and compare what they can do with what their peers can do. When they notice that a peer does something, then they are motivated to do that behavior as well. For example, one child may say, "Him go." However, when he notices that his peers say "He go," the child is motivated to say "He go."

Thus, the parent or professional should note what a child's peers do with speech and language. It is important not to correct a child; rather, the most effective strategy is to provide opportunities in which a child's peer produces utterances that correspond with a child's spoken language objectives. The goal of early intervention with listening and spoken language is for the child with hearing loss to acquire language abilities on par with their peers who have typical hearing. Thus, the child who is deaf or hard of hearing should be 
placed in a setting that encourages calibration to peers who can be models for language learning. Generally, this is a mainstream setting but some students will continue to require services outside the mainstream.

\section{Theory of Mind}

Another important milestone in cognitive-linguistic development is the development of Theory of Mind, the ability to understand another person's point of view. This helps children to attribute intentions, beliefs, and desires to others and to predict their behavior. One type of assessment of the development of Theory of Mind is the utilization of false belief tasks. These are usually the "change-in-location" narrative or the container with "unexpected contents" (e.g. a crayon box that has a plastic spoon inside). In one of the early "change-in-location" narrative experiments (Wimmer \& Perner, 1983), a young boy puts some chocolate in a blue cupboard and leaves the room. While he is away, his mother takes out the chocolate and puts it away in a green cupboard. When asked where the boy will look for the chocolate when he returns, children above 5 or 6 years of age had little difficulty, but younger children predicted that the boy would look where his mother had put it - the green cupboard. These and other experiments indicated that children begin to master false belief tasks and develop a Theory of Mind at about ages 3 to 4 .

Research with children who are deaf or hard of hearing shows a relationship between language delay and the development of Theory of Mind. De Villiers (2005) found that "both semantic features of language (vocabulary) and specific syntactic features (the processing of false-complement clauses) are independently predictive of false-belief reasoning for both oral and ASLsigning children" (p.280). He argued that intervention which would promote the "conversational features of language" and the "mastery of the syntax of complements with verbs of communication and mental state...may provide the representational mechanism for reasoning about false beliefs" (de Villiers, 2005, p.280). Certainly, this is an area that requires further investigation into the real-world consequences of children learning to understand the belief systems and intentions of others (Astington, 2001).

\section{Rational Evidence}

Clinical services should be based on rational evidence. Rational evidence is the collection of philosophical views and theoretical perspectives that underwrite clinical services. In teaching children with hearing loss, sometimes professionals get caught up in learning the "how to" without understanding the theoretical bases, or "why." Graduate students are apt to gravitate towards wanting to learn practical application without understanding why a particular strategy, goal, or learning sequence is appropriate. It is important to 
prepare new professionals entering the field to have a thorough understanding of the underlying philosophical and theoretical foundations of language development.

Searle (1992) critiqued several philosophical views of language for "coherence," or rationally sound evidence, and found constructionism the most coherent and behaviorism the least coherent. This confirmed findings by Muma (1983) who compared behaviorism with contructionism. An instructional approach based on behaviorism centers on the teacher determining the content and sequences of learning, the rate that learning is to be acquired, and the reinforcement of child behaviors (Kohn, 1993). By contrast, in constructionism the child drives the learning. Thus, it becomes necessary to determine the child's repertoire, learning style/strategies, acquisition of learning sequences and active loci of learning (those aspects of language which the child is striving to learn at any given moment in time) to determine how to best scaffold language learning (Muma \& Teller, 2003). The nature versus nurture debate that dominated early theorists has been replaced by the view that both innate and environmental factors interact in language development (Braine, 1994) and that children construct their own learning (Baker, 2003).

The core issues of language are cognition, codification, communication, and expression (CCCE) (Muma \& Teller, 2003; Muma and Cloud, 2008). This is closely allied with the views of Sperber and Wilson (1986), Bloom and Beckwith (1989), and Nelson $(1985,1996)$, returning us, once again, to Brown's model of cognitive socialization $(1956,1986)$.

\section{Ecologically valid evidence}

Bronfenbrenner (1979) made an exceedingly important observation about the literature on child development. He described ecological validity as "an investigation is regarded as ecologically valid if it is carried out in a natural setting and involves objects from everyday life" (Bronfenbrenner, 1979, p. 28). He noted, however, that much of the literature on child development is the outcome of having children perform on various tasks that they have never done before and will never do again. Yet, conclusions were drawn about their use of language based on such performances. To this extent, Bronfenbrenner concluded that much of the literature is ecologically invalid.

Accordingly, the best evidence of what a child can do with spoken language is what he/she does in actual social interaction. Thus, spontaneous speech provides the best evidence of what an individual can do with language (Bronfenbrenner, 1974, 1979; Stone 1988). Indeed, prima facie evidence of social, emotional, and cognitive abilities are best assessed when using actual performances in a child's real world rather than in contrived circumstances, such as those on many language tests. Stone (1988) provides a model for analyzing spontaneous spoken language samples that recognize the role of conversational interaction and context in evaluating a child's linguistic competence. 
This is the first step towards uniquely tailoring learning and play to the interests and abilities of each child.

Brown (1973) and Searle (1992) raised the problem of ecologically invalid evidence when they discussed "as-if" psychology, such as those found in some language tests. It is assumed that how an individual performs on a test is "necessary and sufficient" evidence of that individual's abilities. However, there is increasing concern that the various speech and language tests do not provide necessary and sufficient evidence of a child's language abilities (Muma \& Cloud, 2008; Bernstein Ratner, 2009).

This circumstance raises a paradox for rendering appropriate clinical services because professionals are typically under pressure to report normreferenced test scores and various quantitative data. The basic view is that it is necessary to compare a child's performance to a norm to ascertain if a problem exists or not. However, there are seven issues that should cause us to reassess such practices: 1) questionable validity of the tests, 2) lack of necessary and sufficient evidence, 3) reliance on the "as-if" analogy, 4) peripheral or tangential evidence, 5) loss of assessment power, 6) the objectivity myth, and 7) frequency-based evidence. We will briefly examine each of these.

First, two major developments have occurred in the field of test and measurement, which have raised the question as to whether a test has appropriate construct validity. The 1974 American Psychological Association guidelines indicated that there were three options for test validity: content validity, criterion validity, and construct validity. However, Messick (1980) reviewed 15 kinds of validity and showed that all were derived from construct validity. Cronbach (1989) and Messick (1995) indicated that construct validity should be theorydriven.

Muma and Cloud (2008) reviewed 20 of the most widely used speech and language tests and found that all but one did not have theory-driven construct validity. The one that did have theory-driven construct validity was based on a theory of information processing (Osgood, 1957) that was shown to be inadequate (Clark \& Clark, 1977). The bottom-line is there is a major concern that various speech and language tests lack appropriate construct validity.

A second major concern is that the tests do not provide necessary and sufficient evidence of speech and language (Muma \& Cloud, 2008; Bernstein Ratner, 2009). For example, these tests may include some aspects of the auxiliary system but not the full array. Consequently, a child may have difficulties with the auxiliary system that are not reflected on a test. As a result, the test score could misrepresent that child's abilities. A third concern is that tests provide "as-if" data. That is, performance on a test is considered "as-if" if it is valid evidence of a child's abilities in an actual social interaction. Yet, as indicated above, this assumption is questionable.

A fourth concern is that test scores are only peripherally related to a child's repertoire of language skills for grammatical systems; or that the test scores are useful in ascertaining a child's progress in acquiring language sequences. 
Yet, scholars have indicated that it is necessary to ascertain a child's repertoires for grammatical systems (Ninio, Snow, Pan, \& Rollins, 1994) before drawing conclusions about a child's abilities and to assess progress in acquisition sequences (Brown, 1973). A fifth concern is that when extreme scores (outlier scores) occur, a test has lost power to assess what it claims to assess (Muma, 2008). In such cases, the probabilities are higher that outlier scores are the result of unknown extraneous variables than what is presumably measured by the test. A sixth concern is the notion that tests provide objective evidence, but descriptive assessments provide subjective assessments. Prutting (1983) showed that such thinking is false. Both test scores and descriptive assessments are subjective.

It is necessary to recognize the two sources of subjectivity for tests: development and application. When tests are developed, the authors make many decisions about what will be assessed: the assessment formats, scoring, norms, and the kinds of psychometrics that are used. These decisions are all subjective. Thus, test development (going in) is a subjective enterprise. The application of a test is also subjective simply because the test administrator makes many decisions about a child's performance. Thus, the administration of the test itself (going out) is a subjective enterprise. Lakoff (1987), one of the foremost scholars in the philosophy of language, indicated that all human endeavors are inherently subjective, tests not withstanding.

A seventh concern is the reliance on frequencies, which are often converted into percentages, as presumed evidence of intervention effectiveness. Such practices are not in accord with the literature. Brown (1973) and Cazden (1988) indicated that frequency-based evidence does not constitute appropriate evidence. Rather, they indicated that lexical variations for grammatical systems, progress in acquisition sequences, and repertoires provide appropriate evidence of language growth.

Going forward, training of professionals must address these issues rather than the traditional reliance on test scores and frequency-based evidence. This includes training on obtaining and analyzing spontaneous spoken language samples for the purpose of assessing language growth and selecting targets for development or remediation.

\section{Summary}

Professional training to work with infants and young children with hearing loss and their families needs to reflect the current thinking in the larger field of language learning and development. As children with hearing loss experience language acquisition in a manner more aligned with their peers who have typical hearing, so should our intervention be more aligned with how their typical peers develop. These changes are reflected not only in understanding child language acquisition and how it develops within a social context, but understanding how best to measure language learning over time. The shedding of 
old views of language and adoption of current best practices will substantially advance how professionals are trained and how they will positively interact with children and families.

\section{References}

Astington, J.W. (2001). The future of theory-of-mind research: Understanding motivational states, the role of language, and real-world consequences. Child Development, 72(3), 685-687.

Baker, S. (2003). Cognitive socialization: Implications for the classroom. In J. Muma and H. Teller (Eds.), Proactive deaf education: Cognitive socialization (pp. 25-41). Hillsboro, OR: Butte Publications.

Bates, E. (1979). The emergence of symbols. New York, NY: Academic Press.

Bernstein Ratner, N. (2009). Atypical language development. In J. Berko Gleason \& N. Bernstein Ratner (Eds.), The development of language (7th ed.) (pp. 315-390). Boston, MA: Allyn \& Bacon.

Bloom, L., \& Beckwith, R. (1989). Talking with feeling: Integrating affective and linguistic expression in early language development. Cognition and Emotion, 3, 313-342.

Braine, M.D.S. (1994). Is nativism sufficient? Journal of Child Language, 21, 9-32.

Bronfenbrenner, U. (1974). Developmental research, public policy, and the ecology of childhood. Child Development, 45, 1-5.

Bronfenbrenner, U. (1979). The ecology of human development. Cambridge, MA: Harvard University Press.

Brown, R. (1956). Language and categories. In J. Bruner, J. Goodnow, \& G. Austin (Eds.), A study of thinking (pp. 247-312). New York, NY: Wiley.

Brown, R. (1973). A first language: The early stages. Cambridge, MA: Harvard University Press.

Brown, R. (1986). Social psychology (2nd ed.). New York, NY: The Free Press.

Bruner, J. (1981). The social context of language acquisition. Language $\mathcal{E}$ Communication, 1, 155-178.

Bruner, J. (1986). Actual minds, possible worlds. Cambridge, MA: Harvard University.

Caniglia, J., Cole, N., Howard, W., Krohn, E., \& Rice, M. (1972). Appletree: A patterned program of linguistic expansion through reinforced experiences and evaluations. Lake Oswego, OR: Dormac, Inc.

Cazden, C. (1988). Environmental assistance revisited: Variation and functional equivalence. In F. Kessel (Ed.), The development of language and language researchers (pp. 281-298). Hillsdale, NJ: Erlbaum.

Clark, H., \& Clark, E. (1977). Psychology and language. New York, NY: Harcourt, Brace, \& Jovanovich.

Cole, E. (1992). Listening and talking: A guide to promoting spoken language in young hearing-impaired children. Washington DC: Alexander Graham Bell Association for the Deaf and Hard of Hearing. 
Cole, E., \& Flexer, C. (2007). Children with hearing loss: Developing listening and talking birth to six. San Diego, CA: Plural Publishing.

Cronbach, L. (1989). Construct validity after thirty years. In R. Linn (Ed.), Intelligence: Measurement, theory, and public policy (pp. 147-167). Urbana, IL: University of Chicago.

de Villiers, P.A. (2005). The role of language in theory-of-mind development: What deaf children tell us. In J.W. Astington and J.A. Baird (Eds), Why language matters for theory of mind (pp. 266-29). New York, NY: Oxford University Press.

Easterbrooks, S. \& Baker, S. (2002). Learning language in children who are deaf and hard of hearing: Multiple pathways. Boston, MA: Pearson.

Estabrooks, W. (2006). Auditory-verbal therapy and practice. Washington, DC: Alexander Graham Bell Association for the Deaf and Hard of Hearing.

Fitzgerald, E. (1929). Straight language for the deaf. Staunton,VA: McClure.

John Tracy Clinic. (2010). About John Tracy Clinic - history. Retrieved May 7, 2010, from http:/ / www.johntracyclinic.org/about/history/index.html.

Kaufman, D. (2004). Constructivist issues in language learning and teaching. Annual Review of Applied Linguistics, 24, 303-319.

Kohn, A. (1993). Punished by rewards: The trouble with gold stars, incentive plans, A's, praise and other bribes. Boston, MA: Houghton Mifflin.

Kretschmer, R. \& Kretschmer, L. (1999). Communication and language development. Australian Journal of Education of the Deaf, 5, 17-26

Kripke, S. (1972). Naming and necessity. In D. Davidson, \& G. Harmon (Eds.), Semantics of natural language (pp. 253-355). Boston, MA: Reidel Publishing.

Lakoff, G. (1987). Women, fire, and dangerous things: What categories reveal about the mind. Chicago, IL: University of Chicago Press.

Mandler, J. (1983). Representation. In P. Mussen (Series Ed.), J. Flavell, \& E. Markman (Eds.), Handbook of child psychology: Vol. 3, Cognitive development (4th ed., pp. 420-494). New York, NY: Wiley.

McCarr, J. (1980). Lessons in syntax. Lake Oswego, OR: Dormac Publishing Company.

Messick, S. (1980). Test validity and the ethics of assessment. American Psychologist, 35, 1012-1027.

Messick, S. (1995). Validity of psychological assessment. American Psychologist, 50, 741-749.

Muma, J. (1978). Language handbook. Englewood Cliffs, NJ: Prentice-Hall.

Muma, J. (1983). Speech-language pathology: Emerging clinical expertise in language. In T. Gallagher \& C. Prutting (Eds.), Pragmatic assessment and intervention issues in language (pp. 195-214). San Diego, CA: College-Hill Press.

Muma, J. (1986). Language acquisition: A functionalistic perspective. Austin, TX: PRO-ED.

Muma, J, (1998). Effective speech-language pathology: A cognitive socialization approach. Mahwah, NJ: Erlbaum.

Muma, J. (2008). Scholarship in communication disorders: Raising the bar. Hattiesburg, MS: Natural Child. 
Muma, J., \& Cloud, S. (2008). Advancing communication disorders: 60 basic issues. Hattiesburg, MS: Natural Child.

Muma, J., \& Teller, H. (2003). Proactive deaf education: Cognitive socialization. In J. Muma and H. Teller (Eds.), Proactive Deaf Education: Cognitive socialization (pp. 1-9). Hillsboro, OR: Butte Publications.

Nelson, K. (1985). Making sense: The acquisition of shared meaning. New York, NY: Academic Press.

Nelson, K. (1996). Language in cognitive development. New York, NY: Cambridge University.

Ninio, A., Snow, C., Pan, B., \& Rollins, P. (1994). Classifying communicative acts in children's interactions. Journal of Communicative Disorders, 27, 157-187.

Osgood, C. (1957). Motivational dynamics of language behavior. Nebraska Symposium on Motivation. Lincoln, NB: University of Nebraska Press.

Prutting, C. (1983). Scientific inquiry and communicative disorders: An emerging paradigm across six decades. In T. Gallagher, \& C. Prutting (Eds.), Pragmatic assessment and intervention issues in language (pp. 247-267). San Diego, CA: College-Hill Press.

Searle, J. (1992). The rediscovery of the mind. Cambridge, MA: MIT Press.

Simser, J. (2001). Why does the parent have to participate in the auditoryverbal session? In W. Estabrooks (Ed.), 50 FAQ About AVT (pp. 82-85). Toronto, Ontario, Canada: Learning to Listen Foundation.

Sperber, D., \& Wilson, D. (1986). Relevance: Communication and cognition. Cambridge, MA: Harvard University Press.

Stinson, J.E., \& Milter, R.G. (1996). Problem-based learning in business education: Curriculum design and implementation issues. New directions for teaching and learning, 1996 Winter, Number 68, 33-42. Retrieved on May 1, 2010, from http://www.ouwb.ohiou.edu/Stinson/PBL.html.

Stone, P. (1988). Blueprint for developing conversational competence: A planning/ instruction model with detailed scenarios. Washington, DC: Alexander Graham Bell Association for the Deaf and Hard of Hearing.

Sugarman, S. (1984). The development of preverbal communication. In R. Schiefelbusch, \& J. Pickar (Eds.), The acquisition of communicative competence (pp. 23-67). Baltimore, MD: University Park Press.

Wimmer, H. \& Perner, J. (1983). Beliefs about beliefs: Representation and constraining function of wrong beliefs in young children's understanding of deception, Cognition, 13, 103-128.

Vygotsky, L.S. (1962). Thought and language. Cambridge, MA: MIT Press.

Vygotsky, L.S. (1978). Mind in society: The development of higher psychological process. Cambridge, MA: Harvard University Press. 
The Volta Review, Volume 110(2), Summer 2010, 191-206

\title{
From Pedagogy to Practice: Mentoring and Reciprocal Peer Coaching for Preservice Teachers
}

\author{
Blane Trautwein, Ed.D., and Sarah Ammerman, Ph.D.
}

To facilitate early acquisition of effective teaching strategies, many deaf education teacher preparation programs provide students with opportunities to apply course concepts by working with children in practicum or field experiences. Providing students with guidance and feedback regarding their teaching efforts is an integral component of these practica. Reciprocal peer coaching provides an effective means of sharing feedback when also paired with faculty mentoring of students. Program success is dependent upon the establishment of collegiality, teaching objectives/competencies, and critical evaluation of teaching methodology. This article describes a reciprocal peer coaching/mentoring program currently employed at the University of Texas Health Science Center at San Antonio listening and spoken language teacher preparation program.

\section{Introduction}

Teacher training programs are required to set and maintain benchmarks for teaching expertise. Although researchers, stakeholders, and practitioners agree that the most valuable measure of teaching prowess is actual teaching performance, many teacher preparation programs use grade point averages, Graduate Record Exam scores, placement exam scores, and other data not directly related to effective teaching skills when evaluating a candidate's teaching ability (Roberson, Wolsey, Seabrook, \& Williams, 2004). In addition, many teacher preparation programs wait to provide formal feedback on teaching skills until the preservice teacher is student teaching, a field experience

Blane Trautwein, Ed.D., is an Assistant Professor and Program Director of the Deaf Education and Hearing Science Program at the University of Texas Health Science Center at San Antonio. Sarah Ammerman, Ph.D., is an Assistant Professor in the Deaf Education and Hearing Science Program at the University of Texas Health Science Center at San Antonio. Correspondence concerning this article should be addressed to Dr. Trautwein at trautwein@uthscsa.edu. 
that takes place near the end of teacher preparation. These models tend to incorporate feedback on a limited basis and primarily in an evaluative manner, with professionals providing the only comments. Conversely, teacher preparation programs that employ reciprocal peer coaching and mentoring with traditional evaluation methods at the outset of the program and continue using those methods through graduation provide multiple opportunities for helping students become highly qualified teachers (Anderson \& Radencich, 2001).

In reciprocal peer coaching, students practice new teaching methodologies, master techniques, utilize shared problem-solving skills, and receive feedback from a peer evaluator. The reciprocal nature of this coaching lies in participants' willingness to regularly assume the role of both observer and the person being observed (Bowman \& McCormick, 2000; Zwart, Wubbels, Bergen, \& Bolhuis, 2007). In particular, students find it helpful when the peer has had teaching experience (Anderson \& Radencich, 2001).

Faculty mentors, who initially demonstrate teaching strategies to students while working with a child in a practicum setting, are critical to the success of student teams in reciprocal peer coaching. These early demonstration experiences help build trust and collegiality as the mentor evaluates his/her teaching performance and encourages the students to do likewise; students learn the importance of reflective practice as a mechanism for setting continued professional growth goals (Onchwari \& Keengwe, 2008).

Students in a deaf education teacher preparation program, with the advice of a peer coach (a fellow graduate student) and mentor (university faculty), link these goals to specific instructional competencies. This process empowers the student, as an adult learner, to become responsible for teaching outcomes. Additionally, it provides the peer coach a framework for evaluating specific competencies associated with his/her own learning.

Reflection is a vital but often overlooked component of the feedback process. The ability to view teaching practices through an analytical lens is a hallmark of a skilled educator. Guiding the graduate student to identify teaching strategies that do and do not promote optimal learning and how to make strategy modifications is imperative to developing reflection skills. Deliberately thinking about specific aspects of a lesson is one of the most effective ways to target areas of improvement. If reflection is not a formal (i.e., required through journaling) component of teacher preparation, it is unlikely to happen. If, however, a preservice teacher habitually reflects on every teaching experience, from early one-on-one field experiences to late field experiences where he or she is charged with educating a classroom of students, that teacher is more likely to engage in reflection as a lifelong practice.

\section{A Beginning: Developing Effective Teams}

How does a reciprocal peer coaching and mentoring program begin in a graduate teacher preparation program in listening and spoken language? At 
Table. Demographic variables of current master's students

\begin{tabular}{ccclc}
\hline Student & $\begin{array}{c}\text { Possesses teaching } \\
\text { certification }^{a}\end{array}$ & $\begin{array}{c}\text { Years of teaching } \\
\text { experience }\end{array}$ & Sex & Hearing status \\
\hline A & No & 0 & Female & Deaf \\
B & Yes & 0 & Female & Hearing \\
C & Yes & 0 & Female & Hearing \\
D & Yes & 25 & Female & Hearing \\
E & Yes & 28 & Female & Hearing \\
F & Yes & 0 & Female & Hearing \\
G & Yes & 0 & Male & Hearing \\
H & Yes & 2 & Female & Hearing \\
I & Yes & 0 & Female & Hearing \\
\hline
\end{tabular}

${ }^{a}$ Teaching certifications include elementary education, special education, English, and science.

the University of Texas Health Science Center at San Antonio, we focused the coaching and mentoring program on the development and mastery of effective language teaching practices with nine preservice teachers. Characteristics of the students are reflected in the Table.

Students are enrolled in an introductory language course during their initial semester of graduate school. The language course discusses typical language development, differences in language acquisition for children who are deaf or hard of hearing, and basic language teaching concepts. The core of the curriculum is based upon the notion that educators of children who are deaf must create a language classroom:

- A classroom in which common language targets of students have been identified.

- A classroom in which language targets are used consistently throughout learning activities; anyone observing in the classroom could easily tell what language is being targeted.

- A classroom in which individual language occurs during varied daily opportunities (speech, self-selected reading, centers, etc.).

To explore these concepts and begin joint discussion, students participate in 10 hours of direct classroom observation. Students complete an online observation form (Appendix A), which asks them to identify an instructor's classroom language targets, how the targets were presented to students, which instructor interactions facilitated language acquisition, and student-prompted and spontaneous responses. Faculty respond daily to comments posted on the observation forms by each student to create a continuous mentor-student dialogue about language instruction techniques.

These interactions facilitate self-awareness of effective language teaching methodologies, as described here by one student: 
When she asked them questions, and they said, "I don't know," she encouraged them to ask a peer. When they had difficulty generating the right question to ask, she modeled it for them and encouraged them to imitate it. The teacher made eye contact often. She smiled at them a lot, and laughed with them often. They always smiled back at her when she laughed or smiled. Her body language was very encouraging and accepting. She gave them "high fives" when they were successful, and by the way they responded, you could tell it is something she does often. She also gave frequent and enthusiastic verbal praise, i.e.: "good listener," "excellent," and "very nice"...A good strategy she uses to engage them is pre-teaching. She sent home a newsletter with pictures and conversation starters that the parents used the night before to begin discussion of the topic at home. I observed frequent encouragement and modeling of desired sentences.

Students also note when an instructor did not demonstrate effective language teaching strategies. For example:

What I really didn't understand today was why the teacher didn't use the kids' spontaneous expressions to model and expand. There were a lot of times that she didn't correct the mistakes that they made, and I felt frustrated because there were good language opportunities to use.

In addition to observing teaching strategies, students are asked to observe how children with hearing loss performed during each learning activity. They note how students are grouped for instruction and, most importantly, how engaged the students are, such as:

There were two classes working together. One class is self-contained hearing-impaired [sic], and they are emerging listeners and speakers...The other class is a mainstream class, and they are much further along on the CASLLS [language acquisition scales], according to the teacher. These groups all sat together and did all activities together, with the more advanced listeners modeling for the emerging listeners. Most of the children were very active and really happy. What was kind of sad for me was that one little girl didn't understand what they were doing. She just repeated what her peers did, and she followed her friends. She wasn't listening. I felt like she was lost, and I didn't like it.

Dialogue among students is strengthened through the use of small peer discussion groups. These groups, held at the beginning of each class, require each student to address the following questions:

1. How did you see language targets being taught and facilitated in the classroom? What techniques were successful? Why? What techniques were not successful? Why? 
2. What do you want to remember from your observations as a new deaf education practitioner?

Students consider each question and synthesize their responses to share with the larger group. Group composition varies for each class session to encourage broad interactions among students. These active-learning experiences set the stage for the mentoring and reciprocal peer-coaching model in the following manner:

- Mentoring: Interactions between faculty mentors and students via the online observation forms create ongoing discussion about best practices in language instruction. Ongoing discussion allows faculty to expand upon initial student analysis, modify inaccurate analysis, and encourage more detailed analysis.

- Reciprocal Peer Coaching: Weekly peer discussion groups facilitate open dialogue regarding best practices in language instruction. Each member of the discussion group is required to participate and share perceived strengths and weaknesses of the language instruction.

\section{Guiding Students into Practice}

During the second semester of study, students enroll in an advanced language development course. This course builds upon already learned concepts and student relationships created through observation and weekly dialogue. Curricula discuss typical advanced language development and language development assessment of children with hearing loss. Graduate students learn how to identify areas of need in a child's language form, content, and use, with emphasis on morphology, syntax, vocabulary, semantics, and conversation skills. In addition, connections to speech, audiology, and academics were ever-present.

To transition from theory into practice, graduate students begin working with a child with hearing loss the second week of the semester. Each student participates in approximately eleven 60-minute sessions of language therapy with a student with a hearing loss, another graduate student, and a supervising professor. Supervisors lead the initial four sessions, and graduate student pairs alternate leading the following four sessions using lesson plans and materials provided by supervisors. Responsibility for creating language activity plans and materials for the final three sessions rests with the students. The number of sessions for which each graduate student is responsible depends upon the student's emerging skills and comfort level.

\section{Discussion and Feedback}

Prior to language therapy sessions, the supervisor posts a theme-based lesson plan on the course website. Plans include listening, expressive language, 
and receptive language goals. In addition, scripts include 1) the language to be used by the supervisor and 2) the language expected from the child. Before each session, the supervisor and graduate students meet for 10 to 15 minutes without the child to discuss goals for the lesson and the techniques that should be used to elicit those goals. Then, the child joins the session for approximately 30 minutes. When the activities are completed and the child has exited the session, the supervisor and graduate students meet for another 10 to 15 minutes to discuss the following:

- Goals met

- Strategies used to meet these goals

- Why strategies were successful

- Goals not met successfully

- Strategies attempted

- Why strategies were not successful

- What to try differently next session

Analysis of the language therapy session continues with the graduate students and faculty supervisor utilizing a journaling feature of the course website (Appendix B). Each participant composes an original posting, which expands upon the topics broached in the postsession conference. In addition, each participant replies to the other members' original postings - one week's journal consists of at least nine entries. Journal entries facilitate the development of critical thinking skills related to applying theoretical concepts learned in class to practical situations. Supervisors assess and expand upon students' comprehension of concepts, including reasoning and motivation behind language elicitation techniques. The expectation is that face-to-face and online analysis will develop reflective practitioners with the ability to critically and accurately analyze their peers' teaching techniques.

The following exchange includes journal excerpts sent among members of one of the language therapy groups. This first excerpt is a supervisor's original posting written after the semester's second language therapy session:

Polly has an incredibly hard time with predicates. If she understands that she is to answer a question and not repeat it, she usually answers with a couple of words from the question but does not complete the sentence, or completes it in a way that doesn't make sense. (Ex: Teacher: "What are you doing?" Polly: "I am doing; I am turtle"). Often her syntax is not in English word order. However, that she uses words from the question in her answer is a good strategy and shows us that she is developing this skill.

She did very well with the riddles: both solving them and producing them. This shows us that she has better receptive than expressive language and that she can monologue. Dialogue, however, is a huge challenge. The fact that she breaks down almost completely when the task turns conversational 
is a big concern. We all have better receptive language than expressive; however, her gap is much bigger than most and we have to work hard to close it. We have to set up activities every session, such as role playing and acting out scenes from books and plays, that will help develop her conversation skills...

She did well comprehending and expressing location words. I should have required her to include indicators of future (e.g., gonna) before engaging in tasks, and I should have modeled more instances of inclusion words (too) and intensifiers (very, so). Although it's ok to focus on just a few goals in a session, with Polly we have to make sure that the majority of those goals, most of the time, are focused on improving her spontaneous language.

After reading the posting from the supervisor, a graduate student replied:

I think your 3 suggestions... are excellent. I hadn't thought of your observation, but I find it fascinating - she understands the expectation of action (following auditory prompt) but not the expectation of language (answering a question). I just didn't consider before beginning this program how far-reaching the effects of a hearing loss are in the development of language. This was good - I'm going to print it and study your analysis.

The same graduate student led a lesson for the first time a few weeks later and analyzed her performance in an original posting:

It's odd - in thinking about the lesson, it seemed like Polly talked so much, but when analyzing the targets - it doesn't seem as successful...Target Answer questions about self: I asked Polly, "How old are you?" and the first few times, she repeated me and said, "How old are you?" but when I repeated the question while pointing to her, she paused and thought about it, and after a few more tries, she said, "I am 5" and I was SO excited. Then I asked her what her teacher's name was. She answered correctly...When I asked her what she liked at school, she didn't seem sure about how to respond, so I prompted her with "Playing? Recess? Painting?" and she said, "Painting." I asked for her favorite color, and she replied, "Purple." Asking her what she did not like about school got no response.

Target - Answer "What do you do when...": This part was not successful at all. When I asked Polly, "What do you do when you are hungry?" she replied with a long string of jargon, which was so cute, but not very useful to Polly as far as communication. I guess it showed intention, but what intention? To try to talk, since she knew I wanted her to? Or to avoid talking, while seeming to talk, to see if I would let it go? I have to think about how to assist Polly in achieving this goal. It didn't feel as natural as the other targets, because I can't think of times when I have really talked with children 
about this. I can only recall doing it as part of a very structured lesson, as in "What do you do when you get lost?"

Target - "Uses location words; into, onto, around, on top of, above, below': The masks were the props to elicit this target. Also, I wanted to try Sarah's idea of "sabotage" by asking Jill and Sarah to position the masks incorrectly. The intent here was that Polly would say "Put the mask in front of your face." She said, "your eyes"... that could count as possessive, but that wasn't one of the targets.

There was some success with basic conversation, which we had been working on prior to this week...She self-corrected many times.

I did have goals for myself...wait time... and parallel talk. I think I did OK with both, but could do better, especially with parallel talk. Parallel talk is an interesting concept, useful to both student and teacher. I think it's useful to the student because it's a non-invasive way of validating what they're saying, and useful to the teacher to make the conversation more intelligible on the recording.

The university supervisor responded to the student's analysis:

Great lesson and great journal entry! You're right. That target (What do you do when...) can be tough. One way to work it in is to use the people or characters associated with the lesson (The cat is hungry. What should she do? The witch is lost/cold. What should she do?).

One way to elicit the NP+cop+equiv [Noun Phrase + copula + equivalent] is to ask her to discuss what characters everyone is. (I'm a cat/She's a witch/etc.). You did a great job with the sabotage. Even though she wasn't giving you the exact language you wanted to rearrange the mask, you did a good job of guiding her. This would be a good chance to perform different actions and have her put a noun phrase and a verb together (The (white) cat's running, etc.).

You did a nice job of facilitating Polly's conversation skills. At first she repeated the questions, but then she caught on! It came much more easily than it had in the past. When she didn't know the answer, she jargoned. This is typical of a much younger child, even a child...of Polly's language age. It's ok to tell her that we don't understand and that she has to use words.

You did a great job with your script. It can be helpful to have examples of language you expect from her written down as well so that you know if she has met the target, or if you need to press her for more.

The other graduate student, the third member of the group, also participated in the analysis of the language activity:

Dawn did a good job eliciting conversation with Polly. Polly really enjoyed the Halloween masks. At the beginning of the tutoring session, Dawn asked 
Polly questions that she could easily relate to and answer successfully. Most of her answers were parrot-like, short one- or two-word utterances...however, when Dawn asked her, "Do you like to paint?" and Polly said, "Yes, I like to paint." (good pronoun transition from you to I)...she uttered a long string of loud, nonsense sounds and jargon...whenever she had difficulty understanding the question and/or didn't know how to respond. When location words were presented to Polly to encourage her to describe to us how to wear the masks, she once again repeated what was said to her. At the end of the lesson, when we had all the characters talking and carrying on a conversation, i.e. "Hi, pumpkin, how are you?" "Hi, kitty, how are you?" Polly took part in the conversation and several times I heard her reply correctly. She is coming around, but it will continue to take patience and perseverance on our part.

The following excerpt was written by the same graduate student, several weeks later:

I thought you did a great job modeling your targets. That was a cute idea with the lion "cage." It allowed excellent use of adverbs of place. Polly was very engaged... Your execution was smooth as silk. I liked the way you used the little plastic animals and had Polly categorize them by stripes, horns... She seemed to understand the adverbs of manner, with and without very well, even though she didn't speak much. We need to remember that children are little people, and like us, they sometimes aren't in the mood to talk much, especially when they've just been through a full day of school. Naturally, because you and I feel a little uncomfortable with silence, we end up talking excessively... well, it can't hurt her to hear you model over and over again. I'm guilty of the same thing...when she finally says something, we're still talking, not meaning to mow her down. Wait time can be a challenge at times, but I thought overall you did excellently.

This graduate student demonstrated development in the ability to coach her peer. Subsequently, the faculty mentor modeled specificity with feedback and the creation of concrete suggestions for improving teaching techniques.

One criticism of reciprocal peer coaching in teacher preparation is that "inexperienced pre-service teachers might lack sufficient experience to discern quality in classroom practices" (Britton \& Anderson, 2010, pp. 313). Preservice teachers lack the perceptive skills needed to effectively evaluate and recommend modifications regarding their peers' teaching practices (Hasbrouck, 1997; Ling Li, 2004). However, regular monitoring and evaluation by supervising faculty mitigates the potential negative effects that inaccurate feedback from a novice can have (Britton \& Anderson, 2010).

Consequently, at the onset of this process, graduate students focus more journaling content on analysis of child's goals and objectives. As graduate 
students improve their abilities to evaluate teaching practices, the focus of journaling grows to include evaluation of teaching practices. Supervising faculty are integral participants of every language therapy session and online journal. Journaling provided an additional tool in which all team members assume the roles of both coach and coachee. Students have multiple opportunities to evaluate their supervisor's teaching techniques before they are evaluated. Those experiences enable students to become familiar and comfortable with analyzing language elicitation techniques prior to planning and leading language therapy sessions.

\section{Setting the Stage for Mastery}

To facilitate each student's self-knowledge regarding effective teaching language teaching strategies, particularly those associated with listening and spoken language, a competency list was developed (Appendix C). This list is discussed at the beginning of the second semester and referred to frequently in both language class and language therapy sessions. As students begin planning and leading sessions, these competencies are paramount in developing their personal teaching goals.

The last language therapy session focused on an initial evaluation of each student's teaching capabilities as related to specific competencies from Appendix C. This session, attended by both students and the supervisor, included a three-dimensional oral assessment consisting of a self, peer, and mentor evaluation. Each student was then asked to create a language instruction development plan utilizing listed competencies.

\section{Achieving Mastery: Developing Competencies}

As students approach the third semester of preparation, they continue the reciprocal peer coaching and mentoring process. Each student presents his or her development plan including a rank-ordering of all peer-coaching competencies. The graduate student, reciprocal peer coach, and mentor work together to select two goals for initial mastery. When the student is correctly using a goal $80 \%$ of the time, a new goal will be selected. The mentor will consider all aspects of the lesson while the reciprocal peer coach will collect data on the two selected objectives. The following steps illustrate the process:

1. Student, reciprocal peer coach, and mentor meet to discuss competency list and possible growth areas.

2. Student develops action plan with a rank-ordering of competencies best suited for personal mastery. These competencies are shared with the reciprocal peer coach and mentor.

3. Student selects two teaching competencies as primary goals. 
4. Reciprocal peer coach evaluates application of competencies throughout lesson. Mentor evaluates selected competencies and overall lesson (see Appendix C).

5. When mastery ( $80 \%$ appropriate usage) is achieved, student begins work with next rank-ordered competency.

Journaling will continue as a critical aspect of peer coaching and mentoring, with students assuming the primary responsibilities for online evaluations of peer-coaching goals. Student analysis will discuss methodologies used during the language therapy session and utilize shared problem solving to address perceived growth areas. Faculty members will assume the role of facilitator to ensure that selected competency goals are appropriately mastered.

\section{Just the Beginning}

When developing a new skill, applying pedagogy to practice should occur early. Successful skill attainment occurs when the learning process is divided into transparent, manageable pieces and when students know expected competencies and have opportunities to practice skills sequentially. Regular self, peer, and mentor evaluation provide students with multiple opportunities to critically analyze teaching methodologies and participate in shared problem solving, and are essential to the reciprocal peer coaching and mentoring process. One student's initial self-evaluation illustrates the ongoing process and an increased awareness of effective teaching practices:

My peer coaching goals were wait time... and modeling. I think modeling was the most successful - I certainly said "with" and "without" a lot - even though Polly didn't...I felt in a hurry. This also affected wait time. There were two times I talked right over Polly and if only I had waited a little longer, she might have said more. As it is, most of her utterances were one or two words. I wish I could go back and try again. I think I could do better.

This process should and will continue throughout preservice preparation, translating pedagogy into practice.

\section{References}

Anderson, N.A., \& Radencich, M.C. (2001). The value of feedback in an early field experience: Peer, teacher, and supervisor coaching. Action in Teacher Education, 23(3), 66-74.

Bowman, C.L., \& McCormick, S. (2000). Comparison of peer coaching versus traditional supervision effects. Journal of Educational Research, 93, 256-262. 
Britton, L.R., \& Anderson, K.A. (2010). Peer coaching and pre-service teachers: Examining an underutilized concept. Teaching and Teacher Education, 26(2), 306-314.

Hasbrouck, J. (1997). Mediated peer coaching for training preservice teachers. Journal of Special Education, 31, 251-271.

Ling Li, Y. (2004). A school-based project in five kindergartens: The case of teacher development and school development. International Journal of Early Years Education, 12, 143-155.

Onchwari, G., \& Keengwe, J. (2008). The impact of a mentor-coaching model on teacher professional development. Early Childhood Education Journal, 36(1), 19-24. (ERIC Document Reproduction Service No. EJ805589) Retrieved September 28, 2009, from ERIC database.

Roberson, R., Woolsey, M.L., Seabrooks, J., \& Williams, G. (2004). An ecobehavioral assessment of the teaching behaviors of teacher candidates during their special education internship experiences. Teacher Education and Special Education, 27(3), 264-275.

Zwart, R., Wubbels, T., Bergen, T., \& Bolhuis, S.T. (2007). Experienced teacher learning within the context of reciprocal peer coaching. Teachers and Teaching: Theory and Practice, 13(2), 165-187. (ERIC Document Reproduction Service No. EJ816292) Retrieved September 28, 2009, from ERIC database. 


\title{
Appendix A: UTHSCSA Master of Deaf Education and Hearing Science
}

\author{
QUESTION-BASED PRACTICUM ONLINE OBSERVATION FORM
}

Teacher/Classroom Observed Date:

Observed By:

Length of Observation:

Subject: $\quad$ Language

1. Activity Observed:

2. Language Targets:

3. Modeled Targets as Produced by Classroom Teacher:

Student Language Production

4. How did the teacher facilitate interactions with peers?

5. How were children engaged in the lesson?

6. Language Samples (Record student language production. Note if sample is prompted or spontaneous) 


\section{Appendix B: Online Journaling: Explanation, Requirements, and Rubric}

Every week, you, your Language Lab Supervisor (LLS) and your lab partner will journal together. Think about if you're reaching your goals with your student. If you're observing your partner or supervisor lead, think about the strategies that person used. Were the strategies successful? If not, did the person try something different? How is the person leading lab reaching the student's target(s)?

Every week, you will post one original posting as well as a minimum of two responses (one response to your partner and one response to your LLS). If you were primarily an observer during the lab session, then your original posting should focus on what the lead person (teacher) did (strategies the teacher used) to reach the student's target(s). If you were the teacher that session, your original posting should focus on (1) how you reached the student's target(s), (2) what worked well or did not work well, and (3) what you would do differently next time.

The purpose of the discussion board is to frame and promote collaborative learning. Active and regular participation is not only important for us to see, but also important for you in applying course content to real-world, clinical situations. The three cardinal rules for Discussion Boards: 1) Please remember that the culture of mutual respect that is part of this course extends into the virtual classroom environment; 2) Participation in these discussion boards is required; and 3) Participation alone is not enough - thoughtful and meaningful approach in your posts is required. (Quality counts!) 


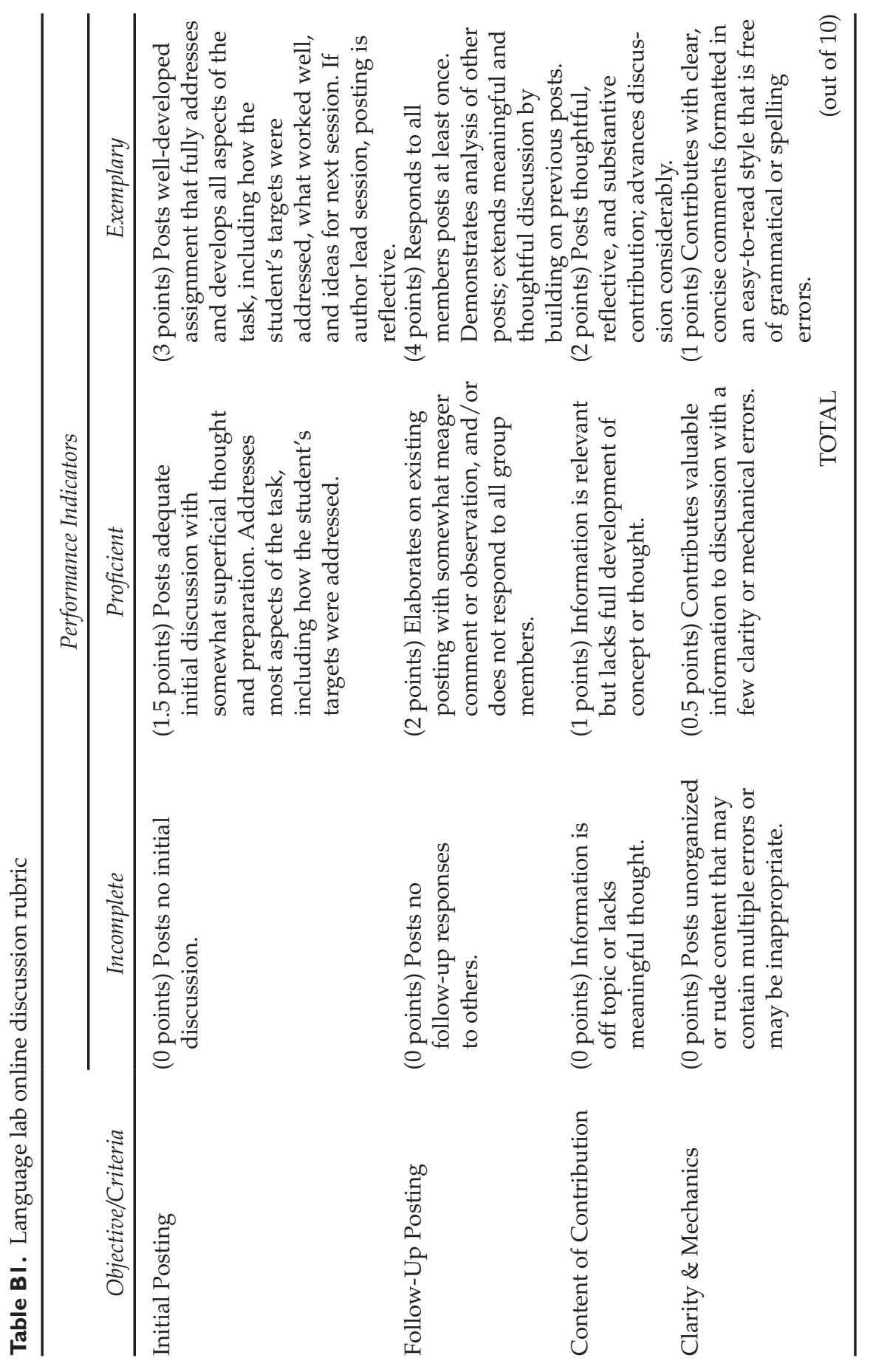




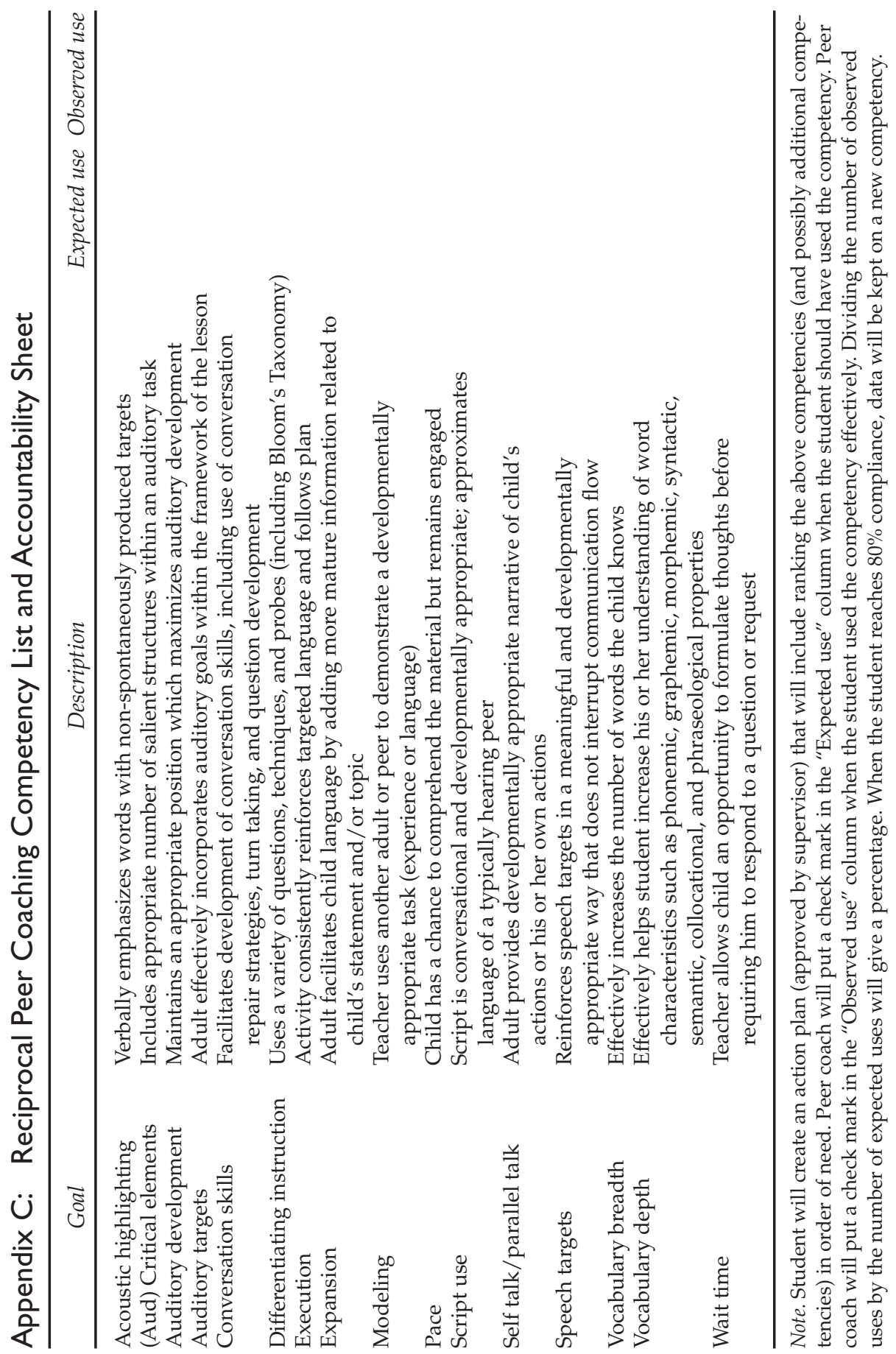


The Volta Review, Volume 110(2), Summer 2010, 207-218

\title{
Educational Preparation of Pediatric Audiologists
}

\author{
Jackson Roush, Ph.D.
}

Pediatric audiologists play a vital role in detection, diagnosis, and intervention for young children with hearing loss and their families. Preparing the next generation of pediatric audiologists necessitates a creative approach that balances the requirements of a broad curriculum with the special skills needed to serve a unique and varied population of children who are deaf or hard of hearing and their families. Fortunately, many university programs across the United States have developed specialty tracks, and a growing number are working in partnership with government and other agencies to improve and expand personnel preparation in pediatric audiology. They are joined in this effort by a cadre of talented students who are genuinely committed to working with this population. Still, many challenges remain, among them the sustained financial resources needed to support graduate training programs and students. There is also a need to substantially increase the diversity of our work force in pediatric audiology.

\section{Introduction}

The roots of clinical audiology can be traced to the early years of the 20th century when "psychoacoustics" emerged as a branch of experimental psychology aimed at the study of auditory perception. However, it was not until the 1940s when thousands of young servicemen and women returned from World War II with noise-induced hearing loss that audiology emerged as a professional discipline. The U.S. government moved quickly to establish hearing rehabilitation programs at the nation's military hospitals where hearing aid fitting and aural (re)habilitation procedures were standardized and implemented across the country. Audiology training programs followed, first at universities in the U.S. mid-west and eventually throughout the nation.

Specialization in pediatric audiology emerged in the 1970s with the refinement of behavioral procedures geared to the assessment of young children.

Jackson Roush, Ph.D., is Professor and Director of the Division of Speech and Hearing Sciences at the University of North Carolina, Chapel Hill, School of Medicine. Correspondence concerning this article may be directed to Dr. Roush at jroush@med.unc.edu. 
This was also a period marked by improvements in amplification and expansion of intervention programs that emphasized development of spoken language. However, until the 1970s few audiologists considered pediatrics a specialty area. In the preface to the first edition of their classic text, Hearing in Children, Northern and Downs (1974) note:

Until recent years there has been an aura of magic around the audiologic evaluation of very young children. Few people were willing to work with this population because of the myth that the very young child could not be tested subjectively - nor indeed, it was felt, could anything beneficial be done for the infant who was found to have a hearing loss. (p. v)

The developments noted by these authors provided the foundation for a branch of audiology geared to the unique needs of children with hearing loss. Still, the progress that has occurred since the 1970s would have been difficult to imagine at that time. An increase in newborn hearing screening programs has lowered the age of identification so dramatically that "infant audiology" has emerged as a subspecialty. Improvements in technology have been accompanied by legal requirements for a "free and appropriate public education," and over the past decade all 50 U.S. states have implemented statewide programs for early hearing detection and intervention (EHDI). Despite these remarkable achievements, however, one thing has not changed. Most parents, faced with the diagnosis of permanent hearing loss, react with shock and apprehension. The audiologists who serve this population must be skilled at the technical aspects of the profession but also capable of providing counseling and family support. Preparing audiologists to serve young children and their families is challenging for students and for training programs, but it is this combination of technical and interpersonal demands that makes pediatric audiology stimulating and rewarding.

Currently, there is high demand for pediatric audiology services and an impressive pool of students interested in working with children and families. It is important to emphasize, however, that program accreditation standards and requirements for certification and licensure require university training programs to offer a general curriculum that provides a broad range of knowledge and skills aimed at delivering service to patients across their lifespan. There is no specialty certification in pediatric audiology at this time; however, the American Board of Audiology (ABA), an organization affiliated with the American Academy of Audiology, is working to implement a specialty certification in pediatric audiology, modeled after a successful cochlear implant specialty certification program it introduced in 2005. Even with the emergence of specialty certification, however, graduate education in audiology will still require a broad-based educational experience since licensure in all 50 U.S. states permits audiologists to serve patients of all ages. 
The growing demand for pediatric audiology services is due to several factors including earlier identification of hearing loss through universal newborn hearing screening; awareness of the impact of all degrees of hearing loss, including those that are mild or unilateral; a growing emphasis on familycentered services provided in natural environments; growth in the number of children from families who are culturally and linguistically diverse; a growing emphasis on inclusion in local schools; and a substantial proportion of children with other disabilities in addition to hearing loss (Roush, Bess, Gravel, Harrison, Lenihan, \& Marvelli, 2004). This article provides a review of educational requirements for audiologists with an emphasis on preparation to serve the needs of young children with hearing loss and their families. Some of the challenges associated with providing specialization in pediatric audiology will be considered along with examples of how specialized educational opportunities have been infused within a general Doctor of Audiology (Au.D.) curriculum.

\section{Educational Preparation of Audiologists}

For nearly 40 years the entry level academic degree for clinical audiology was a master's degree. In 2007, changes in program accreditation standards required a doctoral degree for entry into clinical practice. Accreditation of Au.D. training programs is the responsibility of the Council on Academic Accreditation (CAA), an organization affiliated with the American SpeechLanguage-Hearing Association (ASHA). Programs also have the option of pursuing accreditation by the new Accreditation Council for Audiology Education (ACAE), an organization affiliated with AAA.

\section{Undergraduate Preparation}

Students interested in pursuing an Au.D. typically take undergraduate courses in English, mathematics, physics, chemistry, biology, social sciences, and psychology. They also complete courses in communication sciences including anatomy and physiology of the speech and hearing mechanism, speech science, phonetics, and language development. An introductory course in audiology is usually recommended at the undergraduate level and, in fact, it is through this course that audiology is "discovered" by many students who initially planned to pursue a career in speech-language pathology. Others gravitate to audiology from psychology, bioengineering, or other fields. In recent years, the author has observed a growing number of undergraduates who identify an interest in audiology early in their academic career. This may be due to efforts undertaken by various organizations to promote awareness of the audiology profession. In addition, cochlear implants, digital hearing aids, and newborn hearing screening have brought greater public awareness of the audiology profession. 
Many undergraduates complete a baccalaureate degree in communication sciences and disorders; however, most doctoral programs do not require their applicants to have a specific degree or major. In fact, many Au.D. cohorts are enriched by their non-traditional students. Unfortunately, some groups remain significantly under-represented in the audiology profession and this is true for speech-language pathology as well. Racial minorities in the U.S. comprise nearly $25 \%$ of the nation's population while fewer than $7 \%$ of audiologists and speech-language pathologists are from a racial minority (ASHA, 2009). People with hearing loss are another group that remains significantly under-represented in the audiology profession.

\section{Graduate Education}

Au.D. programs first appeared in the 1990s, although it was not until 2007 that program accreditation standards were revised to require doctoral-level training for entry to the profession. Audiologists who were already practicing were not required to earn the doctorate; it is estimated that in recent years, over 5,000 audiologists have earned the Au.D. through distance education programs at the University of Florida, Central Michigan University (in partnership with Vanderbilt University), Salus University, Nova Southeastern, and A.T. Still University. There are now 70 bachelor-entry, Au.D. degree programs in 35 states with a total enrollment of approximately 2,400 residential students (Audiology Foundation of America, 2010). The typical Au.D. curriculum includes 3 years of course work followed by a full time fourth-year externship. Graduate coursework in audiology includes anatomy; physiology; hearing science; genetics; normal and abnormal communication development; auditory, balance, and neural systems assessment and treatment; diagnostic procedures; hearing aid selection and fitting; cochlear implant assessment and mapping; business management; and professional ethics. In addition to coursework, students participate in extensive laboratory and clinical experiences.

\section{State Licensure}

All 50 U.S. states regulate licensure of audiologists, although requirements vary among states. Every state requires a minimum of a master's degree to be licensed as an audiologist; however, a doctoral degree is now required for new applicants in some states because of changes in accreditation requirement for graduate training programs noted earlier. In 2009, 18 states required a doctoral degree or its equivalent for new applicants to practice audiology, and the number is expected to grow as state licensing bodies adjust their licensing laws to reflect changes in graduate entry-level requirements. In some states audiologists must hold two licenses, one for the practice of audiology and one for the dispensing of hearing aids. In most states audiologists must acquire continuing education credits for renewal of their licenses. 


\section{Professional Certification}

In addition to licensure, which is required for clinical practice, most audiologists choose to obtain professional certification; for some it is required by their employer. The Certificate of Clinical Competence in Audiology (CCC-A) is administered by ASHA. When clinicians apply for ASHA certification they must provide evidence of a doctoral-level program of study that includes a minimum of 75 graduate-level semester credit hours of academic course work and a minimum of 12 months, full-time equivalent of supervised clinical practicum that reflects the acquisition of knowledge and skill across several domains, including foundations, prevention, management, and treatment. For students seeking CCC-A, clinical supervision must be provided by an audiologist who holds ASHA certification. Audiologists may also elect to hold certification administered by ABA, which is affiliated with AAA. Applicants for ABA certification must earn a doctoral degree in audiology from a regionally accredited college or university and complete a minimum of 2,000 hours of professional practice in a 2-year period under the mentorship of an experienced audiologist. Both credentials, CCC-A and ABA, require a passing score on a national examination and both have continuing education requirements for certification renewal.

\section{Pediatric Audiology Specialization at the Preservice Level}

Audiologists play a vital role in achieving the goals set forth by EHDI programs across the country. According to the Joint Committee on Infant Hearing, "Year 2007 Position Statement: Principles and Guidelines for Early Hearing Detection and Intervention Programs" (JCIH, 2007), the role of the audiologist includes management of newborn hearing-screening programs; quality assessment; service coordination; and audiological diagnosis and treatment, including the timely fitting and monitoring of amplification and other sensory devices. The knowledge and skills required for competence in these areas alone could occupy a demanding graduate curriculum; however, these are but a few of the topic areas included in the audiology curriculum. From the foregoing discussion it is apparent that audiology students are responsible for a large body of knowledge that encompasses a broad range of topic areas. For this reason the coursework and practicum required for specialized areas of practice, such as pediatric audiology, is minimally prescribed by existing accreditation standards. For example, audiology programs accredited by CAA must offer a curriculum that includes "principles and methods of prevention, assessment, and intervention across the life span" (ASHA-CAA, 2010). The clinical education component of the curriculum must provide students with "access to a client/patient base that is sufficient to achieve the program's stated mission 
and goals and includes a variety of clinical settings, client/patient populations, and age groups" (ASHA-CAA, 2010). CAA accreditation standards further stipulate that "the program must describe how it ensures that each student is exposed to a variety of populations across the life span and from culturally and linguistically diverse backgrounds" (ASHA-CAA, 2010). Similarly, ACAE accreditation requires Au.D. programs to provide a curriculum that includes basic and clinical sciences, with special emphasis on the auditory and vestibular/balance systems and their interrelationships to human growth and development over the life span (ACAE, 2010). ACAE accreditation also requires a program of study that enables students to develop the skills required to "diagnosis, triage, treat and manage auditory and vestibular/balance conditions and diseases for patients over the lifespan" (ACAE, 2010, p. 7). Clinical education, in ACAE accredited programs, must provide "varied clinical environments and populations that reflect the scope of audiologic practice" (ACAE, 2010, p. 8).

The flexibility that exists under current accreditation standards has allowed programs to pursue specialization in a variety of ways. At some institutions, opportunities to develop a pediatric audiology focus emerge because of faculty interest or expertise. In others, opportunities for specialization emerge because of clinical resources in proximity to the Au.D. program. There is now diversity among Au.D. programs across the United States and opportunities for students to acquire specialization in various ways. Still, as noted earlier, training programs are required to deliver a broad-based general curriculum. For this reason specialization is often achieved through clinical practicum, independent studies, or special projects. Universities can also compete for federally funded personnel preparation grants.

\section{The U.S. Department of Education, Office of Special Education Programs}

For many years, the U.S. Department of Education (DOE), through its Office of Special Education Programs (OSEP) has funded training program grants aimed at improving the quality and availability of personnel who serve young children with special needs. OSEP is a branch within the Office of Special Education and Rehabilitations Services (OSERS) dedicated to improving outcomes for children and youth with disabilities by providing leadership and financial support. The Individuals with Disabilities Education Act (IDEA) authorizes the DOE to award grants to states, institutions of higher education, and non-profit organizations to support a variety of activities, including personnel development. Within the competition for personnel preparation grants, audiology is considered a "related service" and as such must compete with several other professional disciplines including physical therapy, occupational therapy, social work, and speech-language pathology. Even so, 
Table I. Examples of current and recent personnel preparation grants funded by the U.S. Department of Education, Office of Special Education Programs

Gallaudet University, Preparation of Clinical Audiologists with a Pediatric-Educational Audiology Program Emphasis to Serve Culturally and Linguistically Diverse 0-21 Populations

San Diego State University, Preparing Low Incidence Disability Specialists

University of North Carolina, Chapel Hill, Preparation of Pediatric Audiologists to Serve Infants, Toddlers, and School-Age Children with Hearing Loss

University of Pittsburgh, Preparation of Audiologists to Serve Children with Auditory Disorders

Utah State University, Graduate Specialization in Auditory Learning E Spoken Language for Graduate Students in Speech-Language Pathology and Audiology

Vanderbilt University, Preparation of Audiologists to Serve Infants and Toddlers with Hearing Loss

audiology programs have competed successfully for these grants over the years and several universities have OSEP funding for specialized training opportunities related to hearing loss in children (Table 1). From the titles of the personnel preparation grants in Table 1 it is apparent that programs have taken a variety of approaches in their efforts to provide specialization at the preservice level. Students funded on OSEP-sponsored grants must agree to a service requirement that includes 2 years of employment relevant to the needs of IDEA-eligible children for each year of funding. Students can fulfill their obligations through clinical service or by employment that involves research or teaching with this population.

\section{Health Resources and Services Administration and The Maternal and Child Health Bureau}

Leadership Education in Neurodevelopmental and Related Disabilities (LEND) programs provide graduate-level education concurrently with interdisciplinary clinical training. LENDs originated in the 1950s through the Children's Bureau (now the Maternal and Child Health Bureau [MCHB]) of the Health Resources and Services Administration (HRSA) with a goal of promoting the needs of children with disabilities (Association of University Centers on Disabilities [AUCD], 2009). LEND's current mission is to improve the health of infants, children, and adolescents with disabilities through graduate education across a diverse range of professional disciplines, and to provide the training needed to prepare students for leadership roles in their respective disciplines (AUCD, 2009). Most of the LEND programs operate within a university system as part of a "University Center for Excellence in Developmental Disabilities" (UCEDD) working in collaboration with university medical centers. This organizational structure 
enables LEND programs to draw on faculty expertise from a broad range of interdisciplinary resources. Currently there are 39 LENDs in 32 states and the District of Columbia. Together they form a national network of shared information and resources. Through coordination and technical assistance provided by AUCD, LEND programs work collaboratively through a cooperative agreement with MCHB to address issues of importance to children with special health care needs and their families and to facilitate sharing ideas and products. In 2008, AUCD received a contract from HRSA/MCHB to expand pediatric audiology training opportunities through the LEND network. Applications were submitted by LEND programs across the country. Six expansion grants were awarded in 2009 and an additional three were added later that year, bringing the total to nine (Table 2).

In addition, three universities are currently funded by HRSA/MCHB to provide leadership education in pediatric communication disorders (Utah State University, Vanderbilt University, and the University of North Carolina at Chapel Hill). In 2009, representatives from these three institutions proposed that HRSA/MCHB and LEND-supported audiology students and faculty meet at the National EHDI Conference, which is held annually through a partnership of HRSA/MCHB, the American Academy of Pediatrics (AAP), the Centers for Disease Control and Prevention (CDC), and the National Center for Hearing Assessment and Management (NCHAM). The conference was attended by approximately 30 MCHB and LEND-supported students in 2009 and judged by everyone who participated to be a great success. In 2010, student attendance exceeded 60. The National EHDI Conference is an ideal meeting for this group because it brings pediatric audiology students and faculty together with a variety of EHDI stakeholder organizations, agencies, and professional disciplines. The meeting also provides a valuable networking opportunity for future pediatric audiologists.

Table 2. LEND programs receiving supplemental funding made possible through a contract to AUCD from HRSA/MCHB (AUCD, 2009).

- Carolina Institute for Developmental Disabilities, University of North Carolina, Chapel Hill, NC

- Children's National Medical Center, Washington, DC

- UCLID Center, University of Pittsburgh, Pittsburgh, PA

- University of Colorado - Denver, Aurora, CO

- University of Miami Mailman Center for Child Development, Miami, FL

- University of South Dakota Center for Disabilities, Sioux Falls, SD

- University of Washington Center on Human Development and Disability, Seattle, WA

- University of Utah Regional LEND, Salt Lake City, UT

- Vanderbilt Kennedy Center, Nashville, TN 


\section{Future Challenges}

Is there a shortage of pediatric audiologists? The answer to this question is not as simple as it sounds. A systematic workforce analysis has not been conducted for pediatric audiology; however, anecdotal reports and surveys of state EHDI managers consistently point to a need for more and better pediatric audiology services, especially those geared to the needs of infants referred from newborn screening. Unlike nursing, which currently has a large number of unfilled positions, there does not appear to be an overabundance of vacancies for entry-level practitioners who desire specialization in pediatric audiology. Thus, in addition to the need for a steady supply of well qualified entry-level pediatric audiologists, there is also a need for continuing education geared to the needs of practicing professionals. Indeed, "infant audiology" is new even to some experienced pediatric audiologists.

It is important to emphasize, however, that specialized pediatric audiology services require more than skilled personnel and equipment. Appropriate management of infants and young children is time consuming and expensive. In addition to specialized instrumentation and clinical expertise, institutional support is needed to manage the financial burden associated with providing comprehensive care when reimbursement is often insufficient to cover all the costs associated with the program. In most states only a few centers have the expertise and institutional support needed to provide a high level of specialized care for infants. Consequently, some families must travel considerable distance to obtain services and, inevitably, some are unable to access services because of logistical challenges or expenses associated with transportation and follow-up. The difficulties may be especially acute for low-income rural families and those whose first language is not English (Roush, Wilson, \& Alberg, 2008; Alberg, Wilson, \& Roush, 2007).

There are also financial pressures for many families. Although several states now require insurance carriers to include hearing aids for children, most do not. For children under 3 years of age, some states provide funding for hearing aids, repairs, FM systems, and ear molds; however, when the child turns 3 , purchase of hearing technology is a burden for many families. Considering the high cost of hearing instruments, even families with substantial incomes are challenged by the cost of replacing hearing aids or FM systems. The situation is more favorable for children served under the Medicaid program; however, many families have neither Medicaid nor private insurance. Some states reserve special funds for those families but when budgets are reduced, as they have been recently in many states, funding for hearing technology may be in jeopardy. When funding is at risk, parent-professional partnerships must be mobilized to lobby state legislators. This was the case in North Carolina in 2009 when parents and professionals organized a successful effort to convince key members of the state's legislative appropriations committees to retain hearing aid funding. For audiology students, the situation provided 
a valuable learning experience on the importance of advocacy and political activism.

In addition to challenges that exist at a systems level, there are specific areas of audiology management that remain challenging for the clinician and, by extension, for the faculty who provide educational preparation of future clinicians. Challenges include when to provide cochlear implants, especially if hearing aid use is providing some benefit. Other areas where clinical management is controversial or uncertain include management of infants with unilateral hearing loss and those diagnosed with an impairment of neural conduction (e.g. auditory neuropathy spectrum disorder). Clinical research in these areas is underway but detailed, evidenced-based protocols for clinical management are still under development. Students pursuing specialization in pediatric audiology need clinical mentors who can help them appreciate where evidenced-based clinical practice is clear-cut and when clinical management must occur in the absence of explicit guidelines.

Challenges to clinical management are also presented by the variety of conditions that co-exist with hearing loss. It is well documented that a substantial number of children who are deaf or hard of hearing also present with one or more disabilities. The Gallaudet Research Institute (2005) reports that over $40 \%$ of children who are deaf or hard of hearing have additional challenges ranging from severe cognitive impairments to mild learning differences that are not apparent until school age. Children seen in the audiology clinic present with a variety of syndromes, developmental disabilities, and medical conditions; it is essential that students pursuing specialization in pediatrics have access to these special populations and the guidance of experienced clinicians who can mentor them. Indeed, audiological management of children with multiple disabilities is often challenging, even for experienced clinicians.

Finally, it is important to emphasize that specialization in pediatric audiology requires more than mastery of clinical procedures; it requires exposure to models of care that encompass the full continuum of services needed for comprehensive management. Students preparing to specialize in pediatric audiology must recognize that families require access to a variety of services and professional disciplines including otolaryngology, genetics, and ophthalmology, especially during the first year. Children with health concerns or disabilities in addition to hearing loss need even more services and greater coordination of care.

Specialization in pediatric audiology within the general Au.D. curriculum requires faculty expertise, access to varied pediatric populations, and a range of activities that expose students to the full continuum of care needed to provide comprehensive services to young children with hearing loss and their families. Table 3 provides a summary of activities currently employed at the University of North Carolina at Chapel Hill for students pursuing a focus in pediatric audiology. 
Table 3. Pediatric activities employed at UNC-Chapel Hill to support pediatric audiology specialization within the general Au.D. curriculum

- Participation in multi-disciplinary team evaluations and staffing

- Semester-long rotations in well-baby and special care nurseries

- Behavioral assessment of infants and young children, including "lab clinics" with children developing typically

- Diagnostic ABRs in natural sleep, conscious sedation, and general anesthesia (operating room)

- Infant hearing aid fitting and evaluation; hearing aid orientation for parents/ family members

- Multidisciplinary seminars using a problem-based learning format

- Participation in medical resident lectures in cooperation with the Department of Pediatrics and the Department of Otolaryngology

- Leadership workshops with students from Public Health, Social Work, and LEND

- Observation of pediatric ENT examinations and surgical procedures

- Participation in cochlear implant team meetings, candidacy evaluations, and post-surgical management

- Poster presentations of evidenced-based literature reviews in pediatric topic areas

- Participation in Individualized Family Service Plan ( IFSP) and Individualized Education Program ( IEP) meetings

- Home visits with early intervention providers

- Participation in the planning, delivery, and evaluation of UNC's Biennial Pediatric Audiology Symposium

- Attendance at state EHDI advisory board meetings

- Individual and group projects done in cooperation with the state EHDI program

- Participation in legislative initiatives and advocacy efforts

- Independent studies and research projects with faculty and clinical preceptors

- Networking with students from other universities at the National EHDI Conference

- Fourth year externships at UNC Hospitals (Pediatric Audiology) and UNC's Carolina Children's Communicative Disorders Program (Pediatric Cochlear Implants), available to students from UNC-Chapel Hill and from other universities

\section{Conclusion}

Since the observations of Northern and Downs in the 1970s, the nationwide implementation of hospital-based, newborn hearing screening programs combined with the technology needed to provide early diagnosis and intervention have created a pivotal need for pediatric audiologists. Pediatric specialists play a vital role in detection, diagnosis, and intervention for young children with hearing loss and their families and it is essential that universities have the resources they need for comprehensive graduate education. The advocacy and commitment that enabled the successful nationwide implementation of newborn hearing screening is now needed on behalf of personnel preparation in pediatric audiology. 


\section{References}

Accreditation Council for Audiology Education. (2010). Accreditation standards for the doctor of audiology (Au.D.) program. Retrieved May 6, 2010, from http://www.acaeaccred.org/ACAE\%20STANDARDS\%20FINAL*.pdf.

American Speech-Language-Hearing Association-Council on Academic Accreditation. (2010). CAA accreditation manual. Retrieved May 6, 2010, from http://www.asha.org/academic/accreditation/accredmanual.

Association of University Centers on Disabilities. (2009). AUCD is. . Retrieved December 10, 2009, from http:/ / www.aucd.org.

Alberg, J., Wilson, K., \& Roush, J. (2007). Statewide collaboration in providing EHDI services. The Volta Review, 106(3), 259-274.

Gallaudet Research Institute. (2005). Regional and national summary report of data from the 2004-2005 annual survey of deaf and hard of hearing children and youth. Washington, DC: GRI, Gallaudet University.

HRSA: Maternal and Child Health Bureau. (2010). MCH training programs. Retrieved May 6, 2010, from http://mchb.hrsa.gov/training/projects. asp?program $=9$.

Joint Committee on Infant Hearing (JCIH). Year 2007 position statement: Principles and guidelines for early hearing detection and intervention programs. Pediatrics, 120(4), 898-921.

Northern, J.L., \& Downs, M.P. (1974). Hearing in children. Baltimore, MD: Williams and Wilkins.

Roush, J., Bess, F., Gravel, J., Harrison, M., Lenihan, S., \& Marvelli, A. (2004). Preparation of personnel to serve children with hearing loss and their families: Current status and future needs. Proceedings of the Summit on Deafness: Spoken Language in the $21^{\text {st }}$ Century, Predicting Future Trends in Deafness, p. 26-29, 2004, Washington, DC.

Roush, J., Wilson, K., \& Alberg, J. (2008, February 12). Early hearing detection and intervention: Audiologists and SLPs collaborate in successful program. The ASHA Leader. 
The Volta Review, Volume 110(2), Summer 2010, 219-230

\title{
Speech-Language Pathologists: Vital Listening and Spoken Language Professionals
}

\author{
K. Todd Houston, Ph.D., CCC-SLP, LSLS Cert. AVT; and \\ Christina B. Perigoe, Ph.D., CCC-SLP, CED, LSLS Cert. AVT
}

Determining the most effective methods and techniques to facilitate the spoken language development of individuals with hearing loss has been a focus of practitioners for centuries. Due to modern advances in hearing technology, earlier identification of hearing loss, and immediate enrollment in early intervention, children with hearing loss are experiencing greater success in their acquisition of spoken language, especially when they have access to well-trained professionals. Speech-language pathologists who have the necessary knowledge, experience, and skills can play a vital role in the communicative and educational development of young children with hearing loss. Fortunately, some university training programs are providing a needed focus on auditory learning and spoken language for preservice students in speech-language pathology. However, to meet an increasing need for these services, speech-language pathologists currently in the field should commit to ongoing professional development to ensure that all children with hearing loss have access to highly-qualified professionals who can foster listening and spoken language development.

\section{A Brief History of Speech Correction of Individuals with Hearing Loss}

Since the early days of Ponce de Leon of Spain in the 16th century, attempts to teach speech and spoken language to the deaf have met with a various levels of success (Moores, 2001). Unfortunately, Ponce de Leon failed to leave

K. Todd Houston, Ph.D., CCC-SLP, LSLS Cert. AVT, is an Assistant Professor of SpeechLanguage Pathology and Director of the Graduate Studies Program in Auditory Learning \& Spoken Language in the Department of Communicative Disorders and Deaf Education at Utah State University. Christina B. Perigoe, Ph.D., CCC-SCP, CED, LSLS Cert. AVT, is Coordinator of the Early Oral Intervention Graduate Program in Speech and Hearing Sciences at The University of Southern Mississippi. Correspondence concerning this article should be directed to Dr. Houston at todd.houston@usu.edu. 
behind descriptions of his techniques and did not train any successors to carry on his work. It was not until the early 1600s that Juan Bonet published the first book on the teaching of speech to persons who were deaf and "mute" (Moores, 2001). In the 1700s, the methods developed for teaching speech to the deaf by John Wallis, Henry Baker, and Thomas Braidwood in Great Britain and by Samuel Heinicke in Germany appear to have been shrouded in secrecy, which led to the adoption of manual methods in America (see Marvelli in this issue).

By some accounts, references to speech teaching or speech correction in America date back to the days of the early American theologian Cotton Mather in the late 1600s (Duchan, 2002). While little information is known, it is apparent that early teachers of speech for the deaf were usually teachers or physicians as well as the occasional charlatan who made outlandish claims about curing all who would partake of his services.

By the late 1800s, a more formal profession was emerging, and individuals were establishing themselves as elocutionists. Two famous elocutionists of the day were a father and son team, Alexander Melville Bell and Alexander Graham Bell. Both were deeply interested in "understanding, analyzing, and transmitting speech" (Duchan, 2002, p.1), which led Melville Bell to develop Visible Speech in 1872. This method used various combinations of ten basic symbols that detailed how the lips, tongue, and oral cavity could be shaped to more accurately produce the sounds of any language. Philologists, the linguists of the day, praised the language teaching possibilities of the Visible Speech system and sought to use the methods to support a universal language (MacKenzie, 1928). Thus, Melville Bell and his son, Alexander, are credited with elevating the teaching of speech to that of a science (Davis \& Silverman, 1978).

Because of his father's interest in speech correction and his mother, Eliza's, own hearing loss, Alexander Graham Bell was keenly interested in the teaching of speech, especially to children with hearing loss. While he is known as the "father of the telephone" (Grosvenor \& Wesson, 1997), Bell's primary interest at the time was to develop a better speech training device or hearing aid for the many children with hearing loss he was teaching. He believed that if speech could be transmitted across a wire, he could make it louder, and the children he was teaching could hear it better. Bell also believed that by tapping into the auditory centers of the brain, children with hearing loss could more easily - and more naturally - acquire spoken language (Kricos \& McCarthy, 2007).

Bell's interests in audition and speech led him to establish the American Association for the Promotion of the Teaching of Speech to the Deaf (AAPTSD) in 1890, the first national organization to focus its efforts on improving the knowledge and skills of practitioners who were teaching and providing direct services to children with hearing loss; it would later be known as Alexander Graham Bell Association for the Deaf and Hard of Hearing (AG Bell). The 
AAPTSD preceded the establishment of the American Academy of Speech Correction (AASC), a group organized by physicians, scholars, and public school administrators in 1925; it is a forerunner to the American SpeechLanguage-Hearing Association (ASHA) (Duchan, 2002).

Toward the end of the 1800s, Visible Speech was replaced by the Northampton Charts (Worcester, 1885, 1915; Yale, 1929). This visual system, which is closely aligned with English spellings, has been revised (Clarke School for the Deaf, 1971) and continues to be used in some programs to this day (Sullivan \& Perigoe, 2004).

By the early 1900s, others such as Dr. Max Goldstein, founder of the Central Institute of the Deaf (CID) in St. Louis, enthusiastically promoted auditory training for children, regardless of the degree of residual hearing (Kriscos \& McCarthy, 2007). Building on the earlier work of Austrian physician Professor Victor Urbantschitsch, Goldstein utilized speaking tubes to enhance a teacher's or clinician's voice. By the end of World War II, large numbers of veterans were returning home with hearing loss. As the profession of audiology took root, interest grew in applying newly-developed electronic hearing aids for the education and habilitation of young children with hearing loss. This link between listening and speaking was to recur in teaching speech to children with hearing loss.

Embracing the techniques of Urbantschitsch and Goldstein, Pollack et al. (1997) describe the emergence of an auditory "unisensory" approach during this period like "a ball bouncing from group to group" (p. viii). Various practitioners - Helen Beebe, Dr. Ciwa Griffiths, and Marion Downs, among others developed model programs throughout the country and were instrumental in teaching spoken language to children with even the most profound hearing losses. These model programs, many of which were established in the late 1940s and early 1950s, continue to flourish today.

The literature and related texts detailing the use of audition and speech correction techniques for children and adults with hearing loss have evolved over the past century. For example, in 1928, G. Sibley Haycock won the Braidwood Medal in the United Kingdom for his essay on "How best to promote the quality of naturalness in the speech of the deaf," which was published in 1933 as the foundational text The Teaching of Speech (Haycock, 1933). Interestingly, while Haycock was publishing his "how to" on teaching speech, C.V. Hudgins was beginning to research the speech of individuals who were deaf, and the landmark Hudgins and Numbers study (1942) continues to be cited to this day. Hudgins and Numbers investigated and reported on the characteristics of "deaf speech" and this focus on describing errors rather than investigating teaching strategies has dominated the field.

Haycock's book set the standard until the 1970s when several books on the subject were published in quick succession: Connor (1971), Vorce (1974), Calvert \& Silverman (1975), Ling (1976), and Boothroyd (1982). It fell to two audiologists from England, Arthur Boothroyd and Daniel Ling, who migrated to the United States and Canada, respectively, to refocus speech teaching on 
the important link between speech perception and speech production. In addition to the many texts, papers, and presentations, these two pioneers substantiated their methods with research. Like Pollack, Beebe, and Griffiths (see Marvelli, 2010, and Goldberg, 2010, in this issue), Boothroyd and Ling also promoted early intervention and auditory methods which integrated listening, speech, and language development (Perigoe \& Ling, 1986). Ling's landmark book, Speech and the Hearing Impaired Child: Theory and Practice (1976), has served as a primary text for graduate students in speech-language pathology, audiology, and deaf education. Ling's subsequent work, Foundations of Spoken Language for Hearing Impaired Children (1989) and a second edition (2002) of Speech and the Hearing Impaired Child, remain seminal works in the field.

Thus, since the 1600s, substantial efforts have been made to define the professional knowledge and skills that promote the acquisition of spoken language by young children with hearing loss. While only a few of the historical highlights are mentioned here, the fact remains that the needs of children with hearing loss who are acquiring spoken language has emerged as the life work of practitioners across multiple disciplines, including educators, physicians, audiologists, and speech-language pathologists (SLPs). Carney and Moeller (1998) stated,

Speech-language pathologists. . have well-defined scopes of practice that include the treatment of hearing loss. With their educational background, they have the ability to be vital team members in the service delivery to children who are deaf and hard of hearing. Their roles in early identification and management of language and speech are likely to be critical to successful outcomes for these children and their families. (p.S81)

\section{Shortages of Qualified Speech-Language Pathologists}

While Carney and Moeller (1998) described the potential benefits of SLPs in the intervention and education of children with hearing loss, the shortage of experienced SLPs who can facilitate language development with this populations is well documented (JCIH, 2007; Moseley, Mahshie, Brandt, \& Fleming, 1994; Rowan, Sommers, \& Wray, 2005; Watson \& Martin, 1999; Cosby, 2009). In addressing such professional shortages, it is vital that early intervention providers, especially SLPs, have specialized training in order to serve very young children with hearing losses that range from mild to profound (Arehart \& Yoshinaga-Itano, 1999). To be effective, SLPs must be knowledgeable about recent technological breakthroughs in advanced hearing technology (e.g., digital hearing aids, cochlear implants, FM systems) and the potential impact such technology has on helping infants and toddlers develop age-appropriate spoken language communication. For example, newborns identified with hearing loss can be fitted with powerful hearing aids and can receive early intervention services to facilitate listening and spoken language (Cole \& Flexer, 2007). 
SLPs should possess the necessary knowledge and skills to conduct familycentered intervention that will enable the child's parents or caregiver(s) to facilitate language development in their child (ASHA, 2008), including knowledge of cochlear implants for intervention and habilitation (Cosby, 2009). Personnel preparation programs must stay abreast of these changes in the field if their graduates are to possess the necessary knowledge and skills to meet the growing demand for these specialized services.

Reports of large numbers of speech-language pathology vacancies emanating from various state departments of health and state education agencies (SEAs) have become routine. The Study of Personnel Needs in Special Education (2002) reported that school administrators consider the greatest barrier to hiring qualified SLPs is the "shortage of qualified applicants" (p.1). In this same report, a national survey of school administrators rated the vacancy rate at $59 \%$, meaning that for every 100 jobs there were only 41 qualified applicants to fill the positions. According to the U.S. Bureau of Labor Statistics (2009), SLPs rank among the top 20 occupations that will experience the greatest demand. An additional 22,000 SLPs, with a wide variety of specialty areas, are projected to be needed in the labor force for the years 2008-2018 (U.S. Bureau of Labor Statistics, 2009). Wilson (2006) states, "Perhaps the greatest challenge to public school systems is the lack of appropriately trained educators and speechlanguage pathologists to meet the needs of the new generation of infants and toddlers who are deaf and hard of hearing" (p.422).

In 2007, the Joint Committee on Infant Hearing (JCIH) documented the continued shortage of qualified personnel, especially pediatric audiologists, early interventionists, and SLPs, who have the experience and expertise to diagnose hearing loss in infants and to provide speech and language intervention. According to the $\mathrm{JCIH}$, this dearth of qualified personnel contributes significantly to children who are "lost to follow-up." After not passing their newborn hearing screening, these children either do not have a diagnosis of hearing loss confirmed and/or they fail to receive early intervention services. The lack of appropriate, family-centered services for children with hearing loss is a significant contributing factor to a high rate of children lost to follow-up, which in 2009 was reported to be $44.8 \%$ (CDC, 2009). According to these estimates, almost half of the children who did not pass their second newborn hearing screening either do not receive a timely diagnosis and/or are not enrolled in early intervention services. Even when family and caregivers have been diligent in their follow up, children may be at risk of not receiving services or being grossly underserved by their local service providers and early intervention system (Houston, 2009).

\section{A Need for Specialization}

The personnel shortage and resulting vacancy rate among SLPs has caused university administrators and graduate training programs in speech-language 
pathology to focus almost exclusively on increasing the number of SLPs prepared to work with school-aged children. As a consequence, the degree to which newly trained personnel have the knowledge or practical experience to work with very young children with hearing loss has been largely ignored by most graduate training programs. Recent surveys of new and seasoned SLPs serving children with hearing loss indicate a wide gap in their knowledge and skills - with few respondents reporting any exposure to children with hearing loss during their preservice training (Luckhurst, 2008; Compton, Tucker, \& Flynn, 2009). As university training programs in speech-language pathology attempt to keep standards high and respond to pressures to increase the supply of new graduates to fill existing vacancies, they have an additional challenge of providing the expertise necessary to serve the unique needs of children with hearing loss.

Nationally, between one and three children per 1,000 births are identified each year with a permanent hearing loss. When combined with progressive, unilateral, and conductive hearing loss, as many as 15 per 1,000 will have some degree of hearing disorder (Stach \& Ramachandran, 2008). Because newborn hearing screening is now in place in all 50 states, children - on average are being identified and referred to their state's early intervention system within the first months of life, resulting in a potential increase in the number of infants and toddlers with hearing loss who need to be served. While these trends support a dramatic rise in the total number of children with hearing loss who need a range of services, most university training programs have not yet adjusted their curricula to provide SLPs with the specific knowledge and skills needed for this important and growing population (Ying, 2008).

Numerous studies have shown that when children with hearing loss are identified early and receive timely early intervention coupled with advanced hearing technology (e.g., digital hearing aids and/or cochlear implants), they often achieve communication outcomes that are comparable to their same-age peers who have typical hearing (Yoshinaga-Itano, Sedey, Coutler, \& Mehl, 1998; Moeller, 2000; Calderon \& Naidu, 2000) and obtain positive speech, language, and social-emotional outcomes (Yoshinaga-Itano \& Gravel, 2001; YoshinagaItano, 2003). Although the field of speech-language pathology has both a long history of successful early intervention and a clearly defined role (Carney \& Moeller, 1998; ASHA, 2008), the breadth of clinical training currently required by national accreditation standards means that very few master degree programs provide extensive training, much less specialization, in early intervention with children who are deaf or hard of hearing.

In an effort to improve this situation, the Joint Committee of ASHA and the Council on the Education of the Deaf (ASHA-CED) collaboratively developed the technical report, "Service Provision to Children Who Are Deaf and Hard of Hearing, Birth to 36 Months" (ASHA, 2008). This technical report clearly outlines the need for services from qualified professionals, especially SLPs and audiologists, who can provide family-centered early intervention through 
interdisciplinary service delivery models to provide "a more cohesive, cooperative, and organized program of services" (ASHA, 2008, p.1).

\section{A Need to Address Family Choice in Communication}

Another factor contributing to difficulties faced by early intervention systems in the United States is the fact that state-wide early intervention programs for children with hearing loss were developed at a time when the majority of these children were not identified until much later -2 to 5 years of age (White, 2006). Additionally, many early intervention programs were conceived at a time when digital hearing aids and cochlear implants were not available to this population. The result is that the current service delivery model does little to take advantage of this relatively new technology and a limited number of early intervention providers have the knowledge and skills to appropriately serve these children and their families (JCIH, 2007; Marge \& Marge, 2005). Currently, families in many states who have infants and young children with hearing loss receive limited services at best, often settling for one-hour visits once or twice each month from an early intervention specialist (Behl \& Houston, 2010).

Families whose children are using digital hearing aids and/or cochlear implants have encountered significant challenges in identifying SLPs who are trained to teach children how to use this new technology to develop listening and spoken language. As hearing technology continues to advance, children with hearing loss will have greater access to auditory input and spoken language stimulation (O'Neall, O'Donoghue, Archbold, \& Mormand, 2000). This fact, coupled with the realization that approximately $95 \%$ of children with hearing loss are born to parents with typical hearing (Mitchell \& Karchmer, 2004), is changing the communication mode chosen by parents for their children who are deaf or hard of hearing. Specifically, more and more parents are requesting early intervention services and educational programs for their children that focus on facilitating listening and spoken language - if they know that spoken language is a viable option for their child with hearing loss.

To illustrate this point, the longitudinal outcomes in parent choice and communication methodology can be examined in one state. In North Carolina, parents may choose from a range of communication options (e.g., American Sign Language, Total Communication, Cued Speech, Auditory-Oral, AuditoryVerbal), and systematic data tracking indicates that parents' choices have changed dramatically. In 1995, 40\% of parents chose programs focusing on listening and spoken language, compared to $60 \%$ who chose programs focusing on sign language. By 2005, 85\% chose listening and spoken language, compared to $15 \%$ who chose sign language (Brown, 2006; White, 2006). While these statistics represent the results from a single state, such a striking change in parental attitudes and preferences appear to be the result of a convergence of several overlapping factors: early identification of hearing loss; access to and the early fitting of hearing technology; timely information about the range of options 
available; and the availability of well-trained professionals who can provide early intervention services that focus on the acquisition of spoken language.

JCIH (2007) recommended that parents receive unbiased information about all of the communication options available to their child and family from professionals who are knowledgeable about childhood hearing loss. Depending on state early intervention systems, the professional explaining these options could include early interventionists, teachers of the deaf, SLPs, audiologists, early childhood educators, or other related personnel. Parents, in turn, should be able to determine their preference for communication methodology, which should be based on their desired outcomes and the unique learning needs of their child. Through informed decision making and a clear understanding of their child's long-term communication goals, parents can make these decisions when they are supported by access to unbiased information and to professionals who possess the appropriate knowledge and skills.

\section{Summary}

For centuries, practitioners have devoted themselves both professionally and personally to improving the listening and spoken language outcomes of children who are deaf or hard of hearing. Through these pioneers, intervention approaches and treatment strategies have evolved to provide opportunities for children to acquire and improve spoken communication skills. Likewise, technological advances that allow earlier screening and identification of hearing loss as well as access to audition through digital hearing aids and cochlear implantation have become standards of care. As the second decade of the 21st century begins, the potential for children with hearing loss to achieve listening and spoken language outcomes that mirror their peers with typical hearing has never been greater.

However, lack of access to well-trained professionals, especially SLPs, may hinder a child's opportunity for success. In addition to courses that provide a solid research and theoretical foundation, clinical experiences supervised by qualified faculty are needed to prepare SLPs entering the profession so that they can provide appropriate assessment and intervention to young children with hearing loss. Ying (2008) provided a concise summary when she stated:

Few graduate training programs offer practical experiences that are necessary to prepare the average SLP with skills to work with children with hearing loss. The academic preparation of an SLP should prepare clinicians to conduct the evaluation and treatment programs for pediatric patients with hearing loss. Furthermore, SLPs must be prepared to assume additional responsibilities for the student with hearing loss who is enrolled in general education settings (e.g., monitoring amplification, serving as a resource to the classroom teacher, providing preteaching of vocabulary and content, and facilitating social interactions). (p.241) 
Fortunately, a few graduate training programs in speech-language pathology have recognized the need to better prepared SLPs who can provide intervention and related services that support auditory learning and spoken language in young children with hearing loss (see Houston; Rice \& Lenihan; and Wray \& Flexer in this issue). These university programs have developed specializations that provide additional coursework and practicum experiences prior to graduation. While new graduates from these programs will require additional mentoring and experience to hone their knowledge and skills, they at least are leaving their university programs with a stronger academic and clinical foundation on which to build their careers in service to young children with hearing loss and their families who are seeking a listening and spoken language outcome.

The role of SLPs, working in concert with other professionals, is vital to the communication development of children with hearing loss. SLPs who possess the background, knowledge, and experience to help children with hearing loss fully utilize audition for the acquisition of spoken language will continue to be sought out by parents, early intervention systems, educational programs and schools, and cochlear implant teams.

A renewed commitment to personnel preparation and professional development is required by universities, leadership associations, and individual practitioners to ensure that every child with hearing loss has access to SLPs who are well-trained and capable of meeting their listening and spoken language needs.

\section{References}

American Speech-Language-Hearing Association. (2008). Service provision to children who are deaf and hard of hearing, birth to 36 months [Technical Report]. Retrieved May 3, 2010, from www.asha.org/policy.

Arehart, K.H., \& Yoshinaga-Itano, C. (1999). The role of educators of the deaf in the early identification of hearing loss. American Annals of the Deaf, 144(1), 19-23.

Behl, D., \& Houston, K.T. (2010). Building family-provider relationships via tele-intervention. Paper presented at the 2010 Early Hearing Detection and Intervention (EHDI) Conference, Chicago, IL.

Boothroyd, A. (1982). Hearing impairments in young children. Englewood Cliffs, NJ: Prentice Hall, Inc.

Brown, C. (2006). Early intervention: Strategies for public and private sector collaboration. Paper presented at the 2006 Convention of the Alexander Graham Bell Association for the Deaf and Hard of Hearing, Pittsburgh, PA.

Calderon, R., \& Naidu, S. (2000). Further support for the benefits of early identification and intervention for children with hearing loss. The Volta Review, 100(5), 53-84.

Calvert, D.R., \& Silverman, S.R. (1975). Speech and deafness. Washington, DC: Alexander Graham Bell Association for the Deaf. 
Carney, A.E., \& Moeller, M.P. (1998). Treatment efficacy: Hearing loss in children. Journal of Speech, Language \& Hearing Research, 41(1), S61-85.

Center for Disease Control (CDC). (2009). Early hearing detection and intervention program: Annual EHDI data. Retrieved March 14, 2010, from http:// www.cdc.gov/ncbddd/ehdi/data.htm.

Clarke School for the Deaf. (1971). Speech development. Northampton, MA: Clarke School for the Deaf Curriculum Series.

Cole, E., \& Flexer, C. (2007). Children with hearing loss: Developing listening and talking birth to six. San Diego, CA: Plural Publishing.

Connor, L. (1971). Speech for the deaf child: Knowledge and use. Washington, DC: Alexander Graham Bell Association for the Deaf.

Compton, M.V., Tucker, D.A., \& Flynn, P.F. (2009). Preparation and perceptions of speech-language pathologists working with children with cochlear implants. Communication Disorders Quarterly, 30(3), 142-154.

Cosby, J. (2009). Pediatric cochlear implants. Knowledge and skills of speechlanguage pathologists. The ASHA Leader, 14(2), 6-7, 18.

Davis, H. \& Silverman, S.R. (1978). Hearing and deafness. New York, NY: Holt, Rinehart, and Winston.

Duchan, J. (2002, December 24). What do you know about the history of speechlanguage pathology? And why is it important? The ASHA Leader, 7(23), 4-5, 29.

Grosvenor, E.S., \& Wesson, M. (1997). Alexander Graham Bell: The life and times of the man who invented the telephone. New York, NY: Harry N. Abrams, Inc., Publishers.

Haycock, G.S. (1933). The teaching of speech. Stoke-on-Trent, UK: Hill and Ainsworth, Ltd.

Houston, K.T. (2009, August 17). Trends in early identification and early intervention in infants identified with hearing loss. Retrieved February 5, 2010, from www.speechpathology.com/articl es/article_detail.asp? article_id=376.

Hudgins, C.V. \& Numbers, F.C. (1942). An investigation of the speech of the deaf. Genetic Psychology Monograph, 25, 289-392.

Joint Committee on Infant Hearing. (2007). 2007 Position statement: Principles and guidelines for early hearing detection and intervention. Retrieved May 2, 2010, from http:/ / www.asha.org/policy.

Kricos, P.B., \& McCarthy, P. (2007). From ear to there. A historical perspective on auditory training. Seminars in Hearing, 28(2), 89-98.

Ling, D. (1976). Speech and the hearing-impaired child: Theory and practice. Washington, DC: Alexander Graham Bell Association for the Deaf.

Ling, D. (1989). Foundations of spoken language for hearing-impaired children. Washington, DC: Alexander Graham Bell Association for the Deaf.

Ling, D. (2002). Speech and the hearing-impaired child: Theory and practice, $2^{\text {nd }}$ Edition. Washington, DC: Alexander Graham Bell Association for the Deaf.

Luckhurst, J.A. (2008). Professional preparedness for provision of auditory oral programs to children with hearing loss: Results of a survey. Perspectives on Aural Rehabilitation and Its Instrumentation, 15, 2-18. 
Mackenzie, C. (1928). Alexander Graham Bell: The man who contracted space. New York, NY: Grosset \& Dunlap Publishers.

Marge, D.K., \& Marge, M. (2005). Beyond newborn hearing screenings: Meeting the educational and healthcare needs of infants and young children with hearing loss in America. Report of the National Consensus Conference on Effective Educational and Health Care Interventions for Infants and Young Children with Hearing Loss, September 10-12, 2004. Syracuse, New York; Department of Physical Medicine and Rehabilitation, SUNY Upstate Medical University.

Mitchell, R.E., \& Karchmer, M.A. (2004). Chasing the mythical ten percent: Parental hearing status of deaf and hard of hearing students in the United States. Sign Language Studies, 4, 138-163.

Moeller, M.P. (2000). Early intervention and language development in children who are deaf and hard of hearing. Pediatrics, 106, E43.

Moores, D.F. (2001). Educating the deaf. Boston, MA: Houghton Mifflin.

Moseley, M.J., Mahshie, J.J. Brandt, F.D., \& Fleming, L.F. (1994). A survey of professionals delivering speech-language services to children with hearing loss. Language, Speech, and Hearing Services in Schools, 25, 100-104.

O'Neall, C., O'Donoghue, G.M., Archbold, S.M., \& Mormand, C. (2000). A cost utility analysis of pediatric cochlear implantation. Laryngoscope, 110, 156-160.

Perigoe, C., \& Ling, D. (1986). Generalization of speech skills in hearingimpaired children. The Volta Review, 88, 351-365.

Pollack, D., Goldberg, D., \& Caleffe-Schenck, N. (1997). Educational audiology for the limited-hearing infant and preschooler: An auditory-verbal program, $3^{\text {rd }}$ Edition. Springfield, IL: Charles C. Thomas Publisher.

Rowan, L.E., Sommers, R., \& Wray, D. (2005). Lingering evidence of SLP training deficiencies: Fluency disorders and hearing impairments revisited. Presented at the 2005 Ohio Speech-Language and Hearing Association Convention, Columbus, $\mathrm{OH}$.

Stach, B.A., \& Ramachandran, V.S. (2008). Hearing disoders in children. In J.R. Madell, \& C. Flexer, Pediatric Audiology: Diagnosis, Technology, and Management (pp. 3-12). New York, NY: Theime Medical Publishers, Inc.

Study of Personnel Needs in Special Education. (2002). Key findings submitted to the U.S. Department of Education, Office of Special Education Programs. Retrieved May 2, 2010, from www.spense.org.

U.S. Bureau of Labor Statistics. (2009, Winter 2009-10). Charting the projections: 2008-18. Occupational Outlook Quarterly. Retrieved May 2, 2010, from www.bls.gov/ooq.

Vorce, E. (1974). Teaching speech to deaf children. Washington, DC: Alexander Graham Bell Association for the Deaf.

Watson, M.M., \& Martin, K. (1999). Providing services to children with cochlear implants in the public schools: Results of a survey of speechlanguage pathologist. Journal of Educational Audiology, 7, 51-58. 
Wilson, K. (2006). Beyond early intervention: Providing support to public school personnel. The Volta Review, 106(3), 419-431.

White, K.R. (2006). Early Intervention for children with permanent hearing loss: Finishing the EHDI revolution. The Volta Review, 106(3), 237-258.

Worcester, A.E. (1885). Pronunciation at sight. Northampton, MA: The Clarke School for the Deaf.

Worcester, A.E. (1915). Pronunciation at sight. The Volta Review, 17, 85-93.

Yale, C.A. (1929). Formation and development of elementary English sounds. Northampton, MA: The Clarke School for the Deaf.

Ying, E. (2008). Speech/language/auditory management of infants and children with hearing loss. In J.R. Madell \& C. Flexer (Eds.), Pediatric Audiology: Diagnosis, Technology, and Management ( $1^{\text {st }}$ ed., pp. 240-249). New York, NY: Thieme.

Yoshinaga-Itano, C. (2003). From screening to early identification and intervention: Discovering predictors to successful outcomes for children with significant hearing loss. Journal of Deaf Studies and Deaf Education, 8(2), 11-30.

Yoshinaga-Itano, C., \& Gravel, J.S. (2001). The evidence for universal newborn hearing screening. American Journal of Audiology, 10(2), 62-64.

Yoshinaga-Itano, C., Sedey, A.L., Coutler, D.K., \& Mehl, A.L. (1998). Language of early-and later-identified children with hearing loss. Pediatrics, 102, $1161-1171$. 


\title{
Professional Development for In-Service Practitioners Serving Children who are Deaf and Hard of Hearing
}

\author{
Kathryn Wilson, M.A., CCC-SLP, LSLS Cert. AVT; Mary Ellen \\ Nevins, Ed.D.; and K. Todd Houston, Ph.D., CCC-SLP, LSLS Cert. AVT
}

Because children who are deaf or hard of hearing are being identified at birth, fitted with advanced hearing technology, and enrolled in early intervention programs, families increasingly seek professionals who can provide services that support their choice of listening and spoken language. The increased demand for these services and shortages of qualified personnel has led to the development of model in-service training programs for teachers of the deaf, speech-language pathologists, and audiologists. Three of these programs - the Carolina Summer Institute in Auditory-Verbal Practice, First YEARS, and Professional Preparation in Cochlear Implants - provide in-service training opportunities that allow participants to significantly increase their knowledge and skills to serve the needs of children who are deaf or hard of hearing and who are learning to listen and talk.

\section{Introduction}

Numerous studies show that university training programs are failing to adequately prepare graduates to provide family-centered, evidenced-based early intervention services to children with disabilities and their families (Campbell, Chiarello, Wilcox, \& Milbourne, 2009; Bruder, Mogro-Wilson,

Kathryn Wilson, M.A., CCC-SLP, LSLS Cert. AVT, is Director of the First YEARS program at the University of North Carolina at Chapel Hill. Mary Ellen Nevins, Ed.D., is the National Director of the Professional Preparation in Cochlear Implants program and an Independent Contractor to The Children's Hospital of Philadelphia Center for Childhood Communication. K. Todd Houston, Ph.D., CCC-SLP, LSLS Cert. AVT, is the Director of the Graduate Studies Program in Auditory Learning and Spoken Language in the Department of Communicative Disorders and Deaf Education at Utah State University. Correspondence concerning this manuscript may be directed to Ms. Wilson at kathryn_wilson@med.unc.edu. 
Stayton, \& Dietrich, 2009). Likewise, the scarcity of preservice training programs to meet the developmental, communicative, and educational needs of children who are deaf or hard of hearing continues to plague various disciplines, including deaf education (Rice \& Lenihan, 2005; White, 2007), speech-language pathology (Moseley, Mahshie, Brandt, \& Fleming, 1994; Rowan, Sommers, \& Wray, 2005; Watson \& Martin, 1999), and audiology (JCIH, 2007). In the United States, only a limited number of university training programs in deaf education, speech-language pathology, and audiology prepare graduates to work with today's generation of early identified infants and toddlers with hearing loss whose parents choose listening and spoken language (Lenihan, 2009). Whereas appropriate preservice training programs are critical for preparing new professionals, the needs of the current workforce also must be addressed. Many practicing professionals received their education and training before universal newborn hearing screening, digital hearing aid technology, and cochlear implants were available (Marge \& Marge, 2005). Three unique in-service programs have been established in the United States to increase the number of knowledgeable and skilled professionals who support listening and spoken language development. These programs, the Carolina Summer Institute in Auditory-Verbal Practice, FIRST YEARS, and Professional Preparation in Cochlear Implants (PPCI), will be described as models of high quality, in-depth training for practicing professionals.

Proctor, Niemeyer, and Compton (2005) provide additional support for broadening access to ongoing in-service and professional development opportunities for the current workforce. Responses to a survey to determine the training needs of professionals working with infants and toddlers who are deaf or hard of hearing in the United States demonstrated that appropriate services were difficult for families to obtain. Approximately half of the states surveyed reported more training opportunities were needed for professionals in listening and spoken language approaches and developmental intervention. Proctor and colleagues concluded that the "lack of available trained professionals presents tremendous challenges to states in responding to the legal mandates delineated by IDEA" (p. 125).

The Joint Committee on Infant Hearing (JCIH, 2007) also recognizes the importance of qualified personnel for today's new generation of children who are deaf or hard of hearing and their families. The JCIH is comprised of representatives from organizations such as the Alexander Graham Bell Association for the Deaf and Hard of Hearing (AG Bell), the American Academy of Pediatrics (AAP), the American Speech-Language-Hearing Association (ASHA), and several other nationally recognized professional organizations. The JCIH 2007 Position Statement executive summary specifically states "appropriate interdisciplinary intervention programs for deaf and hard of hearing infants and their families should be provided by professionals knowledgeable about childhood hearing loss" (p. 2). These professionals include early 
interventionists, educators of the deaf, speech-language pathologists, and audiologists.

Each of the programs described in this article meet the needs of participants with different learning styles, long-term professional goals, and lifestyles. Each program varies in content, length of training, learning requirements, and cost; however, all include either a coaching or mentoring component to enhance the participant's training experience. This is because change in professional practice rarely occurs in response to attendance at workshops or one-time training sessions (Barth, 2001). Coaching and mentoring, typically used in the corporate world, are associated with growth in the skills and motivation of employees (Onchwari, 2006). The Westchester Institute for Human Services Research (1998) reports that effective adult learning programs will emphasize consistent feedback and follow-up from an established coach-mentor. The three programs described include a coach-mentor model that focuses on improving the knowledge, skills, and teaching practices of professionals providing direct services to children who are deaf or hard of hearing and their families. A discussion of each program follows.

\section{Carolina Summer Institute in Auditory-Verbal Practice}

The Carolina Summer Institute in Auditory-Verbal Practice began as a collaborative project between the faculties of the University of North CarolinaChapel Hill (UNC) and the University of South Carolina (USC) pediatric cochlear implant programs. Recognizing the need to raise the skill levels of professionals providing auditory-verbal intervention, the first Carolina institute was hosted by USC in 1998 and then by UNC the following year. The institute continues to be offered as an annual training opportunity at the Center for the Acquisition of Spoken Language through Listening Enrichment (CASTLE) in Chapel Hill, NC.

The Carolina Summer Institute is an intensive 2-week training program that includes both a lecture series and hands-on practica experiences where participants work with children and families under the guidance of certified Listening and Spoken Language Specialists (LSLS) (i.e., teachers of the deaf, speech-language pathologists, and audiologists). During the first week, participants learn about the development of auditory function, speech and language development, and auditory-verbal practice. Participants are also introduced to a format for conducting a parent participation session and a process for planning lessons that will be delivered during the second week of training.

During the second week of the institute, each participant has a partner with whom to plan and carry out several therapy sessions. Parents are included in each session so that participants have the opportunity to work with children and practice their skills coaching and guiding parents. After conducting a selfassessment, each participant targets individualized teaching behaviors for 
each session. A certified LSLS is present in every session to coach participants as they strive to master their teaching behaviors, help them implement activities, and demonstrate effective auditory-verbal strategies and techniques. Following each session, the coach and trainees meet to discuss the session. Participants are encouraged to self-reflect and identify where they implemented appropriate teaching behaviors and the skills they need additional time and practice to develop. Through this process, the coach and participant determine whether more practice is needed to achieve consistency and mastery of particular teaching behaviors or whether to focus on new ones in the next session. At the conclusion of the second week, each participant meets individually with a member of the faculty to discuss areas of professional growth during the institute and to identify goals for ongoing professional development to help them guide listening and spoken language acquisition.

\section{Program Outcomes}

Data collection regarding institute outcomes dates back to 2002. Since that time, 69 professionals have attended the lecture series only during the first week of the institute, and 135 professionals have attended both the lecture series and the second week of practicum. Data from 2008 and 2009 indicate that participants were speech-language pathologists $(56 \%)$, teachers of the deaf $(36 \%)$, and audiologists ( $8 \%)$. Pre- and posttest data are gathered to determine the effectiveness of the training. The average pretest score for 132 participants who attended in the years $2002-2009$ is $74.4 \%$ while the average posttest score following the lecture series is $84.5 \%$. One participant commented about her learning experience at the institute:

Before arriving for the institute, I truly thought that I knew what to do with a child with hearing loss who was learning auditorily, but I soon found out what I didn't know. This isn't traditional speech and language facilitation. You really have to know speech acoustics and all the auditory-verbal techniques to facilitate listening and spoken language. I never learned this in graduate school, and I'm extremely thankful that I had this opportunity to learn and improve my skills. I feel like I'm much better suited to serve children and families - even though I still have much more to learn!

Demographically, Carolina Summer Institute participants have come from 23 different states plus the District of Columbia and Puerto Rico. Additionally, participants from Canada and Mexico have attended the program. Because of the institute's success and a desire to reach more professionals who could benefit from the training, the model has been replicated in Alabama, Illinois, and Texas. Plans are underway in other states to host their first institute in summer 2011. 


\section{Future Plans}

Following completion of the institute each summer, the faculty reviews all program evaluations from participants and discusses areas of strength and weakness. Based on this feedback, modifications for future institutes are planned. The input from participants has been a critical factor in guiding the program's direction from year-to-year. In fact, because of requests from past participants, faculty are currently developing online resources that participants will be able to review prior to attending the Carolina Summer Institute, which will allow more flexibility in the delivery of content while onsite. And finally, the faculty is exploring options for delivering portions of the content through distance education or other online outlets in an effort to reach more participants. The success of the Carolina Summer Institute and the 2-week model that includes both didactic teaching and onsite practica continues to be validated; no less than 25 professionals eventually have obtained certification as a LSLS Certified Auditory-Verbal Therapist or Certified Auditory-Verbal Educator, and others have developed new competencies in auditory-verbal practice.

\section{FIRSTYEARS}

In 2000, AG Bell received funding for an accessible professional development program from a national foundation that supports auditory learning and spoken language programs for children with hearing loss. AG Bell collaborated with the UNC Division of Speech and Hearing Sciences to design and implement FIRST YEARS - a comprehensive continuing education program. In November 2003, UNC approved the program and the first cohort of students began in August 2004. A new cohort of students is enrolled annually.

The National Center for Education Statistics projects that the number of students enrolled in distance education courses will increase from approximately 3 million individuals in 2000-2001 to over 18 million in the year 2013. A recent study by SRI International for the U.S. Department of Education (2009) found that students enrolled in distance education programs performed better than those in settings with face-to-face instruction. Because of the increasing popularity and effectiveness of distance education, FIRST YEARS is delivered as an online distance education program that takes 20 months to complete. Presently, FIRST YEARS (www.firstyears.org) is the only distance education program in the United States designed to enhance the knowledge and skills of professionals practicing in the fields of deaf education, speech-language pathology, audiology, and early intervention. Specifically, this comprehensive certificate program is for service providers working with children and their families using listening and spoken language approaches.

FIRST YEARS promotes awareness and insight into the practice of listening and spoken language for children who are deaf or hard of hearing by offering 
professional development that is academically rigorous, accessible, experiential, and focused on listening and spoken language development. The five graduate-level courses, totaling 15 credit hours, were developed by nationally and internationally known experts. These courses focus on working with families and teams, speech acoustics, audiology and hearing technologies, spoken language development and intervention, and literacy development in children who are deaf or hard of hearing. Each course includes required readings, partner exercises, quizzes, application activities, and discussion forums where students interact and learn from the course facilitator and fellow students. FIRST YEARS also utilizes a case study approach where students apply information learned in the courses to a hypothetical child with hearing loss and his family.

A primary goal of FIRST YEARS is to offer high quality, accessible in-service professional development. The program was developed with working professionals in mind and features asynchronous distance education where students can learn at any time or any place - as long as they have a viable Internet connection. This means that students are not required to participate in online discussions at required times nor are online lectures a required component of the instruction. The asynchronous format gives the time and space for everyone to think first, and then respond to the questions to be discussed or the problems to be solved. This format also allows students to work at their own pace and engage in study at the times during the week that best fit their schedule.

The mentorship provides a unique learning opportunity that has become a key component of the program's success. The following statement from a graduate of the program sums up the views of many students regarding the value of the mentored experience:

I have loved the materials and readings...they have all been top notch... well written and thorough but nothing compares to actually doing what you have been reading about. The practice during the mentorship puts all the readings into perspective/practice. The video taping of myself reinforces what I am learning...because I am watching myself critically and I am reading great material about my goals, I can see very clearly what needs to change.

The 10-day mentorship begins in the second semester and is typically completed in either the fourth or fifth semester. Since the inception of the program, several professionals from various programs in the United States and Canada have become mentors. Prior to the student arriving at the mentor's site for the first 5 days, new mentors receive approximately 10 hours of faceto-face training to help them gain a better understanding of the objectives of the program, their roles and responsibilities as a FIRST YEARS mentor, and to acquaint them with the FIRST YEARS Competencies Checklist, a compilation of critical teaching behaviors necessary for listening and spoken language 
practice. Videotape review and analysis is also part of the mentorship component. To create a record of competency development across the course of the program, students provide three videotapes of intervention sessions: the first, submitted following admission; the second, submitted after the first week of mentored experience; and the third during the last course. The objectives of requiring three videotapes include:

1. Obtaining a baseline record of intervention skills.

2. Evaluating changes in intervention over time.

3. Providing written feedback and suggestions.

4. Ensuring that skills reflect FIRST YEARS minimal competencies upon completion of the certificate program.

\section{Program Outcomes}

FIRST YEARS has provided professional educational training for 73 students and 46 mentors in 23 states. Most FIRST YEARS participants are either teachers of the deaf $(52 \%)$ or speech-language pathologists $(45 \%)$. Professionals, such as audiologists, administrators, infant development specialists, and music therapists, comprise 3\% of the total population. Participants work in a variety of settings, including public and private schools, hospitals and clinics, and early intervention and private practice settings (Figure 1).

A survey sent to 43 graduates and 10 students examined the impact of the FIRST YEARS courses and mentorship. Thirty-five completed surveys were returned for a response rate of $64 \%$. All respondents indicated that the graduate level courses had either a high impact $(n=24$ or $69 \%$ ) or definite impact

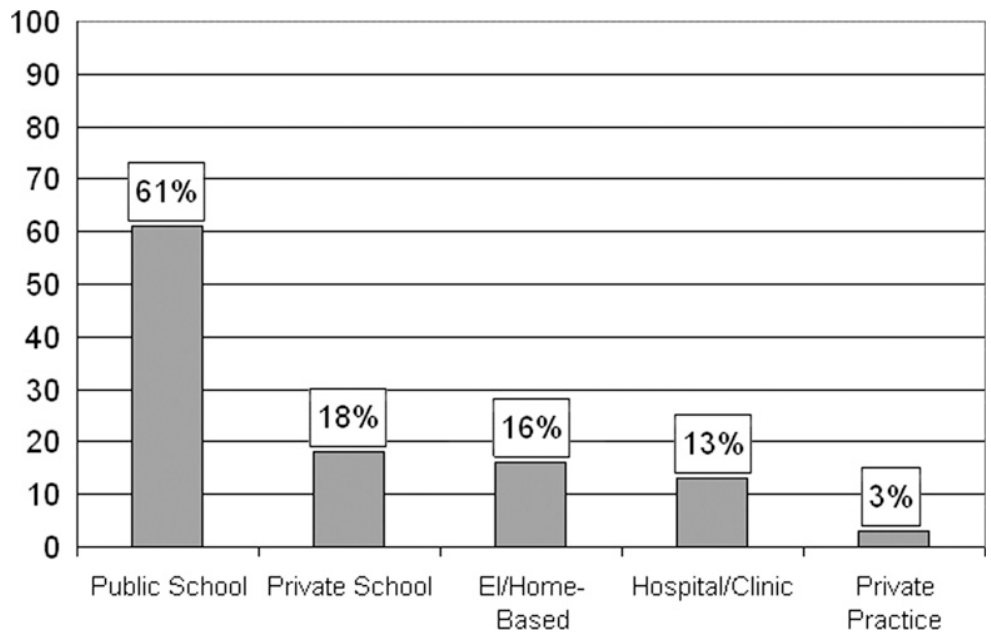

Figure I. FIRST YEARS students by employment setting. 
( $\mathrm{n}=11$ or $31 \%$ ) on their role as a teacher or therapist (see Figure 2). Figure 3 depicts the perceived impact of the mentorship reported as either high impact $(\mathrm{n}=19$ or $54 \%)$, definite impact $(\mathrm{n}=10$ or $29 \%)$, or some impact $(\mathrm{n}=6$ or $17 \%)$. The vast majority of survey participants indicated strongly agree $(\mathrm{n}=27$ or $77 \%)$ in response to the following statement regarding confidence levels: "FIRST YEARS has increased my confidence in working with children who are deaf or hard of hearing and their families" (see Figure 4).

For the fourth and final survey item - "I share information from FIRST YEARS with other professionals in my work setting" - most respondents ( $\mathrm{n}=$ 23 or $66 \%$ ) indicated strongly agree (see Figure 5).

Other direct services provided by FIRST YEARS staff include professional development training for groups of practicing professionals, a quarterly newsletter, phone and e-mail consultation to professionals who are not enrolled as students, and website resources for students, mentors, other professionals, and parents. Over 3,000 visits to the FIRST YEARS' website are made monthly. FIRST YEARS manages a listserve for former graduates where they can share ideas and information and request guidance from other graduates and FIRST YEARS faculty and staff for challenging cases or situations. Thus, learning and networking opportunities continue beyond completion of the program.

\section{Future Plans}

It is expected that new cohorts of students will be admitted each year to begin their course of study during the fall semester. Courses will be updated or rewritten as needed to ensure that all content reflects best practices and

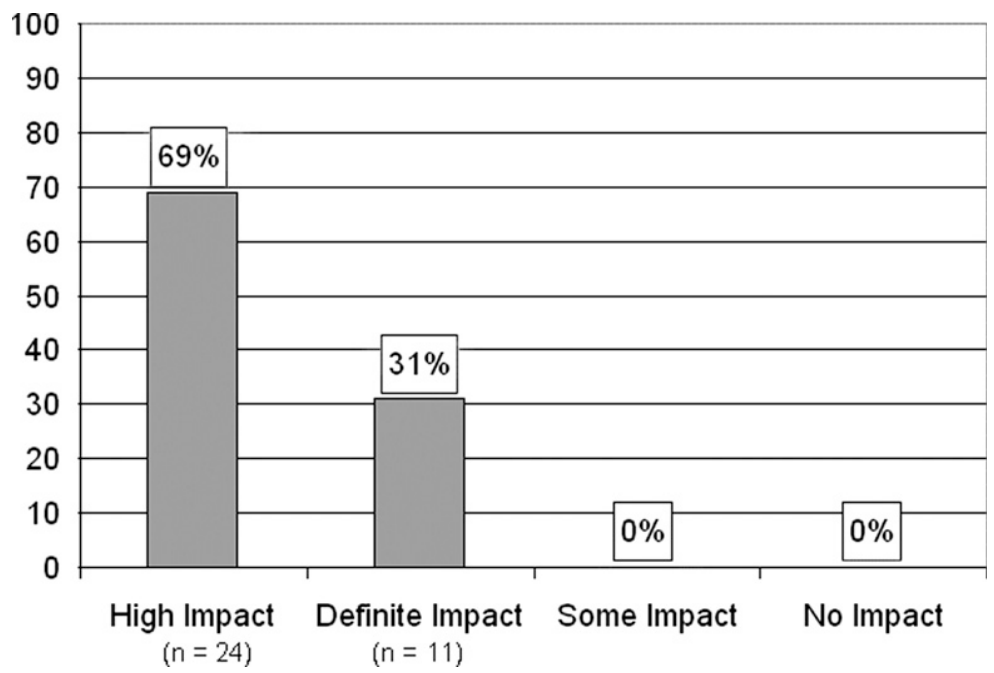

Figure 2. Impact of FIRST YEARS coursework on role as a teacher or therapist. 


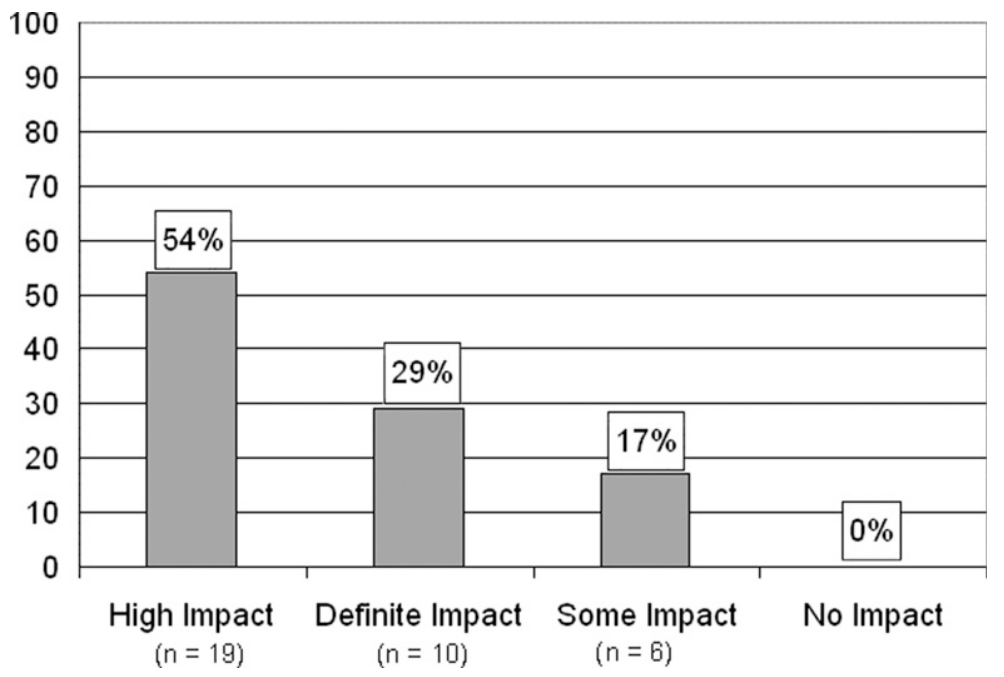

Figure 3. Impact of FIRST YEARS mentorship.

the most current information in deaf education, speech-language pathology, audiology, and early intervention. Increased use of web-streamed video is anticipated to provide students with relevant examples to accompany written descriptions and explanations of course content. New mentorship sites will be identified to increase options in a variety of settings for future students. Presently, students who enroll in FIRST YEARS must take

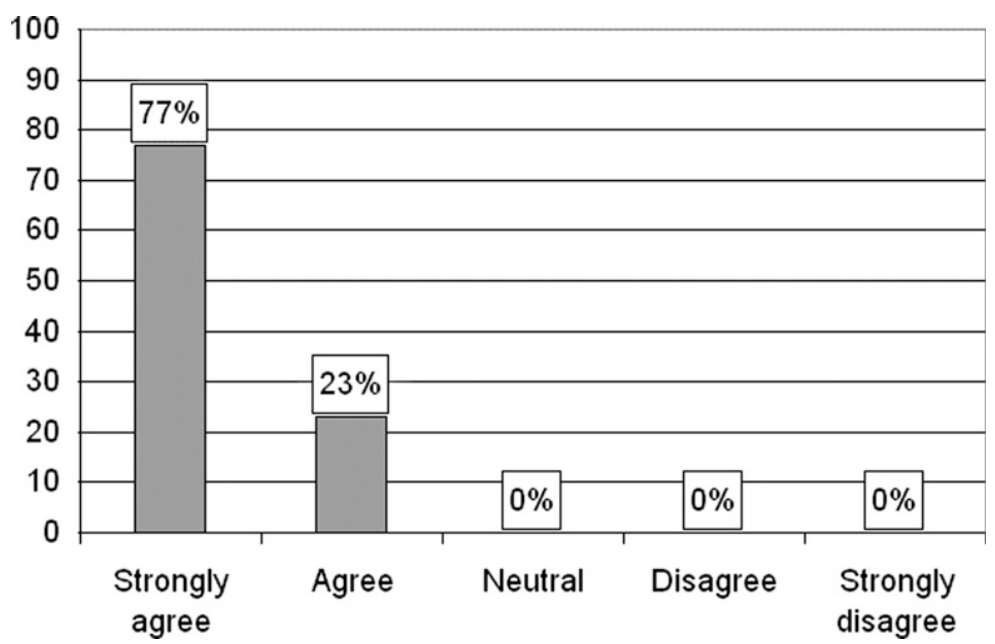

Figure 4. "FIRST YEARS has increased my confidence in working with children who are deaf or hard of hearing and their families." 


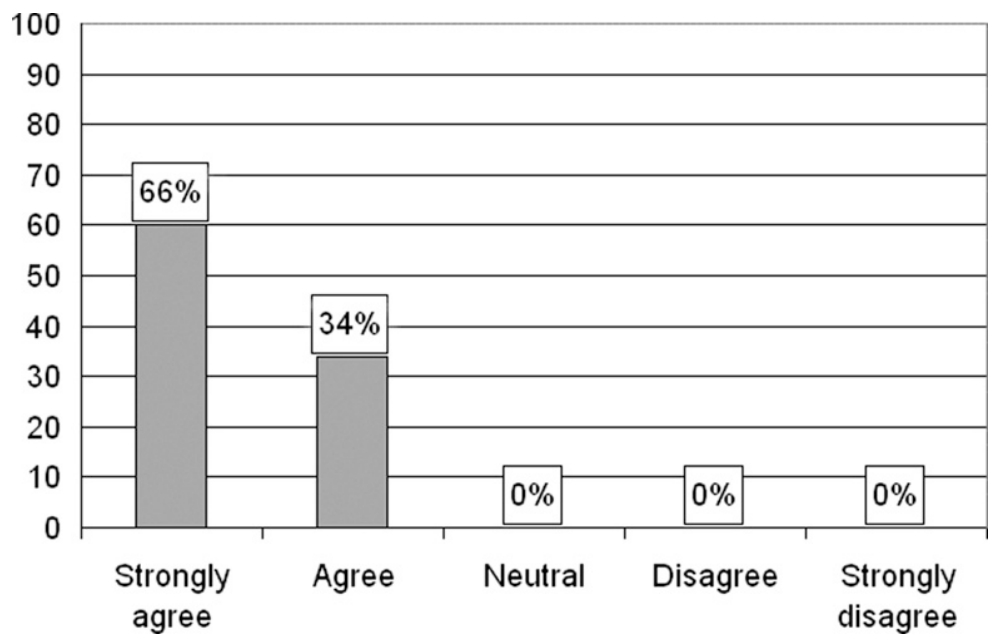

Figure 5. "I share information from FIRST YEARS with other professionals in my work setting."

all five courses. In the future, FIRST YEARS staff will explore the possibility of unbundling the five course requirement to offer one or two courses on a continuing education basis. To maximize the use of existing resources, steps will be taken to work with university programs around the country to make FIRST YEARS courses and materials available to preservice training programs.

\section{Professional Preparation in Cochlear Implants}

Capitalizing on interest in cochlear implant technology and the educational needs of professionals working with children who use it, The Children's Hospital of Philadelphia (CHOP) has offered innovative continuing education programming since 2002. Originally titled the Education Consultant Training Program (ECTP), this first generation professional development program was launched in 2003 in collaboration with Smith College and Clarke Schools for Hearing and Speech (Northampton, MA). ECTP sought to prepare teachers of children with hearing loss to become educational consultants on cochlear implant teams. Adding the Jean Weingarten Peninsula Oral School for the Deaf (Redwood City, CA) as a partner site in 2005 and the Atlanta Speech School (Atlanta, GA) in 2006, the ECTP 6-week, onsite professional education curriculum prepared 74 professionals in 4 years of operation. With a comprehensive curricular revision in 2007, ECTP was redesigned to include additional speech and hearing professionals as participants and to streamline its onsite attendance requirements. Today, Professional Preparation in Cochlear Implants (PPCI) offers both asynchronous and synchronous instructional 
components to educate any speech and hearing professional providing early intervention and transition services for children from birth to age 5 who use cochlear implants and/or other assistive technology. More specifically, PPCI is designed for early intervention specialists, teachers of children who are deaf or hard of hearing, speech-language pathologists, and educational audiologists with beginning-to-limited understanding of the knowledge base and facility with the skill set necessary to provide quality (re)habilitation services to children with cochlear implants or other assistive listening devices. The program has four phases supported by a web-based "community of practice" platform: prerequisite activities, onsite learning, follow-up projects, and a Capstone experience.

PPCI is a comprehensive, entry-level continuing education program designed to build listening and spoken language knowledge and skills. (See Table for a list of key program elements). The program is headquartered at CHOP in partnership with Clarke Pennsylvania in Bryn Mawr, PA. PPCI has additional sites at the Atlanta Speech School and the Jean Weingarten Peninsula Oral School for the Deaf. PPCI offers nine graduate credits from Smith College (an additional partner in the PPCI collaborative), ASHA CEUs, and AG Bell Academy for Listening and Spoken Language CE hours. The specified, graduate-level curriculum is focused and cohesive. Eight prerequisite, self-study modules on topics such as typical development, families as social systems, collaboration, and interventions are completed independently and asynchronously before participants arrive onsite. This model prepares participants to engage in higher level, thoughtful conversations for the 13 days that they spend at an onsite location. Listening and spoken language school partners open their

Table. PPCI program elements

PPCI is purposefully designed to retool the current workforce that is now underprepared to meet the needs of children with hearing loss benefitting from today's unprecedented auditory access

PPCI has a comprehensive curriculum that is grounded in evidenced-based practices to increase knowledge and foster skills that are required of today's educators and speech and hearing professionals

PPCI encourages transdisciplinary and cross-generational collaboration allowing participants to develop the associated skills needed to become both effective service providers and knowledgeable resources in their home communities

PPCI empowers professionals to take an active role in the design of service delivery in their home regions and strategically plan and implement systems change to improve services for children who are deaf and hard of hearing

PPCI harnesses the technology of the internet to create a community of practice that transcends geographical borders and fosters continued professional education through distance learning and collaboration 
doors for guided observations in real classroom and therapy rooms during the onsite period of learning.

PPCI has attracted professionals from across disciplines and with varying levels of work experience. Recent graduates of speech-language pathology programs with limited knowledge of hearing loss have made up a large constituency. The diversity of participating professionals creates learning communities that develop the collaborative skills needed for real world interaction. At the time of publication, 145 professionals will have participated in PPCI since its inaugural cohort in fall 2007. Participants have come from 37 U.S. states, Canada, Nigeria, and South Korea. Teachers of children who are deaf or hard of hearing represent the largest professional group, but speech-language pathologists are choosing PPCI with almost the same frequency. Although PPCI does not have a clinical audiology component, the program continues to attract audiologists who wish to get the "big picture" of intervention. It should be noted that 10 of the 145 participants have identified themselves as university faculty or instructors and have participated in PPCI for the purpose of updating preservice coursework. A breakdown of attendees by discipline can be found in Figure 6.

\section{Program Design}

The PPCI program is designed to offer continuing education to professionals by enlisting them in a Listening and Spoken Language "community

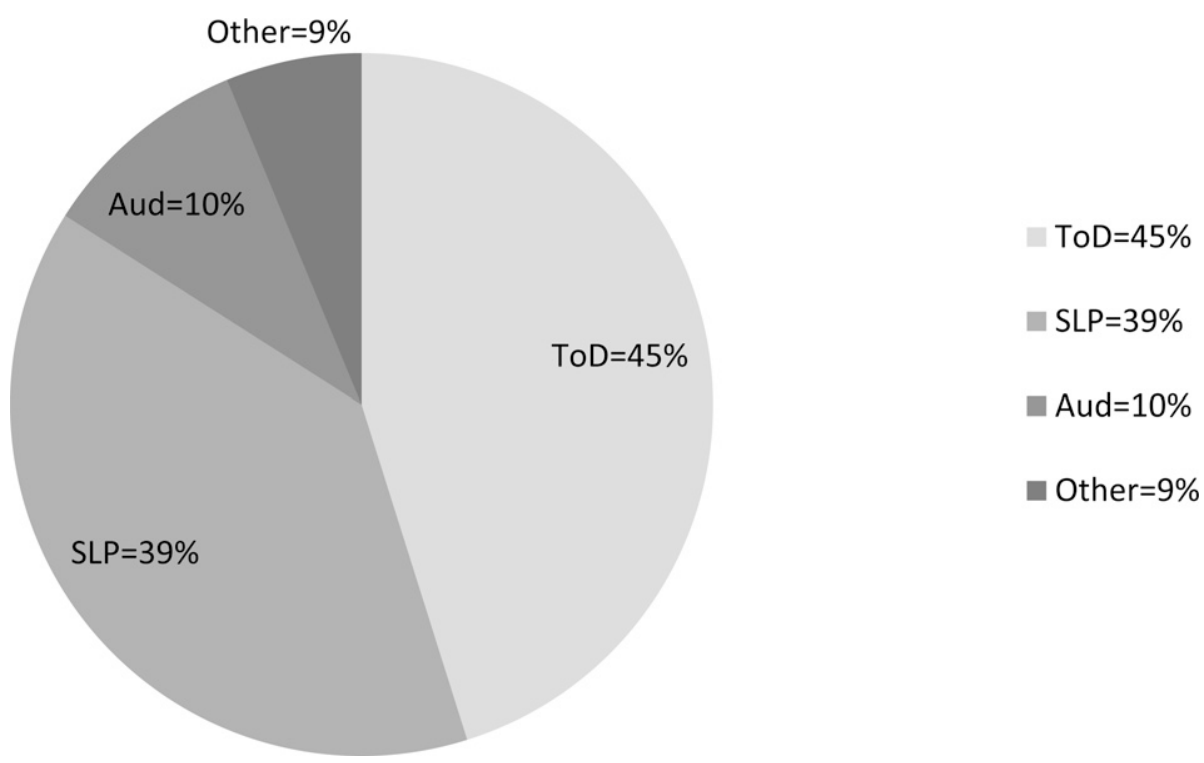

Figure 6. PPCI participants by discipline, $\mathrm{n}=144$. 
of practice" (Lave \& Wenger, 1991). Considering that time is a principal factor in choosing a professional development activity, PPCI bundles prerequisite learning into independent study modules that are supported through a web-based platform called icohere (www.icohere.com) to limit time required onsite. The program empowers professionals to make an impact beyond their immediate scope of influence of the classroom or the caseload in addition to gaining personal knowledge and building skills across the PPCI curriculum. Through a purposeful study of change, participants return to their home schools or regions to institute strategic plans for change. Some of the greatest evidence of the program's value comes from the presentations of change plans at the Capstone experience that occurs some months after the onsite sessions. This 2-day meeting is a culminating, face-to-face event for the purpose of reporting impact of PPCI on practice. PPCI participants have raised awareness to the possibilities of listening and spoken language for children with hearing loss and, in some cases, (e.g., Reno, NV; Yuma AZ; and Lake Charles, LA) have been instrumental in expanding program offerings to include listening and spoken language options in communities where there had been none.

The icohere online platform allows faculty and participants to collaborate across geographic boundaries before, during, and after the onsite learning period; however, synchronous and site-based learning and observations are critical components of the PPCI program. It is the face-to-face interaction and actual observation of expert listening and spoken language practitioners that has the greatest impact in creating community. Once participants return to their home locations, they are assigned a professional mentor who will assist in situating the new procedural knowledge developed during the prerequisite learning and onsite meetings. These mentors have virtual offices in the icohere platform, which allows for private video viewing of teacher/clinicianchild interactions. The upload feature of the platform has streamlined the process by which mentors can provide important feedback to teachers and clinicians who are implementing new strategies and techniques in listening and spoken language. Participants are responsible for commencing a case study project that follows a child in his or her listening and spoken language development through an intervention plan specifically targeting auditory goals. Additionally, a Strategic Plan for Change is conceptualized and initiated; this plan calls for the participant to act on a needs assessment survey conceived onsite regarding the delivery of listening and spoken language services for children with hearing loss. Once a need is identified, PPCI participants create and implement a design for collaboration and action to move the plan forward. All cohorts gather together for a Capstone experience early in the summer that follows their onsite sessions. Prominent leaders in the field have addressed the group at this gathering; participants report on their case studies and present scientific posters on the status of their plans for change in the home district or region. 


\section{Program Outcomes}

While the goal of any professional development program is ultimately to improve a child's achievement, PPCI charges its participants to raise awareness of the potential of listening and spoken language outcomes to other professionals. In an attempt to measure the program's impact, 122 invitations were sent to past and current participants to complete a brief efficacy study using Survey Monkey (an online survey tool). Eighty-five surveys were completed for a return rate of $69 \%$. The large majority of respondents work in public school settings (68\%) and report post-training effects on their knowledge and skill set. Sixty-four respondents who completed their PPCI coursework and Capstone experience at the time of the survey ranked the impact of PPCI on their role as a service provider 1 year after onsite training (see Figure 7). Fiftythree, or $83 \%$, reported a high impact and 10 participants, or $15 \%$, reported a definite impact on their skills as a service provider. A single respondent $(2 \%)$ indicated that PPCI had only some impact on service provision. Given the objective of sharing information with other colleagues back in the home region, the survey posed the following question: "How many administrators, speech and hearing professionals, and/or other teachers have you shared your knowledge and skill set with after your PPCI attendance?" Eighty-four respondents replying to this question reported sharing information with colleagues. Many respondents reported reaching out to more than immediate, local professionals; 22 respondents, or $26 \%$, indicated that they had shared PPCI content with more than 25 additional professionals.

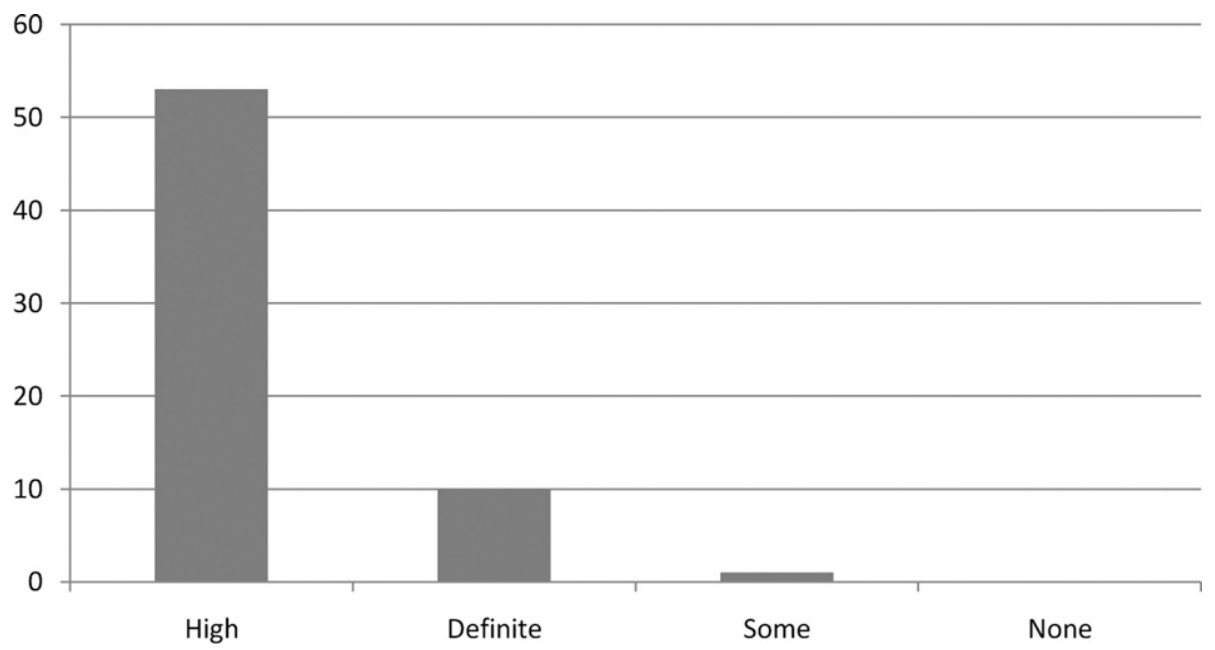

Figure 7. Number of respondents reporting impact of PPCI on role as direct service provider, $\mathrm{n}=64$. 
It has been reported anecdotally that PPCI participants have initiated regional and statewide study groups or task forces and have assisted in the development and planning of continuing education activities in listening and spoken language. Commentary included from the survey participants was overwhelmingly positive; many participants emphasized PPCI's dual impact on skills and community building. In the words of one PPCI participant:

I left my PPCI onsite training very invigorated and impassioned. I feel confident to effect change in our program. I have a high level of energy and commitment to improving not only my own teaching strategies, but those of my peers by example and encouragement. PPCI addressed the challenges I felt in teaching children with cochlear implants - because I sensed it requires a new set of skills. PPCI renewed my commitment to listening and spoken language [outcomes].

\section{Future Plans}

PPCI continues to grow and be responsive to its professional constituency. Plans for a school-age program in Atlanta are underway; an additional location for the Birth to Five emphasis program in Indianapolis is in development for summer 2010. The community of practice supported by the icohere platform will offer online webinars that are accessible through an archived library. These closed captioned webinars can be shared with colleagues at the participant's workplace and will continue to offer programming that complements the PPCI experience. Professionals are invited to learn more about PPCI by visiting the main website of PPCI hosted by CHOP, www.chop.edu/ppci. Academic costs of PPCI are covered by a training grant; participants are responsible only for travel and lodging costs.

\section{Conclusion}

Today's generation of newly identified infants who are deaf or hard of hearing and their families need knowledgeable and skilled professionals to guide listening and spoken language development. University preservice programs cannot adequately meet the training needs of the professionals who are currently in fields that serve young children with hearing loss. Therefore, in-service professional development is crucial to enhancing the knowledge and skills of the current workforce. These three programs - Carolina Summer Institute, First YEARS, and PPCI - are models of in-service training that allow participants opportunities to significantly increase their knowledge and improve their skills in service to children who are deaf or hard of hearing. 


\section{References}

Barth, R.S. (2001). Teacher leader. Phi Delta Kappan, 82(6), 443-449.

Bruder, M.B., Mogro-Wilson, C., Stayton, V.D., \& Dietrich, S.L. (2009). The national status of in-service personnel development systems for early intervention and early childhood special education practitioners. Infants $\mathcal{E}$ Young Children, 22(1), 13-20.

Campbell, P.H., Chiarello, L., Wilcox, M.J., \& Milbourne, S. (2009). Preparing therapists as effective practitioners in early intervention. Infants $\mathcal{E}$ Young Children, 22(1), 21-31.

Estabrooks, W. (Ed.). (2006). Auditory-verbal therapy and practice. Washington, DC: Alexander Graham Bell Association for the Deaf and Hard of Hearing.

Joint Committee on Infant Hearing (JCIH). (2007). Year 2007 position statement executive summary: Principles and guidelines for early hearing detection and intervention programs. Retrieved April 25, 2010, from http://www.jcih.org/ ExecSummFINAL.pdf.

Lave, J., \& Wenger, E. (1991). Situated learning: Legitimate peripheral participation. New York, NY: Cambridge University Press.

Lenihan, S. (2009). From A to Z: Getting started in listening and spoken language. Volta Voices, 16(6), 16-19.

Luckner, J.L. (2003). Job satisfaction: Perceptions of a national sample of teachers of students who are deaf and hard of hearing. American Annals of the Deaf, 148(1), 5-17.

Marge, D.K., \& Marge, M. (2005). Beyond newborn hearing screening: Meeting the educational and health care needs of infants and young children with hearing loss in America. (Report of the National Consensus Conference on Effective Educational and Health Care Interventions for Infants and Young Children with Hearing Loss). Syracuse, NY: SUNY Upstate Medical University, Department of Physical Medicine and Rehabilitation.

Moseley, M.J., Mahshie, J.J., Brandt, F.D., \& Fleming, L.F. (1994). A survey of professionals delivering speech-language services to children with hearing loss. Language, Speech, and Hearing Services in Schools, 25, 100-104.

Onchwari, G. (2006). Benefits of mentoring: Head start teacher perceptions of the effectiveness of a local implementation of a teacher professional development initiative. Retrieved December 7, 2009, from http://www.usca.edu/essays/ vol172006/onchwaritext.pdf.

Proctor, R., Niemeyer, J., \& Compton, M.V. (2005). Training needs of early intervention personnel working with infants and toddlers who are deaf and hard of hearing. The Volta Review, 105(2), 113-128.

Rice, G.B., \& Lenihan, S. (2005). Early intervention in auditory/oral deaf education: Parent and professional perspectives. The Volta Review, 105(1), 73-96.

Rowan, L.E., Sommers, R., \& Wray, D. (2005). Lingering evidence of SLP training deficiencies: Fluency disorders and hearing impairments revisited. Paper 
presented at the 2005 Ohio Speech-Language and Hearing Association Convention, Columbus, $\mathrm{OH}$.

Watson, M.M. \& Martin, K. (1999). Providing services to children with cochlear implants in the public schools: Results of a survey of speech-language pathologists. Journal of Educational Audiology, 7, 51-58.

Westchester CSI for Human Services Research. (1998). The balanced view: Professional development. Retrieved August 16, 2006, from http:/ /www.shar ingsuccess.org.

White, K. (2007). Early intervention for children with permanent hearing loss: Finishing the EHDI revolution. The Volta Review, 106(3), 237-258. 

The Volta Review, Volume 110(2), Summer 2010, 249-260

\section{State and National Accreditation of One University Program: A Case Study}

Maura Martindale, Ed.D., LSLS Cert. AVEd, and Carol A. Bartell, Ed.D.

Programs preparing teachers of the deaf and hard of hearing are typically housed in schools of education and are subject to university requirements as well as state and national accreditation requirements. This article describes how one program to prepare teachers of the deaf, founded in 2007, navigated those requirements and became part of a successful joint accreditation visit. This manuscript focuses particularly on the use of a web-based approach to documentation that was well received by both state and national reviewers.

\section{Introduction}

Accreditation of preservice programs for teachers of the deaf is essential to granting certification or credentials to those who teach children and youth with hearing loss in U.S. public schools. The accreditation processes verify that preservice preparation programs meet the standards of a given state and that they are of sufficient breadth, intensity, and effectiveness. Universities in the United States must meet the accreditation requirements of their state governing education agencies. State agencies or departments of education may also require accreditation from regional or national organizations such as the Council on the Education of the Deaf (CED) or Council for Exception Children (CEC). Each state has its own accreditation system, and this information can be found on each state's website. This article will review the state and national accreditation experience of one university in California.

In California, the California Commission on Teacher Credentialing (CCTC) is the state agency that accredits university programs, which can then award

Maura Martindale, Ed.D., LSLS Cert. AVEd, is an Assistant Professor and Director of the Deaf and Hard of Hearing Program at California Lutheran University. Carol A. Bartell, Ed.D., is the Dean of the School of Education at California Lutheran University. Correspondence concerning this article should be addressed to Dr. Martindale at mmartind@clunet.edu. 
credentials to individuals who may teach students who are deaf or hard of hearing. When schools or programs in California hire a teacher of children who are deaf or hard of hearing, they must choose an individual who holds a state teaching credential.

While CCTC accreditation is required for California programs that offer a professional teaching credential, national accreditation is still voluntary. We consider it a mark of distinction to be nationally accredited. California Lutheran University (CLU) is one of only six private universities in California accredited by the National Council for Accreditation of Teacher Education (NCATE). NCATE is a nonprofit, nongovernmental coalition of more than 30 national associations representing the education profession, and is officially recognized by the U.S. Department of Education as an accrediting body for institutions that prepare teachers and other professional personnel for work in preschool, elementary, and secondary schools. NCATE's purpose is as follows:

Accountability and improvement in teacher preparation are central to NCATE's mission. The NCATE accreditation process determines whether schools, colleges, departments of education, and other organizations preparing educators meet demanding standards for the preparation of teachers and other professional school personnel. Through this process, NCATE provides assurance to the public that the graduates of accredited institutions have acquired the knowledge, skills, and dispositions necessary to help all students learn (NCATE, 2006, p. 1).

California is currently forming a partnership with NCATE to engage in a joint review process. The most recent joint review culminated in a site visit to CLU February 28 - March 4, 2009. All standards were met, resulting in a positive decision for continued state (CCTC) and national (NCATE) accreditation.

At CLU, this process was a time for reflection as well as a time to gather useful feedback from candidates, graduates, employers, and educational partners. The peer review process that is a part of accreditation validated what we already do, but also offered direction for the future.

\section{Preparing for the Visit}

Both NCATE and the CCTC are standards-based accreditation processes. The institution responds to each standard and presents supporting evidence to demonstrate how each standard is met. Unit standards apply to the entire School of Education, and other standards are program-specific. The review process begins about 2 years in advance of the visit and includes an institutional selfstudy of all aspects of each program as well as an overall assessment of the unit. Because California is becoming an NCATE partner state, the national accrediting body accepted the state findings on each of the individual program reviews.

Each institution under review prepares documents addressing the six NCATE unit standards as well as program standards that address the rationale 
and design of the program, course content, and assessment of candidate success in meeting the standards. Both state and national accrediting bodies are increasingly data-driven, and data on candidate performance is essential.

Typically, a university will prepare documents addressing the unit and each individual program and send them to the reviewers approximately 1 month prior to the visit. Supporting evidence and artifacts (i.e., course syllabi, student work samples, faculty vitae, summary reports of data collected, etc.) become a part of an onsite "document room" that reviewers will examine during a 3-day visit.

In our case, we chose to present both our documents and our evidence electronically by creating an accreditation website. Thus, the primary exhibits and evidence are accessible electronically on the university-created website via links to specific evidence of standard attainment. The accreditation team was able to view this site 1 month prior to the campus visit. The overall layout of the accreditation web page is available in Table 1.

In addition to grounding the programs in the expected standards, each university defines for itself the guiding principles or the conceptual framework that underpins all educator preparation. For CLU, the conceptual framework is built on the expectation that the university develops reflective educators who STRIVE to:

Serve as mentors and models for moral and ethical leadership

Think critically to connect theory with practice

Respect all individuals

Include and respond to the needs of all learners

Value diversity

Empower individuals to participate in educational growth and change

Evidence included summary data from elements in each program to verify how CLU and its students achieve the STRIVE vision.

\section{NCATE Standards - Where Do Listening and Spoken Language Programs Fit?}

Preparation programs that focus on the teaching of listening and spoken language must participate with other members of the School of Education community to present all programs together to NCATE. While NCATE does not include specific standards for individual programs, such as deaf education programs, it was necessary to contribute deaf education program-specific goals, course syllabi and activities, assignments, assessments, student and graduate data, practicum, and fieldwork information to the documents to meet NCATE standards for the joint review. The 2009 reaccreditation process provided the first opportunity to include the CLU Deaf and Hard of Hearing program data.

For each of the six NCATE standards, the Deaf and Hard of Hearing program contributed relevant data, which was then integrated into the special 


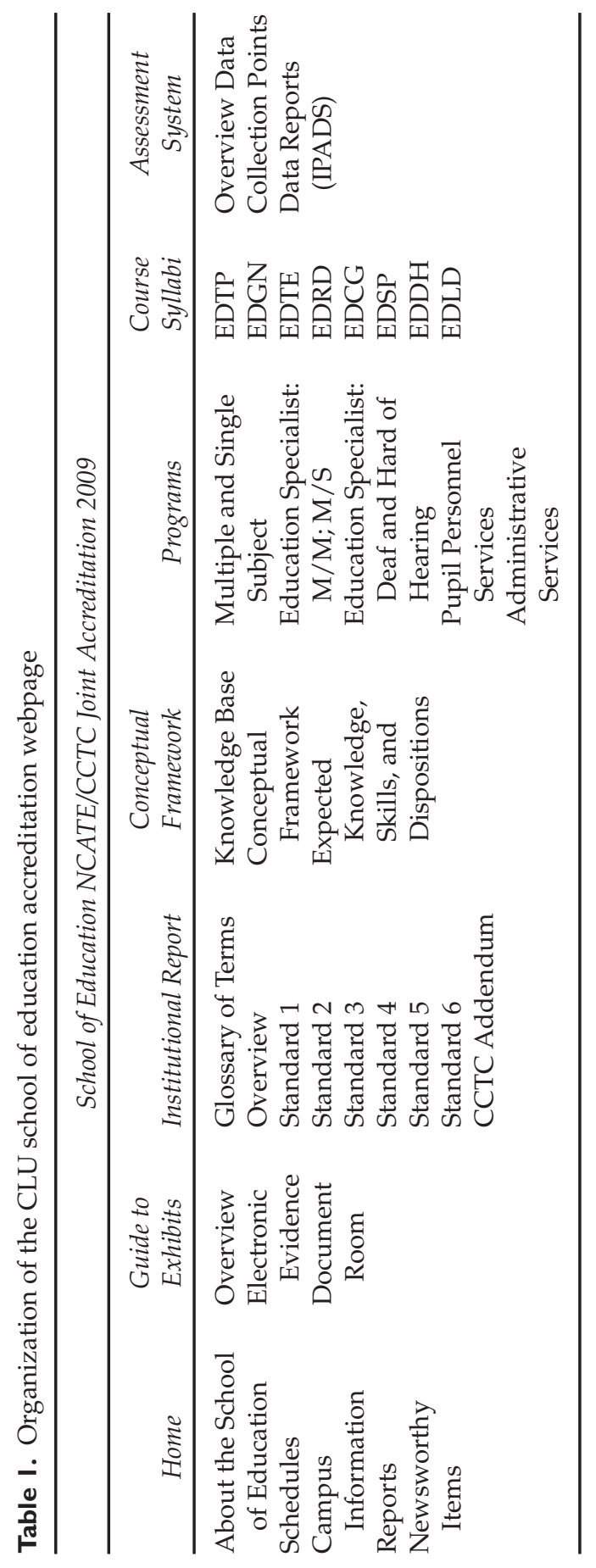


School of Education website constructed exclusively for the joint accreditation visit. Many of the new listening and spoken language-focused program's goals and activities supported and could be integrated into the NCATE standards. Data from the Deaf and Hard of Hearing program was included within the "Institutional Report" and could be found within each standard by clicking on the relevant links on the website. The Deaf and Hard of Hearing program outcomes also aligned fairly well, although not perfectly. The goals and activities must also show that we improve preschool through 12th grade student learning outcomes (Cibulka, 2009). We included achievement scores in language and reading scores from children in our field placements for the reviewers to examine. The standards for the Deaf and Hard of Hearing program are:

Standard 1: Candidate Knowledge, Skills, and Disposition

- Mean scores on candidate content knowledge from signature assignments and exams in audiology, speech acoustics, International Phonetic Alphabet, and language development.

- Data from field supervisors and professors on candidate dispositions while attending parent support groups, working under supervision, and teaching students from diverse cultural backgrounds.

- Verification of fieldwork hours in audiology (e.g., test assisting, observations).

- Mean scores on state-mandated exams for "highly qualified" requirement, skills in teaching reading, and basic skills.

- Evidence of faculty and field supervisors' accomplishments in teaching reading, English language arts, math, and all core curricula.

Standard 2: Assessment System and Unit Evaluation

- Individual Program Assessment Data Summaries (IPADS) with mean scores from program rubrics on major assignments known as "signature assignments."

- Data from external advisory committees and information on how the data was used for program improvement.

- Data-based decision making from discussions during faculty meetings.

- Admissions data, including scores on essays related to school-wide conceptual framework.

- Candidates' benchmarks at key transition points.

- Achievement scores in reading and language from field placements.

Standard 3: Field Experiences and Clinical Practicum

- Evaluations of candidates from clinical speech lab.

- Scores on children's language, speech, and listening growth during CLU's speech lab. 
- Lists of university partners and their contributions, including public and private programs and schools for students with hearing loss.

- Student teaching and internship evaluations in best practices and student achievement scores.

\section{Standard 4: Diversity}

- Demographic and socioeconomic status data from schools and programs in Southern California.

- Demographic data on candidates who are deaf and hard of hearing, including those with disabilities.

- Demographic data on Deaf and Hard of Hearing program faculty, including those with disabilities.

- Data on numbers of children and youth who are deaf and hard of hearing with additional challenges who are part of all practicum experiences.

- Data on the wide range of field experiences serving individuals birth to age 22 and participation in inclusive settings for all candidates.

Standard 5: Faculty Qualifications, Performance, and Development

- Curriculum vitaes (CVs) of faculty, highlighting those with doctorates and university teaching experience.

- Aggregated data from course evaluations.

- Faculty CVs highlighting ASHA (American Speech-Language-Hearing Association) certifications, LSLS Cert. AVEd and LSLS Cert. AVT (Listening and Spoken Language Specialist Certified Auditory-Verbal Educator and Auditory-Verbal Therapist), interpreter certifications, and state of California Credentials - Education Specialist Deaf and Hard of Hearing.

- Evidence of electronic communications between program director and faculty.

- Faculty participation in university-wide trainings, particularly in technology.

- Faculty attendance and presentations at state and national listening and spoken language conferences (e.g., AG Bell, ASHA, CEC, cochlear implant conferences).

- Faculty publication in peer-reviewed journals and books, and participation in scholarly research in listening, spoken language, literacy, inclusion, and audiology.

\section{Standard 6: Unit Governance}

- Program director's participation in all School of Education faculty meetings, committees, and events. 
- Program director's participation in university retreats, committees, meetings, and events.

- Program director's participation in departmental meetings, as recorded in the department chair's minutes.

- Minutes of Deaf and Hard of Hearing program meetings with participation of adjunct faculty members.

- Deaf and Hard of Hearing program syllabi, which reflect school-wide learning outcomes, a conceptual framework, and grading policies.

- Documents and candidate handbooks delineating school-wide policies and program-specific requirements.

\section{State Standards - Where Do Listening and Spoken Language Programs Fit?}

Unlike the NCATE standards, which address the CLU School of Education as a unit, CCTC has developed program-specific standards and all credential programs offered in the state are subject to approval by CCTC. Each credential program offered by the university must meet state standards that have been established by panels of experts in the field. Programs are initially approved through a document review of a proposed plan for meeting each standard. Biennial reports of outcome data are submitted, followed by an onsite review that occurs on a 7-year cycle. This review is conducted by a team of trained reviewers selected for their expertise and experience in the program areas under review.

The Accreditation Framework: Educator Preparation in California (2008) describes the purposes of state accreditation as follows:

Professional accreditation is the process of ascertaining and verifying the quality of each program that prepares individuals for state certification. In this context, state certification is the process of ascertaining and verifying the qualifications of each future member of the education profession. These two processes, professional accreditation and state certification, share a common overarching objective: ensuring that those who teach and provide education services in California's public school system have the knowledge, skills, and abilities necessary to be effective educators. Accreditation of educator preparation in California serves to achieve four purposes: to ensure accountability, to ensure high quality and effective programs, to ensure adherence to standards, and to support ongoing program improvement. (p. 1)

To assist the Deaf and Hard of Hearing program members and the CCTC accreditation reviewers, we developed and organized a number of tables and matrices so that both teams of reviewers would quickly be able to find key pieces of information regarding program goals, standards, courses, assignments, and candidate assessment of knowledge, skills, and disposition (Table 2). 


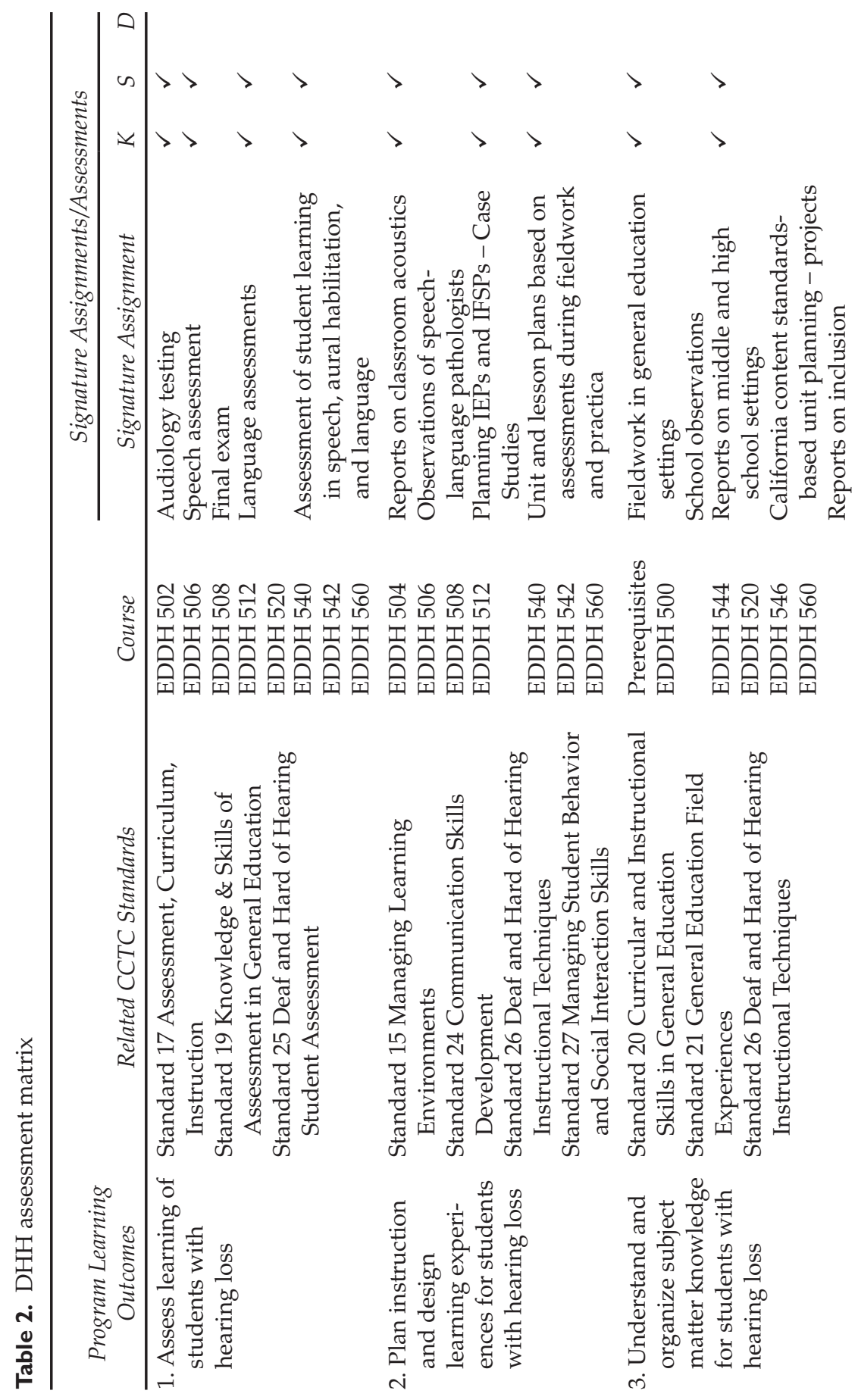




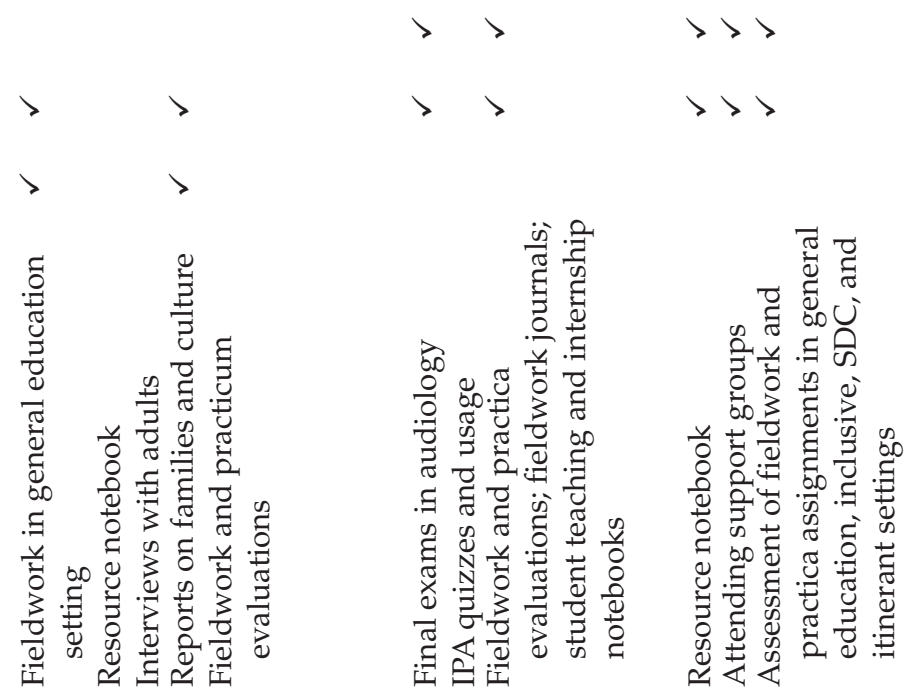

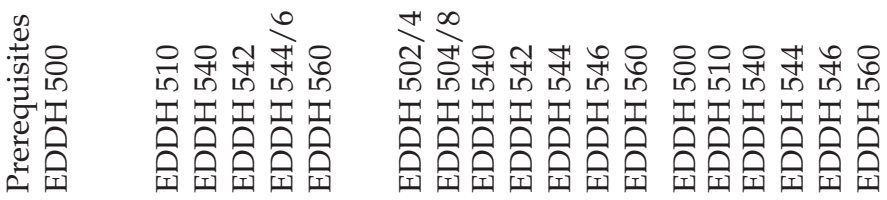

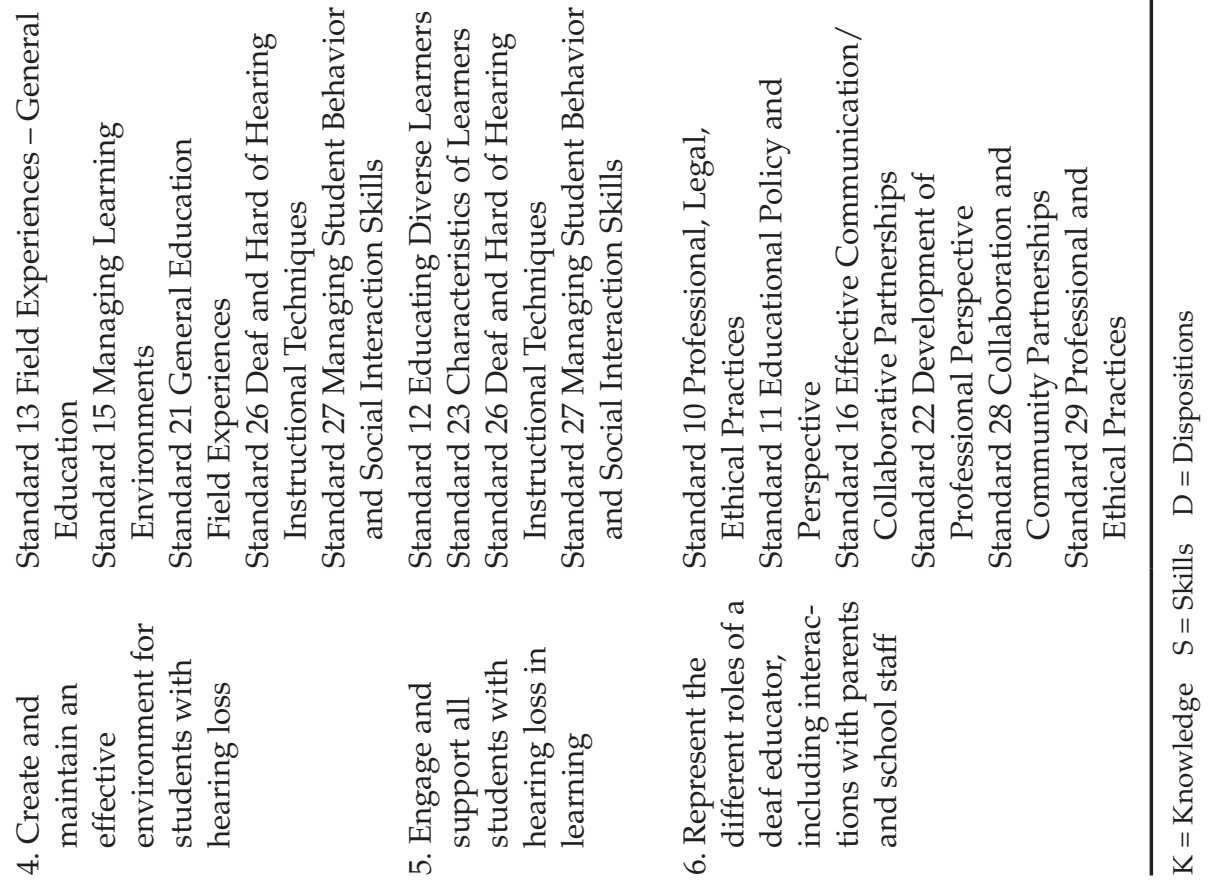




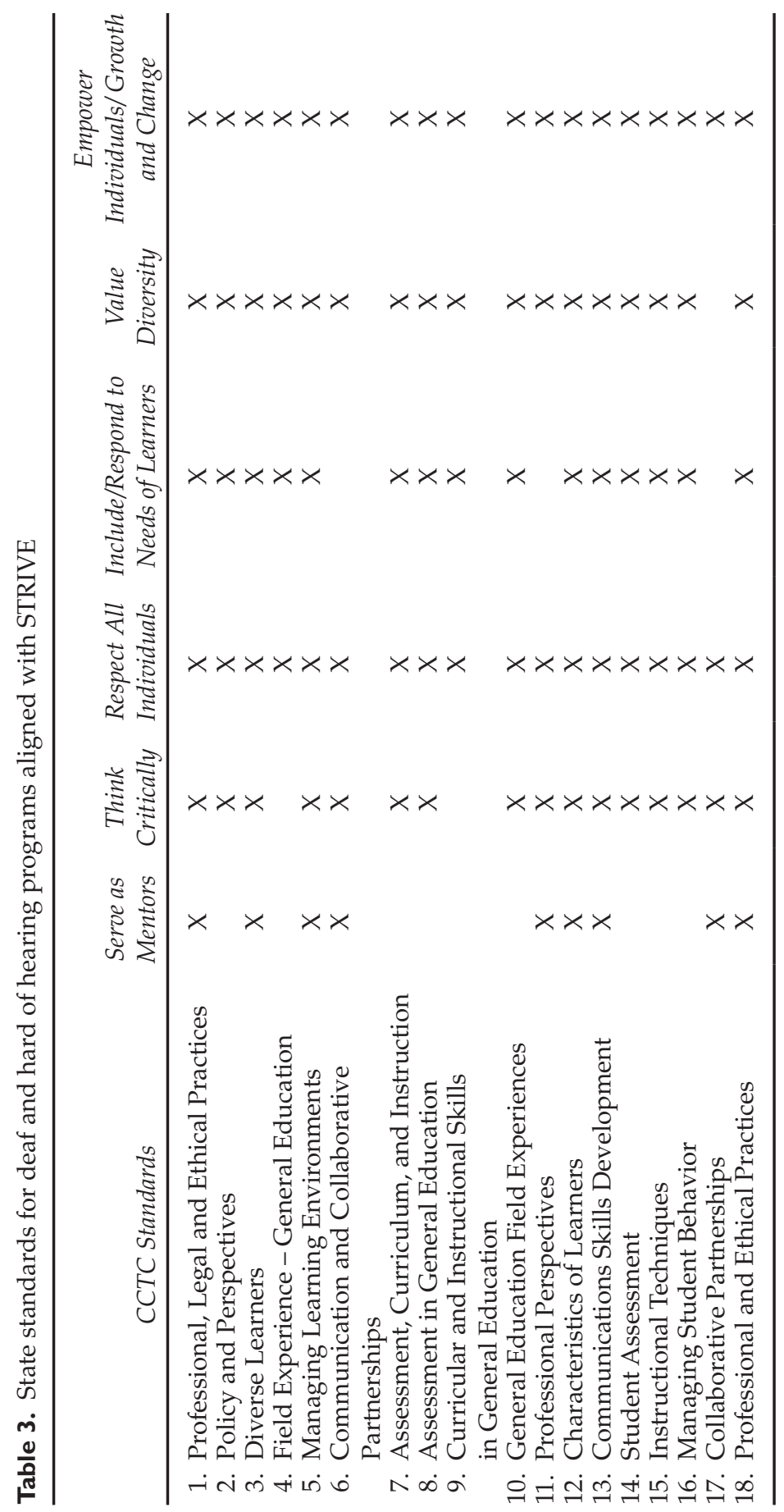


While responding to California state standards and the School of Education conceptual framework, we were able to make the case for evidence-based best practices, which emphasized listening and spoken language development, culturally sensitive pedagogy, and inclusion. An extensive reference list of research was provided to support programmatic decisions. Program activities, which included knowledge, skills, and dispositions in listening and spoken language, were reflected in our response to state standards and in course signature assignments. An example would be candidates' skills in assessing students' speech and spoken language within appropriate coursework and fieldwork.

Reviewers electronically accessed tables, which aligned our program goals and state standards with the CLU School of Education STRIVE framework (Table 3). Candidate outcomes on signature assignments for all CLU credential programs were placed in a shared drive, which was then placed on an IPAD, where the school-wide assessment system is housed.

\section{The Visit - Deaf and Hard of Hearing Program}

Prior to both NCATE and CCTC teams arriving on campus, the Deaf and Hard of Hearing program administrators, faculty, staff, students, supervisors, employers, and other stakeholders were scheduled to participate in on-campus interviews during a 3-day review. Reviewers met confidentially with groups and individuals who were able to verify that information on the website was accurate and to reflect on their experiences with the program. A review of the accreditation-specific website, different from electronic systems created by state departments of education, allowed the reviewers to be well versed on what areas to cover during the interviews.

Both NCATE and CCTC granted full accreditation to the CLU School of Education, with all standards met for initial and advanced teacher preparation. What were the lessons learned and our one area for improvement? It became evident that, although we collected a great deal of data, we need to refine how we analyze the data and explain how we act on that data. We recognize that this article is specific to California, and we encourage communication across states to share ideas on how we can all best prepare teachers for our field.

\section{References}

Alexander Graham Bell Academy for Listening and Spoken Language. (2007). Core competencies/content areas/test domains for LSLS. Retrieved December 1, 2009, from http:/ /nc.agbell.org/NetCommunity/document.doc?id=19.

California Commission on Teacher Credentialing. (2008). Accreditation framework: Educator preparation in California. Retrieved November 10, 2009, from http:/ / www.ctc.ca.gov/educator-prep/PDF/accreditation_framework. pdf. 
California Commission on Teacher Credentialing. (1996). Standards of quality and effectiveness for education specialist credentials (including university internship options) and clinical rehabilitative services credential programs. Retrieved November 9, 2009, from http:/ / www.ctc.ca.gov/educator-prep/standards / speced.pdf.

Cibulka, J.G. (2009). Improving relevance, evidence, and performance in teacher preparation. The Education Digest, 75(2), 44-49.

National Council for Accreditation of Teacher Education (2006). Professional standards for the accreditation of schools, colleges, and departments of education. Washington, DC: Author 
The Volta Review, Volume 110(2), Summer 2010, 261-270

\section{Program Profile}

\section{John Tracy Clinic/University of San Diego Graduate Program: A Distance Learning Model}

\section{Mary McGinnis, LSLS Cert. AVT \\ The History of Distance Learning at John Tracy Clinic}

The John Tracy Clinic (JTC) has a long history in the development and implementation of distance education courses for parents. It began with the founder of JTC, Louise Tracy, who personally corresponded with parents of young children with hearing loss around the globe to provide them hope, guidance, and encouragement. Mrs. Tracy's correspondence with parents was formalized into a course format in 1943 after Mrs. Tracy and her husband, Spencer Tracy, founded JTC in 1942 in honor of their son, John, who was diagnosed with a hearing loss at age 10 months.

In 1946, JTC began offering professional development courses to professionals, which were formalized as a master's degree and credential program in 1954 in partnership with the University of Southern California School of Education. Fifty years later, in 1996, JTC began offering a series of six online courses for professional development leading to a certificate in early childhood deaf education through the JTC Academy, an in-house professional development academy at JTC.

The initial series of professional development courses continued to grow as more and more courses were added to the program offered through the JTC Academy. Pushing the development of new courses was the extraordinary demand from educators around the country who were enrolling in the courses. These educators were spurred to update their knowledge and skills by families who were demanding a listening and spoken language outcome for their babies with hearing loss identified by newborn hearing screening programs and using digital hearing aids or cochlear implants.

In California, pressure to develop an alternate route for teacher credentialing arose from the severe shortage of teachers of the deaf in the state: a shortage that continues to this day. The California Commission on Teacher

Mary D. McGinnis, LSLS Cert. AVT, is the Director of the John Tracy Clinic/University of San Diego DHH Graduate Program in Los Angeles, CA. For more information about this program, please contact her at mmcginnis@jtc.org. 
Credentialing (CCTC) sought to create teacher internships to prepare professionals in the field who were already teaching children with hearing loss in public school classrooms, but who were doing so without appropriate teaching credentials.

To address the state's needs, and to address the urgent calls from teachers in other states who were confronted with children and families desiring listening and spoken language communication, JTC created its online master's program in deaf education in 2002. In the same year, JTC received federal funding to offer the Distance Learning master's degree program with JTC's university partner, the University of Southern California. The program was accredited by the Western Association of Schools and Colleges (WASC) in 2002.

Between 2003 and 2005, the JTC Teacher Education Department made major revisions to the program so that the Distance Learning Program paralleled the onsite program in content and quality, and met the standards of CCTC. During the same period, both programs were re-designed to meet the competencies established by Auditory-Verbal International for auditory-verbal therapists, and subsequently for the nine domains of listening and spoken language established by the AG Bell Academy for Listening and Spoken Language for Listening and Spoken Language Specialists (LSLS) (in both auditory-verbal therapy and auditory-verbal education) (see Monograph Appendix A). The redesigned onsite and distance learning master degree and credential programs were accredited by the CCTC and the National Council for Accreditation of Teacher Education (NCATE). Beginning in 2005, the programs were offered in conjunction with the University of San Diego (USD) School of Leadership and Education Sciences.

\section{Best Practices in Distance Learning}

Though most accredited universities now offer legitimate online courses and degree programs, the spectre of "diploma mills" still colors the public's perception of distance education. Accreditation is a critically important element in distance education, since the program is then required to meet established standards at regular review dates to maintain its accreditation.

NCATE (2009) provides standards for university programs, but does not specify any standards for distance learning programs other than that resources and delivery must be reliable, speedy, and confidential. WASC (2008) has created standards for distance learning programs that specify these programs must meet the same standards as traditional programs. Provisions must be in place to meet standards in the quality of the learning infrastructure, student support services, faculty and student support, program review protocols, the context of the distance learning program within the broader institution mission, and evaluation of student outcomes. In addition, WASC refers university distance learning programs to the guidelines for online programs created by the Council of Regional Accrediting Commissions (2008), of which WASC is a member. 
In addition to accreditation from NCATE, WASC, and CCTC, the JTC / USD Onsite and Distance Learning graduate programs are aligned with other professional standards. These include the Council on Education of the Deaf (CED, 2003), the Council on Exceptional Children (CEC, 2008), the Interstate New Teacher and Assessment Consortium (INTASC, 2001), the California Standards for the Teaching Profession (2009), and the California Teaching Performance Expectations (CCTC, 2008).

Though standards from accrediting bodies provide a broad picture of the key components necessary for high quality distance learning programs, theory in distance education has undergone a radical shift due to innovations in technology. Technology for online courses has progressed from first generation written materials to fifth generation e-learning where there are a variety of ways to gather information and communicate. Deciding which ways are best in terms of student outcomes, however, has been a question that continues to plague the development of distance learning courses and programs.

Recently, the U.S. Department of Education (2009) performed a metaanalysis of online learning research studies from 1996-2008. Research comparing students who took all or part of a course online to students who took the same course through face-to-face instruction revealed that online student outcomes were significantly better $(\mathrm{p}<.01$ level) on the 51 learning effects identified. Blended courses revealed even more of an advantage to learning outcomes than purely online learning.

The type of media employed did not affect outcomes, meaning distance learning is just as effective through e-mail or mobile phone as through a webbased platform. Variations in the type of learning experience showed equivocal effects on outcomes with more interactive and/or collaborative learning resulting in better outcomes than less interactive or purely expository learning. The more interaction the student had with the instructor, the better the outcome as long as the interaction with the instructor did not outweigh the student's collaboration with other students.

Comparison of various practices in online learning (e.g., whether learning involved asynchronous discussions, synchronous chats, quizzes, simulations, video streaming, chats, etc.) revealed no significant differences in student outcomes. However, one aspect did affect learning: student reflection improved student outcomes, regardless of whether the reflection resulted from prompts for reflection, self-explanation, or strategies in self-monitoring of study time or learning process. A second practice that improved student learning outcomes involved the students' integration of ideas from learning materials into a reflective writing assignment.

The U.S. Department of Education (2009) report concludes with a caution that the medium itself is not responsible for greater learning outcomes and that the positive results in online learning are not a mandate to change all face-to-face courses to online courses. Rather, advantageous outcomes are a result of the increased opportunities for learning, increased time on task, and 
increased reflection and integration of ideas demanded of students. The same is true of students who attend face-to-face courses that are enhanced by additional time on task through online assignments outside of class.

A conclusion that can be drawn from the research is that the medium is not the message; rather, the medium must be transparent and not interfere with, but enhance, student learning.

\section{JTC/USD Program Structure}

The Onsite Program is specifically designed for beginning educators who are under constant supervision throughout their program on the JTC campus. The Distance Learning Program, on the other hand, is designed for working teachers of the deaf. When seeking admission, candidates consistently report that their goals for the program include 1) obtaining a master's degree and/ or teaching credential, and 2) furthering their knowledge and skills in auditory-verbal principles and practice, especially as they relate to providing parent support and guidance, working with infants, and working with children who have cochlear implants. Detailed information on the JTC/USD Distance Learning Program can be found at www.jtc.org/professional-ed.

Two overriding principles drive the JTC/USD Distance Learning Program. First, students must see and experience auditory-verbal principles in their own programs and practices. Therefore, they must be teachers in their own practice rather than aides or professionals who provide ancillary services. Their program must actively strive to achieve listening and spoken language outcomes. Second, students must have a mentor experienced in the auditory-verbal approach. The mentor is a crucial link between the courses and the student's practice.

The JTC/USD program structure for both the Onsite and the Distance Learning Programs is based on the "professional development school model" encouraged by NCATE (NCATE, 2001), which creates a partnership between a university teacher education program and an educational environment that works with children in preschool to grade 12. The partnership prepares teachers within the context of the school, develops faculty, fosters inquiry between the university program and the school to improve practice, and enhances student achievement. The partner, in this case, is JTC.

Typically, half of the 16 classes in the 44-unit Distance Learning Program are taken onsite at the JTC campus in Los Angeles, CA. The remainder are taken online while the teacher is engaged in teaching at his or her job during the day. The exact division depends on how the calendar dates and the JTC services for families are laid out for any given year. The Distance Learning Program takes 2 years to complete, including two summer residencies of 30 days each at the JTC campus and online courses organized in a series of 10 -week sessions. Early experience with course scheduling revealed that one course at a time is the best method of delivery for a professional working full-time. Distance Learning Program students typically progress through their program as a 
cohort, as do the Onsite students, and begin the first summer residency with the Onsite cohort for summer classes.

The summer residencies are critical to the program, since they immerse the students in practicum experiences with the JTC educational programs for families and children, following the professional development school model. The graduate students participate in supervised teaching in the JTC Demonstration Home with families and their children birth to age 3, the JTC Demonstration Preschool, and the JTC Auditory-Verbal Therapy Lab. During lecture classes in both summer residencies, students observe the JTC International Summer Sessions in English and Spanish, and have parent guest lecturers share their experiences with different education systems from around the world, giving the students a global perspective.

The first summer residency is also critical for the Distance Learning Program mentors. JTC pays for the mentors' travel and housing while they are at JTC for a week in the Mentorship Program, where they discuss the principles of mentorship, observe JTC programs, and join in on classes with their students. Mentors get an opportunity to understand the program's philosophy first hand so they can assist their students in applying the program's philosophy and principles to the coursework and to the student's practice.

\section{Coursework}

The sequence and content of the coursework listed in the Table meet the requirements for the California teaching credential in deaf and hard of

Table. Sequence of coursework for the JTC/USD distance learning program

\begin{tabular}{ll}
\hline \multicolumn{1}{c}{ Year I } & \multicolumn{1}{c}{ Year II } \\
\hline Summer Residency I & Summer Residency II \\
- Multiple Perspectives (3) & • Early Childhood Curricula (3) \\
- Early Intervention Theory (3) & • Early Childhood Practicum (2) \\
- Early Intervention Practicum (3) & - Auditory-Verbal Practicum (3) \\
- Auditory-Verbal Foundations (2) & Fall Year II \\
Fall Year I & • Language in Elementary School (3) \\
- Audiology-Diagnostics (2) & \\
- Providing Support to Families (2) & Spring Year II \\
Spring Year I & - Research Design \& Methods (3) \\
- Audiology - Amplification (2) & Spring Year II \\
Spring Year I & $\bullet$ Elementary Curricula (3) \\
- Language in Early Childhood (3) & $\bullet$ Elementary Practicum (4) \\
Spring Year I &
\end{tabular}

- Auditory-Verbal Principles (3)

44 Units Total 
hearing as well as the degree requirements for the master's degree in special education/deaf and hard of hearing at USD. Course content also reflects the auditory-verbal philosophy, competencies, and practices in auditory-verbal therapy and education. California requires that the principles for teaching English to children for whom English is a second language and for teaching children with autism spectrum disorders are embedded in all coursework.

\section{Program Delivery}

Courses for the Distance Learning Program cohort during the two summer residencies are taught by JTC faculty who are current practitioners in the field. Online courses are designed and taught by renowned faculty. All faculty are provided an approved model syllabus, which includes the course timeframe, description, objectives, content, and standards to be met. Current and past faculty members are professionals who have shaped the field, including Carol Flexer, Christina Perigoe, and Richard and Laura Kretschmer. Faculty must meet USD criteria and be approved by USD. Online faculty can come from anywhere in the world since the Internet serves as their link to the students. The courseware platform is WebCT, which is provided and supported by USD. Students are trained to use WebCT and other online resources during their USD orientation in the first summer residency. Technical support is then available through USD and the JTC Multimedia Information Technology Department.

The courses provide blended learning and reflective activities, following best practice for distance education. Each course is created by the JTC Multimedia Information Technology Department with the same structure on the homepage for each course, which provides a lesson for each week of the course. Each lesson contains links to readings, slide presentations (which are often narrated), podcasts, videos, assignments, rubrics, and other online resources. Each course is a blend of synchronous (e.g., live chats) and asynchronous learning. Asynchronous, threaded discussions take place on the message board, organized by topic. Videos are mailed to each student if they are too long for WebCT. Besides completing extended assignments and projects, where students engage in reflective activities, students must engage in each week's discussion questions by posting to the threaded discussion board at least five times per week, allowing interaction among the students and instructor in each class.

USD provides other support to the Distance Learning Program by providing resources that are typically involved in graduate education, including admissions, registration, financial aid, online library resources, and technical support.

\section{Practicum Experiences}

Given the promise of distance learning technologies, it would appear to be a simple process to supervise practicum experiences from a distance while 
the student is teaching in his or her own classroom. However, there are several issues regarding practicum experiences that required reorganization of the program.

One issue is that the promise of distance learning technology has not truly been fulfilled yet since technologies generally remain expensive (particularly if they are high quality), are often difficult to use, and can be unreliable. To avoid problems, students' personal technology must be compatible with current systems, so students are required to have technology that is no more than 2 years old, including their computer, specific software, and memory; high-speed Internet; and a webcam. An example of the limits of technology is WebCT's current inability to upload lengthy videos. Other limits of technology are the poor signal quality of videoconferencing, where audio and video signals are often out of sync. Encryption is required for videoconferencing software as well as to maintain compliance with the confidentiality laws of the Health Insurance Portability and Accountability Act (HIPAA) of 1996 (which is an important consideration for ensuring family and student confidentiality online), and may add to the cost.

There are hopeful signs on the technology horizon, however. New cohorts are required to purchase their own video camera with a built-in USB so they can easily record themselves and upload the digital video to a passwordprotected site for their professors to view. This obviates the need for students to locate a video camera at their school sites and mail the video to JTC, where it was transferred to DVD and mailed back to the student and professor. The time and cost of tape transfer for each student was burdensome to say the least, but the delayed feedback on the assignments was worse.

\section{Funding}

Tuition for the graduate program is costly at about $\$ 1,200$ per unit for a total of around $\$ 53,000$. Fortunately, JTC has been awarded grant money from both public and private agencies so that each student is awarded the entire tuition amount. Furthermore, JTC raises private funds to pay for the housing and airfare for both the Distance Learning Program students and their mentors while they attend the two summer residencies at JTC. This is necessary as the financial burden of transportation and housing for the two 30-day residencies in the expensive economy of Los Angeles would have precluded most students from the program. Distance learning students have come from California, Florida, Indiana, Kansas, Missouri, New Jersey, North Carolina, Ohio, Oregon, Pennsylvania, Utah, and Washington. The students pay their own way when they fly back to California in May to attend commencement ceremonies at JTC and USD.

\section{Opportunities and Challenges of Distance Education}

One of the major draws of distance education for professionals is that they can remain in their teaching jobs while enhancing their knowledge, skills, and 
dispositions in the listening and spoken language approach. Directors of programs are also keen to maintain their teaching staff while the staff are furthering their education.

One of the most challenging aspects of the program is recruitment and arises from the reputation of distance learning programs as lax and unregulated degree mills. Potential students often call for information about the program with the assumption that it is somehow different from traditional university programs. The mistaken assumption is that prospective students will be able to "sign up" for the program, rather than meeting prerequisites and applying to the program; that they will be able to sit at home and take all of their courses online, rather than engaging in practicum experiences during a residency program; and that it doesn't matter if they're not employed as a teacher and/or doesn't matter if they do not have the support of their school program. Potential applicants are very disappointed when they realize that their particular situations may not make them eligible for the Distance Learning Program.

Far from a degree mill, the structure of the program is designed to be as rigorous as the Onsite Program that has been offered at JTC for over 50 years. The courses provided through the JTC Academy in 1996 were the first iteration of the Distance Learning Program. They provided valuable lessons in what was needed for transfer of learning from courses to application in the classroom. Early students in the JTC Academy certificate program included professionals teaching in sign language environments. There was no required support from supervisors or school programs. When students arrived at the JTC campus for a residency after successfully completing several courses, it was evident that students had had difficulty in applying principles from the courses to their teaching, since their school environments did not support listening and spoken language principles. Thus, students are now required to be working in an environment that provides a model for the acquisition of spoken language. Students must also have a mentor or supervisor who has a background in listening and spoken language, who will commit to the time necessary to discuss what the student is learning in online coursework, and who will assist the student in transferring and applying principles from the online courses to his or her teaching.

An unexpected impact of the Distance Learning Program has been its effect on the larger context in which the student resides. From the beginning of the program in 2005, when mentors were invited to the JTC campus to learn how to support their teachers through the program, mentors have sought to update their knowledge and skills in auditory-verbal principles and practice through their interaction with the Distance Learning Program and their students. Programs are now seeking to update their programs in auditory-verbal education by creating new collaborative partnerships with JTC through the JTC/ USD Distance Learning Program.

Universities considering adding a distance learning program to their onsite program should be aware that one of the major challenges is the doubling of the workload for staff and faculty. Once underway, there will be twice as many 
recruitment activities, applications, admissions, registrations, financial aid applications, and faculty and student concerns. Special effort is required to maintain the quality and quantity of distance relationships among students, faculty, and mentors. The following serves as an early set of considerations for those considering the feasibility of adding distance learning to an onsite program:

1. Ascertain the quality and reliability of the resources the university can provide to distance learners in all requisite areas (admissions, registration, financial aid, online library resources, courseware platform, and technical support).

2. Consider carefully what the program goals are, who the target student population will be, and how they will be screened to match the program goals and prerequisites.

3. Design the distance learning program to match existing onsite programs in content and quality, and to match the standards of relevant accrediting bodies.

4. Seek out training as an online faculty member to gain knowledge in designing, implementing, and evaluating online courses and programs.

5. Choose faculty who are willing to adhere to the philosophy of the program, to be trained in principles of online teaching, and to be trained and retrained in technologies as they change.

6. Keep technology as simple as possible, but protected and encrypted enough to maintain academic integrity and confidentiality for the protection of families and children.

7. Maintain program quality and student/faculty contact by including residencies where students can be observed and provided feedback in real time.

8. Maintain connection with the distance students through phone contact, as students report that the human voice is the element that is most missed.

\section{Distance Learning:The Hope for the Future}

Evolving technologies continue to further the possibilities for more relevant and interactive distance learning courses and programs that apply directly to professionals' daily practices. With a clear vision for what needs to be accomplished, and with careful planning, appropriate support, and re-evaluation and re-designing based on continuous feedback, distance learning programs can be a viable avenue for preparing professionals.

\section{References}

CCTC. (2008). California teaching performance assessment candidate handbook. Retrieved April 27, 2010, from http://www.ctc.ca.gov/educator-prep/ TPA-files/CandidateHandbook-AppendixA-TPEs.pdf. 
C-RAC. (2008). Guidelines for evaluation of distance education (online learning). Council of Regional Accrediting Commissions. Retrieved December 5, 2009, from http:/ / www.ctdlc.org/neasc/DistanceEdGuidelines982008_3.pdf.

CSTP. (2009). California standards for the teaching profession. Sacramento, CA: California Commission on Teacher Credentialing. Retrieved February 2, 2010, from http:/ / www.ctc.ca.gov/educator-prep/standards/CSTP-2009.pdf. Council for Exceptional Children (6 ${ }^{\text {th }}$ ed.). (2008). What Every Special Educator Must Know: Ethics, Standards, and Guidelines for Special Educators. Arlington, VA: Council for Exceptional Children.

Council on Education of the Deaf. (2003). Standards for programs preparing teachers of students who are deaf and hard of hearing. Retrieved February 2, 2010, from http:/ / www.deafed.net/activities/ManualOneRevised.htm.

Interstate New Teacher Assessment and Support Consortium. (2001, May). Model standards for licensing general and special education teachers of students with disabilities: A resource for state dialogue. Washington, DC: Council of Chief State School Officers. Retrieved February 2, 2010, from http:/ /www.ccsso. org/content/pdfs/SPEDStds.pdf.

NCATE. (2009). Unit standards. National Council for Accreditation of Teacher Education. Retrieved December 5, 2009, from http://www.ncate.org/ institutions/unitstandardsrubrics.asp? $\mathrm{ch}=4$.

NCATE. (2001). Standards for professional development schools. National Council for Accreditation of Teacher Education. Retrieved February 18, 2010, from http:/ / www.ncate.org/documents/pdsStandards.pdf.

U.S. Department of Education. (2009). Evaluation of evidence-based practices in online learning: A meta-analysis and review of online learning studies. Washington, DC: Office of Planning, Evaluation, and Policy Development. Retrieved December 5, 2009, from http:/ /www.blackboard.com/resources / proed/USDE_EvidenceBased_Review_OnlineLearning.pdf.

WASC. (2008). Handbook of accreditation. Western Association of Schools and Colleges. Retrieved February 2, 2010, from http://www.wascsenior.org/ findit/files/forms/Handbook_of_Accreditation_2008_with_hyperlinks.pdf. 
The Volta Review, Volume 110(2), Summer 2010, 271-278

\section{Program Profile}

\section{Washington University School of Medicine: A Distinctive Program in Deaf Education Studies at the Program in Audiology and Communication Sciences (PACS)}

Heather Hayes, Ph.D.

\section{Introduction}

Developments in universal newborn hearing screening programs and assistive hearing technology have had considerable effects on the speech, language, and educational success of children who are deaf or hard of hearing (Blamey et al., 2001; Connor, Craig, Raudenbush, Heavner, \& Zwolan, 2006; Geers, 2003; Geers, Brenner, \& Davidson, 2003; Geers, Nicholas, \& Sedey, 2003; Geers, Tobey, Moog, \& Brenner, 2008; Peng, Spencer, \& Tomblin, 2004). Several recent research studies of children who are deaf or hard of hearing and who use spoken language as their primary method of communication show that many are able to achieve vocabulary, language, and reading skills comparable to their peers who have typical hearing (Hayes, Geers, Treiman, \& Moog, 2009; Geers, 2003; Geers et al., 2008; Nicholas \& Geers, 2006). Thus, it is not surprising that many parents embrace the dramatic results that can be attained with a combination of early diagnosis, auditory access through hearing aids or cochlear implants, and the use of spoken language as a primary communication method. Demand is strong for teachers who have expertise in teaching listening and spoken language to children who are deaf or hard of hearing as well as knowledge of and experience with the latest trends in audiology and speech and hearing science. The unique environment of the deaf education graduate program at Washington University School of Medicine in St. Louis, MO, provides future teachers of the deaf with the cutting-edge, evidence-based skills they need to serve children with hearing loss. This profile describes the historical roots of the program, explains how its history has shaped it into a distinctive program, and proposes some future directions in teacher preparation.

Heather Hayes, Ph.D., is an Assistant Professor and Director of Deaf Education Studies at the Washington University School of Medicine Program in Audiology and Communication Sciences. For more information about this program, contact Dr. Hayes at hhayes@wustl.edu or visit the website http://pacs.wustl.edu. 


\section{History}

The current teacher training program is steeped in history dating from 1914 when Dr. Max Goldstein, a St. Louis physician, opened the Central Institute for the Deaf (CID). Dr. Goldstein's vision was to establish an institute that included an oral school for children who were deaf or hard of hearing and a college program to train teachers of the deaf. With enthusiastic support from the local community, Dr. Goldstein's vision became a reality and CID quickly established a world-wide reputation as a premier research facility, hearing clinic, teacher training program, and school for teaching children with hearing loss to talk.

In 1931, the Teacher Training College at CID became affiliated with nearby Washington University in St. Louis, becoming the first deaf education teacher training program to partner with a university. This affiliation continued until 2003 when the CID graduate program was formally transferred into the School of Medicine at Washington University. The newly-formed Program in Audiology and Communication Sciences (PACS) includes three degree programs: Doctor of Audiology (Au.D.), Master of Science in Deaf Education (M.S.D.E.), and Doctor of Philosophy in Speech and Hearing Sciences (Ph.D.). Although the deaf education graduate program is now housed within the School of Medicine, a close relationship is maintained with the CID school, whose long history and accomplishments helped shape the university program that exists today.

\section{Structure of the Program}

Graduates of the program are awarded an M.S.D.E. degree. They are eligible to be recommended for initial teacher certification in the state of Missouri (Deaf/Hearing Impaired, birth-grade 12) and provisional certification by the Council on Education of the Deaf at the early childhood and elementary levels. Upon graduation, graduates may be employed in a variety of educational settings across the country, helping to alleviate not only the local shortage of teachers of the deaf but also the nationwide shortage (U.S. Department of Education, 2009).

Students in the M.S.D.E. program proceed from broadly-based classroom instruction and observation to progressively more specialized coursework and practica. An important feature of this 2-year program is its design to accommodate students without background or experience in deaf education. The M.S.D.E. program at PACS is an all-inclusive curriculum, which promotes recruitment of individuals who are highly motivated to become teachers of the deaf but who have a nontraditional, non-education background. If accepted, students with any undergraduate degree can enter the program and graduate with the credentials necessary to become certified and start teaching. This characteristic broadens recruitment to prospective students from a variety of 
undergraduate degree programs and backgrounds. Interestingly, many graduate students who are parents of children with hearing loss greatly appreciate this approach because most have degrees in other fields and become interested in a career in deaf education only after having a child with hearing loss.

The M.S.D.E. curriculum requires 69 semester hours. Students who have taken courses that sufficiently cover content areas in Manual Communication and Normal Language Development may be eligible to waive these two required courses at the graduate level, reducing the credit hour obligation to 64 hours. The sequence of courses gives students a strong foundation early in the program in scientific, research, and evidence-based practice related to deaf education and audiology. At the same time, students take coursework covering methods for teaching children even in the first semester. The following sections describe the four foundations of the degree in more detail: coursework, practical experiences, an independent study project, and a comprehensive examination.

\section{Coursework}

The coursework provided by PACS is grounded in the scientific and research foundations of deaf education. Courses such as Anatomy and Physiology of Speech and Hearing, Basic Acoustic Measures, Acoustical Phonetics and Speech Perception, and Evaluating and Reporting Research in Speech and Hearing provide a background for understanding the value of evidence-based methods of instruction for children with hearing loss. All courses are taught by experienced doctoral-level research scientists with extensive peer-reviewed publications. Two of these courses, Anatomy and Physiology and Acoustical Phonetics, are attended by both deaf education and doctoral-level audiology students. By combining students in both degree programs for these two courses, the deaf education students gain valuable insight about hearing science from their audiology counterparts, and the audiology students gain valuable information from the deaf education students about working with young children, which can help them be better pediatric audiologists.

Nearly half of the coursework is classroom-based didactic instruction. Courses in the first year include Behavior Management, Normal Language Development, Language Instruction for Hearing-Impaired Children, Speech for HearingImpaired Children, and Educational Curriculum for Hearing-Impaired Children. Courses in the second year include a second semester of Educational Curriculum, Psychosocial and Educational Foundations of Deafness, Introduction to Manual Communication, Early Intervention, and Counseling Parents of HearingImpaired Children. These courses are taught by senior staff from the CID school and the Moog Center for Deaf Education. Instructors incorporate teaching demonstrations with children from their respective schools, host expert panels of parents and professionals, and create valuable hands-on assignments.

The curriculum also includes a comprehensive audiology class, Clinical Audiology, and a two-semester cochlear implant/aural rehabilitation for 
children course that includes a lecture and lab section, Amplification Systems and Aural Rehabilitation. These courses, taught by audiologists with extensive clinical experience, provide teachers the most current information available on rapidly advancing developments in audiology. The instructor for Clinical Audiology is a clinical audiologist who is also a doctoral candidate in Speech and Hearing Sciences and a trained teacher of the deaf. This instructor provides the M.S.D.E. students with audiological training tailored toward experiences they will likely encounter in school settings.

Several of the courses described above, particularly the audiology and speech science courses, provide content that surpasses the requirements for Missouri state teacher certification. M.S.D.E. alumni, as well as their employers, have reported that the lessons taught in these additional courses provided them with invaluable practical skills. In response to this feedback, those courses have been retained as part of the core curriculum.

\section{Practical Experiences}

The M.S.D.E. curriculum includes direct, individual field, and practical experiences throughout the 2-year course of study. Students enroll in a 1-week intensive field experience at the beginning of the second semester, and 15 credit hours of mentored student teaching during the second year. During the second year, students accumulate at least 448 hours of practicum experience through six classroom teaching experiences. Practicum sites are available both locally and nationally. These regional and national collaborations for practicum placements are one of the program's biggest strengths. During the fall and spring semesters of the second year, a number of local public and private schools serve as practicum sites for M.S.D.E. students. During January of the second year, students are strongly encouraged to travel outside the St. Louis area for a 1-month intensive student teaching experience.

\section{Independent Study}

In the second year, students complete an independent study project under the mentorship of a faculty member. Students are required to design and complete an independent research project that contributes original work to the field of deaf education. The results of the students' studies are presented at the annual PACS Research Forum, held each May. The Research Forum is a 2-day symposium featuring formal presentations by each student.

\section{Comprehensive Examinations}

Students are also required to successfully complete a comprehensive oral examination in May of their second year. The examination is intended to demonstrate the student's ability to integrate knowledge from coursework, observation, and practica. 


\section{A Distinctive Program}

The PACS deaf education program is unique for many reasons. First, the program is situated within the highly ranked School of Medicine at Washington University (ranked \#3, U.S. News and World Report, 2009). Thus, deaf education students have the opportunity to take courses and hear lectures from world-class scientists, researchers, anatomists, audiologists, psychologists, and cochlear implant surgeons. They also learn side-by-side in several classes with students enrolled in the Au.D. program (ranked \#5, U.S. News and World Report, 2009).

Second, faculty members have primary appointments as research scientists, audiologists, or educators of the deaf. In other words, the courses are taught by experts who are actively engaged in their field of expertise every day. Research scientists carry out studies and experiments in their labs on the latest topics in speech and hearing. Audiologists work with children in their clinics on a daily basis and partner regularly with cochlear implant surgeons in the Department of Otolaryngology. Teachers of the deaf are still primarily in the classroom working with children and families, employing the most up-to-date and effective teaching practices. Teachers of the deaf from the CID school and the Moog Center for Deaf Education, who serve as instructors in our deaf education program, are widely recognized as national leaders in the field with an average of 25 years experience as teachers of the deaf or administrators. In short, faculty bring their daily experiences and knowledge to their courses, ensuring that deaf education students receive the latest information about what is happening in the lab, in the clinic, and in the classroom.

A third distinctive characteristic of the program is that it is housed within the same building as the CID school. Students take courses just a few rooms away from the classrooms of children who are deaf. Many M.S.D.E. students choose to participate in lunch duty, recess supervision, or after-school duty at the CID school, which provides them with valuable informal learning experiences and a chance to put their newly-learned knowledge about language instruction, hearing devices, and behavior management to work.

\section{Looking Ahead}

The field of deaf education is a rapidly evolving one, which means teacher training programs must be nimble in responding to the needs of children who are deaf or hard of hearing and their parents. By surveying program graduates in the field, we have learned what types of information they wish they had received during their training. Some graduates have reported that it is important to address the disconnect that often occurs between the cultural and linguistic backgrounds of teachers of the deaf and those of their students and families (Simms, Rusher, Andrews, \& Coryell, 2008). Children who are deaf or hard of hearing and who come from families with bilingual backgrounds are 
a growing population (Mitchell \& Karchmer, 2006). Thus, teacher preparation programs must adequately address the topic of working with culturally and linguistically diverse children and families (Rhoades, Price, \& Perigoe, 2004).

Another aspect of deaf education that warrants closer attention from teacher preparation programs is the need to serve children for whom hearing loss is not their only disability, as this is a growing population (Guardino, 2008). Teacher preparation programs that are housed within medical school environments are uniquely poised to explore issues of educating children with multiple disabilities as physical therapists, otolaryngologists, audiologists, medical specialists, and others are all available on one campus.

Also, there is an ever-present need to aggressively recruit qualified individuals to the field of deaf education. Shortages of certified teachers of the deaf exist throughout the United States (U.S. Department of Education, 2009), particularly for teachers who have experience working with the specific needs of children with cochlear implants who use spoken language as their primary mode of communication. It is imperative that teacher preparation programs recruit not only undergraduates with communication sciences or education backgrounds, but also those from other disciplines. PACS offers an undergraduate course at Washington University that has introduced many students from a variety of backgrounds to the field of speech and hearing science, several of whom have since become M.S.D.E. graduates. To further illustrate the benefit of recruiting from a variety of backgrounds, current deaf education students not only have communication science and deaf education backgrounds, but also psychology, German, business, engineering, marine sciences, marketing, and history backgrounds. PACS' allinclusive curriculum, which provides full eligibility for teacher certification at the end of the program, allows students like these to enter the field of deaf education.

Finally, an often overlooked shortage exists within the field: The future of deaf education depends not only on having outstanding teachers in the classroom, but also on having outstanding leadership outside of the classroom. Teacher preparation programs have a responsibility to identify future leaders in their programs and encourage them to continue their education and experience. Doctoral programs, such as the Ph.D. program offered by PACS, can help train future leaders in deaf education by offering intensive experiences in conducting research, teaching college courses, and gaining leadership skills. Preparing future school administrators, university faculty, and researchers is important to the survival of the field of deaf education.

\section{Conclusion}

The PACS mission - to train teachers how to teach children who are deaf or hard of hearing to talk - has not changed since 1931 when the CID teacher 
training program was founded. However, we are looking to the future: All teacher training programs, including PACS, must strive to stay ahead of the curve so that graduates have the knowledge and skills to be able to teach children who have benefitted from early identification and who use the latest hearing technology.

\section{References}

Blamey, P.J., Sarant, J.Z., Paatsch, L.E., Barry, J.G., Bow, C.P., Wales, R.J., et al. (2001). Relationships among speech perception, production, language, hearing loss, and age in children with impaired hearing. Journal of Speech, Language, and Hearing Research, 44, 264-285.

Connor, C.M., Craig, H.K., Raudenbush, S.W., Heavner, K., \& Zwolan, T.A. (2006). The age at which young deaf children receive cochlear implants and their vocabulary and speech-production growth: Is there an added value for early implantation? Ear and Hearing, 27, 628-644.

Geers, A., Brenner, C., \& Davidson, L. (2003). Factors associated with development of speech perception skills in children implanted by age five. Ear and Hearing, 24, 24S-35S.

Geers, A.E. (2003). Predictors of reading skill development in children with early cochlear implantation. Ear and Hearing, 24, 59-68.

Geers, A.E., Nicholas, J.G., \& Sedey, A.L. (2003). Language skills of children with early cochlear implantation. Ear and Hearing, 24, 46-58.

Geers, A.E., Tobey, E., Moog, J.S., \& Brenner, C. (2008). Long-term outcomes of cochlear implantation in the preschool years: From elementary grades to high school. International Journal of Audiology, 47, S21-S30.

Guardino, C.A. (2008). Identification and placements for deaf students with multiple disabilities: Choosing the path less followed. American Annals of the Deaf, 153, 55-64.

Hayes, H., Geers, A.E., Treiman, R., \& Moog, J.S. (2009). Receptive vocabulary development in deaf children with cochlear implants: Achievement in an intensive auditory-oral educational setting. Ear and Hearing, 30, 128-135.

Mitchell, R.E. \& Karchmer, M.A. (2006). Demographics of deaf education: More students in more places. American Annals of the Deaf, 151, 95-104.

Nicholas, J.G., \& Geers, A.E. (2006). Effects of early auditory experience on the spoken language of deaf children at 3 years of age. Ear and Hearing, 27, 286-298.

Peng, S.C., Spencer, L.J., \& Tomblin, J.B. (2004). Speech intelligibility of pediatric cochlear implant recipients with 7 years of device experience. Journal of Speech, Language, and Hearing Research, 47, 1227-1236.

Rhoades, E.A., Price, F., \& Perigoe, C.B. (2004). The changing American family and ethnically diverse children with hearing loss and multiple needs. The Volta Review, 104(4), 285-305. 
Simms, L., Rusher, M., Andrews, J.F., \& Coryell, J. (2008). Apartheid in deaf education: Examining workforce diversity. American Annals of the Deaf, 153, 384-395.

U.S. Department of Education. (2009). Teacher shortage areas nationwide listing. Retrieved March 12, 2010, from http://www.ed.gov/about/offices/list/ ope $/ \mathrm{pol} /$ tsa.doc.

U.S. News and World Report (2009). Best medical schools. Retrieved March 12, 2010, from http://grad-schools.usnews.rankingsandreviews.com/bestgraduate-schools/top-medical-schools/research-rankings. 
The Volta Review, Volume 110(2), Summer 2010, 279-291

\title{
Program Profile
}

\section{The University of Hartford and CREC Soundbridge: A New Master's of Education in Aural Habilitation and Education of Hearing Impaired Children}

\author{
By Marietta M. Paterson, Ed.D., and Elizabeth Cole, Ed.D.
}

\section{Introduction}

"Become a Specialist in Teaching Hearing-Impaired Children [sic] to Listen and Talk Using Advanced Hearing Technology, Now and Into the Future." This quote was included in an announcement emailed to university and college education programs across the northeast in the summer of 2009 to increase the awareness of the University of Hartford's new Master of Education degree program in Aural Habilitation and Education of Hearing-Impaired Children. The Aural Habilitation and Education graduate program was conceptualized as a model partnership between Capitol Region Education Council (CREC) Soundbridge, the largest public provider of services to children who are deaf or hard of hearing and their families in Connecticut (www.crec.org/ soundbridge), and the University of Hartford, "a private university with a public purpose" (www.hartford.edu/enhp). The program was specifically created to address the nationally recognized need to increase the quality and quantity of professionals in auditory-based deaf education who are prepared to work with advanced hearing technology to promote the listening and spoken language development of children who are deaf or hard of hearing (Billingsly \& McCluskey, 2004; Harrington \& Powers, 2004; McLuskey, Tyler, \& Saunders Flippin, 2004; U.S. Department of Education, 2004). As a result of 9 years of sustained effort, planning, and approvals, the program was launched in July 2007.

Marietta M. Paterson, Ed.D., is the Program Coordinator of the Aural Habilitation and Education of Hearing Impaired Children Program at the University of Hartford. Elizabeth Cole, Ed.D., is the Director of CREC-Soundbridge in Hartford, CT. For more information about this program, contact Dr. Paterson at paterson@hartford.edu. 


\title{
The University of Hartford
}

\author{
Program History
}

The history of the Aural Habilitation and Education program encompasses how two leading professionals from a cutting-edge public program for individuals with hearing loss brought a unique vision of a community-university partnership and succeeded in creating the elements of a new graduate training program. A dean, a chairperson, and a provost at the University of Hartford recognized the important social mission such a unique collaboration could address. As the concept evolved, the generosity and vision of a private funder allowed the concept to evolve into a state-approved course of study. A third leading professional in deaf education/aural habilitation joined the partnership to oversee the operations of the new program as the founding teaching professor and coordinator.

\section{Program Development}

The vision for creating a partnership between a nationally recognized public program and a Connecticut university began about 20 years ago with Jennifer Hulme, founding director of CREC Soundbridge. Hulme knew that the CREC Soundbridge program was ideally positioned to provide an embedded training site for graduate students. The strongest university programs preparing teachers of the deaf have close ties to schools and programs serving children with hearing loss. As the largest mainstream program in Connecticut and one of the largest in the United States, CREC Soundbridge provides a full range of services from birth through high school, including auditory-verbal therapy, integrated classrooms, mainstreaming, audiology, and related audiological and instructional services for children with hearing loss who are learning spoken language, which translate into a variety of practicum placements.

The original vision of an embedded graduate training program became a reality when Dr. Elizabeth Cole joined the Soundbridge team as director of the Early Childhood Center and Audiology Program. Cole brought with her an extensive background in the use of advanced hearing technology and auditory-based spoken language development. Her textbook, Children with Hearing Loss: Developing Listening and Talking Birth to Six (Cole \& Flexer, 2007), is widely used in training programs internationally. For 16 years, she was a professor and clinical coordinator in the 2-year, full-time Master of Science in AuditoryOral (Re)Habilitation and Education of the Hearing-Impaired program at McGill University in Montreal, Canada.

In 1998, with the support of Dr. Bruce Douglas, the head of all CREC programs in Connecticut, Cole and Hulme approached the University of Hartford with the concept for a new graduate program. Dr. Dorothy Zeiser, Dean of the College of Education, Nursing and Health Professions, and Dr. Regina Miller, 
Chair of the Department of Education and Health Professions, were intrigued by the concept and that external funding had already been identified. Both professors understood that CREC Soundbridge has a strong social mission and fulfills a need for children who are deaf or hard of hearing and their families in Connecticut, and that it addresses the intent of the Individuals with Disabilities Education Act (IDEA). Miller's interest and understanding was also based on personal experience with children with hearing loss.

In order to advance the discussions with the university, the team wrote an initial working proposal that included the rationale for creating a training program that would produce new professionals qualified to work with children with hearing loss who were acquiring spoken language as well as the core content of the curriculum and descriptions of the necessary teaching and clinical expertise. The program was modeled after the cutting edge master's program created by Daniel Ling and Agnes Ling Phillips at McGill University. Cole had a strong collaborative relationship with Daniel Ling and succeeded him as director of the program when he left McGill in 1984. The Lings' intent had been to take trained teachers and give them the knowledge base of a speechlanguage pathologist and audiologist (thus combining all three fields) so that graduates would have a scientific basis and understanding of the development and assessment of hearing, listening, speech, and spoken language. In addition, the program emphasized the knowledge and skills needed to work with children who were deaf or hard of hearing and learning spoken language through listening as well as their families in what is now called auditory-verbal practice.

Cole developed the curriculum with the assistance of experts in the field, and the final curriculum flow is roughly based on the McGill program. Program content was adapted and updated so that core knowledge and skills could be addressed in an intensive 3-semester cycle. A private foundation supported both the development of the program concept and the curriculum development. The individual course outlines were provided by Daniel Ling, Richard and Laura Kretschmer, and Richard Seewald.

Several years of meetings and work between the key players from CREC Soundbridge and the University of Hartford ensued until during the 2003-2004 academic year when the final proposal and documents were ready for funders and for university and state approvals. These documents included rationale and needs statements, course outlines, a list of potential instructors, a business plan, a budget, and a grant proposal seeking operational funding. Miller, with support from Frederick Schweitzer, the university's associate dean, managed the documentation for the university approval and worked with Zeiser to guide the new program through the internal and state approval process. In 2006, the Aural Habilitation and Education program was approved by the University of Hartford. In that same year, the Connecticut State Department of Education and the state Board of Governors for Higher Education granted approval and licensure for the program to start accepting students. 
In 2006, the program team initiated a search for a full-time teaching professor who would also be the program coordinator, and Dr. Marietta Paterson accepted the challenge of making the vision and the curriculum a reality. Paterson has an extensive background in speech, listening, and language development with children who are deaf or hard of hearing and has worked as an aural habilitationist/teacher of the deaf, university professor, program chair, principal of St. Joseph Institute for the Deaf, and director of the Vancouver Oral Centre. She has taught in graduate programs in Canada, Australia, and the United States. Prior to coming to the University of Hartford, Paterson was chair of the Department of Deaf Education and Hearing Science at the University of Texas Health Science Center at San Antonio, working in partnership with Sunshine Cottage School for Deaf Children. Paterson's arrival completed a circle of connections as she had received her Master of Science in Auditory-Oral (Re)Habilitation and Education of the Hearing Impaired with Daniel Ling and Agnes Ling Phillips, and later worked collaboratively with Cole and Ling. An outstanding team of adjunct faculty primarily from the faculty at CREC Soundbridge was identified and the first summer semester of teaching began in July 2007.

\section{Graduate Students}

As of May 2010, the program has three cohorts of graduates. Advertising and recruitment for the program have taken more time than anticipated these first 3 years, raising the important question: who seeks training as a specialist in listening and spoken language development for children who are deaf and hard of hearing? Inquiries about the program have come from teachers, speech-language pathologists, parents of children who are deaf, counselors, psychologists, and undergraduates studying communication disorders in Connecticut, the region, and other countries. The state of Connecticut requires that graduate programs in education only accept certified teachers. Numerous undergraduates in communication disorders have expressed a strong interest in the program; however, they do not have the prerequisite teacher certification to be accepted into the program.

To date, program candidates have included parents of children with hearing loss who are seeking retraining, special educators, an experienced specialist in autism therapy, early childhood teachers, elementary teachers, an elementary-trained teacher who has a hearing loss, elementary/special education teachers, a high-school prepared math teacher, and a music teacher. About half of the candidates have had a prior personal connection or interest in deafness, while others found the technological and speech and language focus of the curricula intriguing. A number of candidates who were newly or relatively newly qualified teachers have expressed a strong desire to specialize and focus on individual teaching skills, making them ideal candidates for this program. 
Five of the 11 graduates are working at CREC Soundbridge, another two are teaching in Massachusetts, and the others are teaching in other parts of Connecticut. All but two graduates are working full time with students who are deaf or hard of hearing. These two graduates have returned to their special education positions where their new knowledge and expertise is recognized and children who are deaf or hard of hearing are being referred to them. By the end of the first 3 years of operation, the program will have trained new professionals in listening and spoken language for Connecticut, Massachusetts, New Jersey, and New York.

\section{CREC Soundbridge: A Unique Partner}

The partnership brings together university faculty with audiologists, practicing teachers, and administrators to create a highly specialized program of professional preparation in the education of children who are deaf or hard of hearing.

CREC Soundbridge is a nationally recognized public school-funded program in Connecticut that serves nearly 650 children who have hearing loss and who are learning spoken language through listening as well as their families. The largest provider in Connecticut and one of the largest programs in the country, Soundbridge has a primary mission of supporting children who have hearing loss in their home schools. Ninety percent of the students supported by CREC Soundbridge audiological and instructional services attend mainstream classes in their home school settings. A team of 10 deaf education teachers, seven audiologists, and three audiological technicians provides support to children across the state in preschool through grade 12 mainstream education classrooms.

At the heart of this auditory-based program is an outstanding team of highly skilled pediatric educational audiologists. The seven full-time, clinical pediatric audiologists are supported by four audiology assistants. Services include full educational and diagnostic audiology, cochlear implant mapping, hearing aid prescription and fitting (birth to age 3 only), workshops and inservice support to the districts, and monthly visits to each student and school to ensure that the technology and school personnel are working to provide the student with appropriate auditory access.

Instructional support is provided to nearly 100 students in districts across the state by Educational Consultants in Spoken Language and Listening (ECSLL) who are teachers of the deaf that travel to serve students in their home districts. Direct services focus on listening, spoken language development, reading and writing (literacy), and self-advocacy. ECSLL also regularly consult with school teachers and other personnel to ensure that teachers who have students who are deaf or hard of hearing in their classes are fully informed and skilled at providing the classroom modifications needed to address those students' unique needs. 
CREC Soundbridge is one of the three specialty programs for children with hearing loss within the Connecticut birth to three program. Listening and spoken language specialists are seeing all the babies and families in the early intervention program. Families come to CREC Soundbridge for audiological and parent support meetings. After age 3, families have the option of continuing auditory-verbal therapy or enrolling their child in the Soundbridge Early Learning Center, an integrated, onsite mainstream preschool program accredited by the National Association for the Education of Young Children (NAEYC) with approximately two children with typical hearing for every child with hearing loss.

Of the children from kindergarten through grade 12 who are served by CREC Soundbridge, approximately $10 \%$ of the students require all-day intensive support from a teacher of the deaf. These students attend the Soundbridge Academy, which is located in an elementary, middle, and high school in Wethersfield, CT. These students are mainstreamed to the degree that they are able to benefit from it. Some students are mainstreamed only for art, music, physical education, lunch, and recess whereas others are also mainstreamed for math, science, and social studies, depending upon their abilities. For mainstream subjects, students are offered note takers or C-print as well as any necessary pre- and post teaching.

Students are welcome to observe the professionals or participate in all the sites at CREC Soundbridge to provide access to all aspects of treatment and education of children with hearing loss and their families.

\section{Program Structure}

\section{Coursework}

The Aural Habilitation and Education program is a full-time, 44-credit course of study that consists of 1 summer semester and a fall and spring semester. The candidates move through the program in a cohort model. In summer, the candidates take four content courses in an intensive, 6-week session taught at the University of Hartford. In the fall and spring semesters, all courses are taught off campus at CREC Soundbridge. Approval for this offcampus, embedded teaching model was granted by the provost in recognition of the benefit of in situ training. During the fall semester, the candidates take five content courses and participate in 2 full days of practicum and a weekly practicum seminar. During the spring semester, candidates take five content courses in an intensive 8-week period followed by 10 weeks of fulltime student teaching. Upon successful completion of their student teaching and coursework, graduates can apply to the state of Connecticut for a crossendorsement in Hearing Impairment, Pre-K-12.

The flow of knowledge and skills is cumulative across the 3 semesters and moves from factual, conceptual understandings to integrated case study and 
problem-solving course work. The program was conceptualized to offer a mini-course in speech, listening, and spoken language science. This groundwork lays the foundation for the auditory science and technology, spoken language, and speech course strands.

Through field study, practica, and student teaching, candidates have immediate and enriching opportunities to apply material from class to work with children in real teaching, learning, and diagnostic settings. Candidates thus bring back authentic experiential data to the University classroom. Ten of the 14 courses in this program require a field study component.

The courses were originally conceptualized in three major strands: Perspectives on Education of the Deaf; Speech and Hearing Science and Technology; and Speech, Language, and Communication. The Table lists the courses by semester and includes credit hours and field study hours; the titles of the courses indicate the strand.

Table. Course structure of University of Hartford and CREC Soundbridge collaborative graduate program

Summer Semester (11 credits)

EDAH 550, Perspectives on the Education of Deaf and Hard of Hearing Children

[ 3 credits] and Field Study [15 hours]

EDAH 600, Anatomy and Physiology of Hearing and Speech Mechanisms [3 credits]

EDAH 610, Psychoacoustics and the Development of Auditory Perception and

Processing [ 3 credits] and Field Study [10 hours]

EDAH 620, Articulatory Phonetics [2 credits]

\section{Fall Semester (14 credits)}

EDAH 630, Introduction to Clinical Audiology [3 credits] and Field Study [10 hours]

EDAH 640, Teaching Speech I [2 credits] and Field Study [6 hours]

EDAH 651, Acquisition and Analysis of Spoken Language [3 credits] and Field Study

[6 hours]

EDAH 653, Spoken-Language Intervention II [2 credits] and Field Study [6 hours]

EDAH 621, Acoustic Phonetics [2 credits]

EDAH 680, Practicum and Seminar [2 credits]

\section{Spring Semester (19 credits)}

EDAH 631, Hearing Instruments [3 credits] and Field Study [10 hours]

EDAH 641, Teaching Speech II [2 credits] and Field Study [6 hours]

EDAH 653, Spoken Language Intervention II [2 credits] and Field Study [6 hours]

EDAH 660, Literacy Development in Hearing-Impaired Children [3 credits] and

Field Study [10 hours]

EDAH 670, Educational Methodology for the Mainstream [3 credits] and Field Study

[10 hours]

EDAH 681, 10-Week, Full-Time Teaching Student Teaching [6 credits] 
The Aural Habilitation and Education program is housed in the Hartford University College of Education, Nursing and Health Profession. The College seeks to create teachers who are reflective practitioners and nine areas of reflectivity form the College's Conceptual Framework for teaching and learning. During the year, candidates discuss and write reflective papers based on the following overarching domains: Subject Matter, Learners as Whole Persons, Diversity, Self-Understanding, Pedagogy- Intervention-Leadership, Human Relations, Social and Political Contexts, and Ethics and Outcomes. As a culminating activity, candidates prepare portfolios of their class work as well as student work from their student teaching experience. The portfolio rubric is organized across the domains of the conceptual framework. In addition, the candidates take an oral comprehensive exam or equivalent activity.

The candidates develop knowledge and applied understanding in the use of advanced hearing technology as well as approaches and techniques for individual and small group speech, listening, and spoken language development. The graduates can demonstrate that they have hands-on skills in the daily troubleshooting of a child's cochlear implant, hearing aids, or FM system and that they know how to talk with an audiologist about optimizing auditory access for a child.

\section{Practicum}

During the fall semester, in addition to five content courses, each candidate participates in 12 hours per week of guided practicum in the CREC Soundbridge program, earning two credits. After the first year of experience with the program and feedback from all parties, the timing of the practicum was changed to 2 full-day experiences per week instead of five mornings. This schedule permits the candidates to be on the road all day, which is necessary when they are observing and participating in either the birth to three early intervention program or with the ECSLL. One goal of the practicum experience is to allow candidates to experience the full extent of the audiological, early intervention services, and educational settings available at CREC Soundbridge. Now, candidates have two 5 -week practicum experiences and one rotational practicum where the candidates gain an overview of all the educational services CREC Soundbridge offers. The two 5-week practicum experiences occur in two of the following programs: Birth to Three/AuditoryVerbal Therapy Program, Preschool, Kindergarten to Grade 6, Middle School, High School, or Consulting Teacher Service.

A weekly practicum seminar is held at CREC Soundbridge where candidates can ask questions and share experiences. In addition, content activities for practica have been developed. One primary goal of the program is to create reflective practitioners who integrate understanding of their content areas, their students, and theories of pedagogy. During the year, candidates write reflections on all domains of the College's Conceptual Framework, 
some during fall practicum and the remainder during student teaching. The reflections are written through the lens of their own personal experiences and attitudes and with consideration of their perspectives on the learning and teaching of children who are deaf or hard of hearing.

To aid their reflections, candidates use a checklist developed to guide their observation of specific auditory, speech, spoken language, and parent guidance strategies and techniques employed by teachers of children who are deaf or hard of hearing. These teacher strategies are covered sequentially across the semester through discussion and reflective writing. The semester starts with a focus on strategies that facilitate auditory access, auditory perception, and comprehension. When this concept was first introduced, the candidates were asked to identify and name the strategies. For the second year of the program, the approach was changed and the candidates were first trained on the specific strategies and then asked to identify application of those strategies by the experienced professionals. This second approach has been quite successful in achieving our aim of focusing the candidates on listening, speech, and spoken language strategies.

\section{Student Teaching}

Connecticut requires graduate candidates to complete 10 consecutive weeks of full-time teaching during which candidates take increasing responsibility for full-time planning and teaching. In addition, the cooperating teachers are asked to arrange for the graduate candidates to attend and participate in as broad a range of service experiences as possible during student teaching. Although the candidates have had field study experiences, the program goal seeks to provide as many different and authentic experiences as possible. The candidates maintain a log of educational and clinical experiences outside of their placement that add to the quality of the learning experience. Experiences with hearing testing and technology are very important, and each candidate is to observe and participate in as many audiological experiences as possible including cochlear implant mapping sessions, hearing aid fitting, diagnostic sessions, parent feedback sessions, and technology problem-solving meetings.

To help explain the Individualized Education Program (IEP) process and to prepare candidates for assessment, report writing, and the creation of objectives for an IEP, the cooperating teachers are asked to arrange for the candidates to attend at least one IEP team meeting and related teacher planning sessions. Given the large number of students who are deaf and hard of hearing served by CREC Soundbridge, all candidates will have attended several IEP team meetings during their 10-week student teaching experience.

The "University of Hartford Graduate Student Teaching Handbook" was modified to include standards and competencies relevant to aural habilitation and education of children who are deaf or hard of hearing. Sections on 
audition, speech, and spoken language were added to the formal evaluation form. In addition to the College's Conceptual Framework indicators, new standards for deaf educators from the Council on Education of the Deaf (CED) and the AG Bell Academy for Listening and Spoken Language also have been added as appropriate. The expectation is that graduates of this program are well situated to continuing preparing themselves for the AG Bell Academy Listening and Spoken Language Specialist (LSLS) certification exam, and depending upon their experience, to seek designation as a LSLS Certified Auditory-Verbal Educator or Therapist (LSLS Cert. AVEd or LSLS Cert. AVT).

\section{Faculty}

The graduate program was designed to operate with one full-time faculty member and a team of adjunct faculty identified as outstanding content experts in their area of practice or teaching. Paterson is a full-time, associate professor and program coordinator who serves as the administrative leader under whom the program operates. Paterson is also the project director for the private grant, which has supported the first 3 years of the Aural Habilitation and Education program.

Seven adjunct faculty members teach courses related to their expertise, experience, and practice. Two adjunct faculty have doctoral degrees and also have experience as university professors, and two audiology faculty are working on their clinical doctorates. The other adjunct faculty members are highly experienced and qualified teachers of the deaf who hold master's degrees in their areas of expertise. Each year, another 10 to 15 teachers bring their practical knowledge to the university classroom as guest lecturers. To date, the cooperating teachers for practica and student teaching have been almost exclusively drawn from within CREC Soundbridge. With increasing cohort numbers, the task of identifying other sites and professionals has begun. On average, 20 to 23 teachers of the deaf from across the CREC Soundbridge program participate as mentor teachers for the candidates. While the candidates are in the program, they also benefit from interactions, advice, and mentoring from audiology assistants, paraprofessionals, classroom aides, and office administrators. The experience they have give them insight into how a dedicated team of professionals makes everything work on a day-to-day basis.

\section{Resources}

The graduate program has benefitted from financial, material, and personal resources. The University of Hartford and CREC Soundbridge partnership program could not have started without the generous financial support of a visionary private foundation, which fully funded the program personnel and operating needs during the first 3 years. This generosity has enabled the startup of a new, technologically advanced program in the Northeast. As noted 
above, one of the unique features of this program is that the fall and spring courses are taught at CREC Soundbridge. The grant provides office space and a teaching room at CREC Soundbridge. The University of Hartford provides on-campus office space, a library, and technical and administrative support to the faculty and the students. In the initial start-up, funds were allocated to add deafness-related material to the library collection, and additional books and materials have been added since then. Language and speech testing materials have been purchased to help students learn how to conduct assessments. Other equipment necessary for the students, such as computers for off-campus work, cameras and tripods, digital recorders, and televisions, have been acquired. The grant has also supported advertising and recruitment needs.

\section{Opportunities and Challenges}

\section{Advantages and Disadvantages of Training Teachers in a Public School Program}

CREC Soundbridge, as a public program, serves any child with hearing loss who is learning spoken language through listening without cost to the families. The population of children and families are, consequently, highly diverse. Children who have hearing loss are a heterogeneous group, and teachers in training encounter a range of ethnic, cultural, linguistic, geographic, and socioeconomic diversity from which they can learn. The university students gain experience with the educational, psychological, technological, and realworld issues of children with hearing loss from birth through high school and transition to work. CREC Soundbridge embodies the ideals of the IDEA in that over $90 \%$ of the students are fully included in their home schools and receive support services that take their unique needs into account and allow them to access the general curriculum in regular classrooms. At the same time, CREC Soundbridge also offers educational options for students with hearing loss for whom the mainstream classroom is not the least restrictive environment.

\section{Advice for Other New University Training Programs with a Deaf Education Focus}

There are two major recommendations for others considering the development of a new program. The first deals with the challenge of long-term funding. In order to stabilize a new program, there must be up-front strategic thinking about the long-term funding that will be necessary. There should be a written and agreed upon plan for achieving long-term funding and support systems in place to make it happen.

The second recommendation relates to the number of full-time faculty. The current model with one full-time professor and a supplemental group of adjunct faculty has provided the springboard for the start-up of this program and meets CED requirements for two full-time faculty equivalents. Program graduates have had a rich educational experience and benefited from 
excellence in teaching right from the start, and all partners are proud of that achievement. However, the management, recruitment, fund raising, and academic responsibilities in accreditation work and research have led to increased and unexpected demands on the program coordinator. When determining how to maintain and expand the program, the challenge for one person to try to address all the university requirements and still have a significant relationship with the partner program is clear. It is recommended that the original concept would include funding to support two full-time faculty members who could share the responsibilities and still have time to address all the requirements of being an academic.

\section{Future Goals}

Future goals for the program include maintaining aggressive recruitment in university classrooms, e-mail and e-brochure contact, and advertising in order to build on the program's growing reputation; requesting permission of Connecticut to allow out-of-state student teaching placements; designing collaborative translational research and scholarship projects between the university and CREC Soundbridge to demonstrate how theory influences practice and how practice informs theory for the benefit of students who are deaf or hard of hearing; and determining the ways and means to achieve financial stability for the program.

\section{Conclusion}

There is a need for professionals who have cutting-edge knowledge of advanced hearing technology and advanced aural habilitation and educational practice. There is a shortage of professionals in deaf education who are specifically trained to work in early intervention with parents who choose an auditory-language approach for their infants who are deaf or hard of hearing. Fewer than 15 programs in the country prepare professionals for this specialization. This new professional training program is one of only two programs in the Northeast that specializes in auditory-based learning. The community has responded positively to the quality of the graduates and to the passion they bring as new professionals in the field of education of children who are deaf and hard of hearing. This success makes other challenges worthwhile.

\section{References}

Billingsley, B.S., \& McLusky, J. (2004). Critical issues in special education teacher supply and demand: Overview. The Journal of Special Education, 38, 2-4.

Cole, E.B., \& Flexer, C.J. (2007). Children with hearing loss: Developing listening and talking birth to six. San Diego, CA: Plural Publishing, Inc. 
Harrington, M.L., \& Powers, A. R. (2004). Preparing teachers to meet the needs of children who have cochlear implants. Teacher Education and Special Education, 27, 360-372.

McLuskey, J., Tyler, N.C., \& Saunders Flippin, S. (2004). The supply of and demand for special education teachers: A review of research regarding the chronic shortage of special education teachers. The Journal of Special Education, 38(1), 5-21.

U.S. Department of Education, Office of Special Education and Rehabilitative Services, Office of Special Education Programs. (2004). 26 th Annual (2004) report to Congress on the implementation of the Individuals with Disabilities Education Act. 

The Volta Review, Volume 110(2), Summer 2010, 293-296

\title{
Program Profile
}

\section{Fontbonne University: Collaboration in Speech-Language Pathology and Early Intervention in Deaf Education}

\author{
By Gale Rice, Ph.D., CCC-SLP, and Susan Lenihan, Ph.D., CED
}

\section{Introduction}

Children with hearing loss are best served through the collaborative efforts of their parents and a team of professionals. For communication development and educational achievement, speech-language pathologists and teachers of the deaf working together can have a profound impact. A collaborative approach to assessment, direct instruction, and consultation with parents, general education teachers, and other professionals provides the best support for a child with a hearing loss in all stages including early intervention and mainstream services (Chute \& Nevins, 2006). A collaborative approach involves more than multiple professionals providing services to a child; it is a way of problem solving and interacting that optimizes outcomes for a child's development and educational achievement. While many professionals learn how to collaborate on the job, the Center for Teacher and Therapist Education at Fontbonne University was intentionally designed to encourage the development of collaborative skills in future speech-language pathologists, teachers of the deaf, and general and special education teachers.

\section{A Collaborative Program}

Fontbonne University began offering undergraduate programs in speechlanguage pathology and deaf education in the 1960s and the graduate program in speech-language pathology was established in 1975. In 2001, the university established a graduate program in early intervention in deaf education in response to universal newborn hearing screening programs

Gale Rice, Ph.D., CCC-SLP, is the Chair and a Professor in the Department of Communication Disorders \& Education at Fontbonne University. Susan Lenihan, Ph.D., CED, is a Professor and Director of Deaf Education at Fontbonne University. For more information about this program, contact Dr. Rice at grice@fontbonne.edu. 
that were identifying children with hearing loss at younger ages and to meet the need for professionals to provide services to these infants, toddlers, and their families. Also in 2002, the speech-language pathology program began offering an emphasis on education in deafness to increase the depth of coursework and practicum in that field. Both the early intervention in deaf education and speech-language pathology graduate program with an emphasis on education in deafness were designed through the collaborative efforts of advisory groups of speech-language pathologists and deaf educators who were experienced leaders in auditory-based education. A collaborative approach based on the recommendations of the Joint Committee of the American Speech-Language-Hearing Association (ASHA) and the Council on Education of the Deaf (CED) was implemented (Joint Committee, 2004).

Both programs develop competencies in pediatric audiology, auditory technology, communication development, assessment, cultural factors, additional disabilities, collaboration and communication with professionals and families, and strategies and approaches to speech, and language, listening, and literacy development. The speech-language pathology students meet all ASHA requirements, and the early intervention in deaf education students meet requirements for CED certification. Students from both disciplines take a shared core of six required courses:

- Intervention with Children who are Deaf or Hard-of-Hearing

- Auditory Technology and Cochlear Implants or Pediatric Audiology and Habilitation

- Communication Development for Children who are Deaf or Hard-ofHearing

- Language and Literacy in Learners "At Risk"

- Introduction to Research Methods

- Counseling Issues in Communication Disorders

Both groups of students take a number of elective courses and required courses that are specific to the profession. Case studies, projects, and small group discussions are often designed for interdisciplinary groups to encourage crossdiscipline communication and collaboration. A seminar course that focuses on collaborative skill development and case study analysis was piloted in fall 2009 and may be added to the curriculum.

In addition to in-class opportunities for collaboration, a number of co-curricular opportunities also encourage communication and shared experiences for students. Recent activities include a journal club, guest speakers from the Cochlear Implant Center at St. Louis Children's Hospital, attendance at the AG Bell 2009 Listening \& Spoken Language Symposium, and service learning projects. Study abroad opportunities to England, Belize, and 
Costa Rica have provided deaf education and speech-language pathology students an opportunity to learn about deaf education, special education, and related services in these countries while observing and working with children in schools.

Faculty members in the Department of Communication Disorders and Deaf Education and the Department of Education/Special Education model collaboration through joint research, team teaching, co-presentations at conferences, shared study abroad projects, and collaboration on case studies. Faculty members also collaborate on service provision to children in the campus clinic and in schools that serve as professional development partners. The university administration demonstrates support of the collaborative model through the recruitment and hiring of faculty who are committed to collaboration in professional preparation.

Practicum experiences for students in both disciplines provide another opportunity to develop a collaborative approach. Often speech-language pathology students and deaf education students are working at the same school and with some of the same children in a semester. The students observe practicum supervisors working together in providing services to the children and often have the opportunity to discuss the children's progress and needs.

In order to assess the effectiveness of the program design, exit interviews take place each year and a validation study has been completed for the early intervention in deaf education program (Rice \& Lenihan, 2005). One is being initiated for the speech-language pathology program that emphasizes hearing loss. Portfolios completed by the students at the end of the program reflect the development of collaboration skills and the understanding of the importance of an interdisciplinary approach to assessment and instruction.

\section{Conclusion}

In summary, the best measure of the effectiveness of Fontbonne's collaborative model is in the professional behavior of the graduates. Currently, a number of program graduates are working together in OPTION Schools and public school programs, and we are able to see how they collaborate. When we meet our graduates at professional meetings, we are gratified to see that they've become professionals who value their colleagues in both disciplines and are eager to provide quality services to children with hearing loss and their families through collaboration.

\section{References}

Chute, P., \& Nevins, M. (2006). School professionals working with children with cochlear implants. San Diego, CA: Plural Publishing, Inc. 
Joint Committee of ASHA and the Council on Education of the Deaf. (2004). Roles of speech-language pathologists and teachers of children who are deaf and hard of hearing in the development of communicative linguistic competence. Retrieved December 10, 2009, from http:/ / www.asha.org/docs/html/GL2004-00202. html.

Rice, G., \& Lenihan, S. (2005). Early intervention in auditory/oral deaf education: Parent and professional perspectives. The Volta Review, 105(1), 73-96. 
The Volta Review, Volume 110(2), Summer 2010, 297-304

\title{
Program Profile
}

\section{Nazareth College: Specialty Preparation for Speech-Language Pathologists to Work With Children who are Deaf and Hard of Hearing}

\author{
Paula M. Brown, Ph.D., CCC-SLP, and Cathy Quenin, Ph.D., CCC-SLP
}

\section{Introduction}

The speciality preparation program within the speech-language pathology master's degree program at Nazareth College in Rochester, N.Y., was designed to train speech-language pathologists to work with children who are deaf and hard of hearing, ages 0 to 21 . The program is offered in collaboration with the Rochester Institute of Technology, National Technical Institute for the Deaf (RIT/NTID). The specialization has been offered since 2002 and has received federal funding from the U.S. Department of Education Office of Special Education Programs since its inception. As conceived, the program aims to train speech-language pathologists to meet the diverse needs of infants and children in early intervention programs, mainstream settings, and schools for the deaf. The program design acknowledges the following trends regarding children who are deaf and hard of hearing: 1) the increasing number of children who are receiving cochlear implants or using digital hearing aids, 2) the increasing number of children being educated in mainstream settings where speech-language pathologists are primary service providers, and 3) the increasing linguistic and cultural diversity of children and families who are accessing services (Leigh, 2008). The program was also designed with the belief that speech-language pathologists need specific knowledge and skills to address the social, psychological, linguistic, and vocational needs of the child; work within an interdisciplinary team; and communicate with the family and child in their preferred mode of communication (ASHA, 2004).

The development of this specialized training was motivated by students at RIT/NTID seeking speech-language services who were disgruntled by the services they had received growing up. When collecting case histories,

Paula M. Brown, Ph.D., CCC-SLP, is the Co-Program Director and Professor in the Department of Communication Sciences and Disorders at Nazareth College. Cathy Quenin, Ph.D., CCC-SLP, is the Co-Program Director, Professor, and Chairperson of the Department of Communication Sciences and Disorders at Nazareth College. For more information about this program, contact Dr. Brown at pbrown8@naz.edu. 
speech-language pathologists at RIT/NTID routinely heard stories about delayed identification, inappropriate or insufficient follow-up services, outdated offerings and approaches in school, and inexperienced and possibly inept communication instructors. Many students expressed frustration and feelings that they had been deprived of the opportunity to develop listening and spoken language skills. The students' experiences, coupled with RIT/ NTID faculty observations of poorly managed skill development, led faculty to believe that students needed access to improved services prior to arriving at RIT/NTID. Although many factors had contributed to poor spoken language outcomes for these college students, it was clear that the insufficient quality of personnel and intervention programs had played a significant role.

The desire to address this problem corresponded with RIT/NTID's mission to engage in outreach activities focused on improving instruction of individuals who are deaf and hard of hearing. Reaching out to speech-language pathologists had not been part of the original plan, but the goal was compatible and eventually embraced by faculty and administration. Most of the outreach RIT/NTID provided involved in-service training, but the objectives of this particular outreach were more compatible with an intensive and degreerelated preservice program. Although RIT/NTID employed speech-language pathologists and audiologists, the school did not offer an undergraduate or graduate degree in communication disorders. RIT/NTID partnered with Nazareth College to offer a specialization within speech-language pathology. The collaborative program, now in its eighth consecutive year, relies on the combined strength of Nazareth College's professional training program in speech-language pathology and RIT/NTID's leadership in deaf education, including the provision of clinical services to students who are deaf and hard of hearing.

\section{Program Description}

\section{Philosophy and Beliefs}

This program is grounded in the philosophy that access to spoken language and meaningful interaction using spoken language is essential for developing speaking, listening, reading, and writing skills associated with academic and career success (Blamey, Sarant, \& Paatsch, 2006; Damen, van den OeverGoltstein, Langereis, Chute, \& Mylanus, 2006; Dornan, Hickson, Murdoch, \& Houston, 2007; Spencer, 2004; Gantz \& Knutson, 2004). It is also grounded in the belief that access to language is key (Nittrouer, 2002; Sharma, Dorman, \& Kral, 2005), and that language processing is a neural activity with significant individual variation that is not currently well understood (Fagan, Pisoni, Horn, \& Dillon, 2007; Leybaert \& D'Hondt, 2003; Nittrouer, 2010; Pisoni, Conway, Kronenberger, Horn, Karpicke, \& Henning, 2008). Therefore, individual learners and contexts for learning must be carefully examined (Duchesne, 
Bergeron, \& Sutton, 2008; Spencer, 2004), and multiple pathways for achieving spoken language competence must be considered and pursued (Easterbrooks \& Baker, 2002). This includes considering the complementary nature of vision and audition (Bergeson, Pisoni, \& Davis, 2003) and the possibility that visual cues as provided through cued speech may enhance language access and language learning (LaSasso \& Metzger, 1998). In keeping with this philosophy, students study language and its development in social, familial, and educational contexts and learn a variety of strategies for helping clients develop listening skills, maximize their access to spoken language, and facilitate their acquisition of spoken language competence.

Another foundational belief is that quality parent-child interaction is essential for developing linguistic, social, and cognitive competence (Calderon \& Greenberg, 2000; Vaccari \& Marschark, 1997; Yoshinaga-Itano \& Sedey, 1998). Therefore, students are prepared to work with culturally and linguistically diverse families to foster parental empowerment, involvement, and advocacy.

\section{Focus}

The program prepares speech-language pathologists to work with a linguistically and culturally diverse group of children who are deaf or hard of hearing, specifically with individuals who use cochlear implants, ranging in age from infants to young adults. The program also prepares them to work with individuals who received implants during early childhood as well as those receiving implants as adolescents and who have variable histories of listening and spoken language use.

\section{Curriculum}

Students pursue a sequence of courses in which they develop the necessary knowledge and skills to partner with families and other professionals in early intervention and school settings to foster spoken language competence, literacy, and social-cognitive skills, which lead to academic success. The curriculum specific to auditory-based practices addresses all nine domains of listening and spoken language as identified by the AG Bell Academy for Listening and Spoken Language (see Monograph Appendix A). All courses involve critical analysis of current literature with a focus on evidence-based practice. Students also learn and compare a wide range of philosophies and educational approaches, including bilingual approaches using American Sign Language, cued speech (to visually represent a spoken message), and adopting auditory-verbal strategies to develop listening and spoken language.

Ten courses comprise the specialty sequence: five specialty preparation courses and five core master's degree courses. The five courses in the specialty preparation sequence, which specifically address the domains 
of listening and spoken language, are: Early Intervention (Domains 4, 5), Developmental Issues (Domains 4, 7, 8, 9), Assessment and Intervention for Facilitating Spoken Language (Domains 3, 6, 9), Cochlear Implants: Technology and Use (Domains 1, 2, 6), and Educational Audiology (Domains $1,2)$. The five courses taken to satisfy the regular master's degree program requirements are: Methods of Diagnosis, Research Methodology, Phonological Process Disorders, Seminar: Voice Disorders, and either Seminar: Language Disorders or Language and Literacy. Issues and topics related to spoken language acquisition of children who are deaf and hard of hearing are embedded in these latter courses, and students focus their projects and research papers on individuals who are deaf or who use cochlear implants. Students thus have ample opportunity to develop specialized knowledge and skills related to spoken language as they pursue their master's degree in speechlanguage pathology.

Nazareth College offers all the specialization courses except the cochlear implant course, which is offered at RIT/NTID where a cochlear implant program provides extensive services to over 260 students including new and experienced cochlear implant users. As part of the cochlear implant course, students engage in critical analysis of cochlear implant efficacy studies, learn about cochlear implant technology, and learn to troubleshoot technology problems. They also observe and participate in mapping and listening sessions and attend meetings of the cochlear implant student club. In addition, they can take advantage of various workshops and online training sessions focused on cochlear implants. RIT/NTID's association with cochlear implant companies assures graduate students access to the latest developments in cochlear implant technology and use.

In addition to the 10 courses, students pursuing the specialization who do not enter the program with sign skills are required to complete two courses in sign language and Deaf culture. Students are also required to learn cued speech through various on-campus workshops, seminars, and camps offered at Nazareth College.

Curricular offerings are supplemented with extracurricular offerings. RIT/ NTID offers workshops and colloquia on a vast array of topics related to deaf education, including presentations by international scholars. Students are encouraged to interact with students who are deaf or hard of hearing and attend social and cultural affairs, including theater performances by actors who are deaf or hard of hearing.

\section{Practicum}

In addition to course requirements, students choosing this specialty complete 75 of the ASHA-required 400 hours of clinical practicum at sites that enable them to gain experience with children and adolescents who are deaf or hard of hearing. These hours are accrued through practicum experiences at 
RIT/NTID, the Nazareth College Speech and Hearing Clinic, and other sites where they can work with younger children.

Students begin their practicum experience working with children who are deaf or hard of hearing after they complete their first year of preparatory coursework. Students work with seasoned clinicians who serve these individuals throughout the Rochester area. Practicum sites have included the Rochester School for the Deaf (one of the nation's oldest schools for the deaf), the Rochester City School District's magnet program for students who are deaf and hard of hearing, and a number of local agencies that provide specialized services for infants and young children. Practicum placements outside the Rochester area have included the Moog Oral School at the Buffalo Hearing and Speech Center, New York University's Cochlear Implant Center, and the New York Eye and Ear Cochlear Implant Center.

Sites are selected to provide students a meaningful experience with clients who are deaf or hard of hearing while under the supervision of speechlanguage pathologists with extensive backgrounds and experience in this specialized area. In these practica, students conduct auditory, speech, and language assessments, and plan and implement therapeutic services. They learn to use a variety of assessment tools and how to develop their own techniques.

In early intervention programs, therapy is conducted in children's homes, where clinicians work to help families develop the skills to communicate with their child and to foster spoken language competence in the natural environment. A student clinician might work with a family who has a newly diagnosed child, aid a child in adapting to amplification, provide information about communication options, or educate parents who are considering obtaining a cochlear implant for their child. Students are required to work at least 50 hours with infants and children who are deaf or hard of hearing.

In addition to completing a practicum with younger children who are deaf or hard of hearing, all program students have a practicum experience in the Communication Studies and Services Department at RIT/NTID, working with college students who are deaf or hard of hearing. They are supervised by a team of experienced speech-language pathologists and have an opportunity to collaborate with experienced audiologists to foster students' listening and speaking competence. The RIT/NTID program provides state-of-the-art facilities and technology for speech-language therapy, and the opportunity to work with students who are deaf or hard of hearing with a wide variety of communication needs. Students conduct at least 25 hours of therapy at this site.

\section{Impact/Employment}

Program graduates work with individuals who are deaf or hard of hearing in a variety of settings across the country. While a number have remained in upstate New York, others utilize their unique skills in places such as the Boys' Town Cochlear Implant Center in Omaha, NE, the River 
School in Washington, DC, the Clarke School for Hearing and Speech in Northampton, MA, the Moog School/Buffalo Hearing and Speech Center in Buffalo, NY, Carle Children's Hospital in Urbana, IL, Hear 2 Learn in Syracuse, NY, and the New York School for the Deaf in White Plains, NY. These specialty clinicians are highly qualified to provide the types of therapy services needed by children who are deaf or hard of hearing. In some locales, specialty clinicians have initiated programs, making services available in their area for the first time. In addition, graduates provide inservice professional development for colleagues, thus extending their impact on the quality of services provided to children who are deaf or hard of hearing.

Employers and parents have reported high satisfaction with graduates of the program, and graduates report that they feel they are making a difference for children who are deaf or hard of hearing and their families. Their impact ranges from guiding parents of newly-diagnosed infants as they make decisions regarding amplification and cochlear implantation to helping families advocate for their children to ensure their success in mainstream schools. Graduates work with children who are deaf or hard of hearing at a variety of ages in a variety of settings, feeling that their specialty training will enhance children's attainment of spoken language, literacy, academic, and social success.

\section{Future Directions}

While the program has been successful, a desired change would be to reach more individuals and have a greater impact. This could be accomplished through increased funding for graduate study, bringing more students to campus or increasing enrollment through distance learning. We also would like to expand the number of practicum sites, and would need a way to fund room and board expenses for off-site placements. Finally, we would like to collaborate more with other programs providing similar training, perhaps through the use of distance technology where we could foster student collaboration across programs to analyze case studies and observe and critique therapy.

\section{References}

ASHA. (2004). The roles of speech-language pathologists and teachers of children who are deaf and hard-of-hearing in the development of communicative and linguistic competence: Guidelines. Retrieved April 9, 2010, from http://www.asha.org/ $\mathrm{docs} / \mathrm{html} / \mathrm{PS} 2004-00232 . \mathrm{html}$.

Bergeson, T., Pisoni, D., \& Davis, R. (2003). A longitudinal study of audiovisual speech perception by children with hearing loss who have cochlear implants. The Volta Review, 103(4), 347-370. 
Blamey, P., Sarant, J., \& Paatsch, L. (2006). Relationships among speech perception and language measures in hard-of-hearing children. In P. Spencer \& M. Marschark (Eds.), Advances in the spoken language development of deaf and hard-of-hearing children (pp. 85-102). New York, NY: Oxford University Press.

Calderon, R. \& Greenberg, M. (2000). Challenges to parents and professionals in promoting socioemotional development in deaf children. In P. Spencer, C. Erting, \& M. Marschark (Eds.), The deaf child in the family and at school: Essays in honor of Kathryn P. Meadow-Orlans (chapter 10, pp 167-185). Mahwah, NJ: Lawrence Erlbaum Associates.

Damen, G., van den Oever-Goltstein, M., Langereis, M., Chute, P., \& Mylanus, E. (2006). Classroom performance of children with cochlear implants in mainstream education. Annals of Otology, Rhinology \& Laryngology, 115(7), 542-552.

Dornan, D., Hickson, L., Murdoch, B., \& Houston, T. (2007). Outcomes of an auditory-verbal program for children with hearing loss: A comparative study with matched group of children with normal hearing. The Volta Review, 107(1), 37-54.

Duchesne, L., Bergeron, F., \& Sutton, A. (2008). Language development in young children who received cochlear implants: A systematic review. Communicative Disorders Review, 2(2), 33-78.

Easterbrooks, S., \& Baker, S. (2002). Language learning in children who are deaf and hard of hearing: Multiple pathways. Boston, MA: Allyn \& Bacon.

Fagan, M., Pisoni, D., Horn, D., \& Dillon, C. (2007). Neuropsychological correlates of vocabulary, reading, and working memory in deaf children with cochlear implants. Journal of Deaf Studies and Deaf Education, 12, 461-471.

Gantz, B.J., \& Knutson, J.F. (2004). Outcomes and achievement of students who grew up with access to cochlear implants. Laryngoscope 114, 1576-1581.

LaSasso, C. \& Metzger, M. (1998). An alternate route for preparing deaf children for bi-bi programs: The home language as L1 and Cued Speech for conveying traditionally-spoken languages. Journal of Deaf Studies and Deaf Education, 3(4), 265-289.

Leigh, G. (2008). Changing parameters in deafness and deaf education: Greater opportunity but continuing diversity. In M. Marschark and P. Hauser (Eds.), Deaf cognition: Foundations and outcomes (pp. 24-51). New York, NY: Oxford University Press.

Leybaert, J., \& D'Hondt, M. (2003). Neurolinguistic development in deaf children: The effect of early language experience. International Journal of Audiology, 42(1), 34-40.

Nittrouer, S. (2002). From ear to cortex: A perspective on what clinicians need to understand about speech perception and language processing. Language, Speech and Hearing Services in Schools, 33, 237-251.

Nittrouer, S. (2010). Early development of children with hearing loss (pp. 57-72). San Diego, CA: Plural Publishing. 
Pisoni, D., Conway, C., Kronenberger, W., Horn, D., Karpicke, J., \& Henning, S. (2008). Efficacy and effectiveness of cochlear implants in deaf children. In M. Marschark and P. Hauser (Eds.), Deaf cognition: Foundations and outcomes (pp. 52-101). New York, NY: Oxford University Press.

Sharma, A., Dorman, M., \& Kral, A. (2005). The influence of a sensitive period on central auditory development in children with unilateral and bilateral cochlear implants. Hearing Research, 203, 134-143.

Spencer, P. (2004). Individual differences in language performance after cochlear implantation at one to three years of age: Child, family, and linguistic factors. Journal of Deaf Studies and Deaf Education, 9(4), 395-412.

Vaccari, C., \& Marschark, M. (1997). Communication between parents and deaf children: Implicaitons for social-emotional development. Journal of Child Psychology and Psychiatry, 38, 793-801.

Yoshinaga-Itano, C., \& Sedey, A.L. (1998). Language, speech, and socialemotional development of children who are deaf or hard of hearing: The early years. The Volta Review Monograph, 100(5). 
The Volta Review, Volume 110(2), Summer 2010, 305-313

\title{
Program Profile
}

\section{University of Akron: Training Speech- Language Pathology Specialists to Provide Quality Service to Children who are Deaf or Hard of Hearing - A Collaborative Preservice Program}

\author{
Denise Wray, Ph.D., CCC-SLP, LSLS Cert. AVT, and \\ Carol Flexer, Ph.D., CCC-A, LSLS Cert. AVT
}

\section{Introduction}

Changes in the pre-professional training of speech-language pathologists (SLPs) to meet the language and auditory needs of children with hearing loss have been advocated for years by the Joint Committee of the American Speech-Language-Hearing Association and the Council on Education of the Deaf (ASHA, 2008). This need has increased in importance during the past decade because a) audiologists can accurately and reliably assess the hearing of infants and young children, b) newborn hearing screening is now federally mandated, and c) intense speech-language and auditory intervention for infants, toddlers, and preschoolers who wear modern hearing aids or use cochlear implants has yielded outcomes far more significant than previously reported.

Nevertheless, there are few practicing SLPs with the professional expertise to recognize and provide appropriate training. Typically, SLPs in master degree programs accumulate limited or no clock hours to develop the auditory and speech skills of children who use cochlear implants or hearing aids, and have little or no formal training in principles of early intervention and on functioning in collaborative teams (Teagle \& Moore, 2002; Wilson, 2006). The dearth of qualified providers to work with children who are deaf or hard of hearing continues to resonate in the literature (ASHA, 2008; Luckhurst, 2008; White, 2006).

Denise Wray, Ph.D., CCC-SLP, LSLS Cert. AVT, is a Professor of Speech-Language Pathology at The University of Akron and Director of the Early Intervention Aural Habilitation Clinic. Carol Flexer, Ph.D., CCC-A, LSLS Cert. AVT, is a Distinguished Professor Emeritus of Audiology in the School of Speech-Language Pathology and Audiology at The University of Akron. For more information about this program, please contact Dr. Wray at dwray@uakron.edu. 
Further, given the positive speech-language outcomes achieved by children with hearing loss who are identified early and provided with intense speechlanguage and auditory-based intervention (Dornan, Hickson, Murdoch, \& Houston, 2009; Nicholas \& Geers, 2006), there are ever increasing numbers of parents who select auditory-based intervention programs when offered an option (White, 2006; Wilson, 2006). Literacy outcomes that are commensurate or nearly so with peers who have typical hearing are clearly an attainable outcome (Robertson, 2009; Geers, 2003; Geers, Nicholas, \& Sedey, 2003).

\section{Quality of Services}

A collaborative team of faculty from The University of Akron (UA) in Akron, $\mathrm{OH}$, and Kent State University (KSU) in Kent, $\mathrm{OH}$, were awarded a federal grant from the U.S. Department of Education to develop a specialty area in the graduate SLP programs of UA and KSU that would train a total of 32 SLP students (trainees) over a period of 4 years (eight per year) to work with children who have hearing loss and are acquiring listening and spoken language. The Grant Program is conducted by a faculty of eight professors, four from each university, with a co-director for the Grant Program assigned to each university. The Grant Program has an interdisciplinary and transdisciplinary framework that includes specialists in early intervention, special education, psychology, social work, and preschool education as well as SLPs, audiologists, and auditory-verbal therapists certified as listening and spoken language specialists (LSLS). In addition, university and community-based professionals highly experienced in providing services to infants, toddlers, and children with hearing loss and their families mentor and supervise practicum experiences while providing classroom instruction. Personnel who are involved in supervision and instruction have an extensive background working with students with hearing loss and have established consistent records of positive course ratings from past students.

\section{A Collaborative Teaming Model}

Although the establishment of collaborative teams for children with disabilities is hardly a new concept, actual demonstration of how collaboration is accomplished and evaluated is rarely documented (Teagle \& Moore, 2002; White, 2006). Regardless of whether children use hearing aids or cochlear implants, they require a collaborative team to coordinate services (Madell \& Flexer, 2008). This Grant Program is predicated on a collaborative model.

\section{Grant Program Description}

The Grant Program's primary goal is to improve the quality of SLP preprofessional training to ensure that trainees are capable, upon graduation, of 
accurate assessment and management of the listening and spoken language needs of infants, toddlers, and children with hearing loss.

All coursework and practicum training experiences, including summer sessions, are designed to provide logically sequenced content and are coordinated by the Grant Program co-directors, who come from each of the two universities, UA and KSU. Trainees earn more than four times the typical clock hours working with infants, toddlers, and school-age children who have hearing loss compared to students who obtain a traditional speech-language pathology master's degree. Practicum occurs in home-based settings as well as in school, hospital, rehabilitative, and university environments.

This Grant Program extends the typical SLP pre-professional program by one semester (i.e. one summer session), and trains students to function as qualified personnel who can coordinate services for children with hearing loss. In addition to an extended 2-year course of study, trainees participate in the following supplementary courses and clinics: Hearing Loss Seminar (3 hours, or 1 hour across three semesters); Graduate Audiology Course (4 hours); Course in Family/Professional Collaboration (3 hours); Course in Literacy and Early Intervention ( 2 hours), and a research project that involves children who have hearing loss and that is presented at a state convention. Additional clinical practicum with infants and children with hearing loss includes three extra clinics in at least three different settings to provide a minimum 100 hours in the area of hearing assessment and intervention.

In contrast to typical SLP students who frequently receive little or no training with infants, toddlers, and children with hearing loss, Grant Program trainees are comprehensively trained and receive Specialty Training Certificates from UA and KSU upon graduation. Upon graduation they are qualified to coordinate services for children with hearing loss seeking a listening and spoken language outcome.

\section{Description of Applicants and Students}

The Grant Program was predicated on UA's early intervention aural habilitation clinic specializing in teaching listening and spoken language, established in 1981. All SLP students in the typical pre-professional training program at UA have been given the opportunity to participate in at least one clinical rotation in the aural habilitation clinic. As more families sought services in the clinic, increasing numbers of audiology and SLP graduate students expressed interest in opportunities to learn techniques that maximize the benefits of hearing technologies and listening and spoken language strategies. The Grant Program afforded a unique and expanded opportunity to provide trainees from two universities (UA and KSU) an area of concentration in hearing technology while receiving their routine pre-professional training in speech-language pathology. Further, the Grant Program provided an opportunity for two major state universities in northeast Ohio to embark on a first time formal partnership. 
Notification of the Grant Program award arrived after the 2007 fall class of SLP students at both UA and KSU had been accepted and could not be used as a recruitment tool; however, after showcasing the Grant Program on both universities' websites during the first year, the number of applicants doubled and several candidates from underrepresented populations and from out of state were accepted. The Grant Program supports eight SLP students each year and will ultimately train a total of 32 students. Many of the applicants have prior experience working with children or adults with hearing loss, although observations indicate that most of their experience is limited to basic competency in American Sign Language with little to no knowledge of hearing aids, cochlear implants, or how to achieve listening and spoken language outcomes. Many applicants have participated in a clinical observation class during their undergraduate years and are reportedly intrigued by the therapy process and the significant listening and spoken language outcomes they witnessed. Inquiries about the program continue to come from out-of-state and underrepresented populations. Accepted trainees consistently have a minimum overall grade point average of 3.6.

\section{Student Impressions}

The Grant Program is half complete ( 2 of the 4 years) and is immersed in training its third cohort of eight students. The first trainee cohort has completed the program and all trainees are currently employed in various pediatric settings such as pediatric hospitals, schools, auditory-based preschools, and rehabilitation centers. All but one trainee chose employment within the state of Ohio. Trainees have been surveyed about their experience via various means, particularly through an exit survey. The following are direct quotes describing the trainees' impressions:

- Our focus is on creating appropriate, riveting, and helpful strategies for therapy sessions as well as troubleshooting equipment. Working side by side with professionals across the field, an interactive approach is taken with fabulous mentors.

- I am truly beginning to develop a whole new understanding of working with hearing loss clients...I am confident in the newer technologies and I love being able to learn more about them as they apply to this particular population.

- As a trainee, I have already had people such as parents, teachers, and school personnel turning to me to provide them with information about hearing loss. The Grant traineeship has been a great experience and I am looking forward to all the possibilities, the understanding, and specialty of hearing loss in the future. I am excited to educate those around me about the importance of amplifying early to develop the brain, making the commitment to desired outcomes, and all the possibilities of future technology. 
- The additional trainings, seminars, and classes have not only allowed me to feel comfortable with setting and implementing appropriate auditory goals, but have also allowed my passion for working with children with hearing loss to grow immensely...only until the students acquire enough skills and knowledge about working with this population with hearing loss, can they provide professional service delivery to the children and their families.

- One of the major things that impressed me is the family-centered therapy philosophy. I think that this is something that is not implemented enough. As clinicians, we only see the client for an hour a week. The family is with the client all the time. This is why it is so important to involve the family.

\section{Clinical Placements, Employment Settings, and Employer Impressions}

Clinical placements for all graduate students in the SLP programs in northeast Ohio have historically been diverse and ample. The close proximity to three major urban cities (Akron, Cleveland, and Canton) offers students a vast array of externship opportunities. Clinical placements for trainees have been equally impressive. Currently, the Grant Program has established placement agreements with no fewer than 10 work settings, including the private practice of a LSLS Cert. AVT, school districts that provide either total communication or auditory-based options for children, two major hospitals with criticallyacclaimed CI centers, auditory-based preschools, a hospital-based rehabilitation center, and Regional Infant Hearing Programs (RIHP) in Northeastern Ohio for children ages 0 to 3 years that provide home-based services. Trainees surveyed upon exiting the program averaged 125 clinical hours of hearing assessment and intervention, exceeding the program's goal by $25 \%$.

Recent graduates have been recruited by some of the largest cochlear implant centers in the nation and by many facilities that specifically offer spoken language outcomes for children who are deaf or hard of hearing. Externship sites have also hired trainees upon graduation. In fact, the majority of trainees that graduated in August 2009 were offered jobs prior to graduation. The indication is that this trend will continue, particularly if trainees are mobile. Furthermore, recent inquiries from school special education supervisors throughout the state are specifically requesting trainees because they have experience with auditory-based philosophies. This trend is also expected to continue.

A survey sent to employers of the first set of graduates resulted in the following comments that characterized most reflections:

"Susan's" training sets her apart from other students that I have supervised in the following areas: 1) incorporates audition with speech and language tasks, 2) does not over articulate and/or speak too loudly with the child, 3) displays confidence in attempting troubleshooting with devices, 
4) understands the importance of parental involvement, and 5) formulates new goals based on assessments for child's upcoming cases conferences.

Another supervisor at an implant center noted the necessity for specialization when working with children who have hearing loss:

Working with children with hearing loss requires a unique skill set and knowledge base that often is not a significant part of the general masters in speech-pathology curriculum. The students on the grant are well-trained, have a diverse set of clinic experiences, and have the capability to be hired to work with children with hearing loss immediately upon graduation.

A supervisor from an early intervention center concurred:

It has been a delight to be able to hire such a consummate young professional who has already had all the training (and much of the experience) that I seek! This student is well prepared both in the skill set she needs to work on listening and spoken language and in the skills she needs to work with infants, their families, and the professionals on their service teams.

\section{Unique Strengths of the Grant Program}

UA and KSU have recognized a long-standing commitment to a collaborative early intervention model. This position was underscored by previous projects funded by a private foundation at UA that offered outreach to RIHP serving children ages 0 to 3 in Ohio. Newborn hearing screening mandates and ever-advancing technologies have further supported the philosophy that comprehensive partnerships between service providers across agencies is truly in the best interest of the child with hearing loss, as is the reality that increasing numbers of parents are requesting spoken language outcomes for their children (Luckhurst, 2008; Madell \& Flexer, 2008; White, 2006; Wilson, 2006).

The Internet has become a powerful medium for education and information, and one goal of the Grant Program has been to develop and maintain an online presence at www.auditoryoptions.org. This website provides information about listening and spoken language strategies for children with hearing loss, offers suggestions for therapy sessions, and educates professionals, parents, and students about listening and spoken language outcomes.

The website also provides information about state-of-the-art aural habilitation strategies and resources, particularly those that maximize the use of current technologies. Trainees are encouraged to provide information for the site, such as sample lesson plans, suggested readings for parents and for professionals, and information about rehabilitation strategies.

An additional unique strength of the Grant Program is its close ties to a community parent-support group, Natural Communication, Inc. (NCI), an 
organization that supports families who desire listening and spoken language outcomes for their children in the mainstream. Working with NCI, trainees host social events and arrange opportunities for children with hearing loss to meet others who wear similar technologies and engage in language-based activities while also providing parents time to converse and share ideas with other families.

The Grant Program has modeled interdisciplinary services with SLPs and audiologists working alongside one another in the therapy room and the audiology suite.

Perhaps first-year Grant trainee Kelley, who received her undergraduate training at The Ohio State University, said it best when she explained:

I am a first-year trainee on the grant, and my experience has been amazing so far. I am truly beginning to develop a whole new understanding of working with hearing loss clients. Both of my parents are deaf, and I have been exposed to many different views and methods of teaching and learning for those who are deaf or hard of hearing. I am more confident with the newer technologies, and I love being able to learn more....this grant is really inspiring me to change many lives, and I certainly hope to continue to do so for years to come!

\section{Northeast Ohio Consortium for Children with Cochlear Implants}

The concept of partnering with multiple agencies in the community may be best reflected by the 2006 creation of the Northeast Ohio Consortium for Children with Cochlear Implants (NOCCCI). NOCCCI is a grassroots volunteer organization of professionals who recognize that receiving a cochlear implant is simply a small part of the larger picture for a child with a severe-toprofound hearing loss.

The need for improved communication among stakeholders involved with children who use cochlear implants is well documented. Those stakeholders include the child, family, audiologist, early intervention service providers, cochlear implant team, SLP, and members of the educational team. With the introduction and growing utilization of cochlear implants, educators and clinicians in Northeast Ohio had questions and significant frustrations about the device and the impact of this technology on children with hearing loss. But these questions and important insights were not shared readily with the children's cochlear implant teams; an invisible wall seemed to be preventing communication between the parties.

To address the issue, representatives of the RIHP contacted national organizations, area cochlear implant centers, and cochlear implant manufacturers to identify existing protocols for facilitating communication among agencies, clinics, and schools serving children who use cochlear implants. A review of 
literature revealed forms used for these purposes; however, no systematic, negotiated communication process was found. In response to this challenge, RIHP issued a call-to-action, initiating a brainstorming session to facilitate communication among these parties and establish a positive working relationship. NOCCCI is the result of that call-to-action.

NOCCCI's primary aim is to improve communication among the stakeholders involved with children who use cochlear implants to create strong teams that help these children meet their optimal achievement levels. Over the past 3 years, NOCCCI has continuously evolved and responded to the needs of professionals serving children with cochlear implants. Between 2007 and 2009, NOCCCI organized and delivered an annual Educators' Forum: Have a Great School Year with a Child with a Cochlear Implant in Your Classroom! Professionals from northeast Ohio representing a range of specialties, as well as professionals from the Ohio School for the Deaf, have presented numerous lectures for nearly 500 teachers, SLPs, administrators, teachers of the deaf, students in training, and early interventionists who will encounter children who use cochlear implants in school settings. Trainees have been actively involved in participating and volunteering in these educational forums, working along with audiology students from the Northeast Ohio Audiology Consortium, the joint doctorate of audiology program for UA and KSU. NOCCCI is currently investigating the possibility of expanding its work to other parts of the state and beyond.

\section{Concluding Thoughts}

When UA's early intervention aural habilitation clinic was conceived in 1981, neither of the authors of this article could have imagined the challenges the UA clinic would experience. This clinic that started as a small support and information group for university students who had hearing loss quickly evolved into a comprehensive pediatric aural habilitation clinic for families seeking to maximize their child's use of new technology, which continues to evolve at a rapid pace.

The demographics of the clients at the UA clinic have changed as well. Initially, "early" identification was defined as age 3, whereas currently the clinic's youngest client is 3 months old. While serving a far younger clientele, clinic staff continue to see children who have hearing loss who were identified and received amplification or implants late. Despite the widespread implementation of newborn hearing screening, children's hearing loss continues to be overlooked or misdiagnosed. Consequently, tomorrow's leaders in deaf education, speech-language pathology, and audiology face many and varied challenges. While there will continue to be issues and obstacles, those experiences will be tempered with the promise that the "new generation" of children who are deaf or hard of hearing who embark on the incredible journey that advanced technologies can offer. The trainees are uniquely positioned to work with this new generation of children. 


\section{References}

American Speech-Language-Hearing Association (ASHA). (2008). Service provision to children who are deaf and hard of hearing, birth to 36 months. Retrieved March 20, 2010, from http:/ / www.asha.org/docs/html/TR2008-00301.html. Dornan, D., Hickson, L., Murdoch, B., \& Houston, T. (2009). Longitudinal study of speech perception, speech, and language for children with hearing loss in an auditory-verbal therapy program. The Volta Review, 109(2-3), 61-85.

Geers, A.E. (2003). Predictors of reading skill development in children with early cochlear implantation. Ear \& Hearing, 24(1), 59S-68S.

Geers, A.E., Nicholas, J.G., \& Sedey, A.L. (2003). Language skills of children with early cochlear implantation. Ear \& Hearing. 24(1), 46S-58S.

Luckhurst, J.A. (2008). Professional preparedness for provision of auditory/ oral programs to children with hearing loss: Results of a survey. Perspectives on Aural Rehabilitation and Its Instrumentation, 15, 18-28.

Madell, J.R., \& Flexer, C. (2008). Pediatric audiology: Diagnosis, technology, and management. New York, NY: Thieme.

Nicholas, J.G., \& Geers, A.E. (2006). Effects of early auditory experience on the spoken language of deaf children at 3 years of age. Ear $\mathcal{E}$ Hearing, 27(3), 286-298.

Robertson, L. (2009). Literacy \& Deafness: Listening and Spoken Language. San Diego, CA: Plural Publishing, Inc.

Teagle, H.F.B., \& Moore, J.A. (2002). School-based services for children with cochlear implants. Language, Speech, and Hearing Services in Schools, 33, 162-171.

White, K.R. (2006). Early intervention for children with permanent hearing loss: Finishing the EHDI revolution. The Volta Review, 106(3), 237-258.

Wilson, K. (2006). Beyond early intervention: Providing support to public school personnel. The Volta Review, 106(3), 419-431. 

The Volta Review, Volume 110(2), Summer 2010, 315-322

\title{
Program Profile
}

\section{The University of Southern Mississippi: Developing a State-of-the-Art Graduate Program in Early Oral Intervention}

\author{
Christina B. Perigoe, Ph.D., CCC-SLP, CED, LSLS Cert. AVT, and \\ Henry Teller, Ed.D., C.E.D.
}

\section{Introduction}

The graduate program in Early Oral Intervention for Children who are Deaf and Hard of Hearing at The University of Southern Mississippi (USM) in Hattiesburg, MS, is the result of several circumstances. First, sizeable populations of individuals who are deaf or hard of hearing residing in Mississippi were not being reached by early auditory intervention. In 1997, Mississippi mandated newborn hearing screening, resulting in screenings of 42,000 to 45,000 babies annually (National Center for Hearing Assessment and Management [NCHAM], "Mississippi summary," n.d.; "State summary," n.d.). The Mississippi Department of Health estimates that approximately 650 infants in Mississippi do not pass the newborn hearing screening each year, and between 70 and 87 of those infants are confirmed to have a hearing loss (E. Short, personal communication, March 1, 2010).

Second, new technologies, such as cochlear implants, continue to advance to help this population access sound, provided substantial post-operative intervention is available (Cole \& Flexer, 2007). In Mississippi and the surrounding states, there were clear and demonstrable gaps in the availability of professionals trained to use current best practices to serve the educational needs of young children who are deaf or hard of hearing and seeking a listening and spoken language outcome (U.S. Department of Education, 2006a). In addition, the state had a large community of practitioners, interest groups, and university educators committed to increasing the number of highly qualified

Christina B. Perigoe, Ph.D., CCC-SLP, CED, LSLS Cert. AVT, is Coordinator of the Early Oral Intervention Graduate Program in Speech and Hearing Sciences at The University of Southern Mississippi. Henry Teller, Ed.D., C.E.D., is Professor and Director of the Education of the Deaf Programs at The University of Southern Mississippi. Correspondence concerning this article should be addressed to Dr. Teller at henry.teller@usm.edu. 
interventionists trained to maximize the potential of children with hearing loss in Mississippi and the southeastern United States.

Third, a collaborative relationship between USM and an OPTION school led to the graduate program's creation. Since 1995, the comprehensive undergraduate Education of the Deaf program at USM has collaborated with Magnolia Speech School (Magnolia), a private OPTION school 2 hours away in Jackson, MS, that teaches children with hearing loss to communicate primarily through listening and spoken language and provides practicum and student teaching experiences for professionals preparing to work with school-aged children who are deaf or hard of hearing. Over the years, Magnolia has employed a number of USM graduates. Magnolia has a strong reputation for serving the needs of students with hearing loss in the greater Jackson area, but few other services in the state use the techniques needed to develop listening and spoken language, particularly with children ages 0 to 6 years old.

In 2001, a private foundation (that prefers to remain anonymous) became aware of the collaborative relationship between Magnolia and USM, and encouraged the programs to develop an undergraduate course that focused on listening and spoken language outcomes and provided concurrent field experiences. In 2002, the two organizations were awarded a foundation grant to develop and offer the course on the USM campus along with field experiences at Magnolia.

This collaborative university-OPTION school relationship was an immediate success. The USM undergraduate students in deaf education receive instruction in auditory-based education from the Magnolia faculty, students, and families. In addition to learning from lectures, videotapes, and class discussions, students visit Magnolia several times to observe teaching demonstrations and to participate and assist in the classrooms. The Magnolia director also invites parents and children to the class, affording USM students an opportunity to speak to parents about choosing listening and spoken language for their child and their experiences raising a child in an auditory-based environment. This undergraduate-level course was the impetus to development a graduate program with a concentration in listening and spoken language.

\section{Developing a Graduate Program}

In 2004, the directors of the USM undergraduate program and Magnolia provided a proposal to the same private foundation to create a concentrated graduate program in early auditory intervention for children who are deaf or hard of hearing. In 2006, the team received a grant to design and develop the new graduate program.

During the 2006-2007 academic year, the USM and Magnolia directors conducted extensive research to develop a state-of-the-art program in auditorybased learning with an emphasis on early intervention. This research included a broad review of the literature and visits to several universities, 
including Washington University in St. Louis, Fontbonne University, Vanderbilt University, and the University of San Diego, which all have strong course offerings and field experiences in teaching listening and spoken language skills to young children. To arrive at a best practice model, the planning team - which included Dr. Henry Teller, Director of the Education of the Deaf Program at the University of Southern Mississippi; Anne Sullivan, Executive Director of Magnolia Speech School; and Charlotte Bledsoe, Parent-Infant Coordinator at Magnolia Speech School - conducted interviews with directors, faculty, graduate students, parents, and early auditory intervention practitioners. In addition, the team visited several OPTION schools including the Moog Center for Deaf Education, Central Institute for the Deaf, St. Joseph Institute for the Deaf, the Mama Lere Hearing School at Vanderbilt University, and the John Tracy Clinic. Observations of teaching and interviews with program directors and staff further guided program development. Through this research, a set of competencies and best practices for developing listening and spoken language emerged. The research and interviews also produced a profile of characteristics that comprise the best candidates to work in programs serving young children with hearing loss and their families (Teller, Sullivan, \& Perigoe, 2009).

In the spring of 2007, Dr. Christina Perigoe was contracted to assist in developing the program's curriculum. Working with the USM and Magnolia directors, Dr. Perigoe used her experience in teaching listening and spoken language and in developing training programs for professionals to work with young children who are deaf or hard of hearing and their families to develop 14 new courses for the new graduate program. Combined with three existing courses, the curriculum formed a 42-hour Early Oral Intervention program. By December 2007, all curriculum committees and the Office of Graduate Studies at USM had approved the new Master of Science in Education of the Deaf degree with a Concentration in Early Oral Intervention for Children who are Deaf and Hard of Hearing.

The program team submitted a formal application to the Mississippi Department of Education for a new licensure in Early Oral Intervention in August 2008; licensure was granted in September 2009. Students completing the USM Early Oral Intervention program are now eligible for the Class AA master's degree-level teacher licensure in Early Oral Intervention in the state of Mississippi to work with children ages birth to kindergarten.

The first cohort began the new graduate program in the 2008-2009 academic year and included six full-time graduate students who had received full-tuition scholarships from the same foundation that supported the program's development. During the program's first year, most of the graduate students lived in the Hattiesburg area and commuted 100 miles to Jackson twice a week for practicum and classes. For the second semester, most of the students relocated to the Jackson area, finding it easier to commute to Hattiesburg one day a week for Friday and weekend classes. It also was discovered that students with undergraduate degrees in speech-language pathology 
required additional seminars to increase their foundational knowledge of deaf education.

In July 2009, five of the first cohort of students completed the program and received multiple job offers in public and private programs to work with young children who were deaf or hard of hearing and their families. Two graduates were employed to begin new programs in early auditory intervention one in North Dakota and another at the Mississippi School for the Deaf in Jackson. Another graduate accepted a position in the First Steps program with the Mississippi Department of Health, providing early auditory intervention services to very young children and their families in home settings. Two graduates accepted positions in public school systems providing early auditory intervention services to young children and their families and speech services to other children. The sixth student did not complete the final semester and opted to pursue a doctorate in audiology.

The second cohort of graduate students began in the summer of 2009 after the program start date was moved to June rather than August. The extra summer session spread out the students' course load over 4 semesters. In addition, the first summer session also included a perspectives course to ensure that students had a thorough and contemporary orientation to deaf education.

Other changes implemented for the second cohort of students included recommended residency in the Jackson area, where most of the practicum experiences were offered. Fall and spring semester classes were offered in the afternoons and evenings at Magnolia or taught from USM in Hattiesburg via videoconferencing.

Four full-time students were accepted the second year of the program. Three part-time students were also admitted and expect to complete the program over a 2-year period. The part-time students included two experienced teachers of the deaf from Magnolia and a speech-language pathologist already providing clinical services at The University of Mississippi's Department of Communication Disorders in Oxford, MS. Part-time students commuted to classes in Hattiesburg; attended classes offered at Magnolia; and took classes via videoconferencing.

Because courses developed for the Early Oral Intervention program are based on a best practice model, the topics covered strongly reflect the nine domains of listening and spoken language defined by the AG Bell Academy for Listening and Spoken Language (AG Bell Academy for Listening and Spoken Language, 2007) (see the Table for a comparison). The nine domains support the importance of parent involvement (U.S. Department of Education, 2006b; Simser,1999), culturally sensitive family-centered practice (NCHAM, "Culturally competent", n.d.), early intervention to stimulate auditory brain development (Cole \& Flexer, 2007; Sharma \& Dorman, 2006), spoken language communication (Blamey et al., 2001; Perigoe, 1999, 2001), and early literacy (Robertson, 2009). 
Table. Comparison of nine domains of listening and spoken language and USM early oral intervention graduate program courses

\begin{tabular}{|c|c|}
\hline $\begin{array}{l}\text { Nine Domains of Listening } \\
\text { and Spoken Language }\end{array}$ & $\begin{array}{c}\text { The University of Southern Mississippi Early Oral } \\
\text { Intervention Courses }\end{array}$ \\
\hline $\begin{array}{l}\text { 1. Hearing and Hearing } \\
\text { Technology }\end{array}$ & $\begin{array}{l}\text { - Audiological Assessment and Management of Infants } \\
\text { and Young Children } \\
\text { - Special Topics in Hearing Technology for Young } \\
\text { Children }\end{array}$ \\
\hline 2. Auditory Functioning & $\begin{array}{l}\text { - Audiological Assessment and Management of Infants } \\
\text { and Young Children } \\
\text { - Auditory-Verbal Development and Practice }\end{array}$ \\
\hline 3. Spoken Language & - Speech Perception and Production \\
\hline Communication & $\begin{array}{l}\text { - Assessment and Development of Listening, Speech and } \\
\text { Spoken Language } \\
\text { - Language Development with Infants and } \\
\text { - Young Children with Hearing Loss }\end{array}$ \\
\hline 4. Child Development & $\begin{array}{l}\text { - Implementing a Family-Centered Early Oral } \\
\text { Intervention Program }\end{array}$ \\
\hline $\begin{array}{l}\text { 5. Parent Guidance, } \\
\text { Education, Support }\end{array}$ & $\begin{array}{l}\text { - Implementing a Family-Centered Early Oral } \\
\text { Intervention Program } \\
\text { - Foundations in Adult Education } \\
\text { - Special Topics in Working with Young Children with } \\
\text { Hearing Loss }\end{array}$ \\
\hline $\begin{array}{l}\text { 6. Strategies for LSL } \\
\text { Development }\end{array}$ & $\begin{array}{l}\text { - Auditory-Verbal Development and Practice } \\
\text { - Language Development with Infants and } \\
\text { - Young Children with Hearing Loss } \\
\text { - Special Topics in Working with Young Children with } \\
\text { Hearing Loss }\end{array}$ \\
\hline $\begin{array}{l}\text { 7. History, Philosophy, } \\
\text { Professional Issues }\end{array}$ & $\begin{array}{l}\text { - Special Problems } \\
\text { - Auditory-Verbal Development and Practice }\end{array}$ \\
\hline 8. Education & $\begin{array}{l}\text { - Pre-academic Readiness/Early Literacy } \\
\text { - Advanced Clinical Practicum }\end{array}$ \\
\hline 9. Emergent Literacy & $\begin{array}{l}\text { - Pre-academic Readiness/Early Literacy } \\
\text { - Designs in Research for Speech and Hearing } \\
\text { - Research Applications } \\
\text { - Assessment Procedures for Young Children with } \\
\text { Disabilities } \\
\text { - Teaching Oral Deaf/Hard of Hearing Children with } \\
\text { Multiple Challenges }\end{array}$ \\
\hline
\end{tabular}

Full course outlines are available from the USM website at www.usm.edu/shs/deaf.

In addition, graduate students complete two courses in assessment and intervention with children who have additional disabilities or learning challenges. They also complete two courses in research and are required to design, conduct, and present their findings on a research topic related to their graduate study. 


\section{Program Evaluation}

To evaluate the effectiveness of the graduate program, students in the first cohort were pre- and post tested on the areas identified in the best practice model and covered in the coursework presented in Table 1. The posttest was administered as one part of a day-long comprehensive examination at the conclusion of the 12-month program. Students received no formal review prior to testing, but relied on their ability to integrate information gained through coursework and practicum experiences. The test consisted of fill-in-the blank and short essay questions to determine whether students had gained the requisite knowledge. The pre- and postassessment measures contained identical test questions, which were scored out of a total of 100 points.

Although all students had undergraduate degrees in speech and hearing, they scored less than $50 \%$ on the pretest of their knowledge of intervention with young children with hearing loss and their families. Posttest results showed that the students had gained considerable knowledge of the field. The results indicated gains of 35.3 to 61.1 points, with an average gain of 45.46 points. Interestingly, the student with the lowest pretest score $(29.4 \%)$ showed the most gain (61.1 points) to achieve a final score of $90.5 \%$. These results, and the performance of the graduate students in coursework, practicum experiences, and comprehensive examination, confirmed to faculty that the learning experiences were appropriate and pedagogically sound.

\section{A Regional Center of Excellence}

The graduate program at USM is the only program in the southeastern United States offering professional training and licensure in Early Oral Intervention for children who are deaf or hard of hearing. USM is also a member of an Academic Common Market, a coalition of 16 southern states that offers students living in those states the opportunity to pursue a degree at instate tuition rates, provided no university in the student's home state offers a similar program (Southeastern Regional Education Board, n.d.). Since USM is the only program in the region offering a graduate degree in Early Oral Intervention, it can accept students from every state in the Academic Common Market without charging out-of-state tuition - a savings of approximately $\$ 8,000$ per student (USM, 2009).

The USM program in Early Oral Intervention was developed from researchbased best practices and remains current through regularly scheduled seminars and workshops conducted by leaders in the fields of audiology, technology, teaching, and family-centered intervention. Plans call for cooperative clinical services in listening and spoken language on the Hattiesburg campus of USM and for the Mississippi Gulf Coast. The vision that was first articulated in 1995 is now changing the outlook of the region as graduates address the needs of school boards, schools for the deaf, and state-run organizations providing 
early intervention. In addition, we anticipate that neighboring states, such as Alabama, Georgia, and Florida, will not only hire program graduates, but will also contribute talented candidates to the graduate program and to the field for years to come.

\section{References}

AG Bell Academy for Listening and Spoken Language. (2007). AG Bell Academy international certification program for listening and spoken language specialists (LSLS): Nine domains of listening and spoken language. Retrieved January 9, 2010, from, http://nc.agbell.org/NetCommunity/ Page.aspx?pid=344.

Blamey, P.J., Sarant, J., Paatsch, L., Barry, J., Bow, C., Wales, R., et al. (2001). Relationships among speech perception, production, language, hearing loss, and age in children with impaired hearing. Journal of Speech, Language, and Hearing Research, 44(2), 264-285.

Cole, E.B., \& Flexer, C. (2007). Children with hearing loss: Developing listening and talking, birth to six. San Diego, CA: Plural Publishing, Inc.

National Center for Hearing Assessment and Management (NCHAM). (n.d.). Culturally competent family support. Retrieved December 30, 2009, from http://www.infanthearing.org/familysupport/index.html.

National Center for Hearing Assessment and Management (NCHAM). (n.d.) Mississippi summary of Universal Newborn Hearing Screening legislation. Retrieved December 31, 2009, from http://www.infanthearing.org/ legislative/summary/mississippi.html.

National Center for Hearing Assessment and Management (NCHAM). (n.d.). State summary statistics: Universal Newborn Hearing Screening. Retrieved December 31, 2009, from http://www.infanthearing.org/status/unhsstate. html.

Perigoe, C. (2001). Listening: The road to spoken language. The Listener. Fall 2001, 43-46.

Perigoe, C. (1999). Facilitating early speech development. Australian Journal of Education of the Deaf, 5, 43-48.

Robertson, L. (2009). Literacy and deafness: Listening and spoken language. San Diego, CA: Plural Publishing, Inc.

Sharma, A., \& Dorman, M. (2006). Central auditory development in children with cochlear implants: Clinical implications. Advanced Otorhinolaryngology, 64, 66-88.

Simser, J. (1999). Parents: The essential partner in the habilitation of children with hearing impairment. Australian Journal of Education of the Deaf, 5, $55-62$.

Southeastern Regional Education Board. (n.d.). Academic Common Market. Retrieved December 31, 2009, from http://www.sreb.org/page/1304/ academic_common_market.html. 
Teller, H., Sullivan, A., \& Perigoe, C. (2009). Identifying qualities of successful graduate students. Volta Voices, 16(6), 20-21.

United States Department of Education, Office of Special Education and Rehabilitative Services. (2006a). Letter to Part C coordinators dated July 21, 2006. Retrieved January 7, 2010 from http://www.infanthearing.org/ earlyintervention/index.html.

United States Department of Education, Office of Special Education and Rehabilitative Services. (2006b). Opening doors: Technology and communication options for children with hearing loss. Retrieved January 7, 2010 from http:// www.ed.gov/about/offices/list/osers/products/opening_doors/index. html.

The University of Southern Mississippi. (2009). Tuition and out-of-state charges: Fall 2009/Spring 2010. Retrieved January 8, 2010 from http:// www.usm.edu/bizserv/FA\%202009_SP2010.html. 
The Volta Review, Volume 110(2), Summer 2010, 323-330

\title{
Program Profile
}

\section{Utah State University: Cross-Discipline Training Through the Graduate Studies Program in Auditory Learning \& Spoken Language}

\author{
K. Todd Houston, Ph.D., CCC-SLP, LSLS Cert. AVT
}

\section{Introduction}

Since 1946, Utah State University (USU) has offered specialized coursework in audiology and speech-language pathology, awarding the first graduate degrees in 1948. In 1965, the teacher training program in deaf education was launched. Over the years, the Department of Communicative Disorders and Deaf Education (COMD-DE) has developed a rich history of research and personnel preparation, especially in the areas of childhood hearing loss, family-centered early intervention, and educational audiology. For example, the SKI*HI Institute, a program developed by COMD-DE faculty, has been training early intervention professionals to work with young children with hearing loss, blindness, or deaf-blindness and their families since 1972.

Today, there is growing consensus that a scarcity of educators and related professionals exists (i.e., pediatric audiologists and speech-language pathologists) who are trained and knowledgeable about the current methods of effectively identifying, assessing, and educating young children with hearing loss, especially those children who are acquiring spoken language $\mathrm{JCIH}$, 2007; Proctor, Niemeyer, \& Compton, 2005). Recognizing the opportunity to provide in-depth graduate training to students in audiology, speechlanguage pathology, and deaf education, faculty within COMD-DE and the USU Department of Psychology, developed the Graduate Studies Program in Auditory Learning and Spoken Language (GSPALSL) in 2007 to meet this growing need for preservice training. Initially, expenses for students selected

K. Todd Houston, Ph.D., CCC-SLP, LSLS Cert. AVT, is an Assistant Professor of SpeechLanguage Pathology and Director of the Graduate Studies Program in Auditory Learning $\mathcal{E}$ Spoken Language in the Department of Communicative Disorders and Deaf Education at Utah State University. For more information about this program, contact Dr. Houston at todd.houston@usu.edu. 
to complete the GSPALSL were funded entirely by a private, nonprofit foundation. While the foundation continues to provide tuition support and stipends to students who major in deaf education and special education, students in audiology and speech-language pathology receive tuition support and stipends through a personnel preparation training grant (2008-2012) awarded by the U.S. Department of Education Office of Special Education Programs and Rehabilitative Services (OSEP).

\section{A Commitment to Interdisciplinary and Transdiciplinary Graduate Training}

There is little argument that children under age 5 require practitioners whose knowledge and skills differ from those who are serving older, schoolage children (Hanson \& Bruder, 2001; McCollum, 2000). Personnel preparation programs must recognize these differences and design specialized training programs that meet the communicative and developmental needs of these young children and their families (Bruder \& Dunst, 2005; Campbell, Chiarello, Wilcox, \& Milbourne, 2009). For children with hearing loss, new practitioners must be well-versed in delivering direct, family-centered services that facilitate attainment of developmental and communicative milestones (Rice \& Lenihan, 2005). Likewise, because of family-centered early intervention, multiple professionals - such as audiologists, speech-language pathologists, early interventionists, physicians, nutritionists, physical therapists, and occupational therapists - may be simultaneously co-treating or serving the child and family. Thus, there is a growing need for early intervention practitioners to work across disciplines to serve children and their families through interdisciplinary and transdisciplinary teams (Bruder \& Dunst, 2005; King, Strachan, Tucker, Duwyn, Desserud, \& Shillington, 2009).

Vanderhoff (2009) describes several teaming models used in service delivery for young children and their families. Interdisciplinary teams are defined as: "[I]nteraction among the team members for the assessment and development of the intervention plan (IFSP). The team determines the best method for service delivery that may include one or more providers" (p. 1). Similarly, transdisciplinary teaming is described as: "[O]ne team member provides all of the interventions. To accomplish this, other members must teach the service provider aspects of their discipline. Therapists may teach others activities or intervention strategies that do not require the expertise of the therapist" (p. 2). Within the transdisciplinary team, care must be taken to ensure that professional ethics and scopes of practice are carefully defined and followed. However, transdisciplinary models have been recognized as best practices for early intervention (Bruder, 2000; Guralnick, 2001).

Because COMD-DE prepares students in three key disciplines serving children with hearing loss - audiology, speech-language pathology, and education both interdisciplinary and transdisciplinary teaming models are incorporated 
within the GSPALSL. Students often are paired with peers in a different discipline to develop an intervention plan and/or to provide direct services under appropriate faculty supervision. Students also have the opportunity to work across disciplines to deliver intervention or educational services. For example, a graduate student in audiology may provide direct early intervention services that focus on the acquisition of spoken language. Typically, these services would be provided by either a teacher of the deaf or a speech-language pathologist. While the audiology student may not intend to provide these services (i.e., aural habilitation) after graduation, he or she will learn firsthand how these services should be delivered. By developing goals for early intervention in listening and spoken language, coaching parents in service delivery, and experiencing the progress that most likely will occur in the child's communication acquisition, the audiologist will gain valuable clinical experience in service delivery. Faculty believe these learning opportunities will foster greater appreciation for other practitioners within the various fields and may lessen the tendency of future professionals to restrict themselves to a field.

\section{Structure of the Graduate Studies Program in Auditory Learning \& Spoken Language}

For students majoring in audiology or speech-language pathology, completing the GSPALSL is considered an emphasis within their major. That is, in addition to the standard coursework and requirements for a Master of Science in Speech-Language Pathology or Doctor of Audiology, students take additional courses and complete specialized practica and field-study experiences to develop specific knowledge and skills in the practice of pediatric audiology, auditory-verbal therapy, and auditory-based education for children with hearing loss ages 0 to 6 and their families.

Students who are seeking a graduate degree in education have two specific routes. First, if their undergraduate degree is in early childhood special education, they can specialize at the graduate level. These students obtain a Master of Science in Special Education - through the USU Department of Special Education and Rehabilitation - with an emphasis in auditory learning and spoken language acquisition for children with hearing loss, birth to age 6 . Conversely, if a student has an undergraduate degree in deaf education, he or she may elect to complete a newly established Master of Science in Auditory Deaf Education, which is granted through COMD-DE.

All students must complete 21-28 semester hours of focused coursework and practicum in auditory learning and spoken language acquisition for young children with hearing loss. The total number of emphasis courses taken at the graduate level will vary slightly depending on the student's undergraduate degree and experiences. Students majoring in audiology complete their emphasis during their second and third years of training, because their program of study is 4 years long. Students majoring in speech-language pathology, special 
education, or deaf education are able to complete their programs of study including the emphasis - in 2 years plus one additional summer semester.

\section{Core Coursework and Timeline}

Each new cohort of students selected to complete the GSPALSL, regardless of their major or program of study, begins each June (see the Table for the full coursework outline and timeline). For students in speech-language pathology, deaf education, or special education, the additional summer session occurs at the beginning of their training. Audiology students are already enrolled in their program and have completed their first year of graduate study. By starting each cohort in the summer when few other students are on campus, faculty have found that the students have a chance to build rapport with each other through a shared experience, which leads to stronger personal bonds as well as improved teamwork and collaboration across disciplines.

\section{Practicum and Externship Experiences}

Each semester, graduate students are assigned to complete practicum experiences in Sound Beginnings, an early intervention and preschool program

Table. Core coursework and timeline, Graduate Studies in Auditory Learning \& Spoken Language, Utah State University

\section{Summer 1}

COMD 6340: Facilitating Auditory Learning \& Spoken Language in Young Children with Hearing Loss ( 3 credits)

COMD 6630: Teaching Speech to Children who are Deaf \& Hard of Hearing (3 credits) COMD 6320: Language \& Emergent Literacy in Children with Hearing Loss (3 credits) COMD 6100: Advanced Clinical Practicum/Student Teaching (3 credits)

\section{Fall 1}

COMD 6850: Research Seminar in Auditory Learning \& Spoken Language (1 credit)

COMD 6580: Family Centered Practices for Children with Hearing Loss (3 credits)

COMD 6100: Advanced Clinical Practicum/Student Teaching (3 credits)

\section{Spring 1}

COMD 6850: Research Seminar in Auditory Learning \& Spoken Language (1 credit)

COMD 6730: Multiple Disabilities \& Hearing Loss in Children (3 credits)

COMD 6100: Advanced Clinical Practicum/Student Teaching (3 credits)

\section{Summer 2}

COMD 6100: Advanced Clinical Practicum/Student Teaching (3 credits)

\section{Fall 2}

COMD 7340: Pediatric Audiology (2-3 credits)

COMD 6100: Advanced Clinical Practicum/Student Teaching (3 credits)

\section{Spring 2}

COMD 6300: Externship in Auditory Learning \& Spoken Language

COMD 7520: Cochlear Implantation (2-3 credits) 
serving children with hearing loss from birth through age 6 and their families. Sound Beginnings, which is housed in the Edith Bowen Laboratory School on the USU campus, opened its doors in fall 2007 and served nine children who are deaf or hard of hearing. By spring 2010, enrollment had grown to 26 children, requiring six full-time educators (i.e., two classroom teachers, two speech-language pathologists, and two teacher assistants). Graduate students are assigned to provide classroom-based student teaching, individualized pullout speech, language, and listening therapy, "push-in" small group teaching within the classrooms, parent participation sessions in support of auditoryverbal therapy, home-based intervention, and lead parent-toddler groups.

The USU Speech-Language-Hearing Center (SLHC) is the primary inhouse practicum site for graduate students in audiology and speech-language pathology. Currently, most of the pull-out therapy is conducted within the SLHC, which is located across the street from Sound Beginnings. The SLHC houses multiple therapy rooms that can accommodate individual therapy sessions as well as small group teaching. Additionally, the SLHC provides a full range of audiological services for infants through adults, from diagnostics to hearing aid fitting and cochlear implant programming.

During at least one semester, students are required to complete an externship in a facility that supports auditory learning and spoken language in children with hearing loss. Thus far, students have been placed in sites throughout the United States and in one site in Australia. Students have preferred to be placed in private auditory / oral schools, auditory-verbal centers, private practices, cochlear implant programs, and public school programs supporting children with hearing loss. Each year, new sites have been added to the list of potential externship experiences, which now totals more than 20.

\section{Faculty and Sustaining Resources}

Since 2007, the USU COMD-DE has successfully recruited a total of 10 additional clinical, educational, and research faculty to train graduate students in each of the three disciplines. New faculty have worked collaboratively to develop curricula, secure practica and externship sites, teach new and expanded coursework, develop new lines of research, and create new opportunities for training and field-based experiences. Faculty have secured funding at the state and federal levels and from private foundations to support the ongoing training needs of graduate students as well as the educational and clinical services provided to children with hearing loss and their families.

In fall 2009, ground was broken for the new Emma Eccles Jones Early Childhood Education and Research Center, a \$25 million building that will house Sound Beginnings, faculty offices, research labs, and university classrooms for graduate training. Within the space dedicated to Sound Beginnings, there will be five new classrooms for children with hearing loss, six new "pull-out" therapy rooms with corresponding observation facilities, and an 
audiological suite designed to provide the full range of pediatric services, including diagnostics, hearing aid fitting, and cochlear implant programming. Faculty expect to move into the new building in summer 2010.

\section{Program Successes, Challenges, and Opportunities}

Since its inception, faculty and students within the GSPALSL have experienced several successes, weathered a few challenges, and in turn, developed new opportunities. In terms of successes, faculty have secured critical financial support from multiple sources, an especially difficult task during challenging economic conditions. In addition to financial support, the GSPALSL has enjoyed support from all levels of the USU administration. In fact, the Sound Beginnings classrooms have received visits from the university president and provost on numerous occasions, and they are very familiar with the range of training and educational services that are provided. At each of these administrative levels, there is recognition that the GSPALSL provides unique, cross-disciplinary training that does not occur at most other universities.

The challenges faced when developing a new emphasis or program of study are considerable - even when there is broad support. For example, integrating additional coursework work and practica into existing programs of study can be exceedingly difficult and requires careful and deliberate negotiation. Furthermore, in the case of the GSPALSL, coordinating the schedules of students enrolled in each of the three majors so that they could take courses together and participate in practicum proved to be an obstacle. However, by working with other faculty, solutions were found, such as scheduling practicum within Sound Beginnings in the mornings and moving the GSPALSL coursework to late evening or offering online alternatives. In the early stages, the faculty spent much of their time in program development ensuring that recruitment and admission procedures were in place, courses were developed, and practica placements were defined. Because of tenure-track responsibilities, faculty also were expected to teach courses, provide clinical supervision, conduct lines of research, participate in university service, publish refereed journal articles, and secure external funding. While these performance requirements are common for faculty at most research universities, finding a balance among these expectations has been critical for the success of each faculty member.

As the program has matured, the faculty at USU have been able to develop several new opportunities that will continue to expand graduate training for both preservice and in-service personnel. In summer 2009, for example, the Utah State Office of Education approved a new endorsement (i.e., certificate of training) in auditory learning and spoken language for children with hearing loss for professionals in the public schools who currently hold a teaching license. This allows teachers of the deaf, special educators, speech-language pathologists, and administrators an opportunity to be recognized for their specialized skills in serving children with hearing loss who are acquiring 
spoken language. In turn, professionals can now complete the endorsement by taking all of the GSPALSL coursework online. Since these professionals live throughout the state and are working full time, offering the courses at night or online were the only alternatives. Currently, eight professionals are enrolled, and more are expected to take advantage of the training in the future.

While some in-service professionals are opting to complete the endorsement, others are seeking additional training in the form of workshops. Since January 2008, more than 30 full-day workshops have been presented to over 400 professionals in Utah and Idaho who wish to improve their knowledge and skills in facilitating auditory learning and spoken language development in young children with hearing loss. Because of the demand for these workshops, faculty developed the Auditory Learning Institute (ALI), which now coordinates these training opportunities. The workshops are designed to support the content knowledge requirements articulated by the AG Bell Academy for Listening and Spoken Language for professionals pursuing certification as a Listening and Spoken Language Specialist (LSLS). Beginning in January 2010, one to two workshops are presented each month to meet these training needs.

A feasibility study of delivering early intervention services to infants and toddlers with hearing loss and their families through a model of tele-health has produced another opportunity for students and families alike. Using highspeed Internet connections and placing videoconferencing equipment in the families' homes, weekly auditory-verbal therapy has been offered for the past 18 months with favorable results. The children enrolled in the project are now performing at age level in their spoken language acquisition, the parents have become more comfortable in their ability to use strategies to promote listening and talking, and families have reported a preference for "tele-intervention" over more traditional, home-based early intervention services (Behl \& Houston, 2010). Furthermore, graduate students, under supervision from faculty, have been able to facilitate these tele-intervention sessions and are developing skills for the delivery of these services. Faculty continue to seek ways to expand student training in the area of tele-intervention/tele-health practices so that future graduates will leave the program with these unique and marketable skills.

Finally, another opportunity has presented itself in the area of doctoral training. In fall 2010, an emphasis in auditory learning and spoken language development for young children with hearing loss will be incorporated into the Doctorate in Speech-Language Pathology for students who have this professional interest. Because of continued shortages of university faculty, it is hoped this program will grow and eventually produce several new doctorallevel professionals each year.

\section{Conclusion}

Over the past three years, the GSPALSL has come to embrace a model of cross-disciplinary training for graduate students in audiology, speech-language 
pathology, and deaf education. This has been done to utilize interdisciplinary and transdisciplinary service delivery models and to demonstrate best practices for the children and families served through practica experiences. Because the program is relatively new, more work is needed to refine many aspects of graduate training; however, with continued university support at all levels, funding, and program expansion, the faculty at USU look forward to many years of providing innovative training opportunities at both the preservice and in-service levels.

\section{References}

Behl, D., \& Houston, K.T. (2010). Building family-provider relationships via teleintervention. Paper presented at the Early Hearing Detection \& Intervention (EHDI) Conference, Chicago, IL.

Bruder, M.B. (2000). Family-centered early intervention: Clarifying our values for the new millennium. Topics in Early Childhood Special Education, 20(2), 105-115.

Bruder, M.B., \& Dunst, C.J. (2005). Personnel preparation in recommended early intervention practices: Degree of emphasis across disciplines. Topics in Early Childhood Special Education, 25(1), 25-33.

Campbell, P.H., Chiarello, L., Wilcox, M.J., \& Milbourne, S. (2009). Preparing therapists as effective practitioners in early intervention. Infants $\mathcal{E}$ Young Children, 22(1), 21-31.

Guralnick, M.J. (2001). A developmental systems model for early intervention. Infants \& Young Children, 14(2), 1-18.

Hanson, M.J., \& Bruder, M.B. (2001). Early intervention: Promises to keep. Infants \& Young Children, 13(3), 47-58.

Joint Committee on Infant Hearing (JCIH). (2007). Year 2007 position statement: Principles and guidelines for early hearing detection and intervention programs. Retrieved April 26, 2010, from http://pediatrics.aappublications. org/cgi/content/full/120/4/898?ijkey=oj9BAleq21OlA\&keytype=ref\&site $\mathrm{id}=$ aapjournals.

King, G., Strachan, D., Tucker, M., Duwyn, B., Desserud, S., \& Shillington, M. (2009). The application of a transdisciplinary model for early intervention services. Infants \& Young Children, 22(3), 211-223.

McCollum, J.A. (2000). Taking the past along: Reflecting on our identity as a discipline. Topics in Early Childhood Special Education, 20(2), 79-86.

Proctor, R., Niemeyer, J., \& Compton, M.V. (2005). Training needs of early intervention personnel working with infants and toddlers who are deaf or hard of hearing. The Volta Review, 105(2), 113-128.

Rice, G.B., \& Lenihan, S. (2005). Early intervention in auditory/oral deaf education: Parent and professional perspectives. The Volta Review, 105(1), 73-96.

Vanderhoff, M. (2009). Maximizing your role in early intervention. American Physical Therapy Association. Retrieved March 20, 2010, from http:/ /www.apta.org. 
The Volta Review, Volume 110(2), Summer 2010, 331-338

\title{
Program Profile
}

\section{Professional Training in Listening and Spoken Language - A Canadian Perspective}

\author{
By Elizabeth Fitzpatrick, Ph.D., LSLS Cert. AVT
}

\section{Introduction}

Several factors undoubtedly influenced the development of listening and spoken language options for children with hearing loss in Canada. The concept of providing auditory-based rehabilitation was popularized in Canada in the 1960s through the work of Drs. Daniel Ling and Agnes Ling (Ling Phillips, 1990) in Montreal. The Lings founded the McGill University Project for Deaf Children in 1966 (Ling Phillips, 1990), and through their work brought attention and a research focus to early identification and intervention as well as recognition that parent guidance and participation are fundamental to rehabilitation. Several years later in 1975, Daniel Ling and the McGill University School of Human Communication Disorders established a training program in Auditory/Oral (Re)habilitation and Education of the Hearing-Impaired (Ling \& Ling, 1978), the first in Canada and one of few worldwide dedicated to the training of professions in aural rehabilitation (Ling Phillips, 1990). Through teaching, research, and publications, and subsequently through many graduates, the Lings had considerable influence on the development of rehabilitation and education for children with hearing loss in Canada, particularly in central Canada.

Professionals and parents who directly trained with the Lings or who interacted with them through other learning opportunities have gone on to become leaders in the field of auditory-verbal studies. For example, several graduates have become leaders at well recognized programs such as the Children's Hospital of Eastern Ontario, Montreal Oral School for the Deaf, and the Vancouver Oral Centre for Deaf Children (currently the Children's Centre for Hearing and Speech). Parents who received services from the Lings and who were encouraged by the outcomes undoubtedly influenced and contributed to the development of new programs and parent support groups. Since then, many other regions of Canada have established auditory

Elizabeth M. Fitzpatrick, Ph.D., LSLS Cert. AVT, is an Assistant Professor in the Faculty of Health Sciences Audiology-Speech-Language Pathology Program at the University of Ottawa in Ottawa, Canada. For more information, contact Dr. Fitzpatrick at elizabeth.fitzpatrick@uottawa.ca. 
intervention programs; however, therapy methods and service delivery models are often geographic-specific, with considerable variation between provinces and cities.

Parent associations have also had a tremendous impact on developing and shaping new programs throughout Canada. Early programs at the Montreal Oral School for the Deaf, founded in 1950, and the Children's Centre for Hearing and Speech, founded in 1963, arose from parents' efforts to provide oral communication for their children (Ling Phillips, 1990). A more recent example of parent advocacy and determination is the establishment of the Central Speech and Hearing Clinic in Winnipeg, Manitoba, in 1989 (Fitzpatrick, 1994). Parents who were travelling out of province to access auditory-verbal services assembled the support of community leaders, politicians, professionals, and other parents to create their own clinic to address a perceived need for auditorybased services.

Parent associations, such as VOICE for Hearing Impaired Children, which has a network of chapters throughout Ontario and in several other provinces, have played critical roles, not only in parent support and advocacy but also in the development of listening and spoken language services. For example, VOICE for Hearing Impaired Children is currently engaged in training professionals in auditory-verbal practice. The association has been involved in securing funding to develop professional training programs, including innovative models of training such as the Auditory-Verbal Training and Mentoring Program, which provides field training to help prepare teachers of the deaf to become certified as auditory-verbal educators (LSLS Cert. AVEd) (Bernstein, 2009). Through these initiatives and political advocacy, VOICE is working to establish standards of professional practice across Ontario and has recently created an alliance with other associations to improve standards of care by ensuring equitable access to all children with hearing loss throughout the province (Borer, 2009).

In Ontario, with its population of approximately 11 million, cities such as Toronto and Ottawa have been served by certified Listening and Spoken Language Specialists (LSLS) for many years. ${ }^{1}$ Many professionals from Canada and elsewhere helped create and manage the certification process. In fact, Ontario had the largest number of LSLS certified auditory-verbal therapists (Cert. AVT) in North America for many years. In 2002, Ontario implemented the first provincially mandated universal newborn hearing screening (UNHS) initiative in Canada. Since its inception, the Ontario Infant Hearing Program (IHP) has funded not only screening and diagnostic audiological services but also early communication development services. Reports suggest that since the implementation of the screening initiative, more than $90 \%$ of families choose a listening and spoken language communication option (Ontario Ministry of

\footnotetext{
${ }^{1}$ A number of professionals have embraced the certification process since the 1990s, and were among the first to adopt the LSLS certification.
} 
Children and Youth Service, personal communication, 2009). Although certification as a LSLS is not required to deliver services funded through the IHP, many therapists have received additional training in auditory-verbal practice. However, respect for and the availability of all approaches is an important hallmark of the Ontario IHP initiative (Hyde, 2005). More recently, largely due to the advocacy of VOICE, interest in ensuring the provision of auditoryfocused services to all age groups, not just to preschoolers, has increased.

\section{Services in Canada}

Throughout Canada, publicly funded programs have implemented services focused on listening and spoken language both in clinical and school-based settings. Given Canada's publicly funded health care and education services for children with hearing loss, few LSLS practice in private settings. Early family-centered auditory-verbal services have been provided by a variety of practitioners, including teachers of the deaf and hard of hearing, speechlanguage pathologists, and audiologists through clinical programs such as the Children's Hospital of Eastern Ontario in Ottawa (Fitzpatrick, 1997), schooloperated services such as the Montreal School for the Deaf and the Children's Centre for Hearing and Speech, and more recently funded community-health based programs such as the IHP offered through Toronto Public Health Services. Services for school-aged children tend to be provided by specialized teachers of the deaf and hard of hearing who provide itinerant services in the children's home schools in most regions, although speech-language pathologists and audiologists also may be involved in care. Not surprisingly, regions of Canada that were early adopters of auditory-verbal practice established strong district-based itinerant teacher services to support students in mainstream school settings, such as the Ottawa Carleton Board of Education (Biro et al., 1985) and school districts in the greater Toronto area (Boothroyd-Turner, 1990). In some regions, hospital and school services have worked collaboratively to facilitate the transition between clinical preschool and school services (Eriks-Brophy, Durieux-Smith, Olds, Fitzpatrick, Duquette, \& Whittingham, 2006; Fitzpatrick, 1997).

Within Canada, little differentiation has been made between aural habilitationists, a term commonly used in the 1980s to describe specialists in spoken language development prior to adoption of the terms such as auditory-verbal therapy and auditory-verbal practitioners or LSLS. Given that few therapists work privately, and that the majority of practitioners in auditory-verbal practice focus entirely on children with hearing loss as opposed to those with other communication disorders, there has been little need to compartmentalize one's practice into domains such as aural habilitation, speech-language pathology, and auditory-verbal practice. Indeed, for most Canadian practitioners, auditory-verbal practice is an umbrella term that encompasses knowledge and skills from all these fields to specifically serve children with hearing loss. 
Intervention with children with hearing loss through auditory-based educational techniques became standardized and attained new levels of professional recognition through a certification process developed by Auditory-Verbal International, Inc., now managed by the AG Bell Academy for Listening and Spoken Language. In Canada, professionals working in listening and spoken language readily embraced the LSLS certification. In particular, Ontario welcomed the professional certification and has a large concentration of certified LSLS, the overwhelming majority employed in hospital, clinical, or school settings. Other specialists, who trained through the McGill program or elsewhere, already were practicing auditory-focused methods in schools, clinics, and community settings.

\section{Professional Training Needs}

New developments in audiology and medicine continue to raise expectations for spoken language communication and the positive social-emotional development of children with hearing loss. The unlimited opportunities offered by early identification and intervention coupled with advanced technologies have created an even greater need for family-centered therapies focused on early language acquisition for children with hearing loss. Although some regions of Canada have long enjoyed a wealth of expertise in listening and spoken language development, there is a growing awareness and recognition that a large number of certified LSLS will reach retirement age in the next few years, and that some regions are or will become underserved. In addition, the growth of universal newborn screening initiatives and particularly the observed outcomes in children receiving cochlear implants has ignited new interest in auditory-based therapies on national and international levels.

Since the closure of the McGill graduate program in 1990, no Canadian university has had a program dedicated to graduate training of listening and spoken language professionals. Teacher training programs are available at many Canadian universities including the University of British Columbia, Mount St. Vincent University, and York University. York University offers a Deaf and Hard of Hearing Teacher Education diploma program with an optional specialization in oral/aural communication (http://edu.yorku.ca/deafed). The University of Ottawa offers a similar diploma in French. These programs provide comprehensive teacher education, which adheres to standards established by the Canadian Association of Educators of the Deaf and Hard-of-Hearing (www.caedhh.ca). The University of Moncton, New Brunswick, offers a certificate for teaching children who are deaf and hard of hearing with a focus on auditory-verbal therapy in the French language (www.umoncton.ca/ repertoire/etudes_sup/prog_educ_cert_2cyc_ens_elev_malent.htm). These programs are geared towards teachers and do not address the need for specialized skills in other professional disciplines. Preliminary findings from recent focus groups and interviews of Canadian health and education professionals 
working in listening and spoken language suggest that there is good support for and interest in specialized professional training beyond what is typically offered in professional degree programs in speech-language pathology, audiology, and education of the deaf and hard of hearing.

\section{The University of Ottawa Program}

Specialized university-based training in the development of listening and spoken language for children with hearing loss appears timely. Currently, all but two Canadian provinces have established or are implementing newborn hearing screening programs, and pediatric cochlear implantation has become standard practice for children with profound hearing loss whose parents choose spoken communication. Concern about the potential lack of highly qualified professionals in auditory-verbal practice prompted a group of practitioners to initiate a collaborative professional training project with the Audiology and Speech-Language Pathology Program at the University of Ottawa. The early planning, led by Dr. Andrée Durieux-Smith at the University of Ottawa, provided the foundation for a new training initiative. The university is embarking on a new graduate Certificate in Auditory-Verbal Studies to be offered in 2010 .

To develop the program, investigators at the University of Ottawa recently conducted focus group interviews with practitioners across seven centers who shared their perspectives on program content and delivery, and the needs of future practitioners in listening and spoken language development. Preliminary analysis indicated that practitioners stressed the need for coursework focused on technology, special populations, assessment, and listening and spoken language techniques as well as intensive practicum experiences. These findings and a planning workshop with 12 practitioners from clinical and educational settings have guided the program's content.

The program includes a theoretical base, skill development, and practicum placements. The certificate will require 15 graduate-level credits consisting of 3 courses ( 9 credits, or approximately 120 classroom hours) and approximately 300 hours of practica targeting young children and their parents as well as school-age populations. The program design recognizes the interdisciplinary nature of LSLS by providing advanced training to new graduates and practitioners who have graduate degrees in education of the deaf and hard of hearing, speech-language pathology, or audiology. The program builds on students' prior learning, and its interdisciplinary nature is both a strength and challenge for this new initiative. It is anticipated that the certificate will complement existing teacher training programs as well as professional graduate programs in audiology and speech-language pathology. As health and educational services transition to an increased focus on listening and spoken language development for children with hearing loss, this program has the potential to respond to an important need. 
Developed in consultation with practitioners in the field, the course content aligns with the AG Bell Academy for Listening and Spoken Language nine domains of listening and spoken language (see Monograph Appendix A), and will be revised as required to ensure that all components of the training continue to meet those standards. Next steps involve the refinement of the core curriculum and methods of course delivery. Competencies in the nine domains will be grouped into instructional units and incorporated into three graduate courses. Arranging the course content as individual units or modules will enable diverse experts in auditory-verbal practice, speech-language pathology, audiology, medicine, and psychology to deliver the curriculum and maximize the learning experiences. As an offering within the university's existing audiology and speech-language pathology graduate program, the certificate program can also capitalize on the expertise of professors in related fields and benefit from existing laboratory and research facilities. The current program plan begins with onsite courses, primarily during the summer months, and will transition to a hybrid model with greater opportunities for distance education. Eventually, the delivery model may offer greater flexibility to interested practitioners and may facilitate the involvement of instructors from other regions and similar programs worldwide.

The Certificate in Auditory-Verbal Studies represents the only Canadian university training program of this type and will be offered in both English and French. In the past two years, the objectives, context, and program content have been subjected to a rigorous evaluation, were approved by various academic university committees of the University of Ottawa, and underwent an external review through the Ontario Council of Graduate Studies. Periodic program review will take place in accordance with university and provincial standards.

The University of Ottawa is an ideal setting because of the large base of local expertise in listening and spoken language development. Unique features include collaborative partnerships with the Children's Hospital of Eastern Ontario, an academic institution with a longstanding auditory-verbal program, and with the Ottawa Carleton District School Board, where a team of teachers of the deaf and hard of hearing provide school-based auditory-verbal services that are highly valued by parents (Eriks-Brophy et al., 2006). The hospital and school programs share common goals and characteristics and provide a seamless transition from preschool to school-based services. These local programs are expected to serve as practicum sites for students. The program will also benefit from its partnership with VOICE. The association's long-standing expertise in mentorship and field-based training for teachers can provide rich practicum experiences for teachers enrolled in the certificate program.

\section{Conclusion}

In summary, hearing loss affects an estimated 1,100 newborn children in Canada annually (Hyde, 2005). UNHS is now mandated or being implemented 
in about $90 \%$ of Canada, and is expected to increase the need for LSLS. Better outcomes have been commonly associated with access to high quality intervention services. As noted by Yoshinaga-Itano (2004), there is general agreement that screening itself does not positively affect results but early access to intervention and the quality of intervention services lead to improved developmental outcomes. Through the new Certificate in Auditory-Verbal Studies, the University of Ottawa aims to provide specialized training to establish a new cadre of professionals in listening and spoken language. The program will also aim to identify the needs of future practitioners and contribute to research that helps define the important characteristics of future intervention models, thereby contributing to policies and standards of care related to hearing health in Canada. Working with parents' associations, clinics, and school programs, this university-level training program can heighten the profile of listening and spoken language options for children with hearing loss and enhance outcomes for these children in Canada.

\section{Acknowledgements}

My thanks to my many colleagues at the Children's Hospital of Eastern Ontario, the Ottawa Carleton District School Board, and in Toronto, New Brunswick, Montreal, and Winnipeg who provided input into the development of the certificate program at the University of Ottawa. I am grateful to the Interdisciplinary Initiatives Fund at the University of Ottawa for supporting research to examine practitioner needs and preferences and to Dr. Cheryl Duquette for her ongoing collaboration. I also thank the Consortium National de Formation en Santé for supporting the preliminary development of course modules. I am particularly appreciative of the many parents and children who have taught me so much about family needs and family-centered practice.

\section{References}

Bernstein, A. (2009). The growth of AV in Ontario: We have indeed come a long way. Sound Matters, June, 22-23.

Biro, J., Cumbaa, P., Ficker, J., Kelly, M., Olmstead, T., \& Pugh, C. (1985). Mainstreaming options for hearing-impaired students: A descriptive study. Paper presented at the meeting of the Alexander Graham Bell Association for the Deaf and Hard of Hearing, Chicago, IL.

Boothroyd-Turner, D. (1990). Mainstreaming into the nineties - Are we on track? In M. Ross (Ed.), Hearing-impaired children in the mainstream (pp. 181-196). Parkton, MD: York Press, Inc.

Borer, J. (2009). Alliance for standards in health and education for hard of hearing and deaf children. Sound Bytes: VOICE for Hearing Impaired Children, February, 1-2. 
Eriks-Brophy, A., Durieux-Smith, A., Olds, J., Fitzpatrick, E., Duquette, C., \& Whittingham, J. (2006). Facilitators and barriers to the inclusion of orally educated children and youth with hearing loss in schools: Promoting partnerships to support inclusion. The Volta Review, 106(1), 53-88.

Fitzpatrick, E. (1994). Choices and challenges: Establishing a new program. The Volta Review, 95(5), 107-111.

Fitzpatrick, E. (1997). Using audition to develop language, comprehensive program development: The Ottawa model. Seminars in Hearing, 18(3), 279-295.

Hyde, M. L. (2005). Newborn hearing screening programs: Overview. Journal of Otolaryngology, 34, S70-S78.

Ling, D. \& Ling, A. H. (1978). Aural habilitation. Washington, DC: Alexander Graham Bell Association for the Deaf.

Ling Phillips, A. (1990). Thirty-five years in aural habilitation: A personal viewpoint. Journal of Speech-Language Pathology and Audiology, 14(2), 5-11.

Yoshinaga-Itano, C. (2004). Levels of evidence: universal newborn hearing screening (UNHS) and early hearing detection and intervention systems (EHDI). Journal of Communication Disorders, 37, 451-465. 


\section{Future Directions in Professional Preparation and Development}

This monograph has offered a "snapshot" of professional preparation in North America. In the chapters presented, our contributors endeavored to contextualize the history of the field and celebrate the early pioneers. They explored the challenges and rewards of professional preparation for work with children with hearing loss in the fields of audiology, speech-language pathology, and education of the deaf. Certification as a Listening and Spoken Language Specialist and the process of accreditation for one university program were presented. Authors described new techniques of peer mentoring and acknowledged the debt we have to those mentors who selflessly give of their time to train the next generation. Some authors described programs utilizing distance education models - a growing area in professional preparation. The program profiles provided a variety of interesting initiatives. While not every graduate or professional training program was profiled, there was a good cross-section of the types of programs available and some of the directions they have taken. These articles have provided prospective graduate students, or those who might be seeking additional training, with a starting place. In addition, we have provided a list of resources for readers to use as a reference (see Monograph Appendix C). As these websites are updated, new information will be made available about professional preparation programs and related services.

While it may be easy now to see how the field developed after World War II to the present, we can only speculate on the future. Will we have fully operational "bionic ears" that offer true fidelity? Will we have completely implantable hearing technology? Will the cost of that technology be affordable for everyone? Will there be ways to detect or prevent hearing loss even before birth? Will there be pharmaceutical or medical interventions that treat or prevent some types of hearing losses? Will we have the services in place to followup with children who fail the newborn hearing screening so that all children and families receive the appropriate audiological management and early intervention services?

Most importantly, how will professional preparation programs respond to new innovations? Presumably as they always have - by adapting what they teach but also by maintaining high expectations for their graduate students/ trainees and for children and families.

This is an exciting time for our field. What appears fairly certain is that assuming we see continuing support from governments at all levels - there will be growing interdependence among practitioners: more collaboration; more online opportunities for learning and for the exchange of ideas; more advancements in hearing technology; more collaborative research; more 
initiatives taken with younger children; and more interdisciplinary and transdisciplinary teams.

We have come a long way in a short space of time. But just watch the next generation of professionals who will undoubtedly look back at our awkward steps and marvel that we accomplished anything, given the "primitive" technology. Then, just as we have honored those who went before us, perhaps there will be recognition of what we were able to accomplish through dogged perseverance and determination.

What is clear is that professional preparation is closely linked to the quality of services for children with hearing loss and their families. If we keep our focus on what is best for children and families, then we cannot fail to continue in the right direction.

After all, ultimately it's all about the children.

Sincerely,

K. Todd Houston, Ph.D., CCC-SLP, LSLS Cert. AVT Assistant Professor of Speech-Language Pathology and Director, Graduate Studies Program in Auditory Learning \& Spoken Language Department of Communicative Disorders and Deaf Education Utah State University

Christina Perigoe, Ph.D., CCC-SLP, CED, LSLS Cert. AVT Associate Professor, Coordinator of the Early Oral Intervention

Graduate Program, Education of the Deaf Department of Speech and Hearing Sciences The University of Southern Mississippi 


\section{Monograph Appendix A: Nine Domains of Listening and Spoken Language}

\begin{tabular}{|c|c|c|}
\hline Domain 1 & $\begin{array}{l}\text { Hearing and } \\
\text { Hearing Technology }\end{array}$ & $\begin{array}{l}\text { Includes physiology of hearing, acoustics, type } \\
\text { of hearing loss, audiologic assessments, and } \\
\text { assistive listening technology and devices. }\end{array}$ \\
\hline Domain 2 & $\begin{array}{l}\text { Auditory } \\
\text { Functioning }\end{array}$ & $\begin{array}{l}\text { Includes auditory skill development, and } \\
\text { functional listening skill assessments and } \\
\text { evaluation. }\end{array}$ \\
\hline Domain 3 & $\begin{array}{l}\text { Spoken Language } \\
\text { Communication }\end{array}$ & $\begin{array}{l}\text { Includes the physiology, development, and } \\
\text { instruction of speech and the acquisition } \\
\text { and assessment of language. }\end{array}$ \\
\hline Domain 4 & Child Development & $\begin{array}{l}\text { Sequence of and influences on typical child } \\
\text { development and how hearing loss affects } \\
\text { this dynamic. }\end{array}$ \\
\hline Domain 5 & $\begin{array}{l}\text { Parent Guidance, } \\
\text { Education, and } \\
\text { Support }\end{array}$ & $\begin{array}{l}\text { Family counseling, coaching, and guidance } \\
\text { techniques and impact of external factors. }\end{array}$ \\
\hline Domain 6 & $\begin{array}{l}\text { Strategies for } \\
\text { Listening and } \\
\text { Spoken Language } \\
\text { Development }\end{array}$ & $\begin{array}{l}\text { Language facilitation, prompting and acoustic } \\
\text { highlighting techniques, spoken language } \\
\text { modeling, natural language instruction, } \\
\text { and "learning to listen" strategies. }\end{array}$ \\
\hline Domain 7 & $\begin{array}{l}\text { History, Philosophy } \\
\text { and, Professional } \\
\text { Issues }\end{array}$ & $\begin{array}{l}\text { History of education and communication } \\
\text { strategies of the deaf and hard of hearing } \\
\text { and professional development and practice. }\end{array}$ \\
\hline Domain 8 & Education & $\begin{array}{l}\text { The development and expansion of the } \\
\text { auditory and language skills that underlie } \\
\text { and support the child's progress in the } \\
\text { general education curriculum. }\end{array}$ \\
\hline Domain 9 & Emergent Literacy & $\begin{array}{l}\text { The development of the auditory and } \\
\text { language skills that underlie and support } \\
\text { the acquisition and advancement of literacy. }\end{array}$ \\
\hline
\end{tabular}

For more information and a full description of each domain, please visit http:/ /nc.agbell.org/ NetCommunity/document.doc?id=19 or www.agbellacademy.org. 


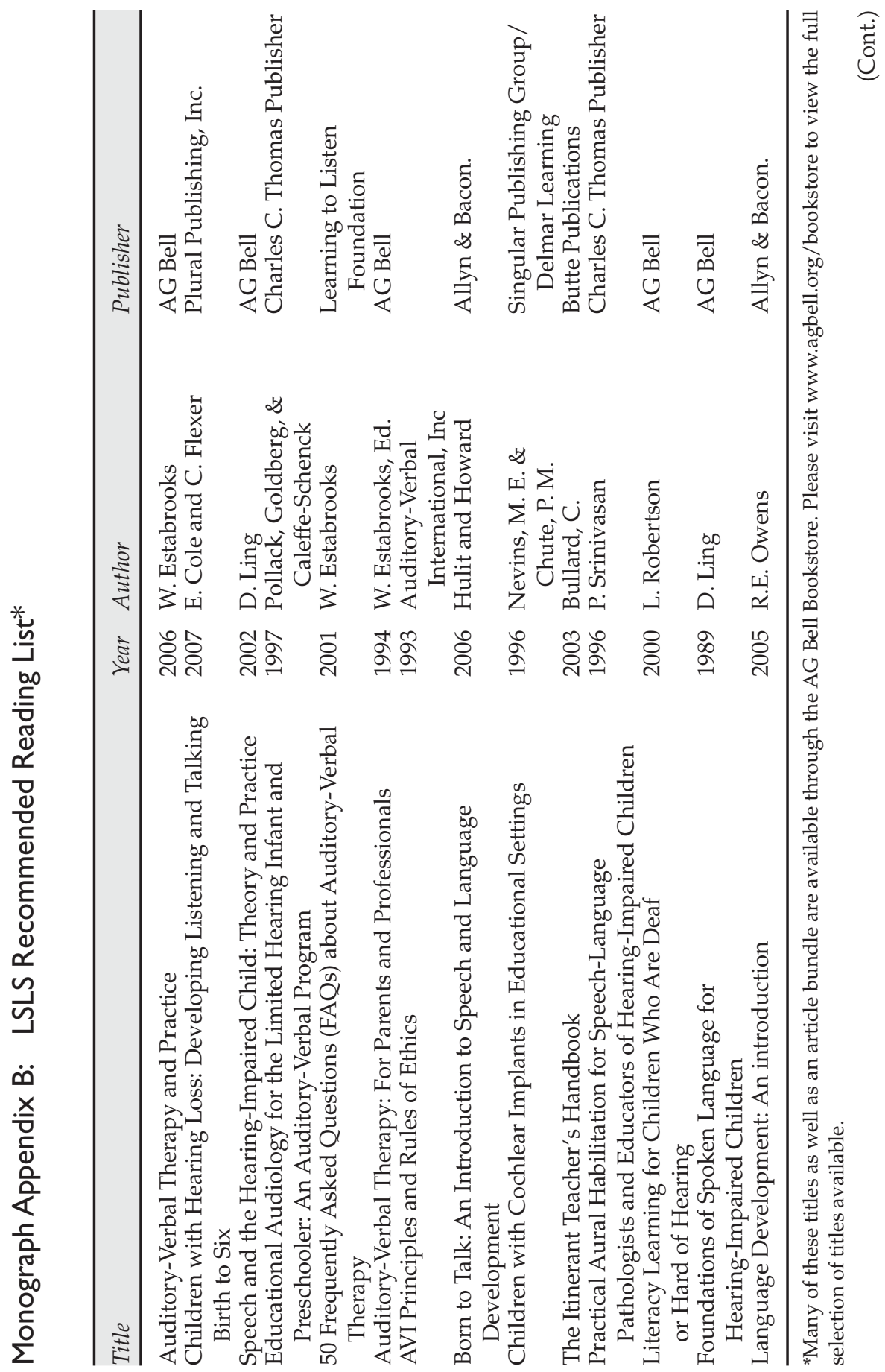




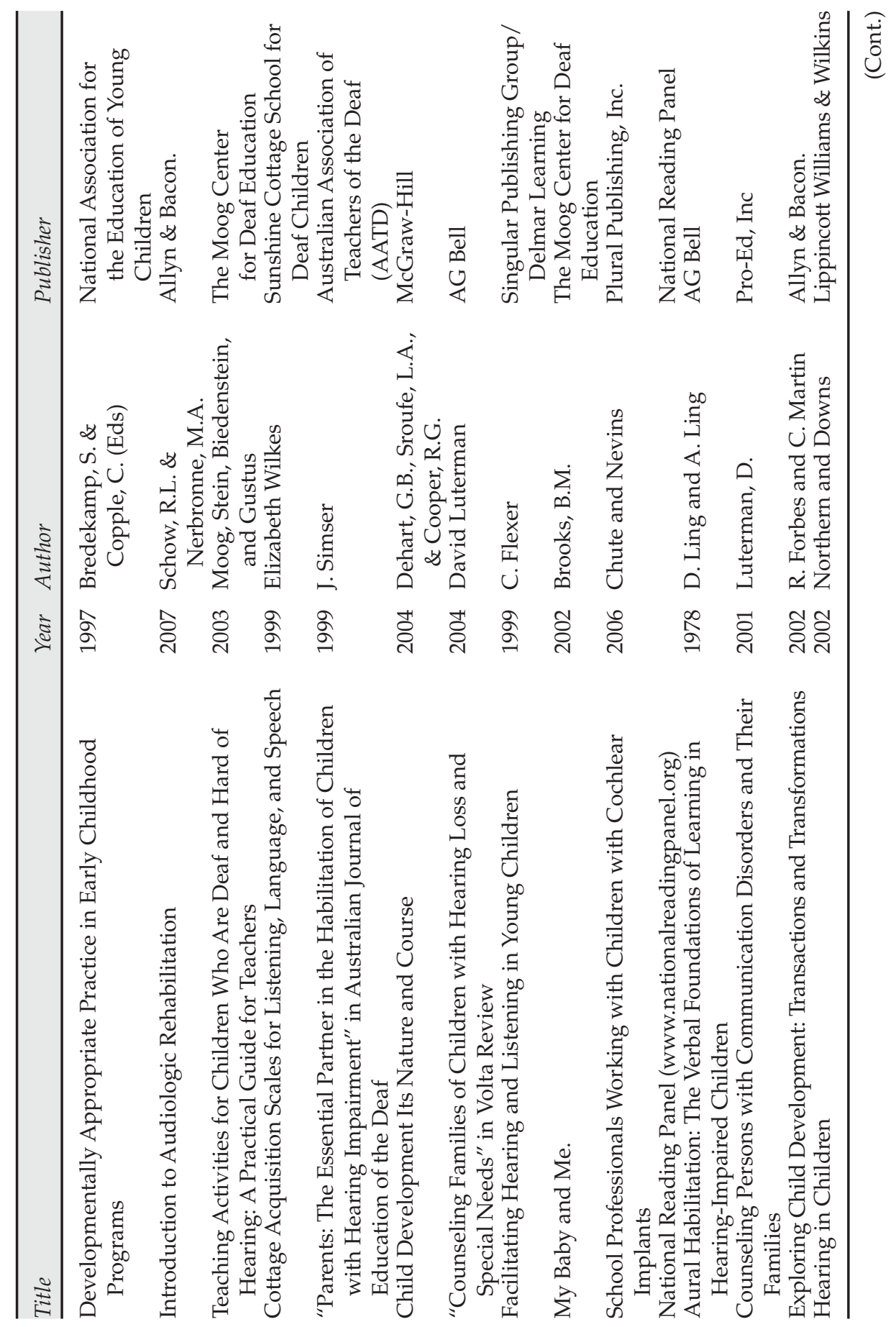




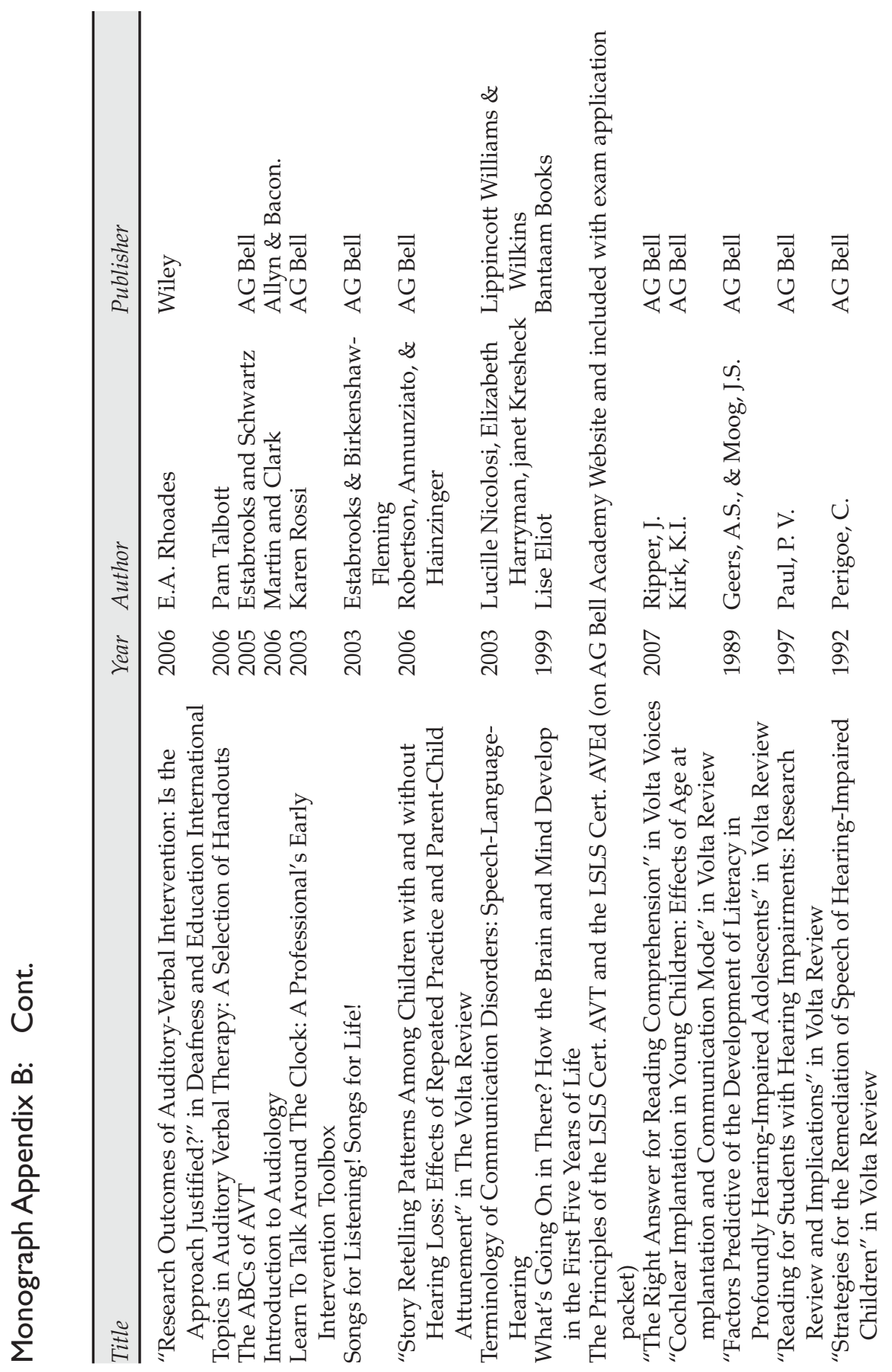




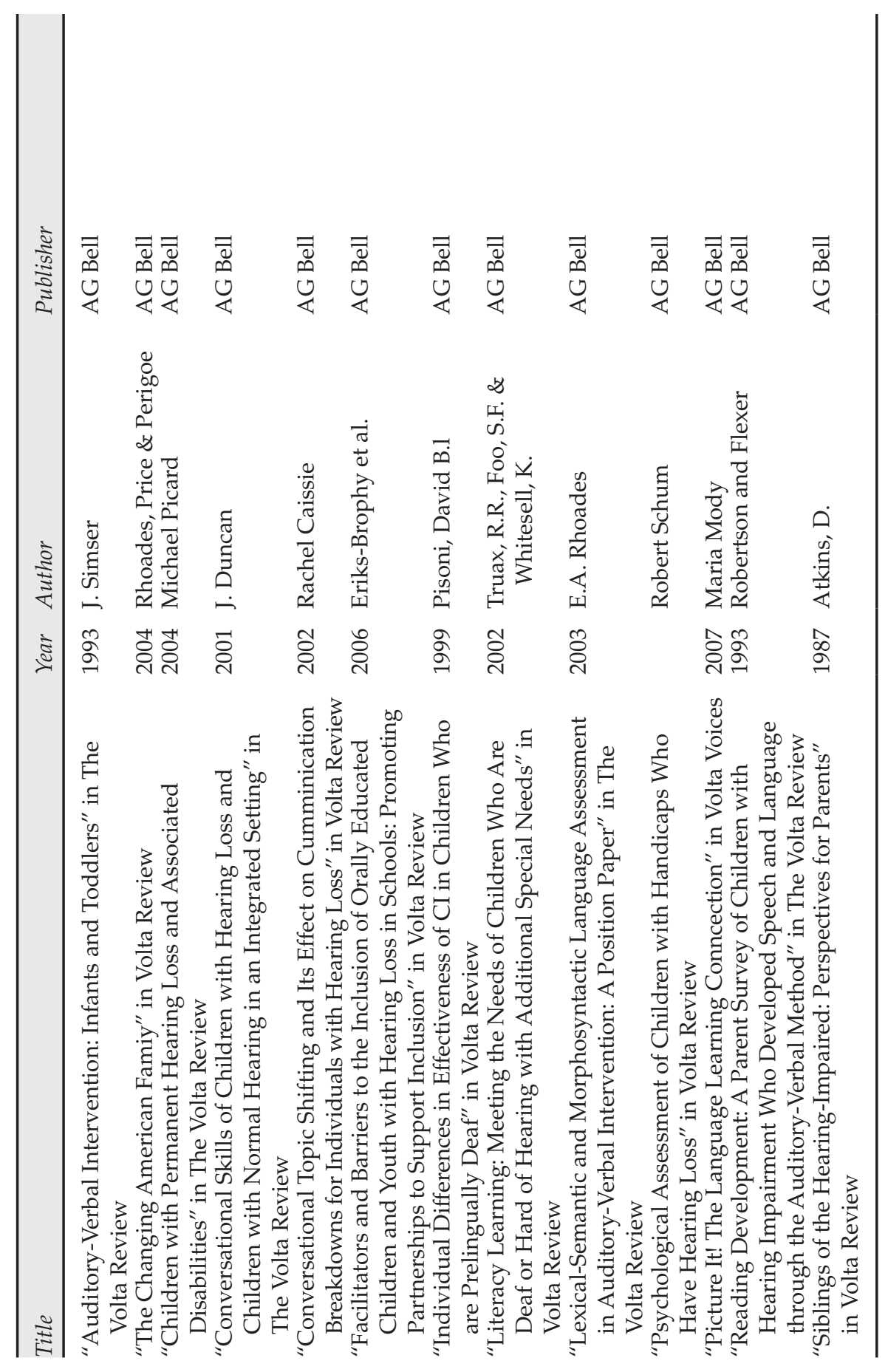




\section{Monograph Appendix C: Resource List}

\section{Accreditation}

Council on the Education of the Deaf (CED) - www.deafed.net

Council for Exceptional Children (CEC) - www.cec.sped.org

National Council for Accreditation of Teacher Education (NCATE) www.ncate.org

\section{Continuing Education}

Advanced Bionics - www.advancedbionics.com/calendar/ index.cfm?langid $=1$

AG Bell Academy for Listening and Spoken Language - http://nc.agbell. org/netcommunity / page.aspx?pid=345 - Lists all summer institutes approved for Continuing Education credit and specialized training American Speech-Language-Hearing Association - www.asha.org/ce Audiology Online - www.audiologyonline.com/total-access

Cochlear Americas HOPE online - www.cochlearamericas.com/ Support/291.asp

First YEARS - www.firstyears.org

MED-EL Corporation: www.medel.com

Professional Preparation in Cochlear Implants (PPCI) - www.chop.edu/ service/cochlear-implant-program/training/professionalpreparation-in-cochlear-implants-ppci.html

We Listen International, Inc. - www.welisteninternational.com/services.html

\section{Government Resources}

U.S. Department of Education - www.ed.gov

U.S. Federal Grant Opportunities - www.grants.gov

\section{Professional Associations}

AG Bell Academy for Listening and Spoken Language (Academy) www.agbellacademy.org

Alexander Graham Bell Association for the Deaf and Hard of Hearing (AG Bell) - www.agbell.org

American Academy of Audiology - www.audiology.org

American Speech-Language-Hearing Association - www.asha.org

Association of College Educators of the Deaf (ACEDHH) www.acedhh.org

Council for Exceptional Children (CEC) - www.cec.sped.org 


\section{Where to Find Graduate Training Programs}

Council on Academic Accreditation (CAA) - www.asha.org/academic/ accreditation/AboutCAA.htm - Provides a list of speech-language pathology and audiology programs that have voluntarily met standards for ASHA-CAA accreditation.

Council of Academic Programs in Communication Sciences and Disorders www.capcsd.org - Provides a list of undergraduate and graduate degree programs in communication sciences and disorders.

DeafEd Teacher Preparation Programs - www.deafed.net/PageText. asp?hdnPageId=120 - Programs endorsed by the CED.

Oral Deaf Education - http:/ / oraldeafed.org/careers - Provides a complete list of graduate programs that train teachers of the deaf with an emphasis on listening and spoken language acquisition. 


\section{Directory of Professional Programs}

The Alexander Graham Bell Association for the Deaf and Hard of Hearing is not responsible for verifying the credentials of the service providers below. Listings do not constitute endorsements of establishments or individuals, nor do they guarantee quality. If you are interested in advertising your program in the Directory of Professional Programs, please contact Gary Yates, manager of advertising, exhibit sales and sponsorships, at gyates@agbell.org or (202) 337-5220.

\section{California}

Sprint Relay, 2455 Naglee Road, Suite 179, Tracy, CA $95304 \bullet$ Phone: (866) 540-4657 • Email: chameen.r.stratton@sprint.com • Websites: www.sprintrelay. com/800i; www.sprintcaptel.com.

Conversations flow freely with Sprint's Captioned Telephone Services! Read conversations real-time while speaking and listening to callers!

\section{CapTel 800i}

Telephones with large displays that, when connected to high speed internet \& phone line, display captions of calls. www.sprintrelay.com/800i.

Sprint WebCapTel

No specialized phone equipment needed. If you have a computer with high speed internet and any telephone, you are ready to read captions on calls! www.sprintcaptel.com.

\section{Illinois}

Expanding Children's Hearing Opportunities (ECHO) Program at Carle Foundation Hospital, 611 West Park Street, Urbana, IL 61801 • Phone: (217) 383-4375 • Email: echo@carle.com • Website: www.carle.org/ECHO • The Expanding Children's Hearing Opportunities (ECHO) Program was established in 1989 to serve children with hearing loss and their families. ECHO has grown to encompass two programs: the Pediatric Hearing Center (PHC) and Carle Auditory Oral School (CAOS). PHC provides audiologic, speech language, and early intervention services as well as an experienced pediatric cochlear implant team. CAOS supports children with hearing loss in developing their spoken language and listening skills from preschool through second grade. 


\section{New York}

Nazareth College Deafness Specialty Preparation Program - Rochester, NY (joint program with National Technical Institute for the Deaf) • Point of Contact: Paula Brown, PhD, CCC-SLP • Email: Pbrown8@naz.edu • Phone: (585) 389-2796 - Website: www.rit.edu/ntid/spslp. The Nazareth College Deafness Specialty Preparation Program in Rochester, NY, prepares graduate students in Speech-Language Pathology for work with children who are deaf or hard of hearing, especially those with cochlear implants. This joint program with the National Technical Institute for the Deaf provides specialized coursework and practica in spoken language and auditory assessment and intervention.

\section{North Carolina}

FIRST YEARS - Kathryn Wilson, Program Director • Phone: (919) 966-0103 - Email: Kathryn_wilson@med.unc.edu - Administered by the University of North Carolina-Chapel Hill, FIRST YEARS is an in-service, certificate program committed to enhancing the knowledge and skills of professionals practicing in deaf education, speech-language pathology, audiology, and early intervention. The FIRST YEARS courses in listening and spoken language development combine convenient distance education with a hands-on mentorship experience to meet the needs of practicing professionals.

\section{Australia}

University of Newcastle - GradSchool, GradSchool Services Building, University of Newcastle, Callaghan, NSW 2308, Australia - Phone: +61249217373 - Fax: +61249218636 - Master of Special Education, distance education through the University of Newcastle. The program provides pathways through specializations in:

- Generic special education

- Emotional disturbance/behavior problems

- Sensory disability

- Early childhood special education

The Master of Special Education (Sensory Disability specialization) is available through the Renwick Centre, which is administered by the Australian Royal Institute for Deaf and Blind Children. Program information and application is via GradSchool: www.gradschool.com.au, +61249218856, or email gs@newcastle.edu.au. 
